Perseus: uma nova técnica para tratar árvores de sufixo persistentes

Caio César Mori Carélo 

SERVIÇO DE PÓS-GRADUAÇÃO DO ICMC-USP

Data de Depósito: 25/06/2009

Assinatura:

\title{
Perseus: uma nova técnica para tratar árvores de sufixo persistentes
}

\author{
Caio César Mori Carélo
}

Orientador: Profa. Dra. Cristina Dutra de Aguiar Ciferri

Dissertação apresentada ao Instituto de Ciências Matemáticas e de Computação - ICMC-USP, como parte dos requisitos para obtenção do título de Mestre em Ciências - Ciências de Computação e Matemática Computacional.

USP - São Carlos

Junho/2009 



\section{Agradecimentos}

À Deus, pois sem Ele nada seria possível.

À minha família, principalmente às minhas avós, pelo apoio incondicional, sobretudo nos momentos mais críticos.

À minha namorada Valéria, por seu amor e carinho.

Aos amigos e colegas que fiz em São Carlos, pela força e incentivo.

Em especial, à orientadora professora Cristina Dutra de Aguiar Ciferri pela competência e dedicação que me proporcionaram grande crescimento.

Aos professores Agma J. M. Traina, Caetano Traina Jr. e Ricardo R. Ciferri, pela ajuda no desenvolvimento deste trabalho.

Ao Conselho Nacional de Desenvolvimento Científico e Tecnológico, pelo auxílio financeiro. 


\section{Resumo}

O avanço tecnológico dos laboratórios de biologia molecular tem proporcionado um grande aumento no volume de seqüências de nucleotídeos armazenadas em bancos de dados biológicos, introduzindo o desafio de pesquisar eficientemente estes dados. Neste contexto, a árvore de sufixo é um método de acesso utilizado por muitas aplicações que envolvem pesquisa em dados biológicos. Entretanto, o custo de construção das árvores de sufixo é alto devido ao tamanho da estrutura de indexação gerado e à necessidade da árvore de sufixo caber em memória principal para ser construída com complexidade linear em relação ao tempo.

Esta dissertação propõe o PERSEus, uma nova técnica para tratar árvores de sufixo persistentes. A técnica Perseus apresenta os seguintes diferenciais. Ela introduz uma abordagem que realiza a construção de árvores de sufixo persistentes cujos tamanhos podem exceder a capacidade da memória principal. Além disso, ela provê um algoritmo que constrói árvores de sufixo por meio do particionamento destas árvores somente quando necessário. Esta construção também permite que o usuário escolha quais subseqüências de uma seqüência devem ser indexadas, de acordo com os requisitos particulares de suas aplicações. Por fim, a técnica proposta também introduz um algoritmo de casamento exato que permite a busca por uma seqüência de consulta em árvores de sufixo que podem estar particionadas.

A validação do Perseus foi realizada por meio de testes de desempenho considerando genomas de vários organismos, os quais possuem diferentes ordens de magnitude de tamanho. Os resultados obtidos foram comparados com a técnica TRELlis +, a qual representa o estado da arte nesta linha de pesquisa. Os testes indicaram que o Perseus construiu árvores de sufixo mais rapidamente do que o Trellis + , reduzindo o tempo total gasto na construção em até $24 \%$. Perseus também criou árvores de sufixo mais compactas, atingindo uma redução média de 27\% no espaço de memória secundária utilizado. Já com relação ao tempo total gasto no processamento de consultas, PERSEUs sempre produziu os melhores resultados, respondendo consultas em média $49 \%$ mais rápido do que o seu principal concorrente. Com relação à indexação de subseqüências escolhidas pelo usuário, comparando os resultados obtidos com o TRELLIS + , os testes mostraram que Perseus proveu uma redução no tempo de construção de árvores de sufixo de 97\% na média e uma redução no tempo gasto no processamento de consultas de genes de $93 \%$ na média. 


\section{Abstract}

Due to the technological advances in molecular biology laboratories, biological databases are extremely voluminous and tend to become more voluminous as data on new genome organisms are available. This introduces the challenge of searching nucleotide sequences efficiently. The suffix tree is an access method used for several applications that search for these data. However, the cost of building suffix trees is high, since they are extremely large data structures and they should fit in the main memory to be constructed in linear time.

In this master's thesis, we propose the PERSEUS, a novel technique that handles persistent suffix trees. The PERSEus introduces the following distinctive good properties. It is based on an approach that constructs persistent suffix trees whose sizes may exceed the main memory capacity. Furthermore, it provides an algorithm that allows for users to indicate which substrings of the input string should be indexed, according to the requirements of their applications. Moreover, it proposes an extended exact matching algorithm that searches for a query string into suffix trees that may be partitioned.

The PERSEUs was validated through performance tests using genomes of several organisms of different sizes. The results were compared with the TRELLIS+ technique, which represents the state-of-the-art in this field. The tests showed that the PERseus reduced the time spent on constructing suffix trees by $24 \%$. The PERSEUs also constructed compacter suffix trees, providing an average reduction in the secondary memory storage of $27 \%$. Furthermore, the PERSEUS reduced the time spent on query processing of nucleotide sequences by up to $49 \%$. As for the functionality of indexing substrings according to the user's requirements, the PERSEUS greatly improved the query performance in comparison to the TRELLIS + . The results showed that the PERSEUS reduced the time spent on constructing suffix trees by $97 \%$ on average and the time spent on query processing of genes by $93 \%$ on average. 


\section{Lista de Figuras}

2.1 Esquema típico de uma célula eucarionte. . . . . . . . . . . . . . . . . . . 6

2.2 Estrutura dupla espiral dos cromossomos. . . . . . . . . . . . . . . . . 6

2.3 Estrutura não espiralizada dos cromossomos. . . . . . . . . . . . . . 7

2.4 Proteínas codificadas a partir de genes distintos. . . . . . . . . . . . . . . 9

2.5 Seqüências de nucleotídeos catalogadas no GenBank. . . . . . . . . . . . 11

2.6 Família de Minkowski. . . . . . . . . . . . . . . . . . . . . . . 14

2.7 Exemplo de consulta por abrangência. . . . . . . . . . . . . . . 15

2.8 Exemplo de consulta dos $k$-vizinhos mais próximos. . . . . . . . . . . 15

2.9 Subespaços gerados pela $K$-D-tree . . . . . . . . . . . . . . . . . 16

2.10 Subespaços gerados pela Point quadtree e Region quadtree. . . . . . . . . . 17

2.11 MBRs gerados pelo método exaustivo da $R$-tree e pela $R^{*}$-tree. . . . . . . . 18

2.12 Subespaços gerados pela GH-tree. . . . . . . . . . . . . . . . . . . 19

2.13 Processo de promoção da M-tree. . . . . . . . . . . . . . . . 20

2.14 Processo de promoção da Slim-tree. . . . . . . . . . . . . . . . . . . 21

2.15 Uso de omni-focos na execução de consultas por abrangência. . . . . . . . . 21

3.1 Árvore de sufixo $T_{s}$ para $s=$ TAGAGA. . . . . . . . . . . 24

3.2 Árvore de sufixo prefixada $P_{s}^{\mathrm{A}}$ da árvore de sufixo da Figura 3.1. . . . . . . 25

3.3 Construção trivial da árvore de sufixo da Figura 3.1. . . . . . . . . . . . 25

3.4 Construção trivial da árvore de sufixo prefixada da Figura 3.2 . . . . . . . 26

3.5 Árvore de sufixo da Figura 3.1 com elos de sufixo. . . . . . . . . . . . . . 27

3.6 Fase de particionamento da técnica de Hunt et al. . . . . . . . . . . . . . 28

3.7 Fase de particionamento do TDD. . . . . . . . . . . . . . . . . . . . . . . . . . . . .

3.8 Exemplo do gerenciamento de buffer do TDD. . . . . . . . . . . . . . . . . 30

3.9 Fase de definição dos prefixos do Trellis $+\ldots \ldots \ldots$. . . . . . . . . 31

3.10 Fase de particionamento do Trellis $+\ldots \ldots \ldots$. . . . . . . . . . 32

3.11 Fase de união das partições do Trellis + . . . . . . . . . . . . . . . . . 32

4.1 Seqüência de entrada $s \ldots \ldots \ldots$. . . . . . . . . . . . . 38

4.2 Árvore de sufixo $T_{s}$ para $s=$ ATGGTTGGATTCATATGC . . . . . . . 38

4.3 Árvore de sufixo prefixada $P_{s}^{\mathrm{TG}}$ da árvore de sufixo da Figura 4.2 . . . . . 38

4.4 Visão geral das propriedades do Perseus. . . . . . . . . . . . . . . . 40

4.5 iTree-representation da árvore de sufixo prefixada $P_{s}^{\mathrm{TG}}$ da Figura 4.3. . . . 41 
4.6 iTree-representation da árvore de sufixo $T_{s}$ da Figura $4.2 \ldots \ldots$. . . . . . . . 42

4.7 Exemplo da pCounting-tree. . . . . . . . . . . . . . . . . 46

4.8 Exemplo do algoritmo Converter. . . . . . . . . . . . . . . . . . . 48

4.9 Exemplo do algoritmo Combiner. . . . . . . . . . . . . . . 50

4.10 Exemplo do algoritmo Insert. . . . . . . . . . . . . . . . . 53

4.11 Exemplo do algoritmo Search. . . . . . . . . . . . . . . . . 56

5.1 Tempo de construção das árvores de sufixo. . . . . . . . . . . . . . . . 62

5.2 Utilização do espaço em memória secundária. . . . . . . . . . . . . . 63

5.3 Resultados dos casamentos exatos. . . . . . . . . . . . . . 65

5.4 Casamentos exatos para consultas de tamanho entre 40 e 10,000 bps. . . . 66

5.5 Casamentos exatos para consultas de tamanho entre 10 e 35 bps. . . . . . . 67

A.1 Diagram of the MRS. . . . . . . . . . . . . . . . . . . 84

A.2 Organization of the nsP-index file. . . . . . . . . . . . . 86

A.3 Building code of the nsP-index. . . . . . . . . . . . . 87

A.4 Organization of the nsP-index. . . . . . . . . . . . . . . 87

A.5 The range query algorithm. . . . . . . . . . . . . . . . . 89

A.6 Elapsed time in building the indexes. . . . . . . . . . . . . . . . . . 90

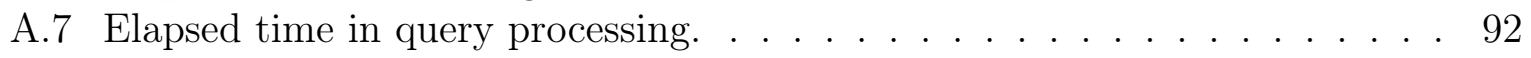

A.8 Elapsed time in building the indexes. . . . . . . . . . . . . . . 93

A.9 Elapsed time in query processing. . . . . . . . . . . . . . . . . 93

B.1 (a) Example of a MM-tree. (b) Example of the semi-balancing technique. . 99

B.2 Overview of the OnION-TREE's distinctive properties. . . . . . . . . . . . 101

B.3 Nodes $N, N^{\prime}$ e $N^{\prime \prime}$, their pivots and regions. . . . . . . . . . . . . 102

B.4 Example of the replacement technique. . . . . . . . . . . . . . . . 104

B.5 Visit order of the expansions and their regions for $s_{q} \ldots \ldots \ldots 7$

B.6 Elapsed time to build the indices. . . . . . . . . . . . . . . . . . 109

B.7 Range queries results. . . . . . . . . . . . . . . . . . . . . . . 111

B.8 $k$-NN queries results. . . . . . . . . . . . . . . . . . . . 113 


\section{Lista de Tabelas}

2.1 Alfabeto estendido de nucleotídeos. . . . . . . . . . . . . . . . . . 7

2.2 Aminoácidos. . . . . . . . . . . . . . . . . . . 8

2.3 Codificação de aminoácidos. . . . . . . . . . . . . . . . . . . 9

3.1 Comparação das técnicas de construção de árvores de sufixo persistentes. 34

4.1 Atributos de um nó $x$ da iTree-representation. . . . . . . . . . . . . . . 41

4.2 Conjuntos de prefixos de tamanhos fixos definidos para diferentes $\mu$. . . . 44

4.3 Atributos de um nó y da pCounting-tree. . . . . . . . . . . . . . . 45

4.4 Comparação das técnicas de construção de árvores de sufixo persistentes. 56

5.1 Genomas utilizados nos experimentos. . . . . . . . . . . . . . . 59

5.2 Resultados experimentais da definição dos prefixos de tamanhos variáveis. . 61

5.3 Resultados experimentais da construção das árvores de sufixo. . . . . . . . . 62

5.4 Resultados experimentais da construção das árvores de sufixo. . . . . . . . 63

5.5 Resultados experimentais da construção guiada pelo usuário. . . . . . . . . 68

5.6 Resultados experimentais da construção guiada pelo usuário. . . . . . . . . 68

A.1 (a) The table verifyPage. (b) The table findMBR. . . . . . . . . . . . . . 88

A.2 Increase in building costs. . . . . . . . . . . . . . . . . 91

A.3 Disk accesses per query. . . . . . . . . . . . . . . . . . . 92

B.1 Regions of space where the element $s_{i}$ can be assigned. . . . . . . . . 99

B.2 The structure of an OnION-TREE's node $N \ldots \ldots \ldots \ldots$. . . . . . . 101

B.3 Visit order of the regions. . . . . . . . . . . . . . . . . 107

B.4 Datasets used in the experiments. . . . . . . . . . . . . 108

B.5 Number of distance calculations to build the indices. . . . . . . . . . . . 109

B.6 The ONION-TREE's performance gains (range queries). . . . . . . . . . . 110

B.7 The OnION-TREE's performance gains $(k$-NN queries). . . . . . . . . . . 112 
1 Introdução 1

1.1 Organização do trabalho . . . . . . . . . . . . . . . . . . . 3

2 Fundamentação Teórica 5

2.1 Biologia Molecular . . . . . . . . . . . . . . . . . . . 5

2.1.1 Nucleotídeo . . . . . . . . . . . . . . . . . . . 5

2.1.2 Genoma . . . . . . . . . . . . . . . 7

2.2 Bioinformática . . . . . . . . . . . . . . . . . . . . . . . 10

2.3 Métodos de Acesso . . . . . . . . . . . . . . . . . . . . . . . . 11

2.3.1 Espaço Multidimensional . . . . . . . . . . . . . . . . . . . . 12

2.3 .2 Espaço Métrico . . . . . . . . . . . . . . . . . . . . . . . 13

2.3.3 Função de Distância . . . . . . . . . . . . . . . . . . . . . . . 13

2.3.4 Consultas por Similaridade . . . . . . . . . . . . . . . . . 14

2.4 Métodos de Acesso Multidimensionais . . . . . . . . . . . . . . . . . . . 15

$2.4 .1 \quad K$-D-tree . . . . . . . . . . . . . . . 16

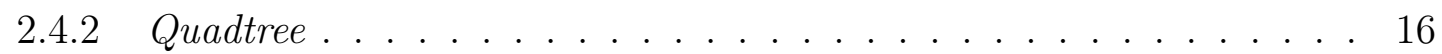

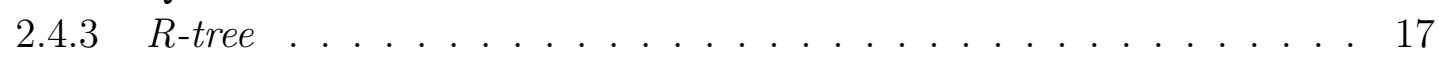

2.5 Métodos de Acesso Métricos . . . . . . . . . . . . . . . . . . . . 18

2.5.1 GH-tree . . . . . . . . . . . . . . . . 18

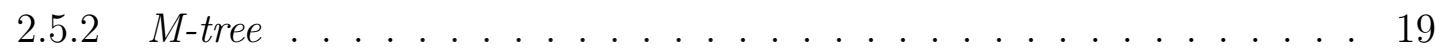

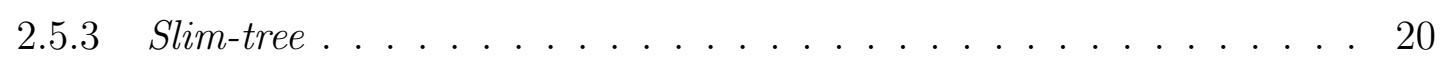

2.6 Considerações Finais . . . . . . . . . . . . . . . . . . 21

3 Trabalhos Correlatos 23

3.1 Árvore de Sufixo . . . . . . . . . . . . . . . . . . . . . . . . . . . . . . . . . . . . . 23

3.1.1 Construção Trivial . . . . . . . . . . . . . . . . . . . . . . . . . . . . . . . . . . . 24

3.1 .2 Construção Linear . . . . . . . . . . . . . . . . . . . . . . . . . . . . . . 26

3.2 A Técnica de Hunt, Atkinson e Irving (2001) . . . . . . . . . . . . . . . . 27

3.3 A Técnica TDD . . . . . . . . . . . . . . . . . . . . . . 29

3.4 A Técnica Trellis $+\ldots \ldots \ldots \ldots \ldots$. . . . . . . . . . . . . . . . . . . . . . . . . . . .

3.5 Outros Métodos de Acesso . . . . . . . . . . . . . . . . . . . . . . . . . . . . . . . . . . . . . . . . . . . . .

3.6 Considerações Finais . . . . . . . . . . . . . . . . . . . 34 
4 A Técnica Perseus $\quad 37$

4.1 Exemplo Corrente . . . . . . . . . . . . . . . . . . . . 37

4.2 A Técnica Proposta Perseus . . . . . . . . . . . . . . . . . 38

4.3 Estratégia de Três Passos . . . . . . . . . . . . . . . . . . . . . . 42

4.3.1 Definição dos Prefixos de Tamanhos Fixos . . . . . . . . . . . . . 43

4.3.2 Contagem dos Prefixos de Tamanhos Fixos . . . . . . . . . . . . . 45

4.3.3 Definição dos Prefixos de Tamanhos Variáveis . . . . . . . . . . . . . 46

4.4 Construção Guiada pelo Usuário . . . . . . . . . . . . . . . . . . . 48

4.4.1 Definição do Conjunto Combinado . . . . . . . . . . . . . . . 49

4.4 .2 Construção . . . . . . . . . . . . . . . . . . . . . 49

4.5 Casamento Exato Estendido . . . . . . . . . . . . . . . . 54

4.6 Considerações Finais . . . . . . . . . . . . . . . . . . 55

5 Testes de Desempenho $\quad 59$

5.1 Custo de Construção das Árvores de Sufixo . . . . . . . . . . . . . . . 60

5.2 Custo de Processamento de Casamentos Exatos . . . . . . . . . . . . . . 62

5.3 Influência do Tamanho das Consultas no Processamento de Casamentos Exatos . . . . . . . . . . . . . . . . . . . . 64

5.4 Benefícios Proporcionados pela Construção Guiada pelo Usuário . . . . . . 66

5.5 Considerações Finais . . . . . . . . . . . . . . . . . . 68

6 Conclusões 69

6.1 Principais Contribuições . . . . . . . . . . . . . . . . . . 70

6.2 Trabalhos Futuros . . . . . . . . . . . . . . . . . 71

Referências Bibliográficas $\quad 72$

$\begin{array}{lr}\text { A nsP-index } & 81\end{array}$

A.1 Introduction . . . . . . . . . . . . . . . . . 82

A.2 Related Work . . . . . . . . . . . . . . . . 83

A.3 The MRS Index . . . . . . . . . . . . . . . . . . . . . . . . . 84

A.4 The Proposed nsP-index . . . . . . . . . . . . . . . . . . 85

A.5 Components of the nsP-index . . . . . . . . . . . . . . 86

A.5.1 The Core Components . . . . . . . . . . . . . . 87

A.5.2 The Tables verifyPage and findMBR . . . . . . . . . . . 88

A.5.3 Additional Aspects of the nsP-index . . . . . . . . . . . . . . . 88

A.6 Performance Tests . . . . . . . . . . . . . . . . . . . . . . . . . . . . . . 89

A.6.1 Synthetic Databases . . . . . . . . . . . . . . . . . 90

A.6.2 Real Databases . . . . . . . . . . . . . . . . . . . . 91

A.7 Conclusions and Future Work . . . . . . . . . . . . . . . . . 93

B ONION-TREE 95

B.1 Introduction . . . . . . . . . . . . . . . . . 96

B.2 Related Work . . . . . . . . . . . . . . . . . . . . . . . . . . . . . . . . . . . . .

B.3 The MM-tree . . . . . . . . . . . . . . . . . . . . . . . . . . . . . . . . . . . . . . . . . . 999

B.4 The Proposed Onion-TreE . . . . . . . . . . . . . . . . . 100

B.5 The Expansion Procedure . . . . . . . . . . . . . . . . . . 101

B.5.1 Creating Expansions and Regions . . . . . . . . . . . . . . 102

B.5.2 Choosing a Region . . . . . . . . . . . . . . . 103 
B.6 The Replacement Technique . . . . . . . . . . . . . . . . . . . . . . 103

B.7 Extended Query Algorithms . . . . . . . . . . . . . . . . . . . . 104

B.8 Experimental Results . . . . . . . . . . . . . . . . . 106

B.8.1 Performance Results for Building the Index . . . . . . . . . . . . 108

B.8.2 Performance Results for Range Query Processing . . . . . . . . . . 110

B.8.3 Performance Results for $k$-NN Query Processing . . . . . . . . . . . 111

B.9 Conclusions and Future Work . . . . . . . . . . . . . . . . . . . 112 


\section{Capítulo \\ 1 \\ Introdução}

A dissertação tem como objetivo desenvolver uma técnica de indexação para dados biológicos. Mais especificamente, esta dissertação propõe o PERSEus (referência a árvores de sufixo persistentes), uma nova técnica para tratar árvores de sufixo persistentes cujos tamanhos podem exceder a capacidade da memória principal.

A biologia molecular é um ramo da ciência biológica que estuda a estrutura do material genético dos seres vivos e as substâncias que são codificadas a partir deste (Calladine et al, 2004). Nesta ciência, os biólogos coletam e analisam dados, os quais são armazenados em bancos de dados biológicos (BDBs). Mais detalhadamente, estes BDBs armazenam dados referentes aos organismos vivos, tais como seqüências de nucleotídeos e aminoácidos, mapas genéticos, estruturas tridimensionais de proteínas, identificação e anotação de genes e literatura associada, além de quaisquer informações derivadas destes ou necessárias para a compreensão dos mesmos (Seibel e Lifschitz, 2002; Lifschitz, 2007). Nos BDBs, as seqüências de nucleotídeos são constituídas por caracteres que representam as bases nitrogenadas adenina $(\mathrm{A})$, citosina $(\mathrm{C})$, guanina $(\mathrm{G})$ e timina $(\mathrm{T})$.

O avanço tecnológico dos laboratórios de biologia molecular tem proporcionado um grande aumento na produção dos dados biológicos, ao ponto de tornar a coleta destes dados mais rápida que a interpretação dos mesmos (Korf et al, 2003). Por exemplo, a versão mais recente do GenBank (i.e., 2008), um dos maiores BDBs existentes, disponibiliza para análise aproximadamente $9,9 \times 10^{10}$ pares de base provenientes de mais de 98 milhões de seqüências de nucleotídeos.

Pode-se notar que existe uma quantidade enorme de dados biológicos ao alcance da comunidade científica. Surge, então, o desafio de pesquisar nestes BDBs, comparando 
duas ou mais seqüências, e identificando se elas possuem relação de homologia. Alguns exemplos de consultas que podem ser respondidas por meio desta pesquisa de similaridade são: (i) Como descobrir qual parte do código genético de um organismo é responsável por uma doença hereditária?; (ii) Como determinar a função de uma nova proteína?; (iii) Como descobrir qual gene é responsável por produzir a enzima capaz de digerir o leite?; e (iv) Em uma comparação entre o genoma do ser humano e o do rato, quais genes são exclusivamente do ser humano ou do rato? Com relação à consulta (iv), comparações realizadas entre o genoma do ser humano e do rato mostraram que pouco mudou deste que estes organismos compartilharam um mesmo ancestral, há aproximadamente 74 milhões de anos. Além disso, poucos genes são exclusivamente do ser humano ou do rato, sendo que seus genomas compartilham mais de $80 \%$ de seqüências idênticas (Korf et al, 2003). Logo, a chave para responder a tais consultas parece estar contida na similaridade existente entre os dados.

A grande maioria das questões envolvendo pesquisa por similaridade possui apenas uma pequena parte do BDB como resposta. Assim, acessar todo o BDB para encontrar poucos dados constitui, em geral, uma estratégia ineficiente. Idealmente, uma determinada consulta deveria acessar apenas os dados que fazem parte de seu resultado (Silberschatz et al, 2005). Para permitir este tipo de operação, existem os métodos de acesso, os quais conduzem a busca a porções do BDB nas quais as dados armazenados têm alta probabilidade de serem similares à consulta.

A árvore de sufixo é um método de acesso utilizado por muitas aplicações que requerem soluções lineares com relação ao tempo para problemas que envolvem pesquisa por similaridade em seqüências de nucleotídeos. Dois tipos de pesquisa são o casamento exato e o casamento aproximado (Gusfield, 1997). Enquanto o casamento exato retorna todas as ocorrências de uma seqüência de consulta $P_{q}$ que existem no BDB, o casamento aproximado retorna todas as ocorrências de $P_{q}^{\prime}$ que existem no BDB, onde $P_{q}^{\prime}$ é uma transformação de $P_{q}$ com um custo menor que um limiar. Nas árvores de sufixo, as consultas por similaridade podem ser feitas por meio de casamentos aproximados, que, por sua vez, utilizam variações de casamentos exatos para encontrar suas respostas.

Entretanto, o custo de construção das árvores de sufixo é muito alto devido a dois motivos principais. Primeiro, árvores de sufixo são muito volumosas e usualmente excedem os tamanhos dos BDBs que elas indexam em uma ou duas ordens de magnitude. Além disso, a construção de árvores de sufixo com complexidade linear em relação ao tempo requer que essas árvores caibam em memória principal (Weiner, 1973; McCreight, 1976; Ukkonen, 1995).

Esta dissertação propõe o PERSEus, uma nova técnica voltada à indexação de seqüências de nucleotídeos. Os principais diferenciais do PERSEus são: 
- Estratégia de três passos: uma abordagem que garante a construção de árvores de sufixo persistentes cujos tamanhos podem exceder a capacidade da memória principal;

- Construção guiada pelo usuário: um algoritmo que constroi árvores de sufixo por meio do particionamento destas árvores quando necessário. Além disto, esta construção também permite que o usuário escolha quais subseqüências de uma seqüência devem ser indexadas, de acordo com os requisitos particulares de suas aplicações; e

- Casamento exato estendido: um algoritmo de casamento exato que permite a busca por uma seqüência de consulta em árvores de sufixo que podem estar particionadas.

A validação do Perseus foi realizada por meio de testes de desempenho considerando genomas vários organismos, os quais possuem diferentes ordens de magnitude de tamanho. Nos testes, foram analisados o custo de construção de árvores de sufixo e o custo de processamento de casamentos exatos. Com relação ao custo de construção, foram coletados o tempo gasto em segundos e o espaço em disco ocupado pelas árvores de sufixo. Já para o processamento de casamentos exatos, foram coletados o tempo total gasto para processar diferentes conjuntos de consultas compostas de seqüências sintéticas e reais. Os resultados obtidos foram comparados com a técnica TRELLIS + (Phoophakdee e Zaki, 2007, 2008), a qual representa o estado da arte nesta linha de pesquisa.

\subsection{Organização do trabalho}

Além deste capítulo introdutório, esta dissertação é organizada em mais cinco capítulos:

- Capítulo 2: resume os fundamentos teóricos de biologia molecular, bioinformática e métodos de acesso, os quais são necessários para o entendimento desta dissertação;

- Capítulo 3: descreve as principais características das árvores de sufixo, além de resumir trabalhos correlatos que visam a construção de árvores de sufixo persistentes;

- Capítulo 4: apresenta uma visão geral da técnica proposta Perseus, destacando os seus diferenciais. Neste capítulo também são detalhados a estratégia de três passos, a construção guiada pelo usuário e o casamento exato estendido;

- Capítulo 5: define o ambiente de testes utilizado na investigação do PERSEus e descreve os resultados dos testes de desempenho realizados, além de comparar estes resultados com a técnica TRELLIS+; e 
- Capítulo 6: conclui a dissertação, apresentando as contribuições e as sugestões para trabalhos futuros.

Motivado pelo estudo e análise da fundamentação teórica e dos trabalhos correlatos, durante o mestrado também foram investigados outros métodos de acesso como atividades complementares ao desenvolvimento do PERSEUs. Estas propostas adicionais estão descritas nos apêndices A e B da seguinte forma:

- Apêndice A: apresenta a nsP-index (Ciferri et al, 2008), um método de acesso voltado à construção de índices compactos na indexação de grandes seqüências de nucleotídeos; e

- Apêndice B: descreve a Onion-tree (Carélo et al, 2009), um método de acesso dinâmico voltado à indexação de dados métricos em memória principal. 


\section{Capítulo \\ 2 \\ Fundamentação Teórica}

Neste capítulo são resumidos os fundamentos teóricos necessários para o entendimento desta dissertação. A Seção 2.1 revisa os principais conceitos de biologia molecular e a Seção 2.2 define o que é bioinformática, ilustrando seus objetivos. A Seção 2.3 descreve conceitos básicos de métodos de acesso, enquanto que as Seções 2.4 e 2.5 investigam os métodos de acesso multidimensionais e os métodos de acesso métricos, respectivamente. O capítulo é concluído na Seção 2.6, na qual são apresentadas as considerações finais.

\subsection{Biologia Molecular}

A biologia molecular é um ramo da ciência biológica que utiliza resultados de outras áreas da ciência, como a genética e a bioquímica, para explicar a estrutura do material genético dos seres vivos e as substâncias que são codificadas a partir deste (Calladine et al, 2004). As Seções 2.1.1 e 2.1.2 discutem a formação e a composição dos organismos vivos.

\subsubsection{Nucleotídeo}

Todos os organismos vivos, com exceção dos vírus, são formados por células. Organismos como as bactérias e os protozoários são formados por uma única célula. Em contrapartida, um ser humano adulto é formado por aproximadamente 30 trilhões de células organizadas em tecidos (Bolsover et al, 2004).

As células, por mais específicas e distintas dentre os vários organismos vivos existentes, podem ser classificadas em dois grupos: (i) procariontes, que são células mais simples, 
sem organelas citoplasmáticas e envoltório nuclear; e (ii) eucariontes, células complexas que possuem duas regiões bem definidas, o citoplasma com organelas e o núcleo delimitado (Lodish et al, 2004).

Todas as células que compõem um organismo compartilham o mesmo material genético. Dentro de cada célula existe um composto químico chamado ácido desoxirribonucléico (DNA), responsável pelo armazenamento do código genético do organismo, possibilitando a transmissão de suas características hereditárias. Nas células procariontes este composto fica disperso no citoplasma, enquanto que nas eucariontes o DNA fica agrupado na região nuclear (Bolsover et al, 2004).

O DNA é fisicamente organizado em uma ou mais estruturas denominadas cromossomos. O número de cromossomos que um determinado organismo possui pode variar de uma espécie para outra. Além disso, os vários cromossomos de uma mesma espécie geralmente possuem tamanhos e formas diferentes. Cada célula do ser humano, por exemplo, contém 23 pares de cromossomos, sendo que um destes pares determina o sexo do indivíduo (Calladine et al, 2004). A Figura 2.1 mostra o esquema típico de uma célula eucarionte. Nesta célula, pode-se observar oito cromossomos agrupados na região nuclear.

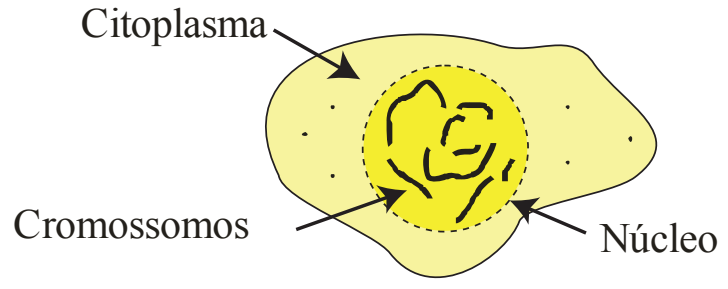

Figura 2.1: Esquema típico de uma célula eucarionte.

Os cromossomos, por sua vez, são compostos formados por grandes seqüências de nucleotídeos dispostos em uma estrutura chamada dupla espiral. Estas seqüências são lidas no sentido de uma extremidade chamada 5' para a outra extremidade denominada 3' (Lodish et al, 2004). A Figura 2.2 ilustra essa estrutura e destaca uma unidade chamada par de base (bp), a qual é utilizada para medir o tamanho dos cromossomos. Os tamanhos Kbps, Mbps, e Gbps referem-se a $10^{3}$ bps, $10^{6}$ bps e $10^{9}$ bps, respectivamente. Já a Figura 2.3 ilustra a mesma estrutura da Figura 2.2, porém em uma forma não espiralizada. Pode-se notar que um par de base é uma ligação entre dois nucleotídeos e que as duas espirais que formam o cromossomo possuem sentidos opostos.

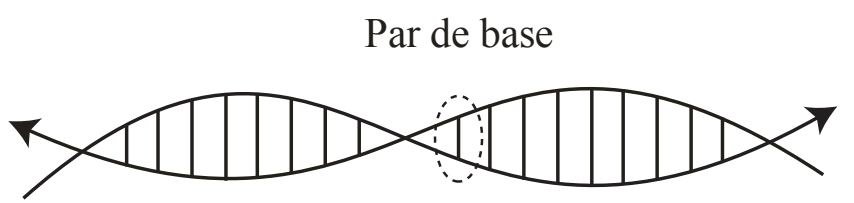

Figura 2.2: Estrutura dupla espiral dos cromossomos. 
$\left(5^{\prime}\right)$

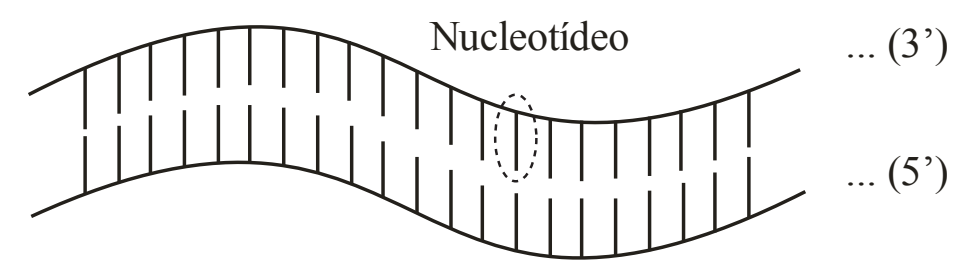

Figura 2.3: Estrutura não espiralizada dos cromossomos.

Cada nucleotídeo é composto por um grupo fosfato, uma pentose e uma base nitrogenada, sendo que esta pode ser de quatro tipos: adenina $(A)$, citosina $(C)$, guanina $(G)$ e timina $(\mathrm{T})$. Como a base nitrogenada é o que diferencia um nucleotídeo de outro, ela é comumente utilizada para representá-lo (Cohen, 2004). Entretanto, além destes quatro caracteres, existe um alfabeto estendido que é utilizado para expressar ambigüidades no processo de identificação dos nucleotídeos. A Tabela 2.1 mostra este alfabeto estendido.

Tabela 2.1: Alfabeto estendido de nucleotídeos.

\begin{tabular}{cl}
\hline Símbolo & Nucleotídeos \\
\hline M & A ou C \\
R & A ou G \\
W & A ou T \\
S & C ou G \\
Y & C ou T \\
K & G ou T \\
V & A, C ou G \\
H & A, C ou T \\
D & A, G ou T \\
B & C, G ou T \\
N & A, C, G ou T \\
\hline
\end{tabular}

\subsubsection{Genoma}

Cada trinca de nucleotídeos é chamada códon. Um códon possui a informação biológica necessária para codificar um aminoácido (Calladine et al, 2004). Os aninoácidos, por sua vez, são pequenos blocos nitrogenados formadores das proteínas. A Tabela 2.2 mostra os 20 aminoácidos existentes, suas abreviações e seus símbolos.

Como um códon codifica um aminoácido e existem quatro tipos de nucleotídeos no DNA, poderiam existir $4 \times 4 \times 4=64$ aminoácidos diferentes. Contudo, como ilustrado na Tabela 2.2, existem apenas 20 tipos de aminoácidos. Isto significa que códons distintos podem codificar um mesmo composto. A Tabela 2.3 mostra todas as possíveis seqüências formadas por três nucleotídeos e os aminoácidos que são codificados a partir de cada uma delas (Korf et al, 2003). 
Tabela 2.2: Aminoácidos.

\begin{tabular}{ccc}
\hline Aminoácido & Abreviação & Símbolo \\
\hline Alanina & Ala & $\mathrm{A}$ \\
Cisteina & Cys & $\mathrm{C}$ \\
Aspartato & Asp & $\mathrm{D}$ \\
Glutamato & Glu & $\mathrm{E}$ \\
Fenilalanina & Phe & $\mathrm{F}$ \\
Glicina & Gly & $\mathrm{G}$ \\
Histidina & His & $\mathrm{H}$ \\
Isoleucina & Ile & $\mathrm{I}$ \\
Lisina & Lys & $\mathrm{K}$ \\
Leucina & Leu & $\mathrm{L}$ \\
Metionina & Met & $\mathrm{M}$ \\
Asparagina & Asn & $\mathrm{N}$ \\
Prolina & Pro & $\mathrm{P}$ \\
Glutamina & Gin & $\mathrm{Q}$ \\
Arginina & Arg & $\mathrm{R}$ \\
Serina & Ser & $\mathrm{S}$ \\
Treonina & Thr & $\mathrm{T}$ \\
Valina & Val & $\mathrm{V}$ \\
Triptofano & Trp & $\mathrm{W}$ \\
Treonina & Tyr & $\mathrm{Y}$ \\
\hline
\end{tabular}

Teoricamente, o processo de codificação de aminoácidos ocorre como descrito a seguir. Dada uma seqüência de nucleotídeos $s$, existem três possíveis janelas de leitura que podem mapear aminoácidos distintos. Por exemplo, considere a seqüência $s=$ TAATCGAATGGGC. Uma janela de leitura ignora o último caractere e retorna os códons TAA, TCG, AAT e GGG. Outra janela de leitura possível ignora o primeiro caractere e seleciona os códons AAT, CGA, ATG e GGC. Uma última possibilidade ignora dois caracteres no início e dois no final, resultando em ATC, GAA e TGG. Este processo de codificação é extensível para qualquer seqüência (Setubal e Meidanis, 1997).

Na prática, porém, existem códons com funções especiais para indicar onde uma codificação deve ser iniciada e onde esta deve parar. O códon ATG codifica o aminoácido metionina, como demonstrado na Tabela 2.2. Além disso, este códon é chamado START-Códon, indicando que aquela região é o ponto de partida de uma janela de leitura. Já os códons TAA, TAG e TGA são conhecidos como STOP-Códons. Estes códons não codificam aminoácidos, mas indicam que a leitura deve parar naquele ponto (Bolsover et al, 2004).

A partir destas propriedades, percebe-se que existem partes do DNA que não são utilizadas para codificar aminoácidos. Por exemplo, a seqüência de nucleotí$\operatorname{deos} s=$ AATTAATCGTCGGGCATGCCA possui uma região (em negrito) que não codifica nada, pois está entre um STOP-Códon (TAA) e um START-Códon (ATG). As 
Tabela 2.3: Codificação de aminoácidos.

\begin{tabular}{cccccc}
\hline $\begin{array}{c}\text { Primeiro } \\
\text { nucleotídeo }\end{array}$ & \multicolumn{3}{c}{ Tegundo nucleotídeo } & Terceiro \\
\hline T & Phe & Ser & His & Cys & T \\
T & Phe & Ser & His & Cys & C \\
T & Leu & Ser & STOP & STOP & A \\
T & Leu & Ser & STOP & Ser & G \\
C & Leu & Pro & His & Arg & T \\
C & Leu & Pro & His & Arg & C \\
C & Leu & Pro & Gin & Arg & A \\
C & Leu & Pro & Gin & Arg & G \\
A & Ile & Thr & Asn & Ser & T \\
A & Ile & Thr & Asn & Ser & C \\
A & Ile & Thr & Lys & Arg & A \\
A & Met & Thr & Lys & Arg & G \\
G & Val & Ala & Asp & Gly & T \\
G & Val & Ala & Asp & Gly & C \\
G & Val & Ala & Glu & Gly & A \\
G & Val & Ala & Glu & Gly & G \\
\hline
\end{tabular}

regiões do DNA que não codificam aminoácidos são chamadas de íntron, e suas origens e funções não foram totalmente desvendadas pela biologia molecular (Lodish et al, 2004).

As regiões do DNA que não fazem parte da região íntron, chamadas de éxon, são responsáveis por codificar seqüências de aminoácidos, também conhecidas como cadeias polipeptídicas. Estas cadeias são as unidades formadoras das proteínas, ou em outras palavras, uma proteína é formada por uma ou mais cadeias polipeptídicas (Calladine et al, 2004). Uma parte da região éxon suficiente para codificar uma cadeia polipeptídica completa é chamada de gene (Lesk, 2002). Já o conjunto de todos os genes de um organismo é denominado genoma (Lengauer et al, 2001). A Figura 2.4 mostra duas proteínas que são codificadas a partir de genes distintos.

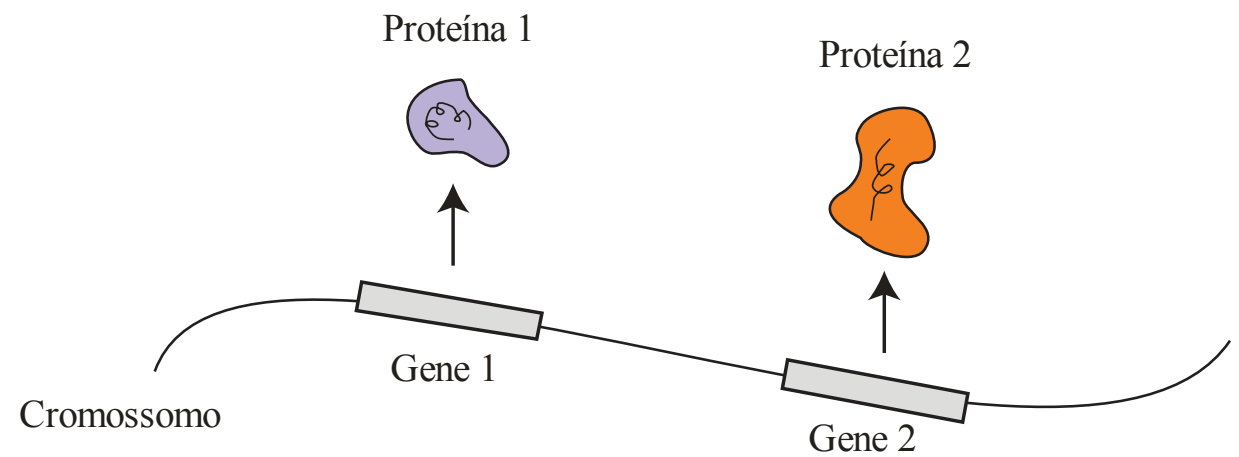

Figura 2.4: Proteínas codificadas a partir de genes distintos. 
O genoma de um organismo simples como o da bactéria Rhodococcus é formado por 9.702.737 bps. Este organismo possui o maior genoma dentre as bactérias disponíveis em http://cmr.tigr.org/tigr-scripts/CMR/shared/Genomes.cgi. Já organismos mais complexos tendem a possuir genomas bem mais extensos. O genoma do ser humano, por exemplo, é formado por aproximadamente 3 Gbps.

\subsection{Bioinformática}

O desenvolvimento de grandes projetos da biologia molecular, como o projeto genoma, destacam a bioinformática como uma área de pesquisa muito relevante (Korf et al, 2003). Contudo, apesar dos vários trabalhos que vem sendo publicados nesta área, ainda não existe uma definição padrão aceita pela comunidade científica para bioinformática. De acordo com Gibas e Jambeck (2001), "a bioinformática é a aplicação da tecnologia de informação ao gerenciamento de dados biológicos", ou em outras palavras, "é a aplicação de técnicas analíticas quantitativas à modelagem de sistemas biológicos". Já para Cohen (2004), a bioinformática é um campo interdisciplinar que surgiu para ajudar os biólogos a utilizar e interpretar seus dados.

No contexto desta dissertação, a bioinformática é definida como uma área da ciência que utiliza métodos da biologia, da matemática e da computação para solucionar questões biológicas relevantes a partir de seqüências de nucleotídeos, de aminoácidos e de informações relacionadas (Baxevanis e Ouellette, 2005). Neste sentido, a bioinformática enfoca a análise de seqüências armazenadas em BDBs e a construção e manipulação destas seqüências com a utilização de programas específicos. Dentre os problemas da biologia molecular enfocados pela bioinformática, destacam-se (Gusfield, 1997):

- Casamento exato: dada uma seqüência $s_{q}$ de consulta e um BDB com as seqüências $s_{1}, s_{2}, \ldots, s_{n}$, um casamento exato retorna todas as ocorrências, se existir alguma, de $s_{q}$ no BDB. Por exemplo, se $s_{q}=$ ACA e $s_{1}=$ TGACAGGACACAG, então $s_{q}$ ocorre em $s_{1}$ nas posições 3,8 e 10 . Note que duas ou mais ocorrências de $s_{q}$ podem se sobrepor, como é o caso das ocorrências nas posições 8 e 10; e

- Casamento aproximado: dada uma seqüência $s_{q}$ de consulta e um BDB com as seqüências $s_{1}, s_{2}, \ldots, s_{n}$, um casamento aproximado retorna todas as ocorrências, se existir alguma, de $s_{q}^{\prime}$ no BDB, onde $s_{q}^{\prime}$ é uma transformação de $s_{q}$ com um custo menor que um dado $\delta$. A transformação de $s_{q}$ em $s_{q}^{\prime}$ é realizada por meio da inserção de espaços em branco e também pela inserção, remoção e substituição de caracteres. Por exemplo, se $s_{q}=$ GAGGAC e $s_{1}=$ TGACAGGACACAG, então $s_{q}$ não ocorre em $s_{1}$. Contudo, se o primeiro nucleotídeo de $s_{q}$ for substituído pelo nucleotídeo C, então $s_{q}$ ocorre na posição 4 de $s_{1}$. Caso o custo desta transformação for menor que $\delta$, este resultado é considerado, então, um resultado válido. 
São diversas as motivações para se encontrar soluções eficientes que resolvam os problemas de casamento exato e aproximado. Um exemplo interessante refere-se à similaridade entre genes específicos da mosca-das-frutas (Drosophila melanogaster) e do ser humano. A mosca-das-frutas possui um gene chamado eyeless que, se removido por métodos de biologia molecular, resulta em descendentes sem olhos. O ser humano, por sua vez, possui um gene que é responsável pelo desenvolvimento da íris. Se este gene do ser humano for inserido em moscas sem o gene eyeless, a produção de olhos nos descendentes destas moscas ocorre normalmente (Gibas e Jambeck, 2001). Isto significa que entender a estrutura e a funcionalidade de genomas pode contribuir na correção de anomalias genéticas.

Contudo, o avanço tecnológico dos laboratórios de biologia molecular tem proporcionado um grande aumento na produção de dados biológicos. A Figura 2.5 ilustra o crescimento anual das seqüências de nucleotídeos catalogadas no GenBank. Por outro lado, a grande maioria dos casamentos exatos e aproximados possuem apenas uma pequena parte do BDB como resposta. Assim, acessar todo o BDB para encontrar poucos dados constitui, em geral, uma estratégia ineficiente. Por exemplo, a consulta "encontre todos os genes que produzem a proteína lactase no genoma humano" retorna poucos Kbps de uma seqüência de aproximadamente 3 Gbps. Idealmente, uma determinada consulta deveria acessar apenas os dados que fazem parte de seu resultado (Silberschatz et al, 2005). Para permitir este tipo de operação, existem os métodos de acesso.

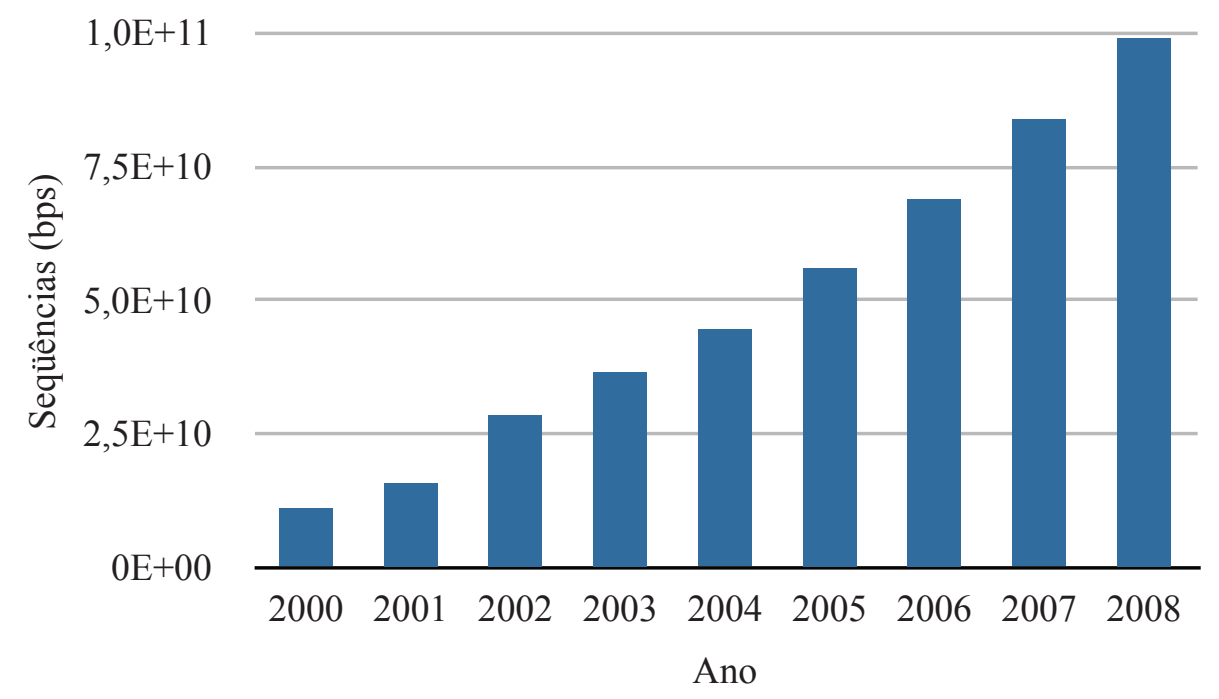

Figura 2.5: Seqüências de nucleotídeos catalogadas no GenBank.

\subsection{Métodos de Acesso}

Um método de acesso (MA) é definido por meio de uma estrutura de dados adaptada ao gerenciamento dos dados, a qual pode ser armazenada em memória primária ou em me- 
mória secundária, e de algoritmos de pesquisa na estrutura que permitem a determinação de diversos tipos de relacionamento (Ciferri, 2002).

Por exemplo, considere a busca por uma pessoa específica em uma lista telefônica. Para encontrar esta pessoa, não é necessário percorrer todos os nomes de uma lista telefônica, visto que esta é ordenada lexicograficamente. Cada elemento indexado divide o conjunto em duas regiões, os que são lexicograficamente anteriores e os que são lexicograficamente posteriores. Desta forma, é possível descartar partes da lista telefônica sem efetivamente compará-las, reduzindo assim, o tempo necessário para realizar esta tarefa como um todo. De forma similar, os MAs utilizam uma ou mais propriedades existentes nos dados que permitem descartar partes da busca seqüencial (Ramakrishnan e Gehrke, 2002).

Inicialmente, diversos MAs foram desenvolvidos para gerenciar a recuperação de dados tradicionais, como números inteiros e caracteres. Dentre estes MAs, destacam-se a tabela hash, a árvore binária, a árvore AVL, a árvore-B (Bayer e McCreight, 1972) e suas variantes (Comer, 1979). Com o desenvolvimento de diversas aplicações que manipulam dados complexos, surgiram métodos de acesso voltados à indexação destes dados. Por dado complexo, entende-se todo dado que não é formado por apenas um tipo de dado tradicional (e.g., imagens, vídeos e coordenadas geográficas).

Esta seção define formalmente os conceitos relacionados aos MAs para dados complexos. As Seções 2.3.1 e 2.3.2 definem espaços multidimensionais e espaços métricos, respectivamente. As funções de distância utilizadas nestes espaços são descritas na Seção 2.3.3, enquanto que os principais tipos de consulta por similaridade são resumidos na Seção 2.3.4.

\subsubsection{Espaço Multidimensional}

Um espaço multidimensional $\mathbb{U}$ de $e$ dimensões (espaço $e$-dimensional) é dado por uma e-upla ordenada de conjuntos. Alguns exemplos de conjuntos que podem formar os espaços multidimensionais são: o conjunto $\mathbb{R}$ dos números reais, o conjunto $\mathbb{C}$ dos números complexos, ou até mesmo conjuntos mais genéricos e/ou finitos, como o conjunto booleano $\mathbb{B}=\{0,1\}$. Em um espaço multidimensional, a seguinte propriedade deve ser satisfeita:

(Imersão) Qualquer elemento $t \in \mathbb{U}$ deve ser formado pela mesma $e$-upla ordenada de conjuntos de $\mathbb{U}$. Por exemplo, todos os elementos imersos em um espaço tridimensional $\mathbb{U}=\langle\mathbb{C}, \mathbb{R}, \mathbb{R}\rangle$ são formados por uma trinca ordenada de um número complexo e dois números reais.

Pode-se notar que os espaços multidimensionais são possuem um conjunto padrão de operadores definidos sobre seus elementos. Na verdade, os operadores de um espaço multidimensional dependem fortemente do domínio da aplicação, apesar de alguns operadores (como a subtração) serem mais comuns que outros (Gaede e Günther, 1998). 


\subsubsection{Espaço Métrico}

Um espaço métrico $\mathbb{M}$ é dado por um par ordenado $\langle\mathbb{X}, d\rangle$, onde $\mathbb{X}$ representa um domínio e $d: \mathbb{X} \times \mathbb{X} \rightarrow \mathbb{R}$ é uma função de distância. Em um espaço métrico, as seguintes propriedades devem ser satisfeitas para quaisquer elementos $t_{1}, t_{2}, t_{3} \in \mathbb{X}$ (Lima, 1975):

(Identidade) $d\left(t_{1}, t_{1}\right)=0$

(Não negatividade) $d\left(t_{1}, t_{2}\right) \geq 0$

(Simetria) $d\left(t_{1}, t_{2}\right)=d\left(t_{2}, t_{1}\right) ; \mathrm{e}$

(Desigualdade triangular) $d\left(t_{1}, t_{2}\right) \leq d\left(t_{1}, t_{3}\right)+d\left(t_{3}, t_{1}\right)$.

Pode-se notar que neste espaço não há nenhuma restrição quanto ao número de dimensões de seus elementos, sendo que estes podem até mesmo ser adimensionais. Desta forma, um espaço multidimensional pode ser considerado um espaço métrico, dada uma função de distância que satisfaça às propriedades citadas.

\subsubsection{Função de Distância}

As funções de distância são utilizadas para medir quão similares ou dissimilares são dois elementos. Por convenção, adota-se que quanto mais próximo de zero o valor retornado por uma função de distância, mais similares são os elementos de entrada. Por outro lado, quanto mais distantes de zero, podendo inclusive tender ao infinito, mais dissimilares são os elementos em questão. Para esta dissertação, são relevantes as funções de distância que formam a Família de Minkowski e a função de distância de Levenshtein.

\section{Família de Minkowski}

Esta família de funções (Wilson e Martinez, 1997), denotada por $L_{p}$, pode ser utilizada para medir a distância entre elementos contidos em um espaço multidimensional. Suponha que $a=\left[a_{1}, a_{2}, \ldots, a_{e}\right]$ e $b=\left[b_{1}, b_{2}, \ldots, b_{e}\right]$ sejam dois elementos existentes em um espaço e-dimensional. A família de Minkowski é definida como:

$$
L_{p}(a, b)=\left(\sum_{i=1}^{e}\left|a_{i}-b_{i}\right|^{p}\right)^{1 / p}
$$

Dentre as várias funções desta família, existem três que são comumente utilizadas: (i) a Manhattan $\left(L_{1}\right)$, que corresponde ao somatório do módulo das diferenças entre as dimensões dos elementos; (ii) a euclidiana $\left(L_{2}\right)$, que representa a distância entre objetos no mundo real; e (iii) a Chebychev $\left(L_{\infty}\right)$, que é calculada no limite da Equação 2.1. A Figura 2.6 ilustra as diferentes formas geométricas geradas pelo mesmo raio nas funções $L_{1}, L_{2}$ e $L_{\infty}$ em um espaço bidimensional. 
Em uma generalização para um espaço e-dimensional, as funções de distância $L_{1}, L_{2}$ e $L_{3}$ geram um hiper-losango, uma hiper-esfera e um hiper-cubo, respectivamente. Na Figura 2.6, a sobreposição representada na imagem mais à direita indica que as diferentes funções da família Minkowski englobam subespaços diferentes, sendo que quanto maior o valor de $p$, menos restritivo é o subespaço gerado.
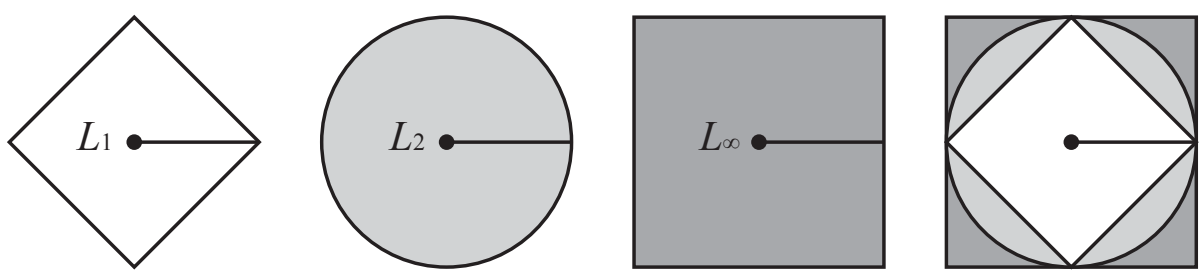

Figura 2.6: Família de Minkowski.

\section{Função de Levenshtein}

A função de Levenshtein (Levenshtein, 1966) é comumente utilizada para medir distâncias entre seqüências de caracteres contidas em um espaço métrico. Ao contrário das funções da família de Minkowski, a função de Levenshtein, denotada por $L_{e d i t}$, pode medir a distância entre elementos de dimensões diferentes. Em sua versão mais simples, a $L_{\text {edit }}\left(s_{1}, s_{2}\right)$ retorna o número mínimo de operações de edição (i.e., inserções, remoções e substituições) necessárias para tornar $s_{1}=s_{2}$. Alguns exemplos dos valores retornados por esta função são:

- $L_{\text {edit }}(\mathrm{ACCTC}, \mathrm{AGGTC})=2$ (i.e., duas substituições);

- $L_{e d i t}(\mathrm{ACCTC}, \mathrm{ACTC})=1$ (i.e., uma remoção); e

- $L_{\text {edit }}(\mathrm{ACCTC}, \mathrm{ACAA})=3$ (i.e., duas substituições e uma remoção).

A função $L_{e d i t}$ é limitada inferiormente por zero, situação que ocorre quando as seqüências de entrada são iguais, e superiormente pelo tamanho da maior seqüência do domínio. Por isso, existem algumas variações desta função que associam pesos às operações de edição, com o intuito de torná-la mais restritiva. No caso específico de comparação de seqüências de nucleotídeos, variações da $L_{\text {edit }}$ também levam em consideração outros fatores, como a probabilidade de mutações (Gusfield, 1997).

\subsubsection{Consultas por Similaridade}

Consultas que medem o grau de dissimilaridade entre elementos são chamadas consultas por similaridade. Estas consultas envolvem um espaço, um objeto de consulta e um conjunto de parâmetros, que é definido pelo tipo de consulta por similaridade em questão. Dado um espaço métrico $\mathbb{M}=\langle\mathbb{X}, d\rangle$ e um subconjunto de $X=\left\{t_{1}, t_{2}, \ldots, t_{n}\right\} \subseteq \mathbb{X}$, no qual as consultas são realizadas, as consultas por similaridade mais comuns são: 
- Consulta por abrangência $\left(R_{q}\right)$ : retorna todos os elementos de $X$, cujas distâncias até $t_{q} \in \mathbb{X}$ são menores ou iguais ao raio de consulta $r_{q}$.

- Consulta dos $k$-vizinhos mais próximos $\left(K N N_{q}\right)$ : retorna os $k$ elementos de $X$ mais próximos de $t_{q} \in \mathbb{X}$.

A consulta "encontre todos os genes que difiram no máximo em $10 \%$ do gene eyeless" é um exemplo de aplicação do operador $R_{q}$. A Figura 2.7 mostra essa consulta em um espaço bidimensional. Nesta figura, o gene eyeless é representado pelo elemento $t_{q}$ e o raio de consulta $r_{q}$ cobre todas as possibilidades de seqüências $10 \%$ distintas de $t_{q}$.

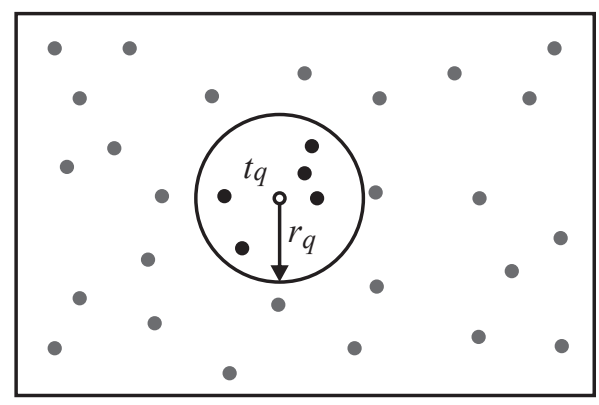

Figura 2.7: Exemplo de consulta por abrangência.

Já a consulta "encontre os dois genes mais parecidos com o gene eyeless" é um exemplo de aplicação do operador $K N N_{q}$. A Figura 2.8 ilustra esta consulta em um espaço bidimensional. Nesta figura, o gene eyeless está representado pelo elemento $t_{q}$.

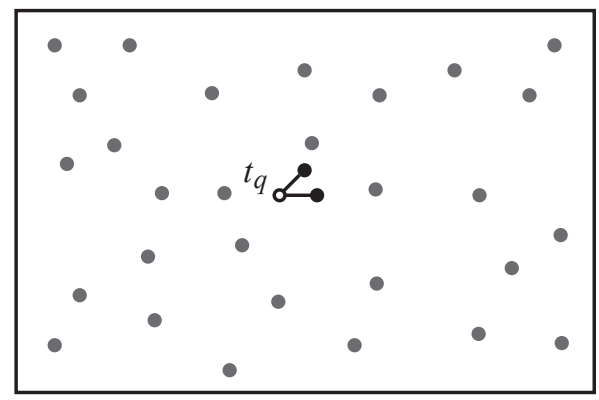

Figura 2.8: Exemplo de consulta dos $k$-vizinhos mais próximos.

\subsection{Métodos de Acesso Multidimensionais}

Para prover acesso eficiente ao número crescente de aplicações baseadas em dados complexos, surgiram os métodos de acesso multidimensionais (MAUs) (Gaede e Günther, 1998). Em geral, os MAUs organizam elementos por meio de uma estrutura hierárquica na forma de uma árvore. Esta estrutura reduz o espaço de busca, conduzindo-a a porções dos elementos indexados que são mais similares ao elemento de consulta. As Seções 2.4.1, 2.4.2 e 2.4.3 descrevem, respectivamente, os MAUs $K$-D-tree, Quadtree e $R$-tree. 


\subsubsection{K-D-tree}

A K-D-tree (Bentley, 1975) é considerada uma das primeiras estruturas de dados e-dimensionais. Este estrutura pode ser vista como uma árvore binária que representa a subdivisão recursiva do espaço multidimensional em subespaços por meio de hiperplanos $(e-1)$-dimensionais. Cada hiperplano divide o espaço em dois subespaços. Estes subespaços são então novamente divididos, sendo que este processo continua recursivamente até que os subespaços gerados não possuam nenhum elemento. A Figura 2.9 mostra um espaço bidimensional particionado por meio desta abordagem. O conjunto de dados considerado nesta figura é $X=\left\{t_{1}, t_{2}, \ldots, t_{10}\right\}$.

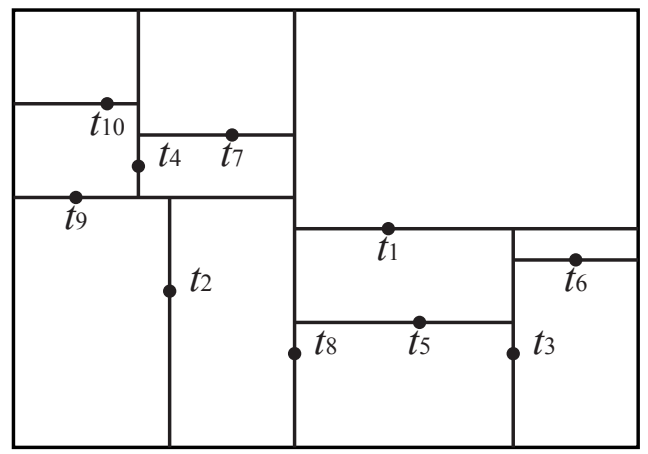

Figura 2.9: Subespaços gerados pela $K$-D-tree.

Uma variação deste método de acesso, chamada Adaptive K-D-tree (Bentley e Friedman, 1979), não traça os hiperplanos interceptando elementos, mas sim em pontos que melhor dividem o número de elementos do conjunto. Desta forma, árvores mais balanceadas são criadas e todos os elementos passam a ser armazenados em nós folhas, pois os nós internos guardam dados do ponto de divisão escolhido.

Já a Bintree (Tamminen, 1984) é uma variação da $K$-D-tree que particiona os subespaços em tamanhos iguais. Apesar de tornar a estrutura menos adaptativa, esta abordagem tem diversas vantagens, como o conhecimento implícito do particionamento dos hiperplanos. Desta forma, este método requer menos processamento durante o processo de particionamento dos subespaços.

\subsubsection{Quadtree}

A Quadtree (Finkel e Bentley, 1974), assim como a $K$-D-Tree, divide o espaço por meio de hiperplanos. Contudo, uma diferença importante encontra-se no fato da Quadtree não ser uma árvore binária. Em um espaço e-dimensional, cada nó da estrutura de dados da Quadtree possui $2^{e}$ filhos. Por exemplo, em um espaço bidimensional, cada partição forma $2^{2}=4$ subespaços. Os particionamentos continuam a ser recursivamente formados até que o número de nós do subespaço atual seja menor que um certo limiar. 
Existem duas variantes bem conhecidas para escolher o local de divisão dos subespaços (Samet, 1984). A primeira variante, chamada Point quadtree escolhe um ponto e o utiliza como centro das subdivisões geradas, em uma abordagem semelhante à da $K$ - $D$-tree. Já a segunda variante, chamada Region quadtree, assim como a Bintree, particiona os subespaços em regiões iguais. A Figura 2.10 ilustra os diferentes particionamentos gerados por estas duas técnicas em um espaço bidimensional, usando como base o mesmo conjunto de dados da Figura 2.9 (i.e., $X=\left\{t_{1}, t_{2}, \ldots, t_{10}\right\}$ ).

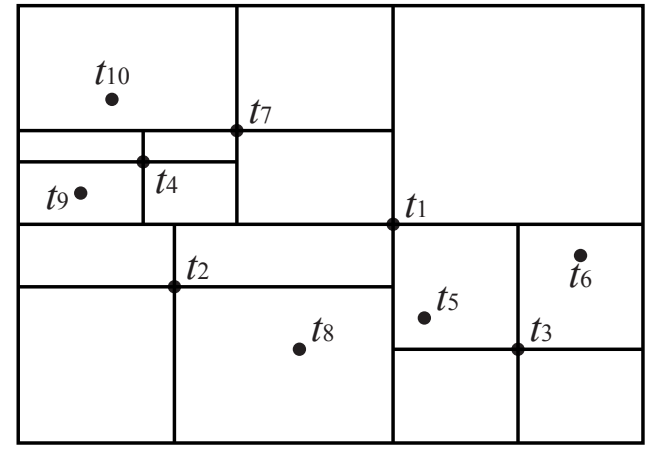

Point quadtree

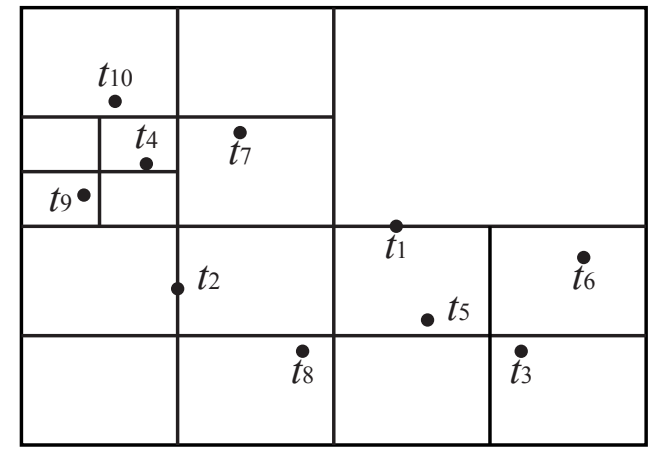

Region quadtree

Figura 2.10: Subespaços gerados pela Point quadtree e Region quadtree.

\subsubsection{R-tree}

A R-tree (Guttman, 1984) é um dos MAUs mais importantes já desenvolvidos. Mesmo nos dias atuais, este MA é muito utilizado como base de comparação para avaliar o desempenho de novas técnicas.

A $R$-tree pode ser vista como uma adaptação da árvore- $\mathrm{B}+$ para espaços multidimensionais. Cada nó da $R$-tree representa o retângulo envolvente mínimo (MBR) que armazena seus elementos. No processo de inserção, quando um nó atinge a capacidade máxima, uma política de particionamento é executada e o MBR representado por este nó é dividido em duas regiões. As políticas de particionamento propostas por Guttman são:

- Método exaustivo: testa todas as possibilidades de novos nós que satisfazem os requerimentos de número mínimo e máximo de elementos por nó e escolhe aquele que minimiza a área dos MBRs gerados;

- Método quadrático: examina os filhos do nó em questão e particiona o par de elementos que gastariam a maior área se fossem inseridos em um mesmo MBR. Os outros elementos são distribuídos minimizando a sobreposição dos MBRs; e

- Método linear: particiona na dimensão com a maior separação normalizada entre dois MBRs. Os demais elementos são distribuídos minimizando as áreas dos MBRs. 
A $R+$-tree (Sellis et al, 1987) é uma variação da $R$-tree que propõe uma maneira de resolver os problemas de sobreposições, armazenando-as como diferentes nós. Apesar de resolver o problema da sobreposição, esta abordagem torna o algoritmo de divisão de nós mais custoso e aumenta o número de acessos à memória secundária.

A $R^{*}$-tree (Beckmann et al, 1990), uma outra variante da $R$-tree, mostra que as técnicas anteriores são altamente dependentes da ordem de inserção dos elementos e propõe uma abordagem que minimiza esta característica. Além disso, a $R^{*}$-tree também propõe uma nova política de quebra de nós baseada no método quadrático de Guttman, minimizando o perímetro dos MBRs gerados e maximizando a ocupação dos novos nós. A Figura 2.11 ilustra os diferentes MBR gerados pelo método exaustivo da $R$-tree e pela $R^{*}$-tree em um espaço bidimensional para o mesmo conjunto de dados da Figura 2.9 (i.e., $X=\left\{t_{1}, t_{2}, \ldots, t_{10}\right\}$ )

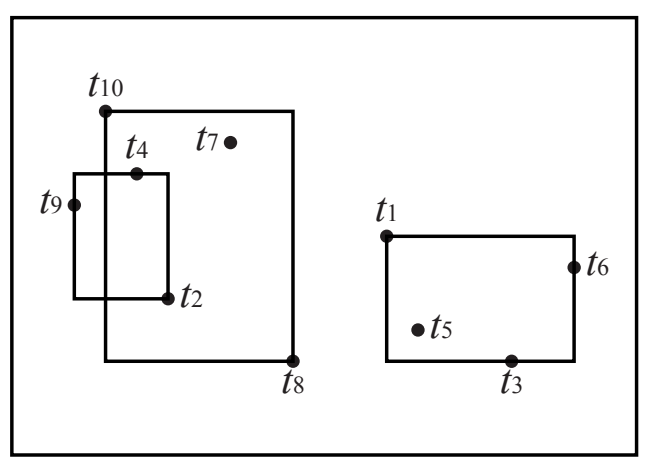

R-tree (método exaustivo)

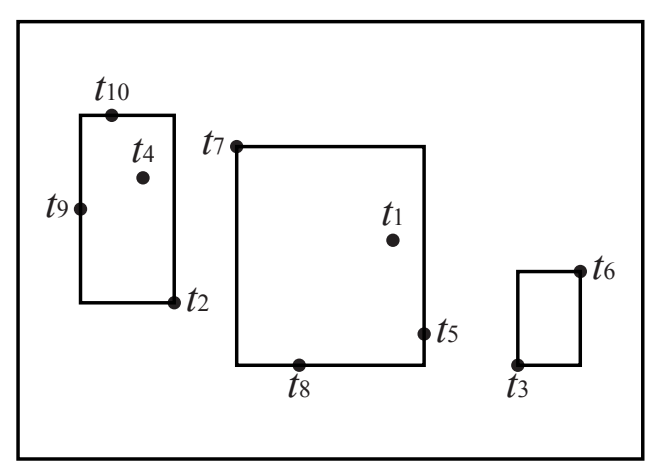

$R^{*}$-tree

Figura 2.11: MBRs gerados pelo método exaustivo da $R$-tree e pela $R^{*}$-tree.

\subsection{Métodos de Acesso Métricos}

Os MAUs possuem duas grandes limitações: (i) todos os elementos imersos em um espaço multidimensional devem possuir o mesmo número de dimensões do espaço em questão; e (ii) dados que possuem muitas dimensões sofrem da maldição da alta dimensionalidade (Chávez et al, 2001). Para acessar eficientemente os dados complexos que não são suportados pelos MAUs, surgiram os métodos de acesso métricos (MAMs) (Hjaltason e Samet, 2003). As Seções 2.5.1, 2.5.2 e 2.5.3 resumem, respectivamente, os MAMs GH-tree, M-tree e Slim-tree.

\subsubsection{GH-tree}

A GH-tree (Uhlmann, 1991) foi um dos primeiros MAMs propostos na literatura. A estrutura de dados deste MAM é construída escolhendo dois elementos aleatórios do espaço métrico e traçando um hiperplano generalizado entre eles, gerando então dois subespa- 
ços. Este hiperplano é formando da seguinte forma. Dados os elementos $t_{i}$ e $t_{j}$, um ponto $t_{k}$ pertence ao hiperplano se $d\left(t_{i}, t_{k}\right)=d\left(t_{j}, t_{k}\right)$. Os elementos mais próximos de $t_{i}$ são agrupados em $t_{i}$, e os elementos mais próximos de $t_{j}$ são agrupados em $t_{j}$. Este processo continua recursivamente nos subespaços gerados até que todos os pontos tenham sido escolhidos. A Figura 2.12 ilustra essa divisão em um espaço bidimensional para o mesmo conjunto de dados da Figura 2.9 (i.e., $X=\left\{t_{1}, t_{2}, \ldots, t_{10}\right\}$ ).

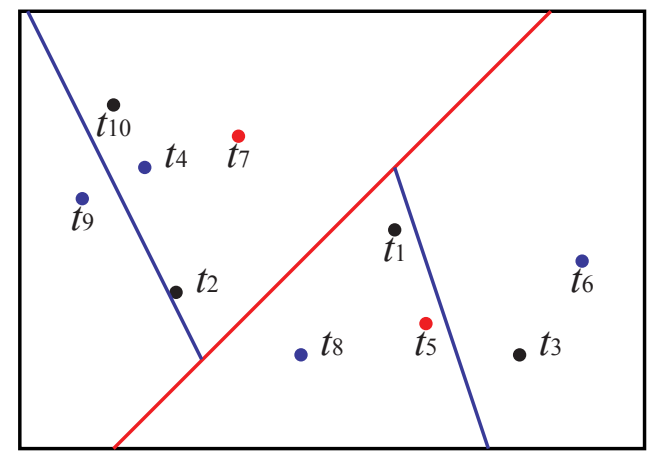

Figura 2.12: Subespaços gerados pela GH-tree.

Uma das desvantagens da GH-tree encontra-se no fato de que somente consultas pontuais podem ser realizadas, pois apenas pontos podem ser comparados às partições. Além disso, cada nó pode conter no máximo dois elementos. Esta propriedade limita o uso da GH-tree para memória primária.

\subsubsection{M-tree}

A $M$-tree (Ciaccia et al, 1997) foi um dos primeiros MAMs desenvolvidos para memória secundária a surgir na literatura. Como na árvore-B+, os nós folhas da $M$-tree armazenam todos os elementos do espaço métrico em questão. Os nós internos guardam elementos chamados representantes, que possuem um raio de cobertura e são escolhidos a partir dos algoritmos de promoção. Dentre as várias políticas de promoção, Ciaccia et al (1997) descrevem as seguintes abordagens:

- m_RAD: testa todas as possibilidades e promove o par de elementos que minimiza a soma dos raios após o particionamento;

- mM_RAD: similar à m_RAD, porém minimiza o valor máximo dos raios;

- SAMPLING: aplica a política mM_RAD sobre uma amostra dos elementos, reduzindo o processamento envolvido nesta operação;

- M_LB_DIST: difere das políticas anteriores no sentido que apenas usa distâncias pré-calculadas. Um dos elementos escolhidos é fixado como sendo o representante do nó e o outro é determinado pelo elemento mais distante deste representante; e 
- RANDOM: seleciona aleatoriamente um par de elementos. Apesar de não ser uma estratégia inteligente, é rápida e pode ser utilizada para comparar e validar outras abordagens.

Por exemplo, a Figura 2.13 mostra à esquerda um nó com a capacidade excedida e à direita a nova redistribuição resultante do processo de promoção. Primeiramente, devese escolher dois elementos para serem promovidos como representantes utilizando uma das políticas de promoção definidas. Em seguida, cria-se um novo nó e todos os outros elementos são redistribuídos de acordo com sua distância aos elementos representantes. Por fim, o novo par de elementos representantes é copiado para o nó pai, formando uma hierarquia. Caso o nó pai esteja cheio, o processo de promoção é realizado novamente, e assim recursivamente.

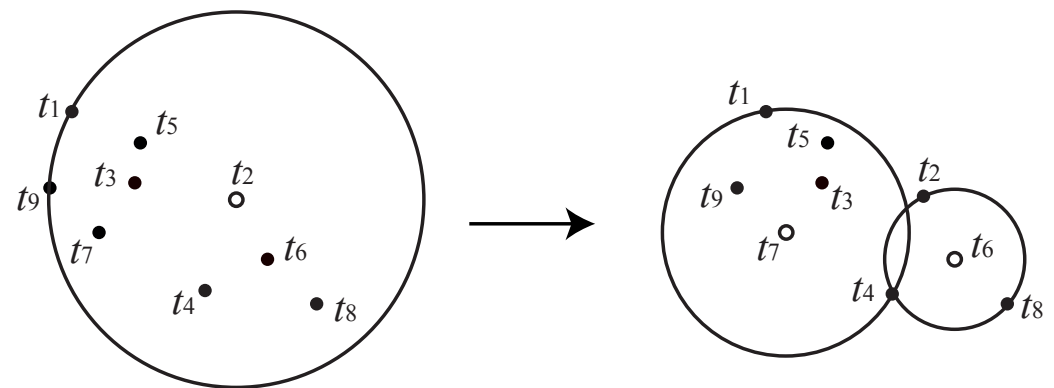

Figura 2.13: Processo de promoção da M-tree.

A $M$-tree possui duas grandes desvantagens. Uma primeira desvatagem é que não existe nenhum mecanismo de manutenção para diminuir as sobreposições conforme a estrutura cresce. Outra desvantagem é que os algoritmos de particionamento propostos são custosos.

\subsubsection{Slim-tree}

A Slim-tree (Traina-Jr et al, 2000) é um método de acesso considerado uma evolução da $M$-tree, com melhorias no processo de inserção de elementos e uma política de particionamento mais eficiente. Esta política calcula a árvore geradora mínima (MST) dos elementos em questão e remove sua maior aresta. Os dois subgrafos conexos resultantes originam as novas partições. A Figura 2.14 exemplifica uma execução desta política para o mesmo conjunto de dados da Figura 2.13.

Além disso, a Slim-tree é o primeiro MAM que tenta resolver o problema das sobreposições entre subespaços, propondo uma técnica de minimização chamada Slim-down. Idealmente, uma consulta pontual em um método de acesso métrico deve visitar apenas um nó por nível. Neste caso, o fator de sobreposição pode ser considerado zero. Já no pior caso, todos os nós são visitados e o fator de sobreposição é total e igual a um. Os fatores de sobreposição dos casos médios podem ser medidos pela divisão do número de 


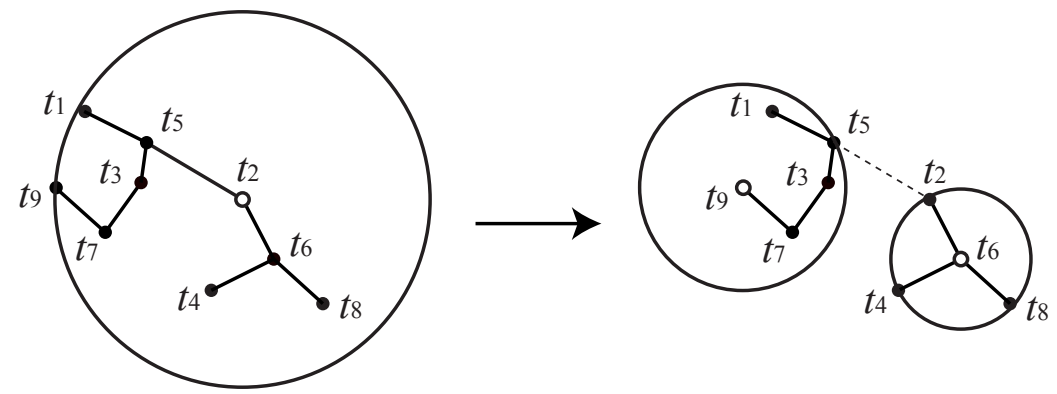

Figura 2.14: Processo de promoção da Slim-tree.

elementos em regiões sobrepostas pelo número total de elementos. A partir desta medida, pode-se acionar o procedimento Slim-down, que tem por objetivo reorganizar a estrutura de dados, de forma a minimizar as sobreposições nos nós internos.

A DF-tree (Traina-Jr et al, 2002) é uma evolução da Slim-tree que faz uso de elementos representativos chamados omni-focos (Santos-Filho et al, 2001) para otimizar a execução de consultas por abrangência. Neste MAM, o número de omni-focos é igual a $D_{2}+1$, onde $D_{2}$ é a dimensão de correlação fractal, como uma aproximação da dimensão intrínseca dos dados (Belussi e Faloutsos, 1995). Esta técnica pode ser utilizada em qualquer MAM gerando toda uma nova família de MAMs denominada Omni-family. A Figura 2.15 ilustra o uso de dois omni-focos. Pode-se notar que a utilização destes elementos permite descartar grande parte do espaço de busca, sendo que apenas a região cinza precisa ser investigada.

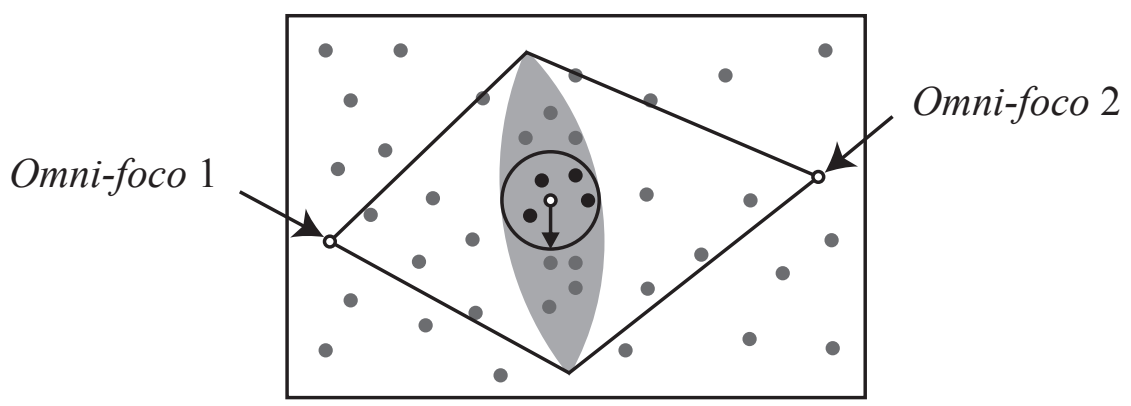

Figura 2.15: Uso de omni-focos na execução de consultas por abrangência.

\subsection{Considerações Finais}

Neste capítulo foram descritos conceitos básicos relacionados à biologia molecular e à bioinformática. Com relação à biologia molecular, foram discutidos os nucleotídeos, compostos que podem ser considerados a menor unidade estrutural do material genético, e o genoma, que é o conjunto de todas as informações hereditárias que um indivíduo transmite aos seus descendentes. Já com relação à bioinformática, foram definidos os problemas de 
casamentos exato e aproximado. Além disso, foi ilustrado o grande crescimento na produção de dados biológicos.

Em seguida, foram discutidos conceitos relacionados aos métodos de acesso. Com relação aos métodos de acesso multidimensionais, foram descritos a $K$-D-tree, a Quadtree e a $R$-tree, que representam as primeiras tentativas de recuperar eficientemente dados complexos. Já com relação aos métodos de acesso métricos, foram resumidos a GH-tree, a $M$-tree e a Slim-tree, técnicas que utilizam propriedades do espaço métrico para melhorar a recuperação dos dados complexos. O estudo e a análise das características e limitações desses métodos de acesso motivaram a proposta de métodos de acesso complementares ao objetivo principal desta dissertação, os quais são descritos nos Apêndices A e B.

Contudo, os métodos de acesso discutidos neste capítulo não funcionam eficientemente com seqüências de nucleotídeos. Estes dados biológicos apresentam alta dimensionalidade e, quando utilizados com os MAUs e MAMs detalhados, não geram bons resultados. Neste sentido, o Capítulo 3 descreve a árvore de sufixo, uma estrutura de dados muito utilizada na solução de problemas sobre seqüências, além de resumir trabalhos correlatos que visam a construção de árvores de sufixo persistentes. 


\section{Capítulo \\ 3 \\ Trabalhos Correlatos}

Este capítulo resume trabalhos correlatos que buscam resolver os problemas de casamento exato e casamento aproximado discutidos no Capítulo 2. A Seção 3.1 descreve a árvore de sufixo, uma estrutura de dados muito importante na resolução destes problemas. A Seção 3.2 investiga a técnica de Hunt et al (2001), uma das primeiras técnicas que criam árvores de sufixo persistentes para seqüências de escala cromossômica (i.e., tamanho dos cromossomos do ser humano, em média 125 Mbps). Já as Seções 3.3 e 3.4 resumem, respectivamente, o TDD (Tata et al, 2004; Tian et al, 2005) e o TrELlis + (Phoophakdee e Zaki, 2007, 2008), que são as únicas técnicas de construção de árvores de sufixo existentes na literatura que atingem escala genômica (i.e., tamanho do genoma humano, totalizando aproximadamente $3 \mathrm{Gbps}$ ). A Seção 3.5 lista outros métodos de acesso que têm sido propostos para resolver problemas de casamento exato e casamento aproximado. O capítulo é finalizado na Seção 3.6, com uma análise comparativa dos trabalhos correlatos descritos neste capítulo.

\section{1 Árvore de Sufixo}

Seja $\Sigma=\left\{\alpha_{1}, \alpha_{2}, \ldots, \alpha_{\sigma}\right\}$ um alfabeto com $\sigma$ caracteres. Seja $\Sigma^{*}$ um conjunto com todas as seqüências que podem ser construídas a partir de $\Sigma$ e seja $s \in \Sigma^{*}$ uma seqüência com $|s|$ caracteres. Seja $s[i: j]$ uma subseqüência entre (e inclusive) o $i$-ésimo e o $j$-ésimo caracteres de $s$. Sejam todas as subseqüências $s[1: i]$ prefixos e todas as subseqüências $s[i:|s|]$ sufixos de $s$. Seja $\$ \notin \Sigma$ um caractere terminal que representa o final de uma seqüência. 
A árvore de sufixo $T_{s}$ é uma árvore com exatamente $|s|$ nós folhas numerados de 1 a $|s|$. Nesta estrutura, cada nó interno, com exceção da raiz, tem pelo menos dois filhos e cada aresta representa uma subseqüência de $s$. Duas arestas que partem do mesmo nó não podem representar subseqüências com prefixo comum. Além disso, a concatenação das subseqüências representadas pelas arestas no caminho da raiz ao nó folha $i$ forma o sufixo $s[i:|s|]$ (Gusfield, 1997).

A Figura 3.1 mostra a árvore de sufixo $T_{s}$ para $s=$ TAGAGA. Por exemplo, a concatenação das subseqüências representadas pelas arestas no caminho da raiz ao nó folha 4 forma o sufixo AGA, indicando que este sufixo começa na quarta posição de $s$.

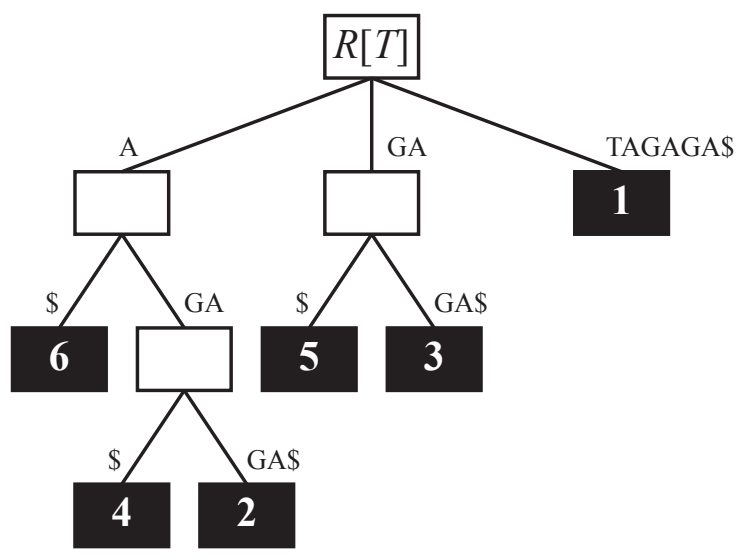

Figura 3.1: Árvore de sufixo $T_{s}$ para $s=$ TAGAGA.

Em uma árvore de sufixo, sufixos que possuem o mesmo prefixo compartilham a mesma sub-árvore. Por exemplo, os sufixos AGAGA e AGA na Figura 3.1 compartilham a mesma sub-árvore porque possuem um prefixo comum. Desta maneira, os prefixos de uma seqüência $s$ podem ser utilizados para particionar $T_{s}$ em sub-árvores menores, chamadas de árvores de sufixo prefixadas. Mais especificamente, uma árvore de sufixo prefixada $P_{s}^{p}$ é uma árvore de sufixo que contém apenas os sufixos de $s$ que começam com o prefixo $p$ (Hunt et al, 2001; Phoophakdee e Zaki, 2007). A Figura 3.2 mostra a árvore de sufixo prefixada $P_{s}^{\mathrm{A}}$ da árvore de sufixo ilustrada na Figura 3.1.

Um aspecto adicional relacionado ao uso de árvores de sufixo e árvores de sufixo prefixadas diz respeito à forma na qual elas são construídas. Neste sentido, as Seções 3.1.1 e 3.1.2 apresentam, respectivamente, um algoritmo trivial e um algoritmo linear para construção destas estruturas.

\subsubsection{Construção Trivial}

O algoritmo trivial de construção de uma árvore de sufixo $T_{s}$ contempla $|s|$ iterações. Inicialmente, uma aresta é criada para representar o maior sufixo de $s$ (i.e., $s[1:|s|]$ ). Em seguida, são adicionados os sufixos $s[i:|s|]$, para $i$ variando entre (e inclusive) 2 e $|s|$. Em cada iteração, as arestas são particionadas de modo a preservar a propriedade de não repre- 


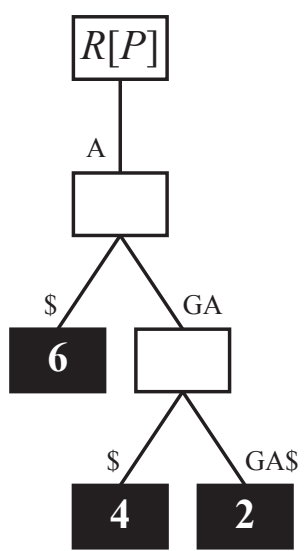

Figura 3.2: Árvore de sufixo prefixada $P_{s}^{\mathrm{A}}$ da árvore de sufixo da Figura 3.1.

sentar prefixo comum. Este algoritmo possui complexidade $O\left(|s|^{2}\right)$ em relação ao tempo no pior caso, mas seu comportamento médio apresenta complexidade $O(|s| \times \log |s|)$ na indexação de seqüências de nucleotídeos (Hunt et al, 2001).

A Figura 3.3 mostra as iterações do algoritmo trivial na construção da árvore de sufixo da Figura 3.1. A primeira iteração deste algoritmo cria uma aresta para representar o sufixo $s[1: 6]=$ TAGAGA, como ilustrado na Figura 3.3a. Em seguida, as Figuras 3.3b e 3.3c mostram as adições dos sufixos $s[2: 6]=$ AGAGA e $s[3: 6]=$ GAGA, respectivamente. Depois disso, a Figura 3.3d ilustra a inserção do suxifo $s[4: 6]=$ AGA. Durante esta iteração, a aresta AGAGA é particionada, garantindo que as arestas que partem da raiz não tenham prefixo comum. Um particionamento similar ocorre durante a inserção do sufixo $s[5: 6]=$ GA (Figura 3.3e). Por fim, a Figura 3.3f mostra a árvore de sufixo gerada após a inserção do último sufixo (i.e., $s[6: 6]=\mathrm{A}$ ).

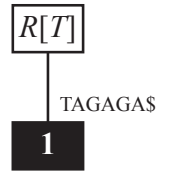

(a)

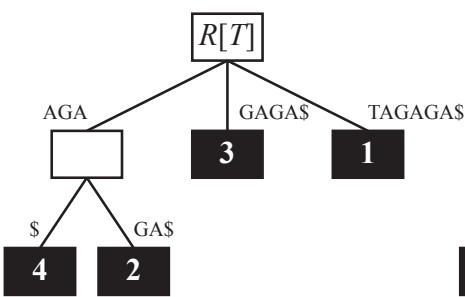

(d)

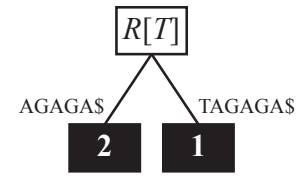

(b)

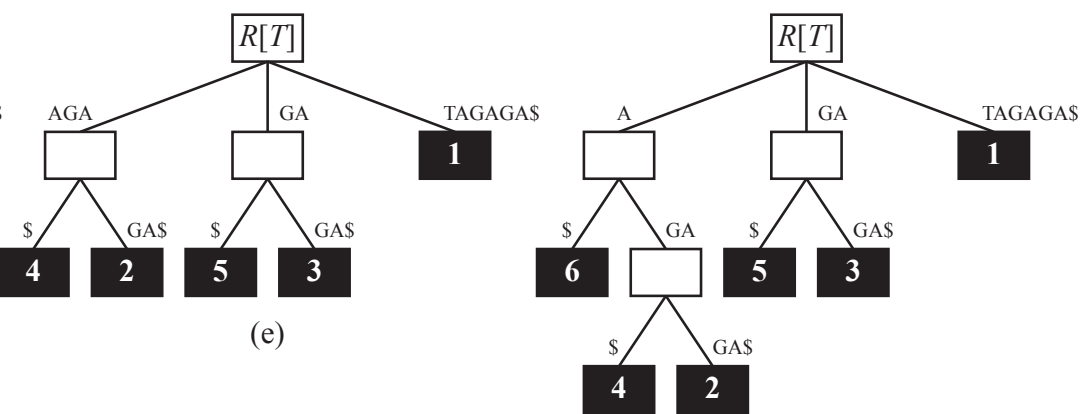

(f)

Figura 3.3: Construção trivial da árvore de sufixo da Figura 3.1.

Note que o algoritmo trival pode ser facilmente adaptado para criar árvores de sufixo prefixadas. A cada iteração, deve-se verificar se o sufixo atual começa com o prefixo da 
árvore de sufixo prefixada em questão. Os sufixos que não começam com este prefixo devem ser descartados. Por exemplo, a Figura 3.4 mostra as iterações do algoritmo trivial na construção da árvore de sufixo prefixada da Figura 3.2.

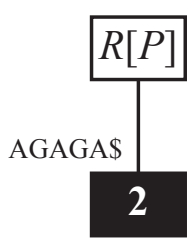

(a)

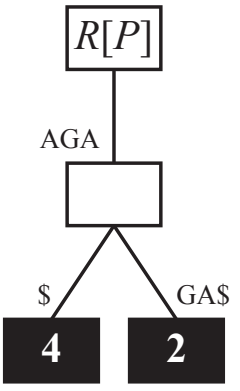

(b)

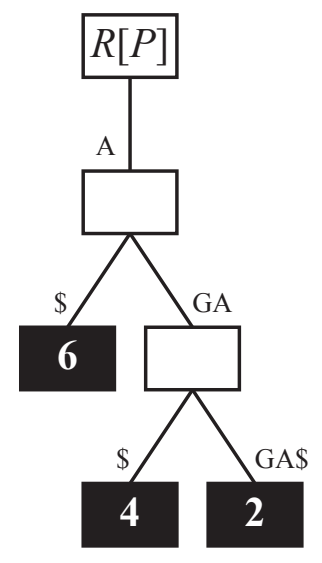

(c)

Figura 3.4: Construção trivial da árvore de sufixo prefixada da Figura 3.2.

\subsubsection{Construção Linear}

O primeiro algoritmo com complexidade linear em relação ao tempo para construir árvores de sufixo foi desenvolvido por Weiner (1973). No trabalho de McCreight (1976), foi proposto um algoritmo que requer menos espaço de memória principal durante o processo de construção desta estrutura. Posteriormente, Ukkonen (1995) desenvolveu um algoritmo conceitualmente simples que preserva as propriedades do algoritmo de McCreight (1976) e que tem sido muito utilizado na literatura (Gusfield, 1997).

De forma geral, estes algoritmos são baseados na utilização de ponteiros denominados elos de sufixo. Estes ponteiros otimizam as iterações de construção dos árvores de sufixo, permitindo melhorias nos caminhos entre nós internos a partir da raiz.

Seja uma seqüência $\alpha s$, onde $\alpha$ denota um único caractere e $s$ uma subseqüência possivelmente vazia. Um elo de sufixo é um ponteiro de um nó interno $x$, tal que o caminho da raiz a $x$ forma $\alpha s$, para outro nó interno $y$, tal que o caminho de raiz a $y$ forma $s$. A Figura 3.5 mostra a árvore de sufixo da Figura $3.1 \mathrm{com}$ todos os seus elos de sufixo representados por setas com linhas tracejadas. Note que o uso de elos de sufixo não permite que os algoritmos lineares sejam utilizados para construir árvores de sufixo prefixadas, dado que o elo de sufixo de um nó pode pertencer a outra subárvore da estrutura de dados. 


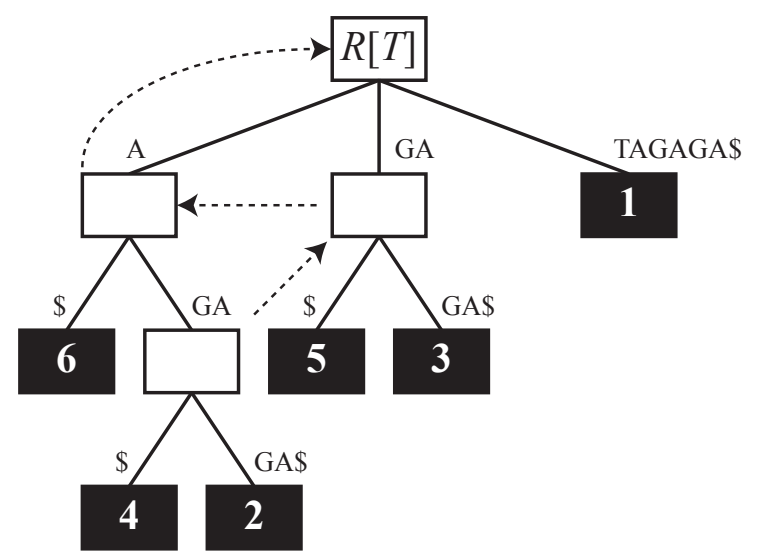

Figura 3.5: Árvore de sufixo da Figura 3.1 com elos de sufixo.

\subsection{A Técnica de Hunt, Atkinson e Irving (2001)}

Vários trabalhos têm surgido na literatura propondo técnicas de construção de árvores de sufixo persistentes. Bieganski (1995) construiu esta estrutura para seqüências com até 1 Mbps, enquanto que Navarro e Baeza-Yates (1999) atingiram o mesmo resultado em uma máquina com apenas $64 \mathrm{MB}$ de memória principal. Uma das primeiras técnicas para construir árvores de sufixo que excedem a memória principal é a técnica de Hunt et al (2001), a qual pode indexar seqüências de escala cromossômica.

A técnica de Hunt et al é caracterizada por abandonar o uso de elos de sufixo e por particionar a árvore de sufixo em árvores de sufixo prefixadas. O Algoritmo 3.1 mostra o pseudo-código desta técnica.

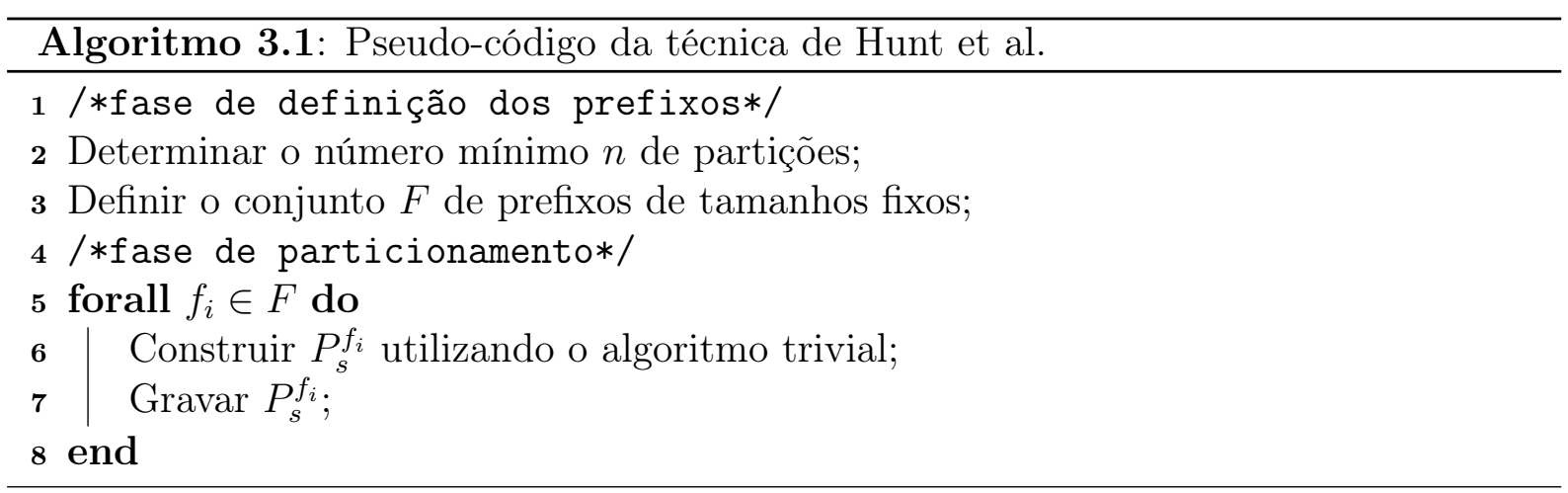

Inicialmente, na fase de definição dos prefixos, a técnica determina o número mínimo $n$ de partições necessárias para construir uma árvore de sufixo $T_{s}$ (linha 2). Este número é calculado de acordo com a Equação 3.1, onde sizeof $\left(T_{s}\right)$ é o tamanho esperado da estrutura de indexação e $\mathrm{MM}_{a}$ é a quantidade de memória principal disponível.

$$
n=\left\lceil\frac{\operatorname{sizeof}\left(T_{s}\right)}{\mathrm{MM}_{a}}\right\rceil
$$


Em seguida, o número $n$ é utilizado para definir o conjunto $F=\left\{f_{1}, f_{2}, \ldots, f_{i}\right\}$ de prefixos de tamanhos fixos (linha 3). Mais especificamente, se são necessárias $n$ partições para se construir $T_{s}$ de uma seqüência do alfabeto $\Sigma=\left\{\alpha_{1}, \alpha_{2}, \ldots, \alpha_{\sigma}\right\}$, então a técnica define $F$ como o conjunto de todas as seqüências de $\Sigma^{*}$ que possuem $\left\lceil\log _{\sigma}^{n}\right\rceil$ caracteres. Por exemplo, se são necessárias no mínimo 12 partições (i.e., $n=12$ ) para se construir a árvore de sufixo de uma seqüência do alfabeto $\Sigma=\{\mathrm{A}, \mathrm{C}, \mathrm{G}, \mathrm{T}\}$, então esta fase define o conjunto $F=\{$ AA, AC, AG, AT, CA, CC, CG, CT, GA, GC, GG, GT, TA, TC, TG, TT $\}$, dado que $\left\lceil\log _{4}^{12}\right\rceil=2$.

Por fim, na fase de particionamento, a técnica realiza múltiplas leituras sobre a seqüência que está sendo indexada. Em cada iteração, o algoritmo trivial é aplicado para construir a árvore de sufixo prefixada de um dos prefixos de tamanhos fixos (linha 6). Após serem construídas, estas árvores são gravadas em memória secundária, liberando o espaço em memória principal para a construção da próxima iteração (linha 7). A Figura 3.6 ilustra a fase de particionamento da técnica de Hunt et al.

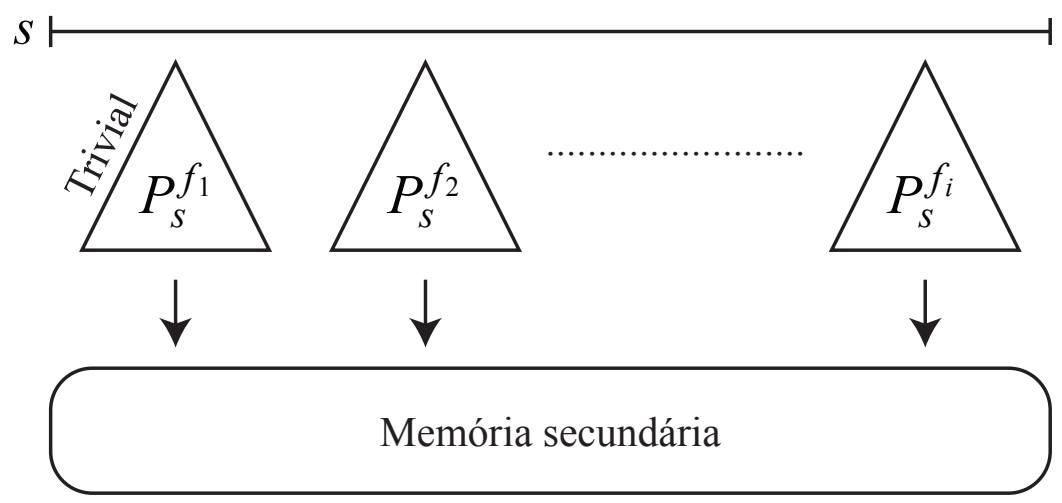

Figura 3.6: Fase de particionamento da técnica de Hunt et al.

Apesar de construir árvores de sufixo persistentes para seqüências de escala cromossômica, a técnica de Hunt et al possui algumas desvantagens. Dado que as freqüências dos prefixos em seqüências não são necessariamente distribuídas uniformemente, o particionamento por meio de prefixos de tamanhos fixos pode gerar árvores de sufixo prefixadas que não cabem na memória principal, criando casos nos quais a técnica não funciona. Isso é conhecido na literatura como o problema das partições (Phoophakdee e Zaki, 2007).

Diferentemente da técnica de Hunt et al, o DynaCluster (Cheung et al, 2005) e o TOP-Q (Bedathur e Haritsa, 2004) são técnicas de construção de árvores de sufixo persistentes que não sofrem do problema das partições, dado que não utilizam árvores de sufixo prefixadas. Enquanto o DynaCluster particiona árvores de sufixo por meio de agrupamentos dinâmicos de nós, o TOP-Q propõe uma política de gerenciamento de buffer para o algoritmo de Ukkonen e não define partições. Contudo, experimentos descritos em (Phoophakdee e Zaki, 2007) indicam que o DynaCluster e o TOP-Q não constroem eficientemente árvores de sufixo persistentes de seqüencias de escala genômica. 


\subsection{A Técnica TDD}

O TDD (Tata et al, 2004) e sua extensão (Tian et al, 2005) foram as primeiras técnicas que surgiram na literatura para construir árvores de sufixo persistentes de seqüencias de escala genômica sem o problema das partições. Estas técnicas incluem um novo algoritmo de construção de árvores de sufixo prefixadas, chamado Partition and Write Only Top Down (PWOTD), e uma política de gerenciamento de buffer especificamente projetada para o algoritmo proposto. O Algoritmo 3.2 mostra o pseudo-código do TDD.

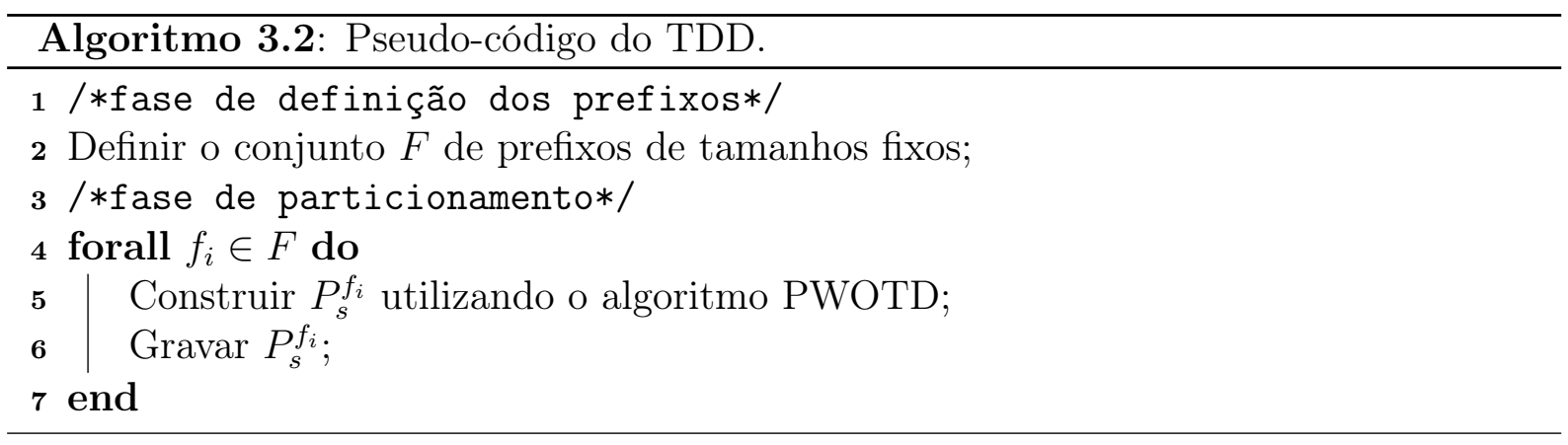

Assim como na técnica de Hunt et al, a fase de definição dos prefixos do TDD também define um conjunto $F=\left\{f_{1}, f_{2}, \ldots, f_{i}\right\}$ de prefixos de tamanhos fixos. Contudo, o TDD não propõe uma maneira de estimar o tamanho dos prefixos. Ao invés disso, TDD define um conjunto com $|\Sigma|^{\text {prefixlen }}$ prefixos, onde $|\Sigma|$ é o número de caracteres do alfabeto da seqüência $s$ que está sendo indexada e prefixlen é um parâmetro de entrada que representa a profundidade do particionamento. Por exemplo, para o alfabeto $\Sigma=\{\mathrm{A}, \mathrm{C}, \mathrm{G}, \mathrm{T}\}$ e prefixlen $=2$, o conjunto definido é $F=\{\mathrm{AA}, \mathrm{AC}, \ldots, \mathrm{TT}\}$.

Em seguida, na fase de construção das árvores prefixadas, cada prefixo $f_{1}, f_{2}, \ldots f_{i}$ é submetido ao algoritmo PWOTD (linhas 4 a 7). Este algoritmo, por sua vez, possui duas etapas. Na primeira etapa, os sufixos de $s$ são particionados de acordo com os prefixos do conjunto $F$, sendo que a $i$-ésima particação é composta por ponteiros para as posições de todos os sufixos de $s$ que começam com o prefixo $f_{i}$. Por exemplo, o particionamento da seqüência ATTAGTACA com prefixlen $=1$ gera quatro partições de sufixos (i.e., $|\Sigma|^{\text {prefixlen }}=4^{1}=4$ ). Neste exemplo, a partição A fica igual a $\{1,4,7,9\}$, representando os sufixos ATTAGTACA, AGTACA, ACA, A\}, enquanto que a partição T fica igual a $\{2,3,6\}$, representando os sufixos \{TTAGTACA, TAGTACA, TACA .

Já na segunda fase do algoritmo PWOTD, cada partição de sufixos é ordenada lexicograficamente em tempo linear com a ajuda partições temporárias. Uma vez que esta etapa parcial termina, a árvore de sufixo prefixada da partição atual é construída e armazenada em disco. Este processo continua até que todas as partições tenham sido criadas. A Figura 3.7 ilustra a fase de construção das árvores prefixadas do TDD.

Apesar de utilizar um conjunto de prefixos de tamanhos fixos, o TDD não sofre do problema das partições, pois seu gerenciamento de buffer permite que as árvores de sufixo 


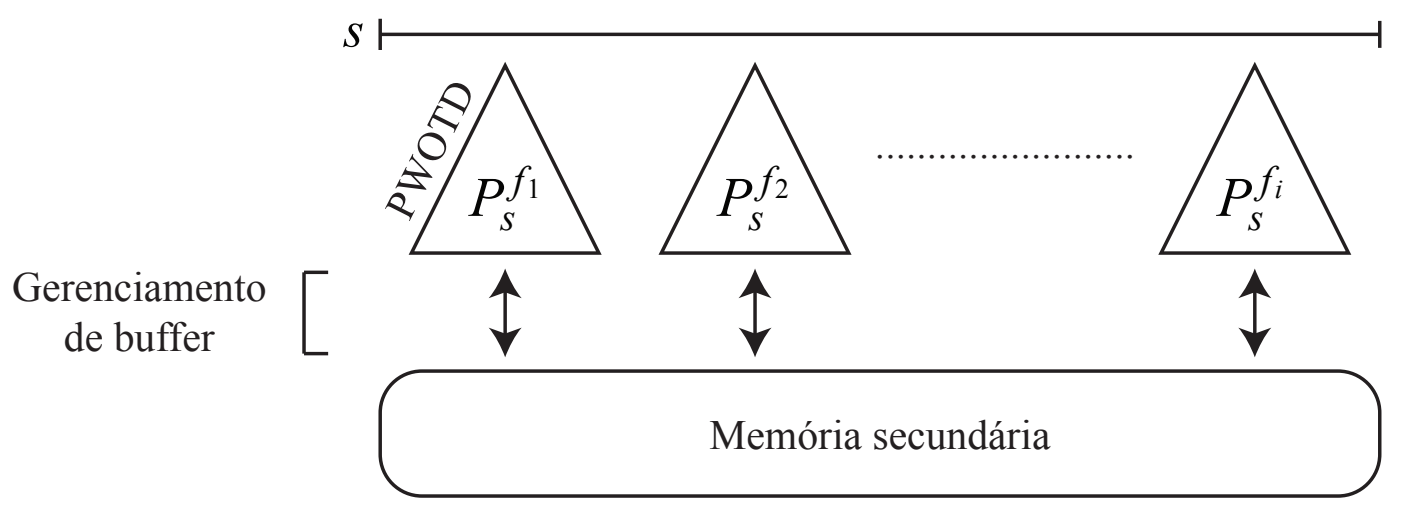

Figura 3.7: Fase de particionamento do TDD.

prefixadas que excedem a memória principal sejam construídas. Neste sentido, o TDD define um buffer para cada uma das estruturas manipuladas pelo algoritmo PWOTD e propõe uma heurística para determinar suas características. Mais especificamente, esta heurística é responsável por determinar a política de troca de páginas e o tamanho de cada um dos buffers de acordo com o tamanho da seqüência que está sendo indexada. A Figura 3.8 ilustra um exemplo do gerenciamento de buffer do TDD, no qual as políticas Least Recently Used (LRU) e Most Recently Used (MRU) são aplicadas no gerenciamento dos diferentes buffers.

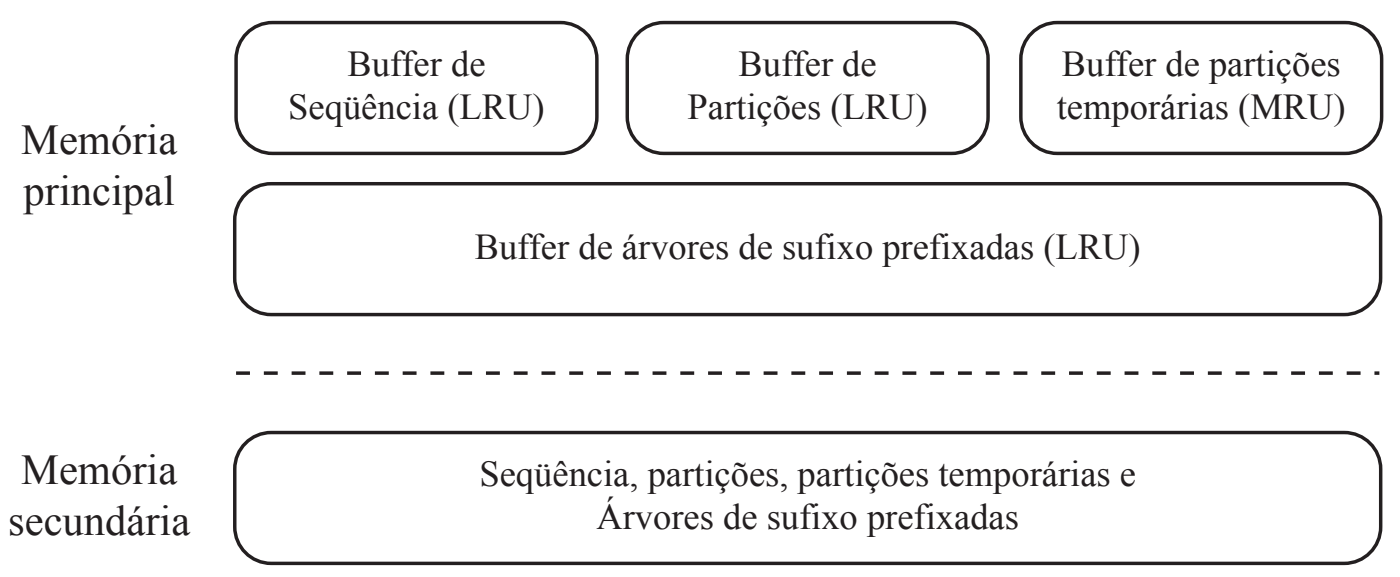

Figura 3.8: Exemplo do gerenciamento de buffer do TDD.

\subsection{A Técnica Trellis+}

O TRELlis + (Phoophakdee e Zaki, 2007, 2008) é outra técnica capaz de construir árvores de sufixo persistentes de seqüencias de escala genômica. A estratégia de construção do TRELlis + pode ser dividida conceitualmente em quatro fases. O Algoritmo 3.3 mostra o pseudo-código desta estratégia.

Baseado na observação de que alguns prefixos precisam ser mais longos que outros para que todas as árvores de sufixo prefixadas caibam na memória principal, a fase de definição 


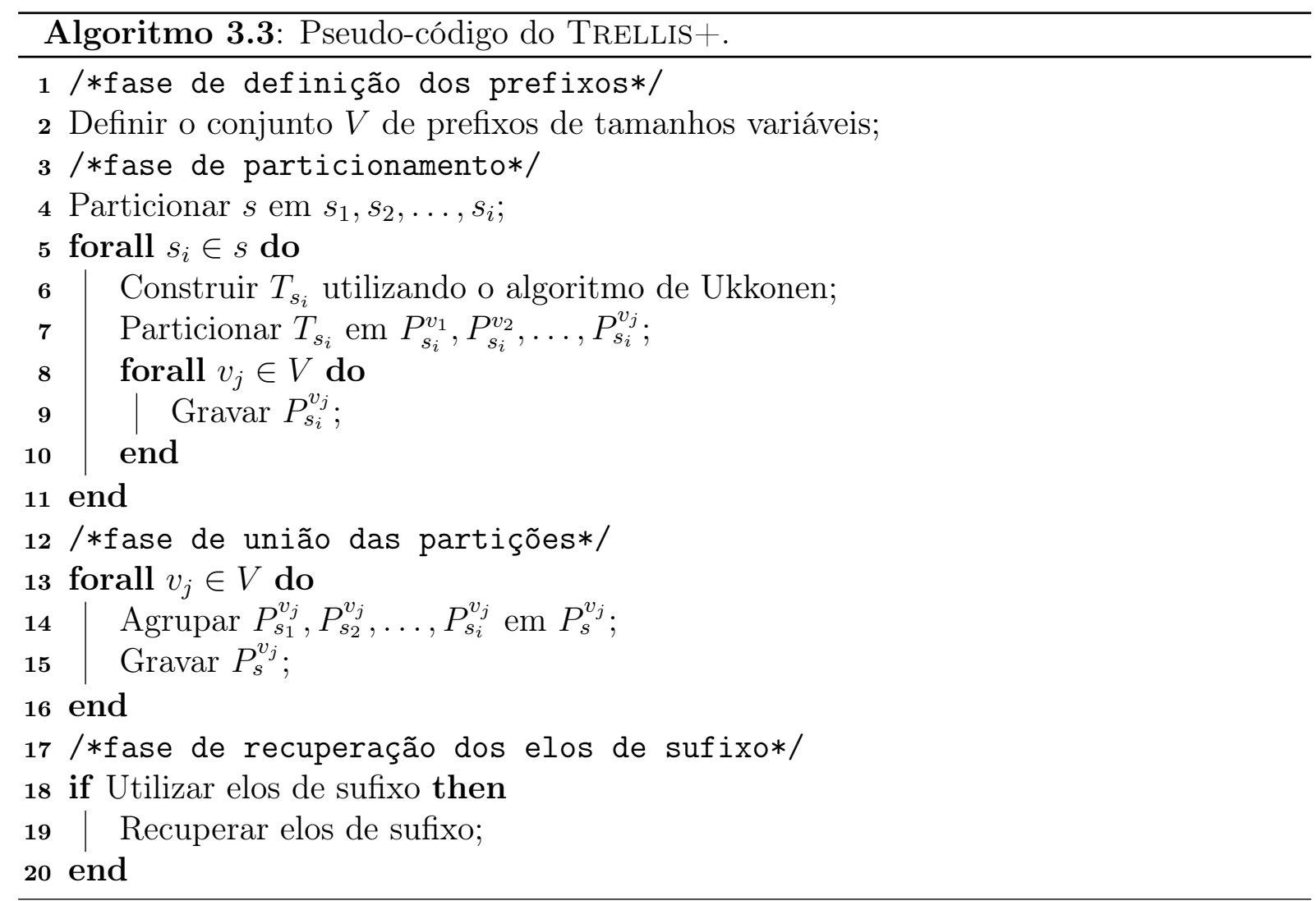

dos prefixos (linha 2) cria um conjunto $V=\left\{v_{1}, v_{2}, \ldots, v_{j}\right\}$ de prefixos de tamanhos variáveis que não apresenta o problema das partições. Para definir este conjunto, uma leitura inicial da seqüência que está sendo indexada é realizada para contar as freqüências de todos os possíveis prefixos de tamanho $l$, que é um parâmetro de entrada. Depois disso, os prefixos que tiverem freqüência maior que um limiar $t$ são expandidos e leituras adicionais da seqüência são realizadas para verificar as novas freqüências. Esse processo continua até que nenhuma freqüência seja maior que $t$. A Figura 3.9 ilustra um exemplo da fase de definição dos prefixos, onde foram necessárias uma leitura inicial e duas leituras adicionais. A primeira leitura expande o prefixo $\mathrm{CC}$, enquanto que a segunda leitura expande o prefixo CGG, supondo que as freqüências destes prefixos sejam maiores do que o limiar $t$. Nenhuma nova expansão é realizada na terceira leitura, supondo que as freqüências dos novos prefixos sejam menores do que o limiar $t$.

Leitura 1) AA, AC, AG, AT, CA, CC, CG, CT, GA, GC, GG, GT, TA, TC, TG, TT $\Gamma_{1}$

Leitura 2) CGA, CGC, CGG, CGT

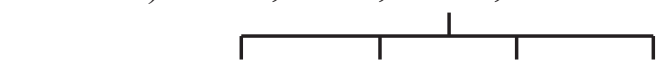

Leitura 3) CGGA, CGGC, CGGG, CGGT

Figura 3.9: Fase de definição dos prefixos do TrELLIS + . 
Em seguida, a fase de particionamento é realizada em dois níveis. No primeiro nível, a seqüência de entrada $s$ é particionada em subseqüências $s_{1}, s_{2}, \ldots, s_{i}$, de forma que suas árvores de sufixo caibam individualmente na memória principal e, portanto, possam ser construídas com algoritmo de Ukkonen (linha 6). Já no segundo nível, cada árvore de sufixo $T_{s_{1}}, T_{s_{2}}, \ldots, T_{s_{i}}$ gerada é particionada nas árvores de sufixo prefixadas $P_{s_{i}}^{v_{1}}, P_{s_{i}}^{v_{2}}, \ldots, P_{s_{i}}^{v_{j}}$ (linha 7 ), as quais são armazenadas em memória secundária (linhas 8 a 10). A Figura 3.10 ilustra os dois níveis da fase de particionamento.

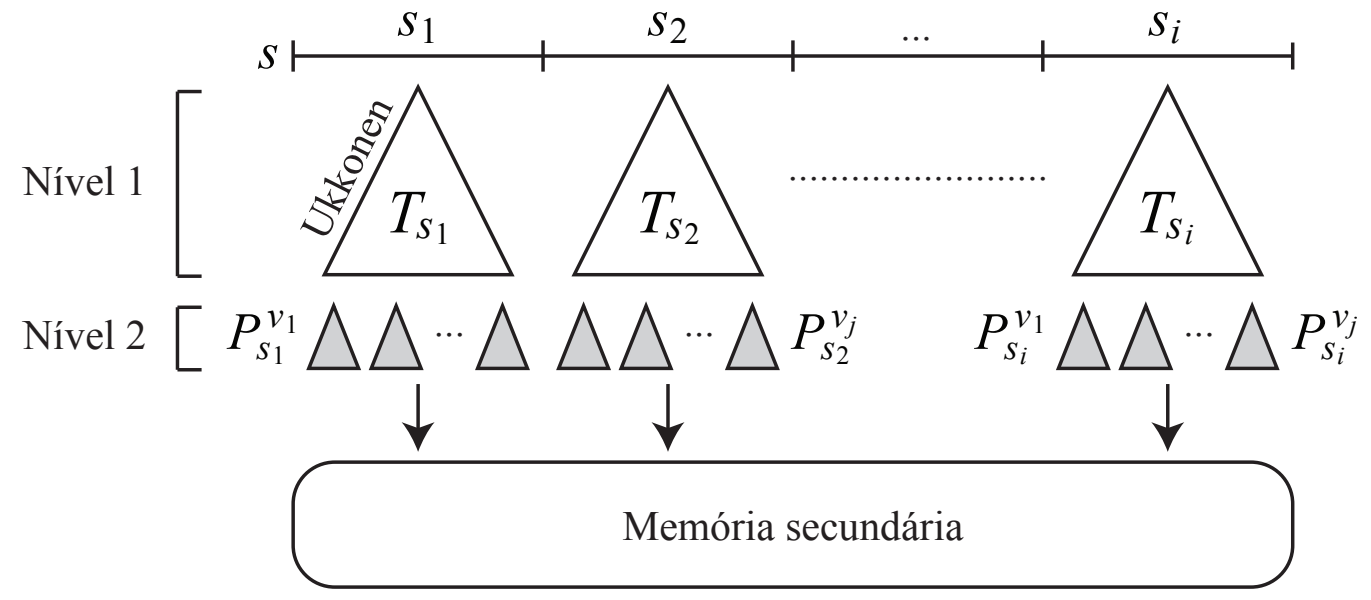

Figura 3.10: Fase de particionamento do TRELlis + .

Na fase de união das partições (linhas 12 a 16), todas as árvores de sufixo prefixadas referentes a um mesmo prefixo $v_{j}$ são agrupadas em uma única árvore $P_{s}^{v_{j}}$. Quando esta etapa parcial termina, $P_{s}^{v_{j}}$ é armazenada em disco e o processo continua para os demais prefixos. A Figura 3.11 ilustra esta fase.

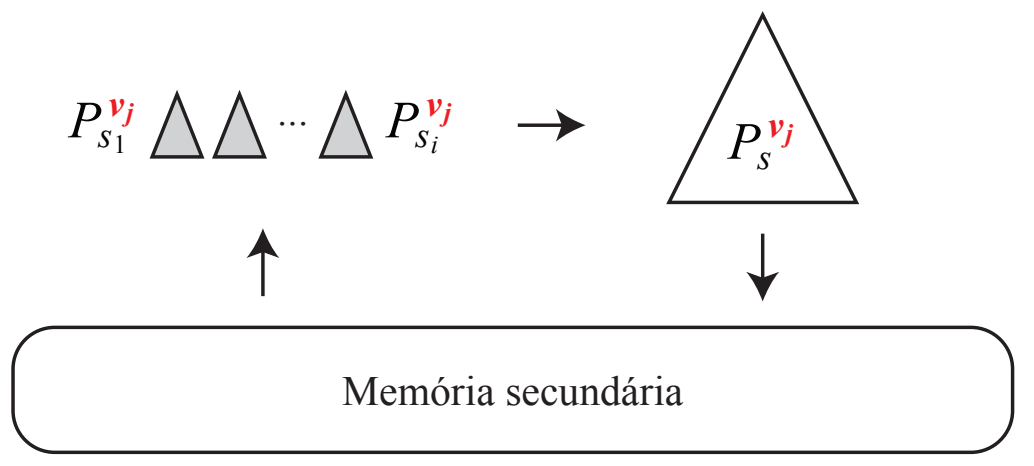

Figura 3.11: Fase de união das partições do TRELLIS + .

Apesar do TRELLIS + utilizar o algoritmo de Ukkonen para construir as árvores de sufixo $T_{s_{1}}, T_{s_{2}}, \ldots, T_{s_{i}}$, os elos de sufixo criados na fase de particionamento não são armazenados na terceira fase. Existem dois motivos principais que justificam esta abordagem. O primeiro deles refere-se ao fato de que vários nós internos sem elos de sufixo são criados durante a fase de união das partições. Outro motivo é que descartar todos os elos de su- 
fixo e recuperá-los posteriormente requer aproximadamente o mesmo tempo que manter os elos de sufixo originais.

Desta forma, o TRELLIS + propõe uma fase opcional de pós-processamento (linhas 18 a 20), chamada de fase de recuperação de elos de sufixo. Esta fase é realizada da seguinte forma. Para cada nó interno $x$ da árvore de sufixo em questão, o método localiza o seu nó antecessor e o nó apontado pelo elo de sufixo deste antecessor. A partir destes dados, o algoritmo de Ukkonen é reaplicado para localizar o elo de sufixo de $x$. Este procedimento continua recursivamente até que todos os filhos de $x$ tenham sido verificados.

\subsection{Outros Métodos de Acesso}

Além dos trabalhos descritos neste capítulo, diversos outros trabalhos acadêmicos têm sido voltados à proposta de métodos de acesso para seqüências. Como exemplo, pode-se citar os trabalhos que constroem um método de acesso compacto chamada suffix array (Manber e Myers, 1993; Crauser e Ferragina, 2002; Dementiev et al, 2008). O casamento exato nesta estrutura requer tempo igual a $O\left(\left|s_{q}\right|+\log |s|+k\right)$, onde $\left|s_{q}\right|$ é o tamanho da seqüência de consulta $s_{q},|s|$ é o tamanho da seqüência indexada $s$ e $k$ é o número de ocorrências de $s_{q}$ em $s$. Entretanto, nas árvores de sufixo, esta mesma operação pode ser realizada em $O\left(\left|s_{q}\right|+k\right)$ com relação ao tempo. Além disso, o suffix array não permite a execução de casamentos aproximados.

Outro método de acesso sendo atualmente investigado é a string B-tree (Ferragina e Grossi, 1999; Na e Park, 2004; Bender et al, 2006). Ao contrário da árvore de sufixo, a string B-tree é uma estrutura de dados balanceada que reduz o número de acessos à memória secundária. Contudo, esta estrutura requer que a seqüência de entrada possa ser dividida em palavras, o que limita seu uso na indexação de seqüências de nucleotídeos.

Já o trabalho de Kahveci e Singh (2001) propôs a MRS-index, uma estrutura de dados matricial que tem sido alvo de diversos trabalhos (Kahveci e Singh, 2003; Sun et al, 2003; Kahveci et al, 2004). Esta estrutura faz uso de transformações wavelet e aproximações para criar índices compactos. Entretanto, estes trabalhos são voltados apenas para memória principal e não criam índices persistentes, que é uma característica necessária na indexação de seqüências de escala genômica.

Além destes métodos de acesso, também existem trabalhos que propõem modificações para as árvores de sufixo. As árvores de sufixo generalizadas (Bieganski et al, 1994; Chen et al, 2003; Barsky et al, 2008) estendem a árvore de sufixo para indexar mais de uma seqüência. Já as árvores de sufixo comprimidas (Grossi e Vitter, 2005; Sadakane, 2007; Välimäki et al, 2007; Russo et al, 2008) fazem uso de processamento adicional para criar representações mais compactas para as árvores de sufixo. 


\subsection{Considerações Finais}

Este capítulo apresentou a árvore de sufixo, uma estrutura de dados muito utilizada na solução de problemas sobre seqüências, como o casamento exato e o casamento aproximado. Em seguida, foram descritos três trabalhos correlatos, demonimados técnica de Hunt et al, TDD e TRELLIS +, os quais propõem abordagens para construir árvores de sufixo persistentes de seqüências de nucleotídeos. Por fim, este capítulo também identificou outras estruturas de dados que são utizadas na indexação de seqüências.

A Tabela 3.1 resume as principais características dos trabalhos correlatos descritos neste capítulo. São consideradas cinco características: (i) a escala das seqüencias suportadas; (ii) o tamanho dos prefixos utilizados para construir as árvores de sufixo que excedem a memória principal; (iii) o algoritmo empregado na construção das árvores de sufixo; (iv) a presença do problema das partições; e (v) o uso de elos de sufixo.

Tabela 3.1: Comparação das técnicas de construção de árvores de sufixo persistentes.

\begin{tabular}{lccc}
\hline Propriedades & Hunt et al & TDD & TrelLis + \\
\hline Escala suportada & Cromossômica & Genômica & Genômica \\
Tamanho dos prefixos & Fixos & Fixos & Variáveis \\
Construção & Trivial & PWOTD & Ukkonen \\
Problema das partições & Sim & Não & Não \\
Elos de sufixo & Não & Não & Sim \\
\hline
\end{tabular}

Atualmente, o TRELLIS + representa o estado da arte nesta linha de pesquisa, dado que é a única técnica que suporta seqüências de escala genômica e não sofre do problema das partições. Os experimentos descritos em (Phoophakdee e Zaki, 2007) mostram que o TRELlis + constrói árvores de sufixo mais rapidamente que o TDD, que, por sua vez, é mais rapido que a técnica de Hunt et al. Além disso, o TRELlis + é o primeiro trabalho que reporta o desempenho de consultas considerando árvores de sufixo persistentes de seqüências de escala genômica. Em particular, o desempenho de casamentos exatos usando o TRELLIS + é 2-3 vezes mais rápido que o desempenho do TDD.

Contudo, o TRELLIS + apresenta quatro desvantagens principais: (i) sua fase de definição dos prefixos é lenta, pois depende de um parâmetro de entrada e realiza múltiplas leituras sobre a seqüencia que está sendo indexada; (ii) o TRELLIS + define muitos prefixos, porque o algoritmo de Ukkonen requer uma estrutura de dados em memória principal muito volumosa (i.e., 48 bytes por nó interno mais 20 bytes por nó folha); (iii) seu particionamento em dois níveis introduz a necessidade de processar grandes quantidades de 
dados temporários (i.e., $\approx 27$ vezes o tamanho da seqüência); e (iv) experimentos preliminares realizados durante o mestrado mostraram que o TRELLIS + não é otimizado para responder casamentos exatos quando o número de ocorrências da seqüência de consulta é maior que um (e.g., para a árvore de sufixo do genoma humano, seqüências de consulta com tamaho entre 10 e 35 bps).

As limitações nos trabalhos correlatos existentes na literatura motivam o desenvolvimento de um nova técnica para tratar árvores de sufixo, que é o objetivo da dissertação. Este objetivo é detalhado no Capítulo 4. 


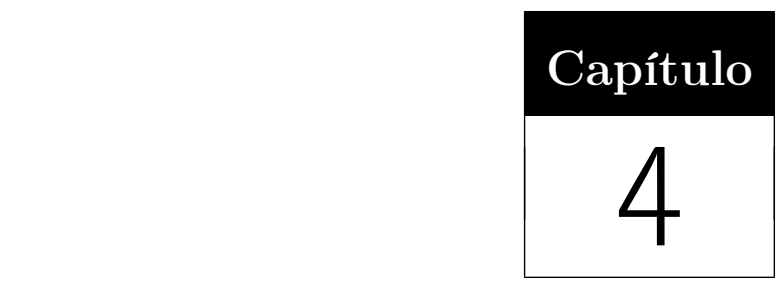

A Técnica Perseus

Este capítulo apresenta o PERSEus (referência a persistent suffix trees), uma nova técnica para tratar árvores de sufixo cujos tamanhos podem exceder a capacidade da memória principal.

O capítulo está estruturado da seguinte forma. A Seção 4.1 ilustra a seqüência de entrada, a árvore de sufixo e a árvore de sufixo prefixada que serão utilizadas para ilustrar os exemplos discutidos neste capítulo. A Seção 4.2 mostra uma visão geral do PERSEus, apresentando seus três diferenciais: estratégia de três passos, construção guiada pelo usuário e casamento exato estendido. Cada um destes diferenciais é detalhado nas Seções 4.3, 4.4 e 4.5 , respectivamente. O capítulo é concluído na Seção 4.6, com as considerações finais. Nesta seção também é feita uma análise comparativa entre o PERSEus e os trabalhos correlatos descritos no Capítulo 3.

\subsection{Exemplo Corrente}

Todos os exemplos deste capítulo são ilustrados usando a seqüência de entrada $s$, a árvore de sufixo $T_{s}$ e a árvore de sufixo prefixada $P_{s}^{\mathrm{TG}}$ mostradas nas Figuras 4.1, 4.2 e 4.3, respectivamente. Note que algumas arestas das Figuras 4.2 e 4.3 estão abreviadas para melhor visualização. Na Figura 4.2, por exemplo, a aresta de entrada do nó folha 3 representa TTGGATTCATATGC\$. 
Seqüência de entrada:

A T G G T T G G A T T C A T A T G C

$\begin{array}{llllllllllllllllll}01 & 02 & 03 & 04 & 05 & 06 & 07 & 08 & 09 & 10 & 11 & 12 & 13 & 14 & 15 & 16 & 17 & 18\end{array}$

Figura 4.1: Seqüência de entrada $s$.

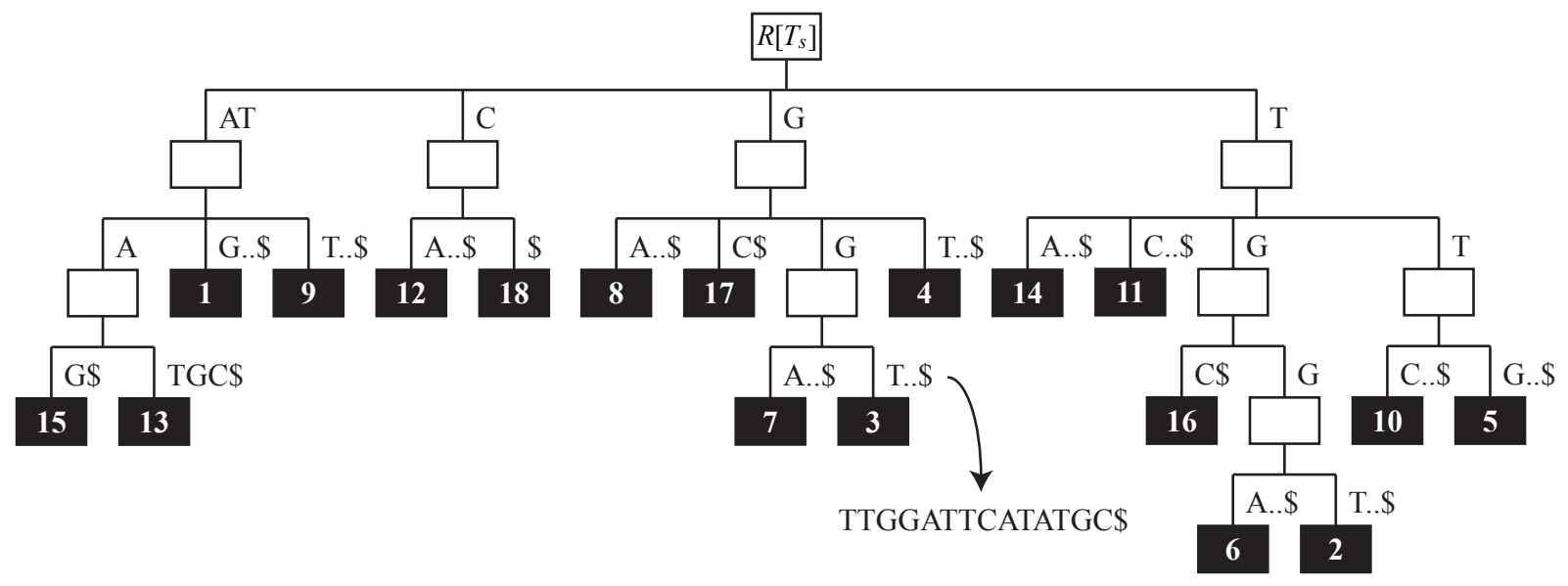

Figura 4.2: Árvore de sufixo $T_{s}$ para $s=$ ATGGTTGGATTCATATGC.

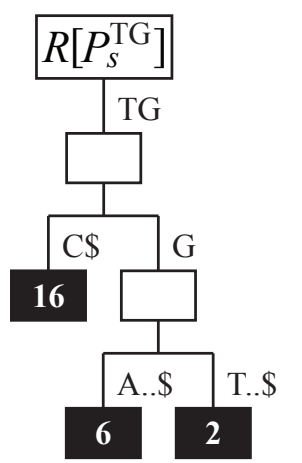

Figura 4.3: Árvore de sufixo prefixada $P_{s}^{\mathrm{TG}}$ da árvore de sufixo da Figura 4.2.

\subsection{A Técnica Proposta Perseus}

Esta seção mostra uma visão geral do PERSEus, uma nova técnica para tratar árvores de sufixo cujos tamanhos podem exceder a capacidade da memória principal. Para construir e executar casamentos exatos em árvores de sufixo persistentes, a técnica PERSEus introduz os seguintes diferenciais:

- Estratégia de três passos: uma abordagem que define um conjunto de prefixos de tamanhos variáveis. Para uma determinada seqüência de entrada, o passo de definição dos prefixos de tamanhos fixos cria um conjunto de prefixos que é utilizado para gerar uma estimativa inicial das partições necessárias para construir uma árvore de sufixo que excede a capacidade da memória principal. O segundo passo, chamado de contagem dos prefixos de tamanhos fixos, conta a freqüência de cada prefixo definido no primeiro passo na seqüência de entrada. Estas freqüências 
são então utilizadas no passo de definição dos prefixos de tamanhos variáveis para identificar quais prefixos de tamanhos fixos devem ser removidos, expandidos ou reduzidos, definindo o conjunto de prefixos de tamanhos variáveis. A estratégia de três passos introduz as seguintes vantagens. Ela garante que o PERsEus não sofra do problema das partições. Ela realiza uma única leitura da seqüência de entrada, melhorando o desempenho do passo de contagem dos prefixos de tamanhos fixos. Além disso, ela identifica automaticamente o conjunto de prefixos de tamanhos variáveis sem requerer intervenção do usuário. A Figura 4.4a mostra uma visão geral da estratégia de três passos aplicada à seqüência de entrada da Figura 4.1. A estratégia de três passos é detalhada na Seção 4.3.

- Construção guiada pelo usuário: um algoritmo voltado à construção de árvores de sufixo (prefixadas). A construção guiada pelo usuário estende o algoritmo trivial (Seção 3.1.1) para permitir que os usuários indiquem quais subseqüências da seqüência de entrada devem ser indexadas, de acordo com suas necessidades. Perseus combina este conjunto de entrada do usuário com o conjunto de prefixos de tamanhos variáveis gerados pela estratégia de três passos para determinar quais árvores de sufixos prefixadas devem ser construídas. Indicar quais subseqüências devem ser indexadas é um requisito importante em aplicações que executam consultas específicas. Por exemplo, aplicações que buscam por genes precisam indexar apenas os sufixos de um genoma que começam ATG. Para estas aplicações, não há necessidade de se construir toda a árvore de sufixo. Outra vantagem da construção guiada pelo usuário é que ela apenas divide a árvore de sufixo quando necessário, evitando o desperdício de recursos computacionais. Além disto, a construção guiada pelo usuário usa o algoritmo quick search (Sunday, 1990) para melhorar a localização dos sufixos na seqüência de entrada durante a construção das árvores de sufixo prefixadas. A Figura 4.4b mostra as árvores de sufixo prefixadas construídas pelo PERSEus após combinar o conjunto de entrada do usuário \{AT, GTT, TG \} com o conjunto de prefixos de tamanhos variáveis da Figura 4.4a-3. A construção guiada pelo usuário é detalhada na Seção 4.4.

- Casamento exato estendido: uma extensão do casamento exato que oferece suporte para árvores de sufixos que podem estar particionadas em árvores de sufixo prefixadas. A Figura 4.4c mostra um exemplo no qual o PERSEus apenas procura por ocorrências da seqüência de consulta TGGA na árvore de sufixo prefixada apropriada (i.e., $\left.P_{s}^{\mathrm{TG}}\right)$. O casamento exato estendido é detalhado na Seção 4.5.

Para oferecer suporte para os diferenciais descritos anteriormente, PERSEUs introduz uma representação de árvore melhorada, chamada de iTree-representation (i.e., improved tree representation), a qual tem como objetivo armazenar árvores de sufixo (prefixadas) em memória secundária. Cada nó $x$ de uma iTree-representation é composto pelos 
Seqüência de entrada:

A T G G T T G G A T T C A T A T G C

$\begin{array}{llllllllllllllllll}01 & 02 & 03 & 04 & 05 & 06 & 07 & 08 & 09 & 10 & 11 & 12 & 13 & 14 & 15 & 16 & 17 & 18\end{array}$

(a-1) Definição dos prefixos de tamanhos fixos

(a-2) Contagem dos prefixos de tamanhos fixos

(a-3) Definição dos prefixos de tamanhos variáveis

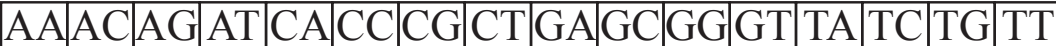

\begin{tabular}{|l|l|l|l|l|l|l|l|l|l|l|l|l|l|l|l|}
\hline AA & AC & AG & AT & CA & CC & CG & CT & GA & GC & GG & GT & TA & TC & TG & TT \\
\hline
\end{tabular}

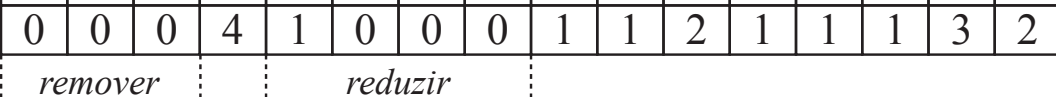

\begin{tabular}{|l|l|l|l|l|l|l|l|l|l|l|}
\hline & C & GA & GC & GG & GT & TA & TC & TG & TT \\
\hline
\end{tabular}

ATA|ATCATG|ATT

(a) Estratégia de três passos

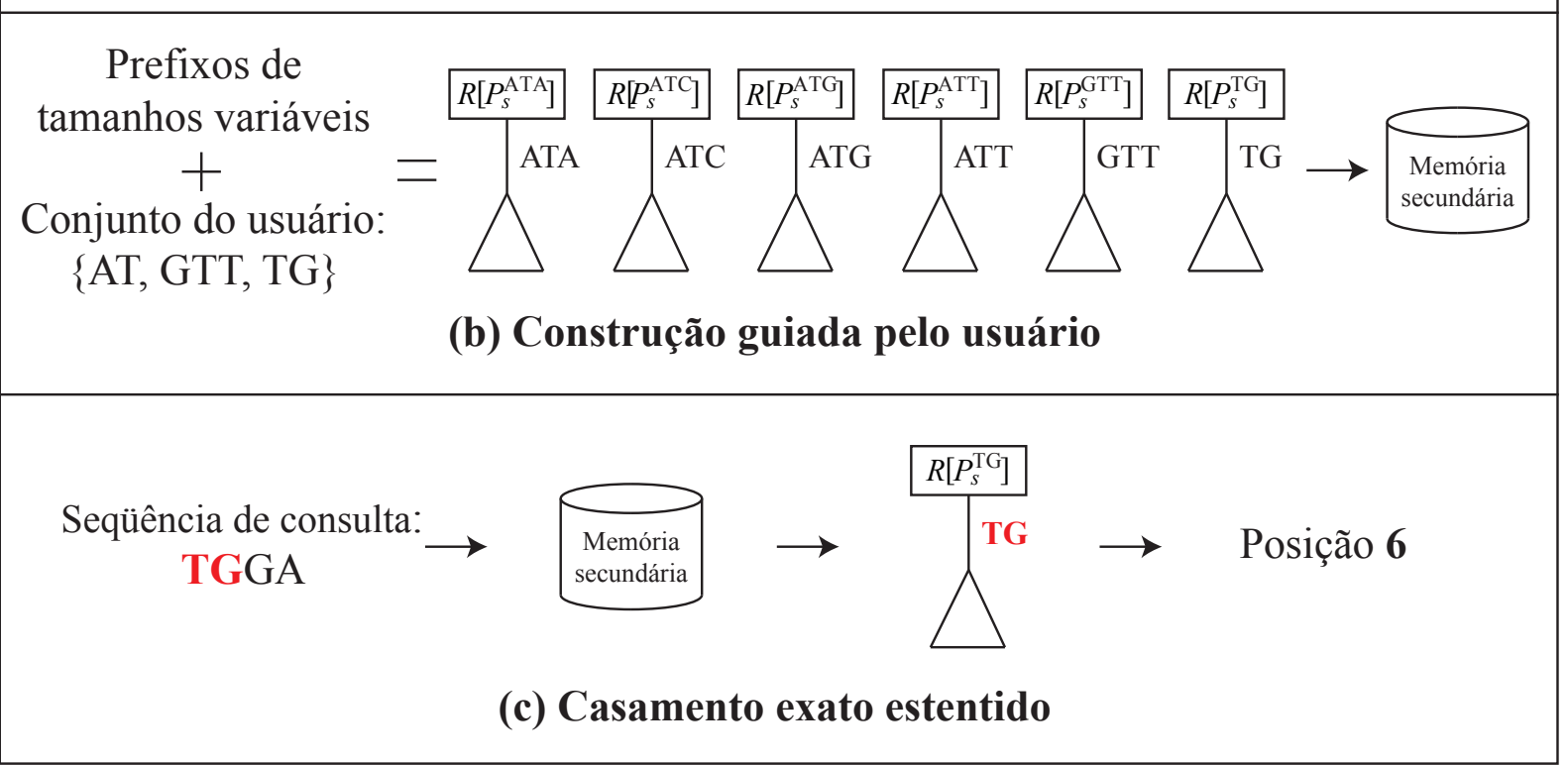

Figura 4.4: Visão geral das propriedades do PERSEUS.

atributos descritos na Tabela 4.1. Os atributos $x$.Início e $x$. Tamanho indicam que a aresta de entrada de $x$ é $s[x$.Início $: x$.Início $+x$. Tamanho -1$]$ (i.e., é a subseqüência de $s$ que começa na posição $x$.Início e termina na posição $x$.Início $+x$. Tamanho -1$)$.

$\mathrm{O}$ uso dos atributos $x$.Folha e $x$.Filho permite que a iTree-representation seja composta apenas pelos nós internos de uma árvore de sufixo (prefixada). Esta característica é alcançada por meio do armazenamento de ponteiros ou identificadores de sufixo no atributo $x$.Folha. Desta forma, não há necessidade de se criar nós folhas, gerando estruturas mais compactas. Dado um caractere $\alpha_{i}$, onde $1 \leq i \leq \sigma+1$, o conteúdo de $x$.Filho $\left[\alpha_{i}\right]$ é determinado por $x$.Folha $\left[\alpha_{i}\right]$ da seguinte forma:

Conteúdo de $x$. Filho $\left[\alpha_{i}\right]=\left\{\begin{array}{l}\text { Ponteiro, se } x \cdot \text { Folha }\left[\alpha_{i}\right]=0 \\ \text { Identificador de sufixo, caso contrário }\end{array}\right.$ 
Tabela 4.1: Atributos de um nó $x$ da iTree-representation.

\begin{tabular}{llc}
\hline Atributo & Descrição & Tamanho (bytes) \\
\hline$x$. Início & Posição inicial da aresta de entrada de $x$ & 4 \\
$x$. Tamanho & Tamanho da aresta de entrada de $x$ & 4 \\
$x$. Folha $\left[\alpha_{1}, \ldots, \alpha_{\sigma}, \$\right]$ & $\begin{array}{l}\text { Flags que determinam o conteúdo dos ele- } \\
\text { mentos de } x . \text { Filho }\end{array}$ & $\left\lceil\frac{\sigma+1}{8}\right\rceil$ \\
$x$. Filho $\left[\alpha_{1}, \ldots, \alpha_{\sigma}, \$\right]$ & $\begin{array}{l}\text { Ponteiros para os filhos de } x \text { ou identifica- } \\
\text { dores de sufixo }\end{array}$ & $(\sigma+1) \times 4$ \\
& & \\
\hline
\end{tabular}

Por fim, o termo $\sigma+1$ representa o número de caracteres do alfabeto $\Sigma$ mais o caractere terminal \$. Com relação à coluna tamanho, o valor 4 representa o número de bytes de um inteiro sem sinal em modo 32 bits, enquanto que o valor 8 representa o número de bits em um byte.

Por exemplo, a Figura 4.5 mostra a iTree-representation da árvore de sufixo prefixada da Figura 4.3. Com relação ao nó $x_{1}$, os atributos $x_{1}$. Início e $x_{1}$. Tamanho indicam que sua aresta de entrada é $s[2: 3]=$ TG. O atributo $x_{1}$. Folha possui cinco flags, dado que $\Sigma=\{\mathrm{A}, \mathrm{C}, \mathrm{G}, \mathrm{T}\}$ e $\sigma+1=5$. O valor da flag $\mathrm{G}$ é igual a zero, indicando que o conteúdo de $x_{1}$. Filho $[\mathrm{G}]$ é um ponteiro para o nó $x_{2}$. Os valores das flags A, T e $\$$ também são iguais a zero, mas dado que a seqüência de entrada não possui prefixos que começam com TGA, TGT ou TG\$, os conteúdos de $x_{1}$.Filho[A], $x_{1}$.Filho[T] e $x_{1}$. Filho $[\$]$ são referências nulas. Por outro lado, o valor da flag $\mathrm{C}$ é igual a um, determinando que o conteúdo de $x_{1}$.Filho[C] é o identificador de sufixo 16. Desta maneira, o sufixo TGC ocorre na posição 16 da seqüência de entrada. Neste exemplo, o tamanho de cada nó é 29 bytes.

Seqüência de entrada:

A $T$ T $G$ G T $T$ T $G$ G A

$\begin{array}{llllllllllllllllll}01 & 02 & 03 & 04 & 05 & 06 & 07 & 08 & 09 & 10 & 11 & 12 & 13 & 14 & 15 & 16 & 17 & 18\end{array}$

Árvore de sufixo prefixada:

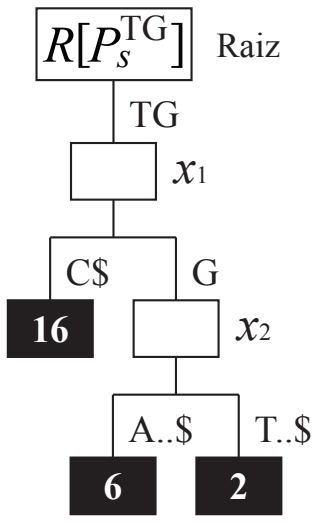

iTree-representation:

\begin{tabular}{|c|c|c|c|c|c|}
\hline \multicolumn{6}{|c|}{ Raiz } \\
\hline Início & \multicolumn{5}{|c|}{0} \\
\hline Tamanho & \multicolumn{5}{|c|}{0} \\
\hline \multirow{2}{*}{ Folha } & A & $\mathrm{C}$ & $\mathrm{G}$ & $\mathrm{T}$ & $\$$ \\
\hline & 0 & 0 & 0 & 0 & 0 \\
\hline Filho & $\square$ & 口 & 口 & 5 & 口 \\
\hline \multicolumn{6}{|c|}{$x_{1}$} \\
\hline Início & \multicolumn{5}{|c|}{2} \\
\hline Tamanho & \multicolumn{5}{|c|}{2} \\
\hline \multirow{2}{*}{ Folha } & $\mathrm{A}$ & $\mathrm{C}$ & $\mathrm{G}$ & $\mathrm{T}$ & $\$$ \\
\hline & 0 & 1 & 0 & 0 & 0 \\
\hline Filho & $\square$ & 16 & $\Phi$ & 무 & 口 \\
\hline \multicolumn{6}{|c|}{$x_{2}$} \\
\hline Início & \multicolumn{5}{|c|}{4} \\
\hline Tamanho & \multicolumn{5}{|c|}{1} \\
\hline \multirow{2}{*}{ Folha } & $\mathrm{A}$ & $\mathrm{C}$ & $\mathrm{G}$ & $\mathrm{T}$ & $\$$ \\
\hline & 1 & 0 & 0 & 1 & 0 \\
\hline Filho & 6 & $\square$ & 口 & 2 & E \\
\hline
\end{tabular}

Figura 4.5: iTree-representation da árvore de sufixo prefixada $P_{s}^{\mathrm{TG}}$ da Figura 4.3. 
A iTree-representation da Figura 4.5 possui três nós porque sua árvore de sufixo prefixada possui três nós internos. Por outro lado, a Figura 4.6 mostra a iTree-representation da árvore de sufixo $T_{s}$ da Figura 4.3, que possui mais nós porque indexa todos os sufixos da seqüência de entrada (i.e., a árvore de sufixo não está particionada).

Seqüência de entrada:

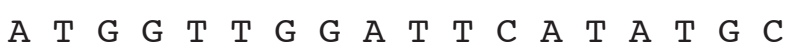
$\begin{array}{llllllllllllllllll}01 & 02 & 03 & 04 & 05 & 06 & 07 & 08 & 09 & 10 & 11 & 12 & 13 & 14 & 15 & 16 & 17 & 18\end{array}$

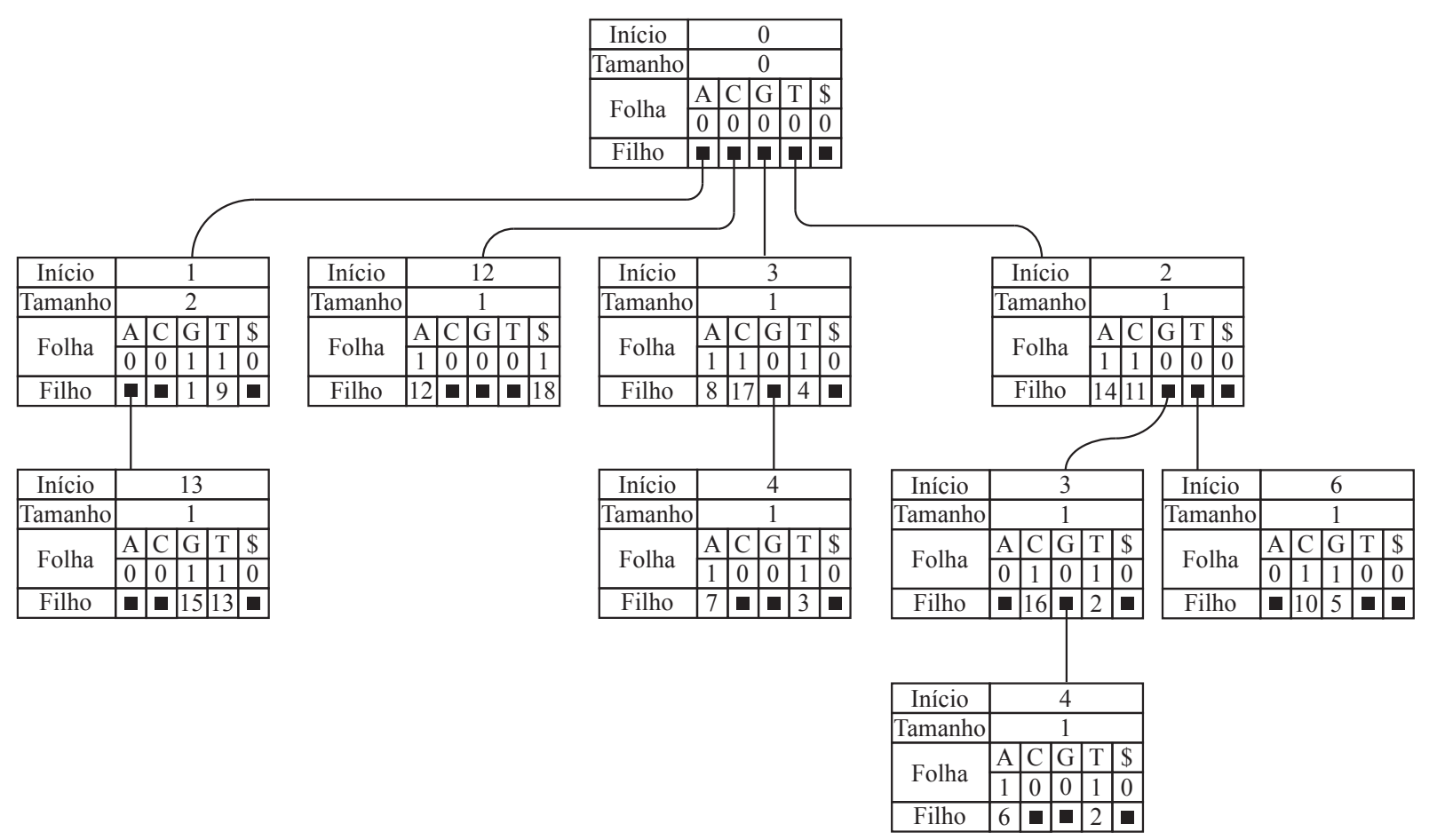

Figura 4.6: iTree-representation da árvore de sufixo $T_{s}$ da Figura 4.2.

\subsection{Estratégia de Três Passos}

Para construir árvores de sufixo que excedem a memória principal, PERSEus particiona as árvores de sufixo em árvores de sufixo prefixadas. A idéia é gerar várias árvores de sufixo prefixadas, cada uma indexando um prefixo de tamanho variável específico que ocorre na seqüência de entrada. Para atingir este objetivo, a estratégia de três passos investiga se uma árvore de sufixo pode ser construída sem ser particionada ou se ela deve ser particionada em árvores de sufixo prefixadas. Como resultado, a estratégia garante que cada árvore de sufixo (prefixada) criada durante a construção guiada pelo usuário caiba na memória principal disponível.

O primeiro passo da estratégia de três passos (Seção 4.3.1) identifica quando uma árvore de sufixo deve ser particionada. Isto é feito definindo um conjunto de prefixos de tamanhos fixos que é utilizado para gerar uma estimativa inicial das partições necessárias 
para se construir uma árvore de sufixo. Se este conjunto for vazio, a árvore de sufixo não deve ser particionada. Em contrapartida, ela deve ser particionada utilizando como base o conjunto definido.

Entretanto, a freqüência dos prefixos de tamanhos fixos não segue uma distribuição uniforme na maioria das seqüências. Desta maneira, é importante determinar o número de vezes que cada prefixo de tamanho fixo ocorre na seqüência de entrada, para prover um bom particionamento da árvore de sufixo durante sua construção. Esta funcionalidade é executada pelo segundo passo da estratégia de três passos (Seção 4.3.2).

Por fim, o terceiro passo da estratégia de três passos (Seção 4.3.3) utiliza o conjunto de prefixos de tamanhos fixos obtido no primeiro passo e suas freqüências determinadas no segundo passo para definir um conjunto de prefixos de tamanhos variáveis. O objetivo é identificar quais prefixos devem ser removidos, expandidos ou reduzidos de acordo com suas freqüências e, desta forma, gerar um conjunto de prefixos de tamanhos variáveis que garanta que o problema das partições não aconteça durante a construção das árvores de sufixo prefixadas.

Note que o segundo e o terceiro passos são aplicados apenas quando o primeiro passo identifica que a árvore de sufixo deve ser particionada.

\subsubsection{Definição dos Prefixos de Tamanhos Fixos}

O primeiro passo da estratégia de três passos define, em tempo constante, um conjunto de prefixos de tamanhos fixos que é utilizado para gerar uma estimativa inicial das partições necessárias para construir uma árvore de sufixo. Isto é realizado por meio do cálculo dos seguintes valores.

1. Memória principal disponível $\mathbf{M M}_{\mathbf{A}}$ : quantidade de memória principal que pode ser utilizada durante a construção da árvore de sufixo, dado que PERsEus usa parte da memória principal $\mathrm{MM}_{\mathrm{T}}$ para armazenar a seqüência de entrada $s$. Esta quantidade é calculada pela Equação 4.1, onde o termo $\frac{1}{\beta} \times|s|$ representa o espaço de memória principal requerido por $s$. Por exemplo, dado o genoma do organismo Oryzias latipes $(|s|=582.126 .392)$, um empacotamento de bits que armazena quatro pares de base por byte $(\beta=4)$ e uma memória principal de $1,5 \mathrm{~GB}$, a memória principal disponível $\mathrm{MM}_{\mathrm{A}}$ para construir a árvore de sufixo é 1,36 GB.

$$
\mathrm{MM}_{\mathrm{A}}=\mathrm{MM}_{\mathrm{T}}-\left(\frac{1}{\beta} \times|s|\right)
$$

2. Número mínimo de partições $p_{\text {min }}$ : número que determina quantas partições são requeridas para construir a árvore de sufixo com a memória principal disponível $\mathrm{MM}_{\mathrm{A}}$. Este número é calculado pela Equação 4.2, onde o dividendo representa uma estimativa em bytes do tamanho da árvore de sufixo. O termo $r$ é a razão 
entre o número de nós internos da árvore de sufixo e o tamanho da seqüência de entrada. Para seqüências genômicas, testes preliminares mostraram que o valor de $r$ é 0,7 , dado que o número de nós internos na árvore de sufixo é igual a aproximadamente $70 \%$ do tamanho da seqüência de entrada. Já o termo $\operatorname{sizeof}(x)$ é o tamanho de um nó $x$ da iTree-representation, o qual é 29 bytes para seqüências genômicas (Seção 4.2). Por exemplo, dado o genoma do organismo Oryzias latipes, a estimativa da árvore de sufixo é aproximadamente 11 GB e, desta forma, o número mínimo de partições $p_{\min }$ é 9 quando $\mathrm{MM}_{\mathrm{A}}=1.36 \mathrm{~GB}$.

$$
p_{\min }=\left\lceil\frac{r \times|s| \times \operatorname{sizeof}(x)}{\mathrm{MM}_{\mathrm{A}}}\right\rceil
$$

3. Tamanho dos prefixos $\mu$ : valor utilizado para definir o tamanho dos prefixos de tamanhos fixos, o qual é calculado pela Equação 4.3. A idéia é determinar um valor de $\mu$ de forma que o número de todos os possíveis prefixos $\sigma^{\mu}$ de tamanho igual a $\mu$ seja maior que o número mínimo de partições $p_{\min }$ requerido para construir a árvore de sufixo. Por exemplo, dado o genoma do organismo Oryzias latipes ( $p_{\min }=9$ e $\left.\sigma=4\right)$, o valor de $\mu$ é igual a 2 e, em conseqüência, o número de todos os possíveis prefixos de tamanho igual a 2 é $16\left(\sigma^{\mu}=4^{2}=16\right)$. Isto significa que estes 16 prefixos de tamanhos fixos são suficientes para permitir a construção de uma árvore de sufixo que precisa ser particionada em, no mínimo, 9 partições.

$$
\mu=\left\lceil\log _{\sigma}\left(p_{\min }\right)\right\rceil
$$

A Tabela 4.2 mostra os conjuntos de tamanhos fixos definidos para diferentes valores de $\mu$ na indexação de seqüências genômicas. Note que um valor de $\mu$ igual a zero determina um conjunto vazio, indicando que a árvore de sufixo pode ser construída na memória principal disponível $\mathrm{MM}_{\mathrm{A}}$ sem ser particionada.

Tabela 4.2: Conjuntos de prefixos de tamanhos fixos definidos para diferentes $\mu$.

\begin{tabular}{ccc}
\hline$\mu$ & $\sigma^{\mu}$ & Conjunto de prefixos de tamanhos fixos \\
\hline 0 & 1 & $\varnothing$ \\
1 & 4 & $\{\mathrm{~A}, \mathrm{C}, \mathrm{G}, \mathrm{T}\}$ \\
2 & 16 & $\{\mathrm{AA}, \mathrm{AC}, \mathrm{AG}, \mathrm{AT}, \mathrm{CA}, \ldots, \mathrm{TT}\}$ \\
3 & 64 & $\{\mathrm{AAA}, \mathrm{AAC}, \mathrm{AAG}, \mathrm{AAT}, \mathrm{ACA}, \mathrm{ACC}, \ldots, \mathrm{TTT}\}$ \\
4 & 256 & $\{\mathrm{AAAA}, \mathrm{AAAC}, \mathrm{AAAG}, \mathrm{AAAT}, \mathrm{AACA}, \mathrm{AACC}, \ldots, \mathrm{TTTT}\}$ \\
$\vdots$ & $\vdots$ & $\vdots$ \\
\hline
\end{tabular}

Com relação ao genoma do organismo Oryzias latipes $(\mu=2)$, o conjunto de prefixos de tamanhos fixos utilizado para gerar uma estimativa inicial das par- 
tições necessárias para construir sua árvore de sufixo é $\{\mathrm{AA}, \mathrm{AC}, \mathrm{AG}, \mathrm{AT}, \mathrm{CA}, \mathrm{CC}$, CG, CT, GA, GC, GG, GT, TA, TC, TG, TT\}, como ilustrado na Figura 4.4a-1.

\subsubsection{Contagem dos Prefixos de Tamanhos Fixos}

O segundo passo da estratégia de três passos realiza uma única leitura na seqüência de entrada para contar todos as freqüências dos prefixos de tamanhos fixos. Esta funcionalidade é realizada, portanto, em $O(|s|)$.

Para realizar uma única leitura, PERseus cria uma estrutura de dados auxiliar, chamada de pCounting-tree (prefix counting tree). Cada nó y da pCounting-tree é composto pelos atributos descritos na tabela 4.3. O atributo y. $\alpha$ representa um caractere do alfabeto $\Sigma$, enquanto que cada atributo $y$.Filho $\left[\alpha_{i}\right]$, onde $1 \leq i \leq \sigma$, armazena ponteiros para os $\sigma$ filhos de $y$. Já o atributo $y$.Contador guarda a freqüência do prefixo formado pela concatenação dos caracteres representados pelo nós no caminho do nó raiz até $y$. As demais características da pCounting-tree são descritas a seguir. Se y for o nó raiz, são armazenados apenas os ponteiros para seus filhos. Por outro lado, se $y$ for um nó folha, o conteúdo de cada $y$.Filho $\left[\alpha_{i}\right]$ é uma referência nula.

Tabela 4.3: Atributos de um nó y da pCounting-tree.

\begin{tabular}{ll}
\hline Atributo & Descrição \\
\hline$y$. Folha & Indica se $y$ é um nó folha \\
$y \cdot \alpha$ & Caractere representado por $y$ \\
$y$.Contador & Contador da freqüência do prefixo representado por $y$ \\
$y$. Filho $\left[\alpha_{1}, \ldots, \alpha_{\sigma}\right]$ & Ponteiros para os filhos de $y$ \\
\hline
\end{tabular}

A construção de uma pCounting-tree é feita da seguinte forma. Inicialmente, a pCounting-tree com altura $\mu+1$ é criada para representar todos os prefixos de tamanhos fixos que podem ser formados com $\mu$ caracteres. Em seguida, todos os seus contadores são zerados. Por fim, uma janela de tamanho $\mu$ é deslizada pela seqüência de entrada. Para cada posição desta janela, são incrementados os contadores no caminho do nó raiz até o nó folha que forma a janela atual. Isto é realizado até o final da seqüência de entrada.

Dada a seqüência de entrada da Figura 4.4 e o conjunto de prefixos de tamanhos fixos obtidos da Seção 4.3.1 para $\mu=2$. A Figura 4.7 mostra a pCounting-tree resultante deste passo, a qual possui altura igual a três e contadores que armazenam as freqüências de todos os prefixos de tamanhos fixos na seqüência de entrada. Com relação ao deslizamento da janela de tamanho $\mu$, o primeiro deslizamento incrementa os contadores dos nós $y_{1}$ e $y_{8}$, dado que esta janela contém a subseqüência AT. Similarmente, o segundo deslizamento incrementa os contadores dos nós $y_{4}$ e $y_{19}$, dado que esta janela contém a subseqüência TG. Este processo continua até o final da seqüência de entrada. O último 
deslizamento incrementa os contadores dos nós $y_{3}$ e $y_{14}$, dado que a janela contém a subseqüência GC.

Seqüência de entrada:

A T G G T T G G A T T C A T A T G C

$\begin{array}{llllllllllllllllll}01 & 02 & 03 & 04 & 05 & 06 & 07 & 08 & 09 & 10 & 11 & 12 & 13 & 14 & 15 & 16 & 17 & 18\end{array}$

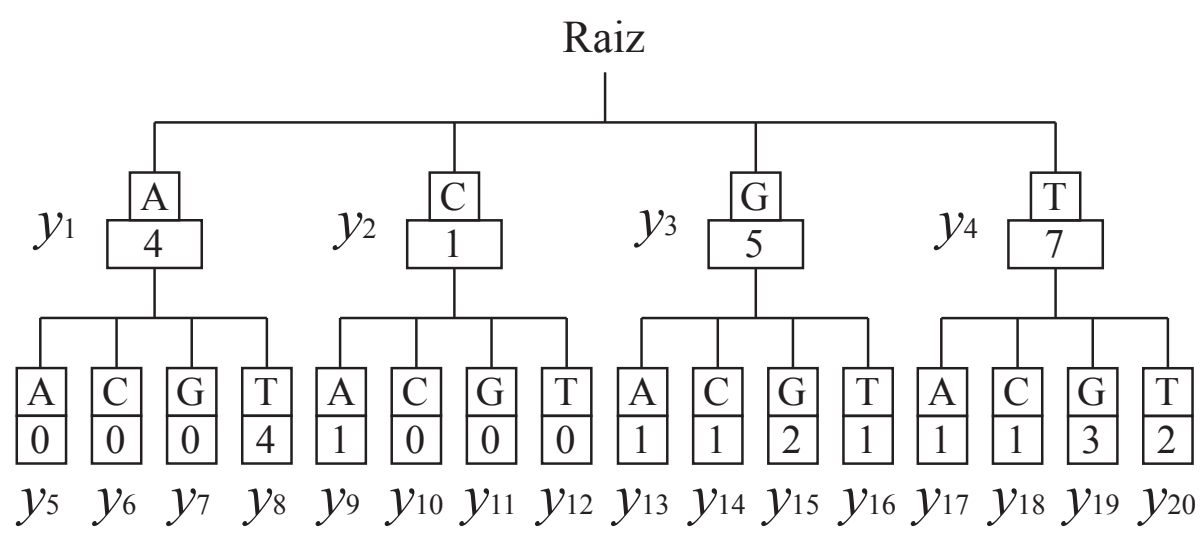

Figura 4.7: Exemplo da pCounting-tree.

A pCounting-tree da Figura 4.7 é, na verdade, uma representação detalhada do passo de contagem dos prefixos de tamanhos fixos ilustrado na Figura 4.4a-2.

\subsubsection{Definição dos Prefixos de Tamanhos Variáveis}

O terceiro passo da estratégia de três passos utiliza o conjunto de prefixos de tamanhos fixos (Seção 4.3.1) e suas freqüências (Seção 4.3.2) para definir um conjunto $V$ de prefixos de tamanhos variáveis em $O\left(\sigma^{\mu}\right)$. Isto é feito inicialmente estimando o limiar $|s|_{\max }$, e então aplicando o algoritmo Converter para a pCounting-tree que contém as freqüências dos prefixos de tamanhos fixos.

O limiar $|s|_{\max }$ (Equação 4.4) indica o número máximo de sufixos que podem ser inseridos em uma árvore de sufixo prefixada de forma que esta fique menor que a memória principal disponível $\mathrm{MM}_{\mathrm{A}}$. Os termos $r$ e sizeof $(x)$ são os mesmos utilizados na Equação 4.2.

$$
|s|_{\max }=\frac{\mathrm{MM}_{\mathrm{A}}}{r \times \operatorname{sizeof}(x)}
$$

O algoritmo Converter analisa cada filho do nó raiz da pCounting-tree e procede da seguinte maneira. Nas linhas 1 e 2, ele verifica se o nó atual y é um nó folha com contador igual a zero. Neste caso, o algoritmo remove $y$ porque o prefixo que ele representa não ocorre na seqüência de entrada. Desta forma, este prefixo não deve fazer parte do conjunto de prefixos de tamanhos variáveis.

Por outro lado, o algoritmo verifica se o contador do nó folha y é maior que $|s|_{\max }$ (linha 4). Um nó folha com contador maior que $|s|_{\max }$ indica que o tama- 
nho da árvore de sufixo prefixada do prefixo representado por y pode exceder a memória principal disponível $\mathrm{MM}_{\mathrm{A}}$. Neste caso, o algoritmo expande o nó $y$, garantindo que o problema das partições não aconteça durante a construção guiada pelo usuário. A expansão transforma um nó folha em um nó interno.

Quando y é um nó interno, o algoritmo testa se seu contador é menor que $|s|_{\max }$ (linha 7). Um nó interno com contador menor que $|s|_{\max }$ indica que a árvore de sufixo prefixada do prefixo representado por $y$ cabe na memória principal disponível $\mathrm{MM}_{\mathrm{A}}$. Neste caso, o algoritmo reduz o nó y, evitando o desperdício de recursos computacionais. Sem esta redução, várias árvores de sufixo prefixadas com tamanho menor que $\mathrm{MM}_{\mathrm{A}}$ seriam construídas pela construção guiada pelo usuário. A redução transforma um nó interno em um nó folha.

O algoritmo é chamado recursivamente enquanto existem nós para serem analisados (linha 9).

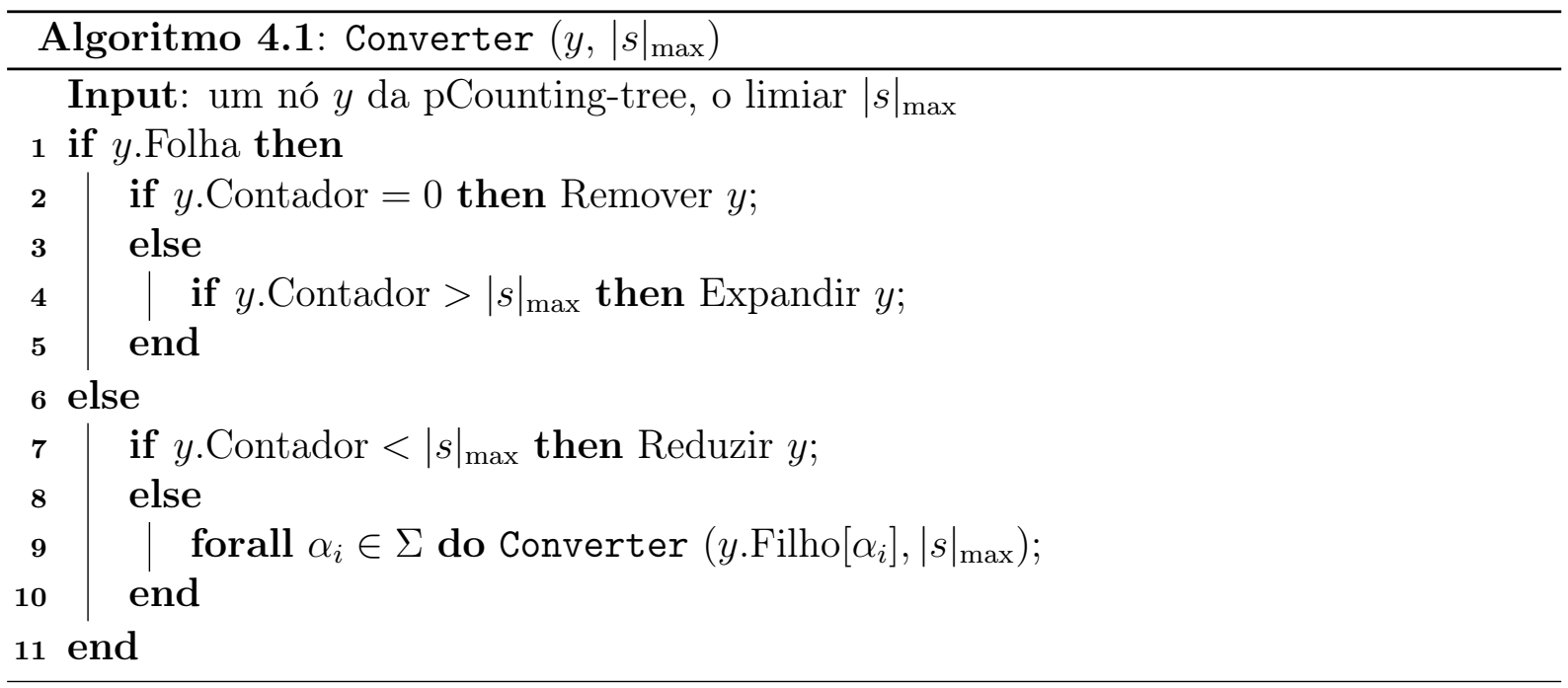

Por exemplo, a Figura 4.8 mostra o algoritmo Converter aplicado à pCounting-tree da Figura 4.7, utilizando um limiar ilustrativo $|s|_{\max }=3$. Neste exemplo, os nós folhas $y_{5}, y_{6}$ e $y_{7}$ foram removidos. Estes nós folhas representam os prefixos AA, $\mathrm{AC}$ e $\mathrm{AG}$, respectivamente, os quais não ocorrem na seqüência de entrada. Por outro lado, o nó folha $y_{4}$ foi expandido, dado que seu prefixo ocorre quatro vezes na seqüência de entrada (i.e., $4>3$ ). Esta expansão transformou o nó $y_{4}$ em um nó interno, criando os novos nós $y_{21}$ a $y_{24}$. Portanto, o prefixo AT foi expandido nos prefixos ATA, ATC, ATG e ATT. Por fim, o nó interno $y_{2}$ foi reduzido, porque seu prefixo ocorre uma única vez na seqüência de entrada (i.e., $1<3$ ). Esta redução transformou o nó $y_{2}$ em um nó folha, removendo os nós $y_{9}$ a $y_{12}$. Desta forma, os prefixos CA, CC, CG e CT foram reduzidos no prefixo $\mathrm{C}$.

Após executar o algoritmo Converter, Perseus define o conjunto de prefixos de tamanhos variáveis, o qual é composto pelos prefixos representados por todos os nós 
Seqüência de entrada:

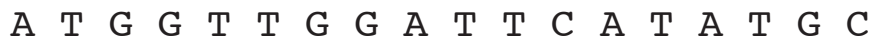

$\begin{array}{llllllllllllllllll}01 & 02 & 03 & 04 & 05 & 06 & 07 & 08 & 09 & 10 & 11 & 12 & 13 & 14 & 15 & 16 & 17 & 18\end{array}$

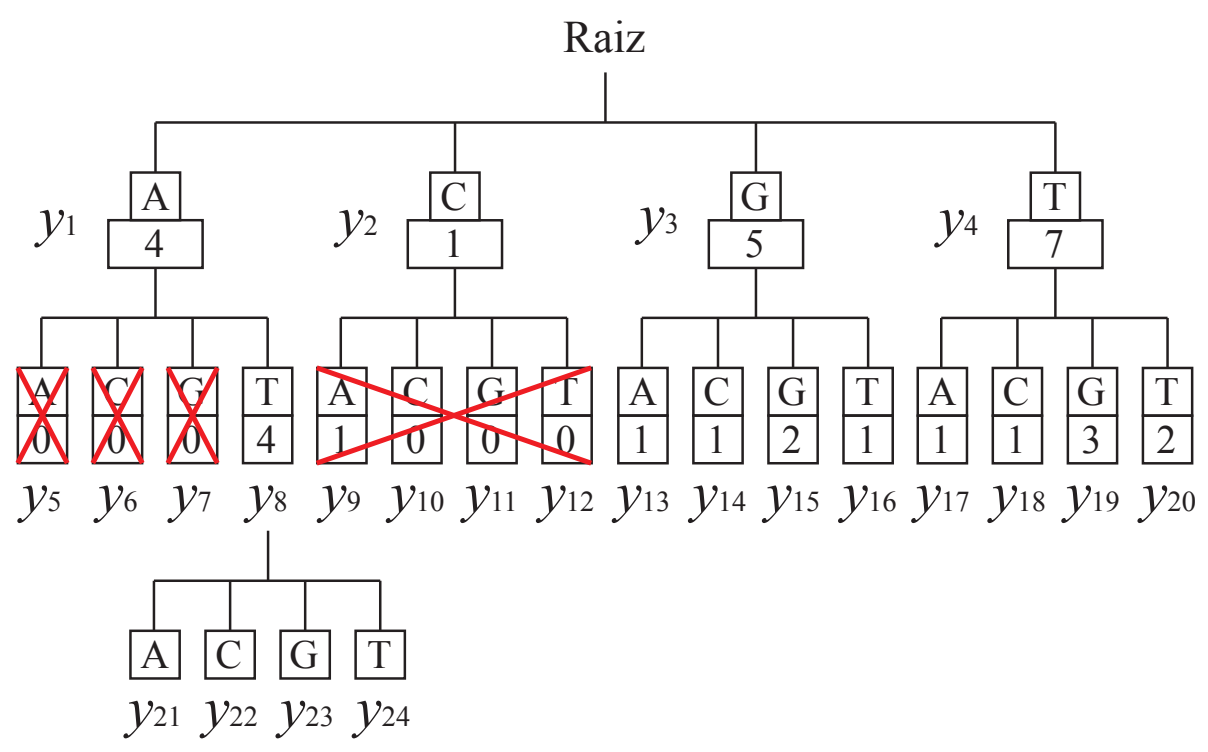

Figura 4.8: Exemplo do algoritmo Converter.

folhas da pCounting-tree convertida. Na Figura 4.8, o conjunto de prefixos de tamanhos variáveis obtido é $\{$ ATA, ATC, ATG, ATT, C, GA, GC, GG, GT, TA, TC, TG, TT\}, o qual é o mesmo conjunto ilustrado na Figura 4.4a-3.

\subsection{Construção Guiada pelo Usuário}

O resultado da estratégia de três passos é um conjunto de prefixos de tamanhos variáveis que indica se uma árvore de sufixo de uma seqüência de entrada deve ser particionada para ser construída sem introduzir o problema das partições. Se este conjunto é vazio, a árvore de sufixo deve ser construída sem ser particionada. Caso contrário, a árvore de sufixo dever ser particionada em árvores de sufixo prefixadas, cada uma indexando um prefixo específico do conjunto definido.

A construção guiada pelo usuário é voltada à construção de árvores de sufixo (prefixadas), usando como base não só o resultado produzido pela estratégia de três passos, mas também um conjunto de prefixos definido pelo usuário. Desta forma, a construção guiada pelo usuário usa o conjunto de prefixos de tamanhos variáveis produzido pela estratégia de três passos e o conjunto definido pelo usuário para gerar um conjunto combinado (Seção 4.4.1), o qual é então utilizado para construir as árvores de sufixo (prefixadas) da seqüência de entrada (Seção 4.4.2). 


\subsubsection{Definição do Conjunto Combinado}

O algoritmo Combiner cria um conjunto $C$ de prefixos de tamanhos variáveis, o qual contém uma combinação entre os prefixos de tamanhos variáveis do conjunto $V$ gerado no terceiro passo da estratégia de três passos e um conjunto de prefixos $U$ definido pelo usuário.

O algoritmo analisa três situações distintas. Na primeira situação, o usuário não informa prefixos específicos $(U=\varnothing)$ e, portanto, toda a seqüência de entrada é indexada. Neste caso, o algoritmo define $C$ igual a $V$ (linha 1).

A segunda situação diz respeito a quando o usuário informa um conjunto de prefixos $U$ e a estratégia de três passos identifica que a árvore de sufixo não precisa ser particionada $(V=\varnothing)$. Neste caso, o algoritmo define $C$ igual a $U$ (linha 2), indicando que a árvore de sufixo será particionada de acordo com as necessidades do usuário, apesar do resultado da estratégia de três passos.

Na última situação, tanto $U$ quanto $V$ não estão vazios, indicando que os prefixos destes dois conjuntos devem ser combinados. Neste caso, o algoritmo analisa cada prefixo $u_{i} \in U$ (linha 5), e adiciona $u_{i}$ a $C$ se $u_{i}$ também estiver presente em $V$ (linha 6). Por outro lado, se $V$ não contém $u_{i}$, o algoritmo investiga cada prefixo $v_{j} \in V$ (linhas 8 a 14), determinando se $v_{j}$ compartilha um prefixo comum com $u_{i}$. Para cada par $\left(u_{i}, v_{j}\right)$ encontrado, o algoritmo identifica qual prefixo é maior e o adiciona a $C$. Escolher o prefixo maior garante que os prefixos requeridos pelos usuário sejam indexados sem introduzir o problema das partições.

O algoritmo Combiner termina gravando o conjunto combinado $C$ em memória secundária (linha 18).

Dado o conjunto do usuário $U=\{\mathrm{AT}, \mathrm{GTT}, \mathrm{TG}\}$ e o conjunto de prefixos de tamanhos variáveis $V=\{$ ATA, ATC, ATG, ATT, C, GA, GC, GG, GT, TA, TC, TG, TT $\}$ (Seção 4.3.3), a Figura 4.9 mostra o conjunto combinado $C$ definido pelo algoritmo Combiner. Com relação ao primeiro prefixo do usuário, existem quatro prefixos em $V$ (i.e., ATA, ATC, ATG e ATT) que compartilham um prefixo comum com AT. Dado que estes quatro prefixos são maiores do que AT, os prefixos ATA, ATC, ATG e ATT são adicionados a $C$. Por outro lado, o prefixo do usuário GTT é maior do que o prefixo GT, que é o único prefixo de $V$ que compartilha um prefixo comum com GTT. Neste caso, o prefixo GTT é adicionado a $C$. Já o prefixo do usuário TG é adicionado diretamente a $C$, pois ele também está presente em $V$. Desta maneira, o conjunto combinado definido é $C=\{$ ATA, ATC, ATG, ATT, GTT, TG $\}$, o qual é o mesmo ilustrado na Figura 4.4b.

\subsubsection{Construção}

O algoritmo Construction (Algoritmo 4.3) constroi árvores de sufixo (prefixadas) de acordo com o conjunto combinado $C$. Se $C$ é um conjunto vazio, o algoritmo constrói 


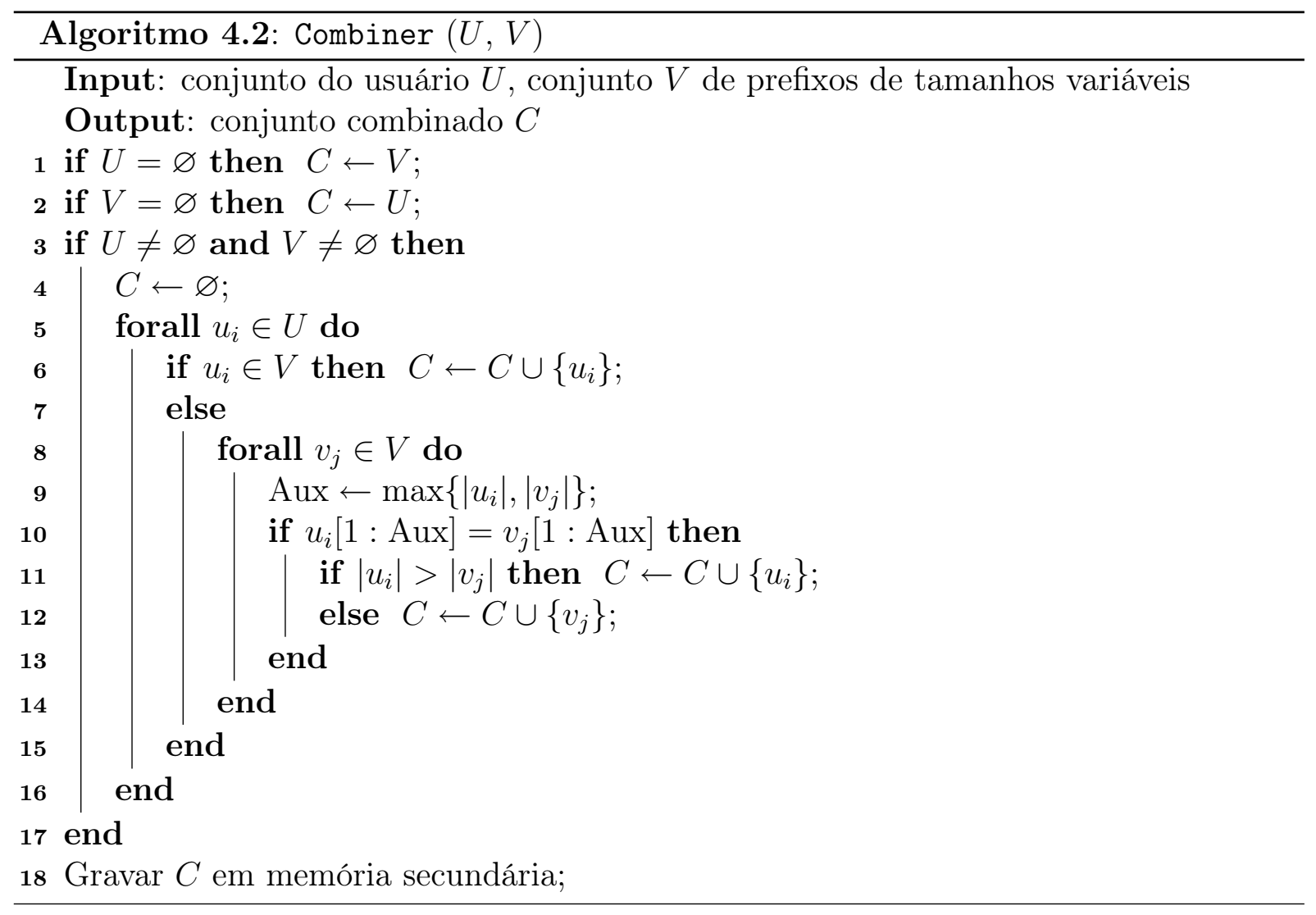

\section{Conjunto do usuário:}

$\begin{array}{ccc}\text { Prefixos de tamanhos variáveis: } & \underline{\mathbf{A T}} \\ \underline{\mathbf{G T T}}+\underline{\mathbf{T G}}\end{array}+\underline{\mathbf{A T A}}, \underline{\mathbf{A T C}} \underline{\underline{\mathbf{A T G}}, \underline{\mathbf{A T T}}, \mathrm{C}, \mathrm{GA}, \mathrm{GC}, \mathrm{GG}, \underline{\mathbf{G T}}, \mathrm{TA}, \mathrm{TC}, \underline{\mathbf{T G}}, \mathrm{TT}}=\begin{gathered}\text { ATA,ATC,ATG,ATT } \\ \text { GTT } \\ \text { TG }\end{gathered}$

Figura 4.9: Exemplo do algoritmo Combiner.

a árvore de sufixo sem partições (linhas 2 a 6). Caso contrário, uma árvore de sufixo prefixada é construída para cada prefixo $c_{i} \in C$ (linhas 8 a 15).

Em particular, a linha 10 encontra as ocorrências de $c_{i}$ na seqüência de entrada, sendo que cada ocorrência indica a posição de um sufixo que deve ser inserido na árvore de sufixo prefixada. Cada sufixo encontrado é imediatamente inserido na iTree-representation sem requerer armazenamento intermediário. A busca pelas ocorrências de $c_{i}$ é feita por meio do algoritmo quick search (Sunday, 1990).

Outra característica do algoritmo Construction é que as árvores de sufixo (prefixadas) são gravadas em memória secundária (linhas 6 e 14) visitando-se os nós da iTree-representation por meio de buscas por profundidade.

O algoritmo Construction utiliza o algoritmo Insert (Algoritmo 4.4) para inserir sufixos na iTree-representation de uma árvore de sufixo (prefixada). O algoritmo Insert primeiro determina o maior caminho a partir da raiz que representa um prefixo do sufixo $s[i:|s|]$ que está sendo inserido. Este caminho é encontrado casando-se recursiva- 


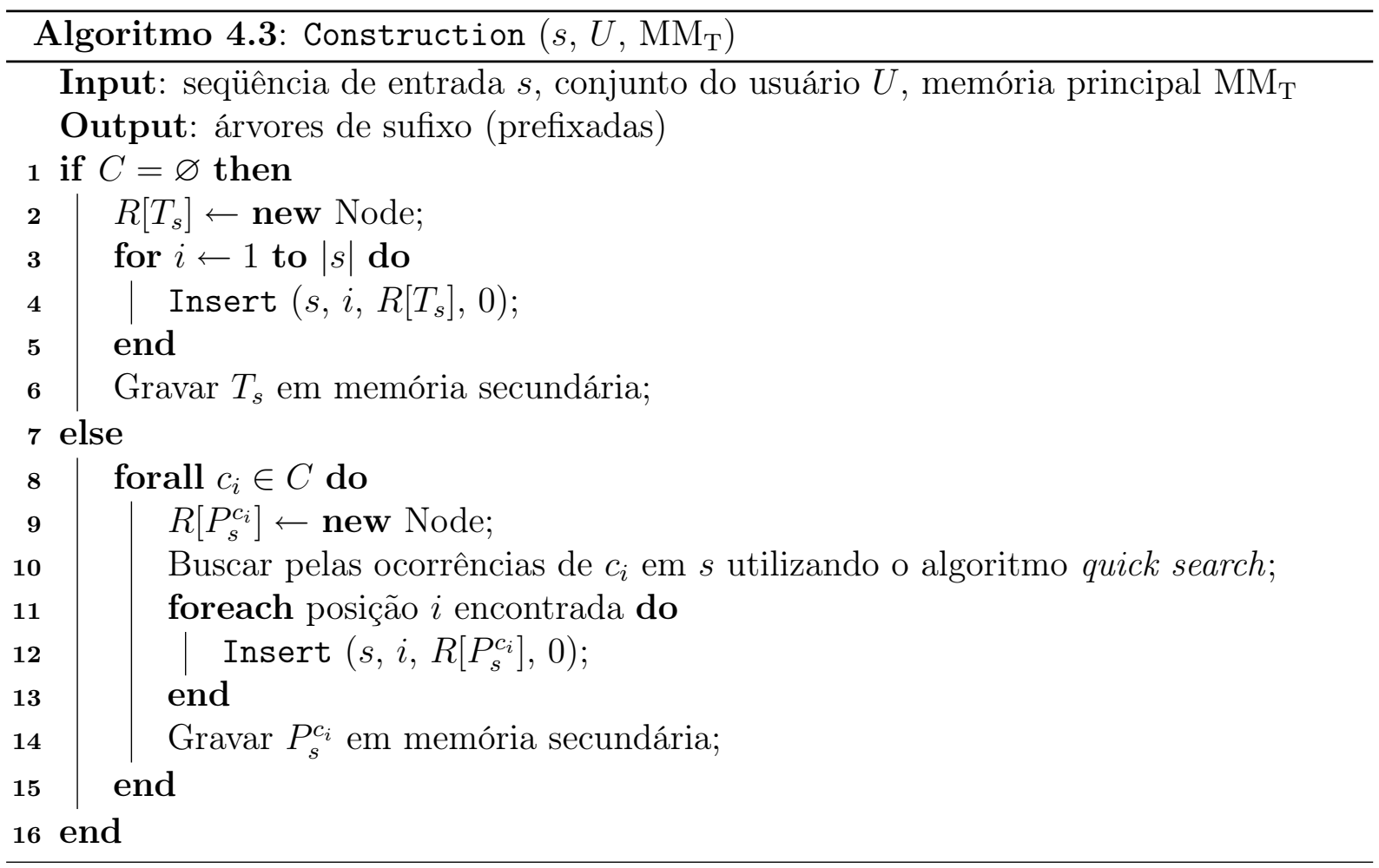

mente as arestas de entrada dos nós ao longo de um caminho único a partir da raiz, até que o casamento não seja mais possível (linhas 1 a 7). Este caminho é único porque duas arestas que partem do mesmo nó não podem representar subseqüências com prefixo comum.

Mais detalhadamente, o primeiro caractere do sufixo é armazenado em uma variável auxiliar $\alpha$, a qual é utilizada para identificar se existe um caminho no qual ocorre o casamento. Dado um nó $x$, esta condição é satisfeita quando o conteúdo de $x$.Folha $[\alpha]$ é igual a zero (linha 2) e o conteúdo de $x$.Filho $[\alpha]$ armazena um ponteiro para um filho de $x$ (linha 3). Neste caso, o nó apontado por $x$.Filho $[\alpha]$ é armazenado em um nó temporário $x_{\alpha}$ (linha 4). Se o casamento ocorrer (linha 5), a variável auxiliar Aux, a qual armazena a quantidade de caracteres casados, é atualizada (linha 6). Depois disso, o algoritmo Insert é chamado recursivamente utilizando como parâmetros o nó temporário $x_{\alpha} \mathrm{e}$ o novo valor de Aux (linha 7).

Quando o algoritmo identifica que novos casamentos não são possíveis, o caractere $\alpha$ sendo analisado está ou em uma aresta de entrada ou em um nó, definindo três casos de inserção:

- Caso 1: o primeiro caso de inserção ocorre quando o caractere sendo analisado está no meio de uma aresta de entrada (i.e., a condição da linha 5 não é satisfeita). Neste caso, o algoritmo insere o novo identificador de sufixo $i$ no nó temporário $x_{\alpha}$ (linha 9), o qual é o nó atual, e quebra sua aresta de entrada, criando um novo nó com a parte que não satisfaz o casamento (linha 10). 
- Caso 2: o segundo caso de inserção ocorre quando o caractere sendo analisado está em um nó $x$ e novos casamentos não são possíveis (i.e., a condição da linha 3 não é satisfeita). O algoritmo verifica esta situação quando os conteúdos de $x$. Folha $[\alpha] \mathrm{e}$ $x$.Filho $[\alpha]$ são zero e uma referência nula, respectivamente. Neste caso, o algoritmo atualiza o conteúdo de $x$.Folha $[\alpha]$ com o valor um e o conteúdo de $x$.Filho $[\alpha]$ com o novo identificador de sufixo $i$ (linhas 13 e 14). Este caso de inserção não cria um novo nó.

- Caso 3: o terceiro caso de inserção ocorre quando o caractere sendo analisado está em um nó $x$ e o caminho onde o casamento deveria continuar possui um identificador de sufixo (i.e., a condição da linha 2 não é satisfeita). Neste caso, o algoritmo cria um novo nó $x^{\prime}$ para armazenar os dois identificadores de sufixo $x$.Filho $[\alpha]$ e $i$ (linha 17). O algoritmo também transforma $x^{\prime}$ em um filho de $x$, atualizando o conteúdo de $x$.Folha $[\alpha]$ com o valor um e o conteúdo de $x$.Filho $[\alpha]$ com um ponteiro para o nó $x^{\prime}$ (linhas 18 e 19).

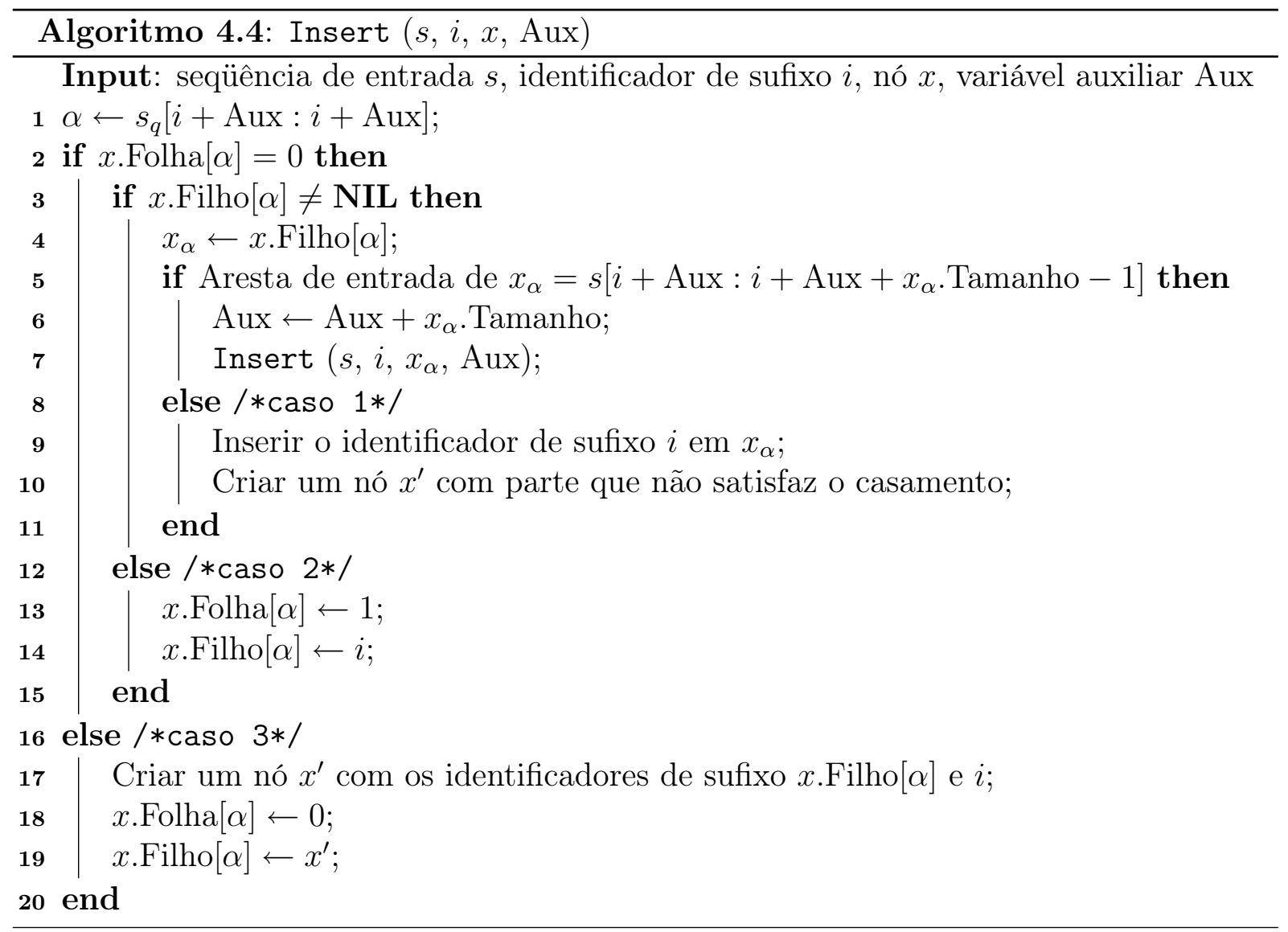

Por exemplo, a Figura 4.10 mostra, passo a passo, a construção da iTree-representation da Figura 4.5, a qual corresponde à árvore de sufixo prefixada $P_{s}^{\mathrm{TG}}$. Inicialmente, o algoritmo Construction cria uma árvore vazia (Figure 4.10a). Em seguida, o primeiro sufixo 
de $s$ que começa com o prefixo TG (i.e., sufixo $s[2: 18]$ ) é inserido. Nesta iteração, o casamento falha no caractere T. Dado que os conteúdos de Raiz.Folha $[T]$ e Raiz.Filho $[T]$ são iguais a zero e a uma referência nula, respectivamente, o caso 2 é aplicado. A Figura 4.10b mostra a iTree-representation após esta primeira inserção.

Depois disso, o algoritmo insere o segundo sufixo de $s$ que começa com o prefixo TG (i.e., sufixo $s[6: 18]$ ). Nesta iteração, o casamento também falha no caractere T. Contudo, dado que o conteúdo de Raiz.Folha $[T]$ é igual a um, o caso 3 é aplicado. A Figura 4.10c mostra a iTree-representation após esta segunda inserção.

A primeira e a segunda inserções não requerem chamadas recursivas, dado que seus casamentos falham na primeira chamada do algoritmo. Por outro lado, a recursão é utilizada na inserção do terceiro sufixo de $s$ que começa com o prefixo TG (i.e., sufixo $s[16: 18]$ ), dado que o casamento no nó raiz é satisfeito. Nesta iteração, o casamento falha no caractere $\mathrm{A}$ e, dado que $\mathrm{A}$ encontra-se na aresta de entrada de $x_{1}$, o caso 1 é aplicado. A Figura 4.10d mostra a iTree-representation após esta última inserção.

Seqüência de entrada:

A T G G T T G G A T T C A T A T G C

$\begin{array}{llllllllllllllllll}01 & 02 & 03 & 04 & 05 & 06 & 07 & 08 & 09 & 10 & 11 & 12 & 13 & 14 & 15 & 16 & 17 & 18\end{array}$

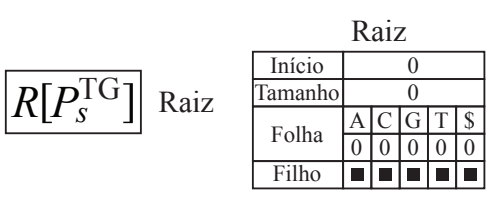

(a)

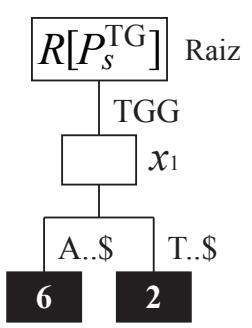

(c)

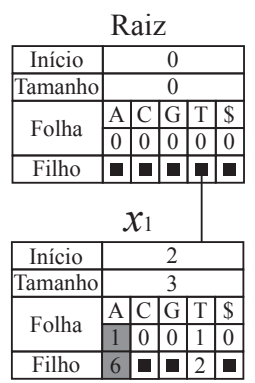

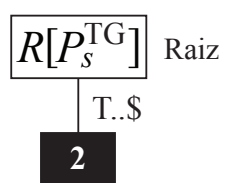

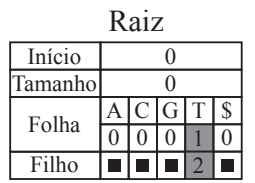

(b)
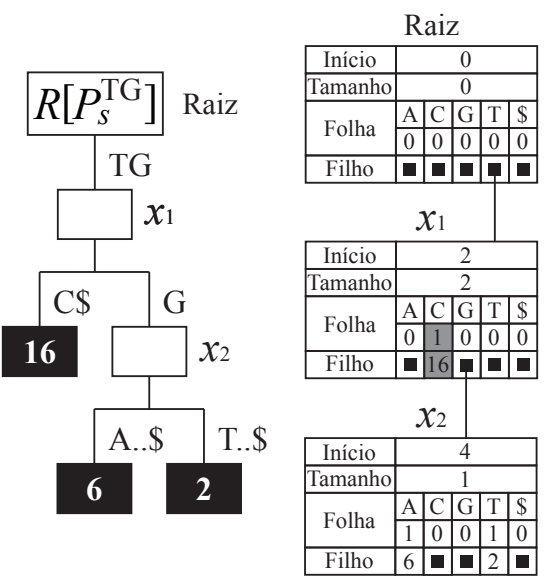

(d)

Figura 4.10: Exemplo do algoritmo Insert.

Com relação ao conjunto combinado $C=\{$ ATA, ATC, ATG, ATT, GTT, TG $\}$ (Seção 4.4.1), PERSEus utiliza o algoritmo Construction para construir seis árvores de sufixo prefixadas, cada uma indexando um dos prefixos de $C$, como ilustrado na Figure 4.4b. 


\subsection{Casamento Exato Estendido}

O algoritmo original de casamento exato (Gusfield, 1997) trata apenas árvores de sufixo não particionadas. Para utilização conjunta com a construção guiada pelo usuário, este algoritmo foi estendido para suportar árvores de sufixo de podem estar particionadas em árvores de sufixo prefixadas.

A busca por ocorrências de uma seqüência de consulta em árvores de sufixo (prefixadas) é feita pelo algoritmo ExtendedExactMatching (Algoritmo 4.5). Este algoritmo investiga se o conjunto combinado $C$ gerado pela construção guiada pelo usuário é vazio (linha 1). Se esta condição for satisfeita, o algoritmo procura por identificadores de sufixo na árvore de sufixo não particionada (linha 2). Caso contrário, o algoritmo procura por identificadores de sufixo apenas na árvore de sufixo prefixada do prefixo que ocorre no começo da seqüência de consulta (linhas 4 a 6 ).

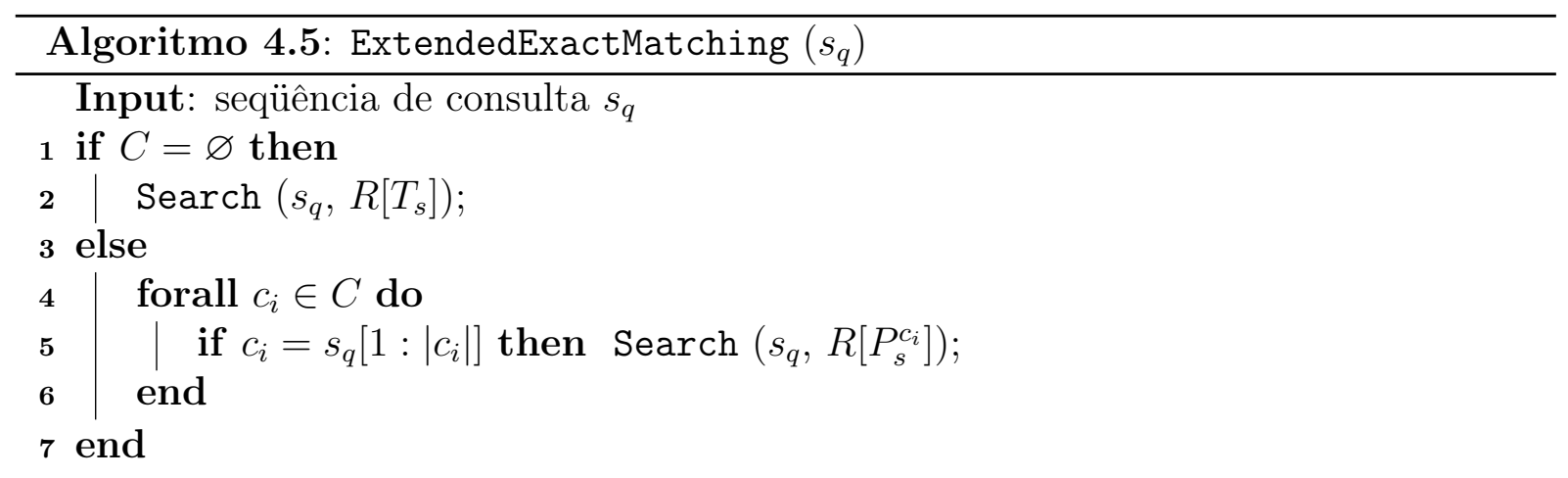

O algoritmo ExtendedExactMatching utiliza o algoritmo Search (Algoritmo 4.6) para procurar por identificadores de sufixo nas árvores de sufixo (prefixadas) de uma seqüência de entrada s. O algoritmo Search começa inicializando o valor de Aux, que é uma variável auxiliar que armazena a posição em $s_{q}$ do caractere que está sendo analisado. Em seguida, o algoritmo investiga o primeiro caractere $\alpha$ da seqüência de consulta $s_{q}$ (linha 3 ). Dado um nó $x$, o algoritmo verifica se o conteúdo de $x$.Folha $[\alpha]$ é igual a um (linha 4 ). Esta condição indica que existe apenas uma ocorrência de $s_{q}$ em $s$. Neste caso, o algoritmo termina retornando o identificador de sufixo $x$.Filho $[\alpha]$ (linhas 5 e 6). Por outro lado, um valor igual a zero no conteúdo de $x$.Folha $[\alpha]$ e uma referência nula no conteúdo de $x$.Filho $[\alpha]$ indicam que $s_{q}$ não ocorre em $s$. Desta forma, o algoritmo termina sem retornar identificadores de sufixo (linha 8). Por fim, se o conteúdo de $x$.Filho[ $\alpha]$ é um ponteiro, o algoritmo atualiza o valor de Aux, indicando a posição em $s_{q}$ do próximo caractere a ser analisado, e continua a busca no nó apontado, até que não existam mais caracteres em $s_{q}$ para serem analisados (linhas 10 a 12). Nesta situação, $s_{q}$ pode ocorrer mais de uma vez em $s$. O algoritmo termina, então, retornando todos os identificadores de sufixo de $x$ e seus filhos (linha 13). 


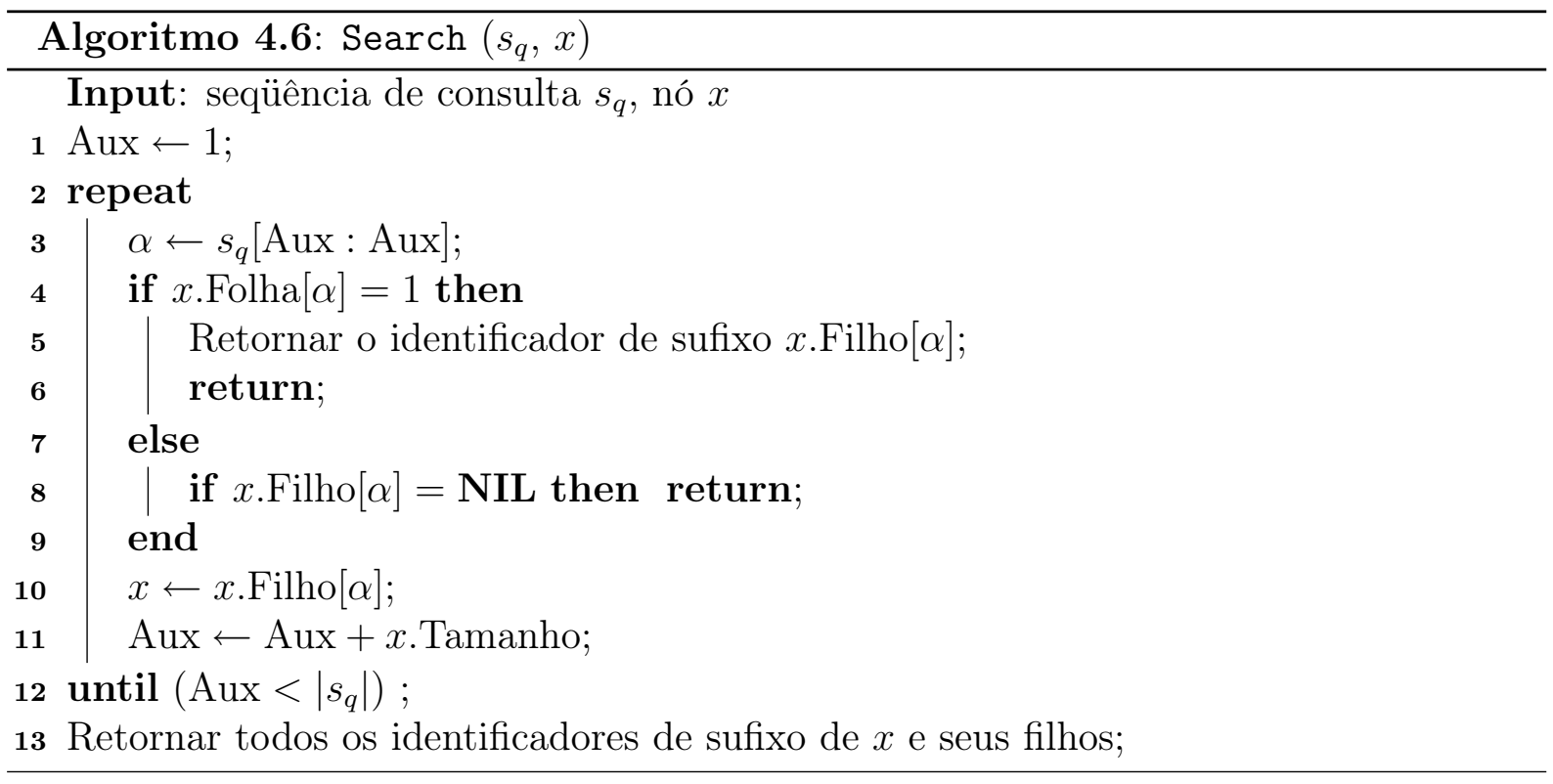

Por exemplo, a Figura 4.11 mostra, passo a passo, como as ocorrências da seqüência de consulta $s_{q}=$ TGGA na seqüência de entrada $s=$ ATGGTTGGATTCATATGC são encontradas utilizando o algoritmo Search e a iTree-representation da Figura 4.5. O algoritmo começa analisando o nó Raiz e o caractere $\mathrm{T}$, o qual é o primeiro caractere de $s_{q}$ (i.e, Aux =1). Dado que o conteúdo de Raiz.Folha[T] é igual a zero e o conteúdo de Raiz.Filho[T] é um ponteiro para o nó $x_{1}$, o valor de Aux é atualizado usando $x_{1}$. Tamanho e o algoritmo é chamado recursivamente para analisar $x_{1}$ (Figura 4.11a). Na segunda iteração, o caractere sendo analisado é o G, o qual é o terceiro caractere de $s_{q}$ (i.e., Aux $=3$ ). Semelhantemente à primeira iteração, dado que o conteúdo de $x_{1}$. Folha $[T]$ é igual a zero e o conteúdo de $x_{1}$.Filho[T] é um ponteiro para o nó $x_{2}$, o valor de Aux é atualizado usando $x_{2}$. Tamanho e o algoritmo é chamado recursivamente para analisar $x_{2}$ (Figura 4.11b). Já na terceira iteração, o caractere sendo analisado é o A, o qual é o quarto caractere de $s_{q}$ (i.e., Aux =4). Dado que o conteúdo de $x_{2}$.Folha $[G]$ é igual a um, o algoritmo termina retornando o identificador de sufixo armazenado no conteúdo de $x_{2}$.Filho $[G]$, que é o valor 6 (Figura 4.11c). Isto indica que existe uma única ocorrência de $s_{q}$ em $s$, a qual começa na posição 6 de $s$. Note que o exemplo atual detalha a Figura 4.4c.

\subsection{Considerações Finais}

Este capítulo detalhou o PERSEus, uma nova técnica para tratar árvores de sufixo persistentes. Inicialmente, o capítulo apresentou uma visão geral da técnica proposta, destacando seus três diferenciais. Em seguida, cada um destes diferencias foi detalhado. O primeiro diferencial introduziu uma abordagem chamada de estratégia de três passos, a qual permite a construção de árvores de sufixo cujos tamanhos podem exceder a capacidade da memória principal e que garante, portanto, que o problema das partições não 
Seqüência de consulta:

T G G A

$0102 \quad 0304$

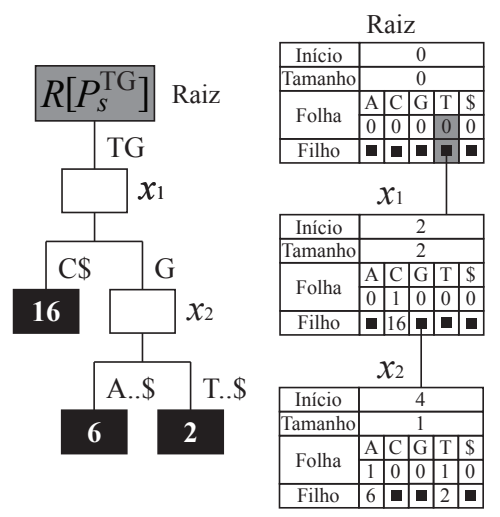

(a)

Seqüência de entrada:

A $T$ G G T T G G A T T C A TA T G C

$\begin{array}{llllllllllllllllll}01 & 02 & 03 & 04 & 05 & 06 & 07 & 08 & 09 & 10 & 11 & 12 & 13 & 14 & 15 & 16 & 17 & 18\end{array}$

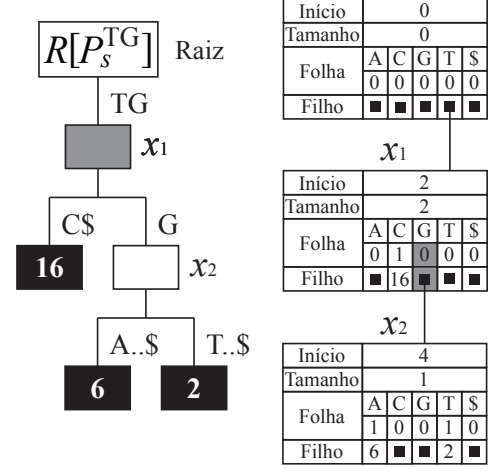

(b)

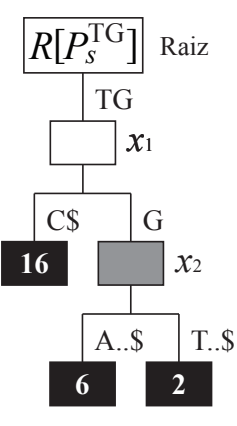

(c)

Figura 4.11: Exemplo do algoritmo Search.

ocorra. O segundo diferencial enfocou a construção guiada pelo usuário, que permite que o usuário escolha quais subseqüências de uma seqüência devem ser indexadas, além de particionar as árvores somente quando necessário. Por fim, o terceiro diferencial apresentou um algoritmo de casamento exato estendido que permite a busca por uma seqüência de consulta em árvores de sufixo que podem estar particionadas.

A Tabela 4.4 mostra a Tabela 3.1 com uma coluna adicional, na qual são comparadas as características do PERSEus com as características dos trabalhos correlatos resumidos no Capítulo 3. O uso conjunto da estratégia de três passos (i.e., prefixos de tamanhos variáveis) e da construção guiada pelo usuário permite que PERSEus indexe seqüências de escala genômica sem sofrer do problema das partições. Além disso, apesar da técnica proposta não utilizar elos de sufixo durante a construção das árvores de sufixo (prefixadas), Perseus pode ser complementado com o suporte a elos de sufixo por meio da fase opcional de recuperação de elos de sufixo do TRELLIS + , dado que ambas técnicas produzem árvores de sufixo logicamente idênticas.

Tabela 4.4: Comparação das técnicas de construção de árvores de sufixo persistentes.

\begin{tabular}{lcccc}
\hline Propriedades & Hunt et al & TDD & Trellis + & PERseus \\
\hline Escala suportada & Cromossômica & Genômica & Genômica & Genômica \\
Tamanho dos prefixos & Fixos & Fixos & Variáveis & Variáveis \\
Construção & Trivial & PWOTD & Ukkonen & Guiada pelo usuário \\
Problema das partições & Sim & Não & Não & Não \\
Elos de sufixo & Não & Não & Sim & Não* \\
\hline
\end{tabular}


Além da comparação das características do PERSEus com os trabalhos correlatos destacados na Tabela 4.4, a técnica proposta também foi validada por meio de testes de desempenho realizados contra a técnica TRELLIS + , a qual representa o estado da arte nesta linha de pesquisa. Os testes de desempenho realizados são apresentados e discutidos no Capítulo 5. 


\section{Capítulo \\ 5 \\ Testes de Desempenho}

O Perseus foi analisado por meio de testes de desempenho utilizando genomas de vários organismos, os quais foram selecionados do repositório ftp.ensembl.org/pub/current_ fasta. Para construir árvores de sufixo do alfabeto $\Sigma=\{\mathrm{A}, \mathrm{C}, \mathrm{G}, \mathrm{T}\}$, foram removidos todos os nucleotídeos desconhecidos (representados pelo caractere $\mathrm{N}$ ) dos genomas selecionados. A remoção destes nucleotídeos é comumente realizada na indexação de seqüências de nucleotídeos e não compromete a pesquisa conforme demonstrado por (Barsky et al, 2008). A Tabela 5.1 mostra estes genomas, seus tamanhos com e sem nucleotídeos desconhecidos, e sua distribuição de nucleotídeos.

Tabela 5.1: Genomas utilizados nos experimentos.

\begin{tabular}{lcccccc}
\hline \multirow{2}{*}{ Genoma } & \multicolumn{2}{c}{ Tamanho do genoma } & \multicolumn{4}{c}{ Nucleotídeos (\%) } \\
& Com N & Sem N & A & C & G & T \\
\hline Caenorhabditis elegans (CE) & $97,2 \mathrm{Mbps}$ & $95,6 \mathrm{Mbps}$ & 32,28 & 17,73 & 17,70 & 32,28 \\
Anopheles gambiae (AG) & $223,7 \mathrm{Mbps}$ & $214,7 \mathrm{Mbps}$ & 27,72 & 22,27 & 22,28 & 27,72 \\
Oryzias latipes (OL) & $702,2 \mathrm{Mbps}$ & $555,2 \mathrm{Mbps}$ & 29,93 & 20,08 & 20,06 & 29,92 \\
Gallus gallus (GG) & $1.000,6 \mathrm{Mbps}$ & $939,2 \mathrm{Mbps}$ & 29,34 & 20,64 & 20,64 & 29,37 \\
Canis familiaris (CF) & $2,32 \mathrm{Gbps}$ & $2,2 \mathrm{Gbps}$ & 29,48 & 20,51 & 20,50 & 29,50 \\
Rattus norvegicus (RN) & $2,57 \mathrm{Gbps}$ & $2,31 \mathrm{Gbps}$ & 29,02 & 20,97 & 20,97 & 29,04 \\
Homo sapiens (HS) & $2,92 \mathrm{Gbps}$ & $2,66 \mathrm{Gbps}$ & 29,53 & 20,44 & 20,45 & 29,57 \\
\hline
\end{tabular}

Foram selecionados sete genomas com diferentes ordens de magnitude de tamanho (i.e., $10^{7} \mathrm{bps}, 10^{8} \mathrm{bps}$ e $10^{9} \mathrm{bps}$ ). Estes genomas foram separados em três grupos, de acordo com estas magnitudes. O grupo 1 é composto apenas pelo genoma do organismo Caenorhabditis elegans $\left(10^{7} \mathrm{bps}\right)$. Este organismo possui seis cromossomos, definindo 
seis seqüências de entrada, cada uma formada pela concatenação da seqüência anterior e o cromossomo atual. Por outro lado, o grupo 2 é composto pelos genomas dos organismos Anopheles gambiae, Oryzias latipes e Gallus gallus ( $\left.10^{8} \mathrm{bps}\right)$, enquanto que e o grupo 3 é composto pelos genomas dos organismos Canis familiaris, Rattus norvegicus e Homo sapiens $\left(10^{9} \mathrm{bps}\right)$.

O Perseus foi comparado com o Trellis +, dado que este representa o estado da arte, superando outras técnicas como a técnica de Hunt et al, o DynaCluster, o TOP-Q e o TDD (Phoophakdee e Zaki, 2007). O Perseus foi implementado em $\mathrm{C}++$ e compilado no GNU g++ versão 4.1 .2 com otimizações ativadas. O código fonte do TRELLIS + foi obtido de seus autores e compilado sob as mesmas configurações. Todos os experimentos foram conduzidos em uma máquina executando Linux (32-bits) com um processador Intel P4 3.0 GHz, 3 GB de memória principal e 750 GB de memória secundária. A quantidade total de memória principal em todos os testes foi limitada em 1,5 GB (i.e., $50 \%$ da memória principal) para as duas técnicas.

Nos testes de desempenho, foram analisados o custo de construção das árvores de sufixo e o custo de processamento de casamentos exatos. Para o custo de construção das árvores de sufixo, foram coletados o tempo total em segundos e o espaço em memória secundária em GB (Seção 5.1). Já para o custo de processamento de casamentos exatos, foram coletados o tempo total gasto em segundos para processar diferentes conjuntos de consultas compostas de seqüências sintéticas e reais (Seção 5.2). Além disso, também foi investigada a influência dos tamanhos das consultas no processamento de casamentos exatos (Seção 5.3). Outros testes realizados referem-se a testes específicos para analisar os benefícios proporcionados pela construção guiada pelo usuário (Seção 5.4). Além das seções que apresentam e discutem os resultados de desempenho, este capítulo possui uma seção adicional, a qual descreve as considerações finais (Seção 4.6).

\subsection{Custo de Construção das Árvores de Sufixo}

Para técnicas que constroem árvores de sufixo prefixadas, o custo de definição do conjunto de prefixos é um aspecto muito importante e, portanto, deve ser investigado em uma análise comparativa. Desta forma, foram realizados testes que compararam a estratégia de três passos do Perseus com a fase de definição dos prefixos do Trellis + . A Tabela 5.2 mostra o tempo total gasto em segundos para se definir o conjunto de prefixos nas duas técnicas. Os resultados mostram que o PERSEUs superou o TRELLIS + para todas as seqüências de entrada, obtendo uma redução no tempo total de 46,37\% a 94,08\%. Para o genoma do Homo sapiens(HS), por exemplo, TRELLIS + demorou 2.473 segundos (41 minutos) para definir o conjunto de prefixos, enquanto que o PERSEus demorou apenas 168 segundos (2,7 minutos). Ou seja, Perseus foi aproximadamente 15 vezes mais rápido. TRELLIS + sempre requereu mais tempo de processamento porque adota uma abordagem 
que requer múltiplas leituras da seqüência de entrada, enquanto que o conjunto de prefixos do Perseus é definido em uma única leitura da seqüência de entrada. Em geral, a redução proporcionada pela técnica Perseus foi superior a 89\%. Mesmo para genomas pequenos, esta redução foi significativa, sendo superior a $45 \%$.

Tabela 5.2: Resultados experimentais da definição dos prefixos de tamanhos variáveis.

\begin{tabular}{ccrrc}
\hline \multirow{2}{*}{ Grupo } & Genoma & \multicolumn{2}{c}{ Tempo total (segundos) } & Redução no \\
& & TRELLIS + & PERSEUS & tempo total \\
\hline 1 & CE & 6,9 & 3,7 & $46,37 \%$ \\
2 & AG & 86 & 9 & $89,53 \%$ \\
2 & OL & 406 & 28 & $93,10 \%$ \\
2 & GG & 795 & 47 & $94,08 \%$ \\
3 & CF & 1.972 & 126 & $93,61 \%$ \\
3 & RN & 1.852 & 131 & $92,92 \%$ \\
3 & HS & 2.473 & 168 & $93,20 \%$ \\
\hline
\end{tabular}

Também foram comparados os tempos totais de construção da árvore de sufixo (Figura 5.1). PERSEus sempre produziu os melhores resultados para os grupos 1 e 2. Além disso, Perseus também produziu os melhores resultados para a maior parte dos genomas do grupo 3. Comparado com o Trellis+, o ganho de desempenho do Perseus foi de $12 \%$ para o grupo 1 , de $20 \%$ para o grupo 2 , de $12,27 \%$ para o genoma do Canis familiaris (CF) e de $0,82 \%$ para o genoma do Homo sapiens (HS), o que proporciona uma boa de redução do tempo total de construção. PeRseus requereu um aumento apenas para construir a árvore de sufixo do genoma do Rattus norvegicus (RN), o qual foi de $16 \%$ com relação ao Trellis + . Este aumento deve-se ao fato de que a construção guiada pelo usuário do Perseus possui complexidade $O\left(|s|^{2}\right)$ com relação ao tempo no pior caso.

Com relação ao espaço em memória secundária (Figura 5.2), PERSEus sempre construiu árvores de sufixo com tamanhos menores. Enquanto que no TRELLIS + as árvores de sufixo construídas apresentaram tamanho 27 vezes maior que a seqüência de entrada, no Perseus este valor foi de apenas 20 vezes maior, aproximadamente. A redução média em todos os testes foi de 27\%, com uma pequena variação entre 26,91\% e 28,57\% (Tabela 5.3). O espaço em memória secundária requerido pelo TRELLIS + foi maior porque sua representação em disco armazena nós folhas, enquanto que a iTree-representation usada pelo PERSEUs não requer o armazenamento de nós folhas, gerando estruturas mais compactas. Note que o uso de uma estrutura de dados mais compacta permitiu que o conjunto de prefixos de tamanhos variáveis definidos pelo PERSEus fosse sempre menor (e.g., 157 prefixos com tamanhos variando entre 2 e 4 para o PERSEus contra 613 prefixos com tamanhos variando entre 3 e 6 para o TrELlis + ) (Tabela 5.4). 


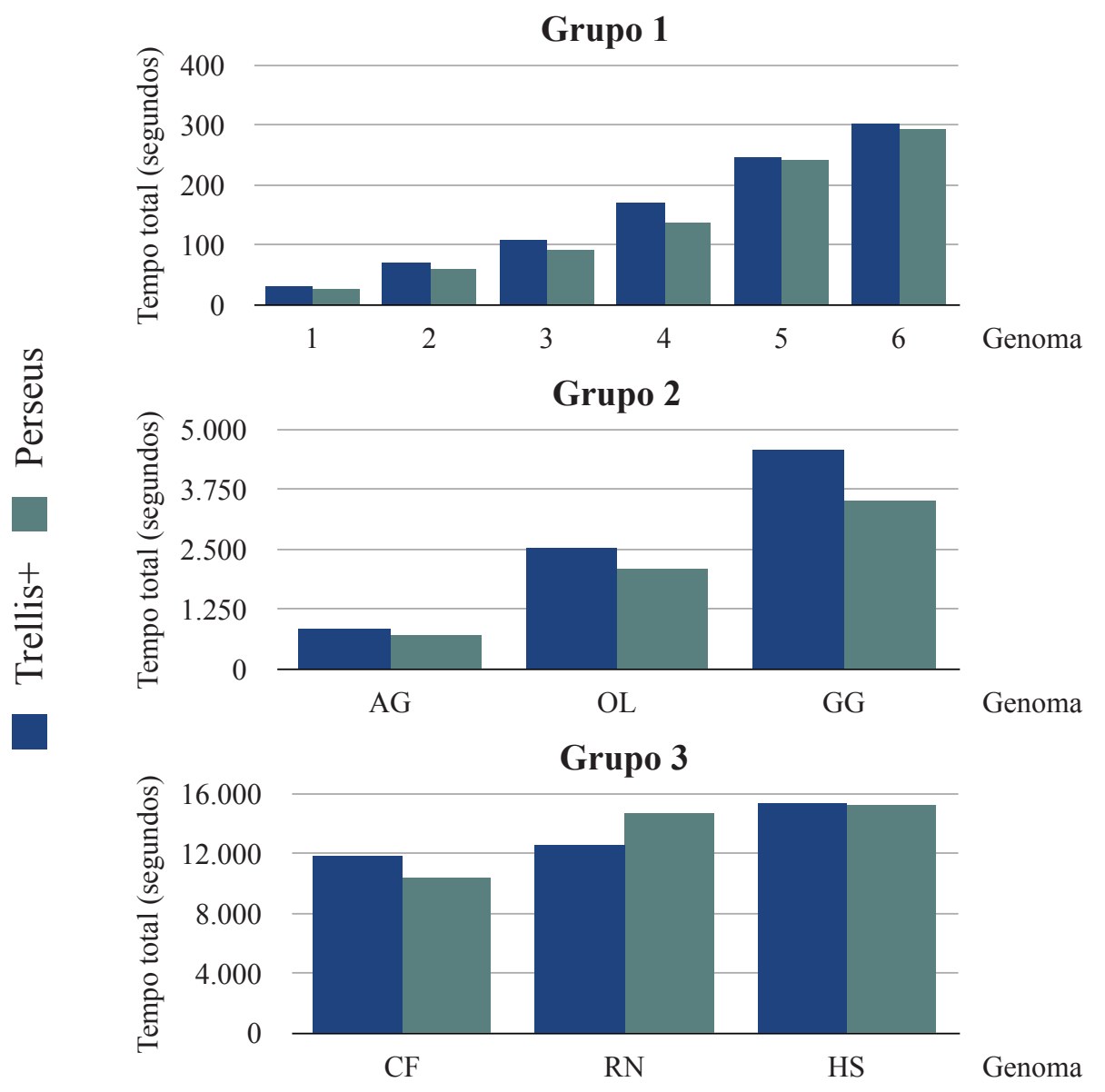

Figura 5.1: Tempo de construção das árvores de sufixo.

Tabela 5.3: Resultados experimentais da construção das árvores de sufixo.

\begin{tabular}{|c|c|c|c|}
\hline \multirow{2}{*}{ Genoma } & \multicolumn{2}{|c|}{ Memória secundária (GB) } & \multirow{2}{*}{$\begin{array}{l}\text { Redução no espaço } \\
\text { de memória secundária }\end{array}$} \\
\hline & TRELlis + & Perseus & \\
\hline $\mathrm{CE}$ & 2.5 & 1.8 & $27.50 \%$ \\
\hline $\mathrm{AG}$ & 5.6 & 4.0 & $28.57 \%$ \\
\hline $\mathrm{OL}$ & 14.6 & 10.6 & $27.40 \%$ \\
\hline GG & 24.2 & 17.5 & $27.69 \%$ \\
\hline $\mathrm{CF}$ & 57.4 & 41.6 & $27.53 \%$ \\
\hline $\mathrm{RN}$ & 62.8 & 45.9 & $26.91 \%$ \\
\hline HS & 72.4 & 52.9 & $26.93 \%$ \\
\hline
\end{tabular}

\subsection{Custo de Processamento de Casamentos Exatos}

Para investigar o custo de processamento de casamentos exatos, foram realizados experimentos com as árvores de sufixo em memória secundária dos sete genomas selecionados (CE, AG, OL, GG, CF, RN e HS), utilizando diferentes conjuntos de consultas com seqüências de nucleotídeos sintéticas e reais. Cada conjunto de consultas foi composto por 1.400 seqüências de nucleotídeos, ou, mais especificamente, 100 seqüências de 14 inter- 


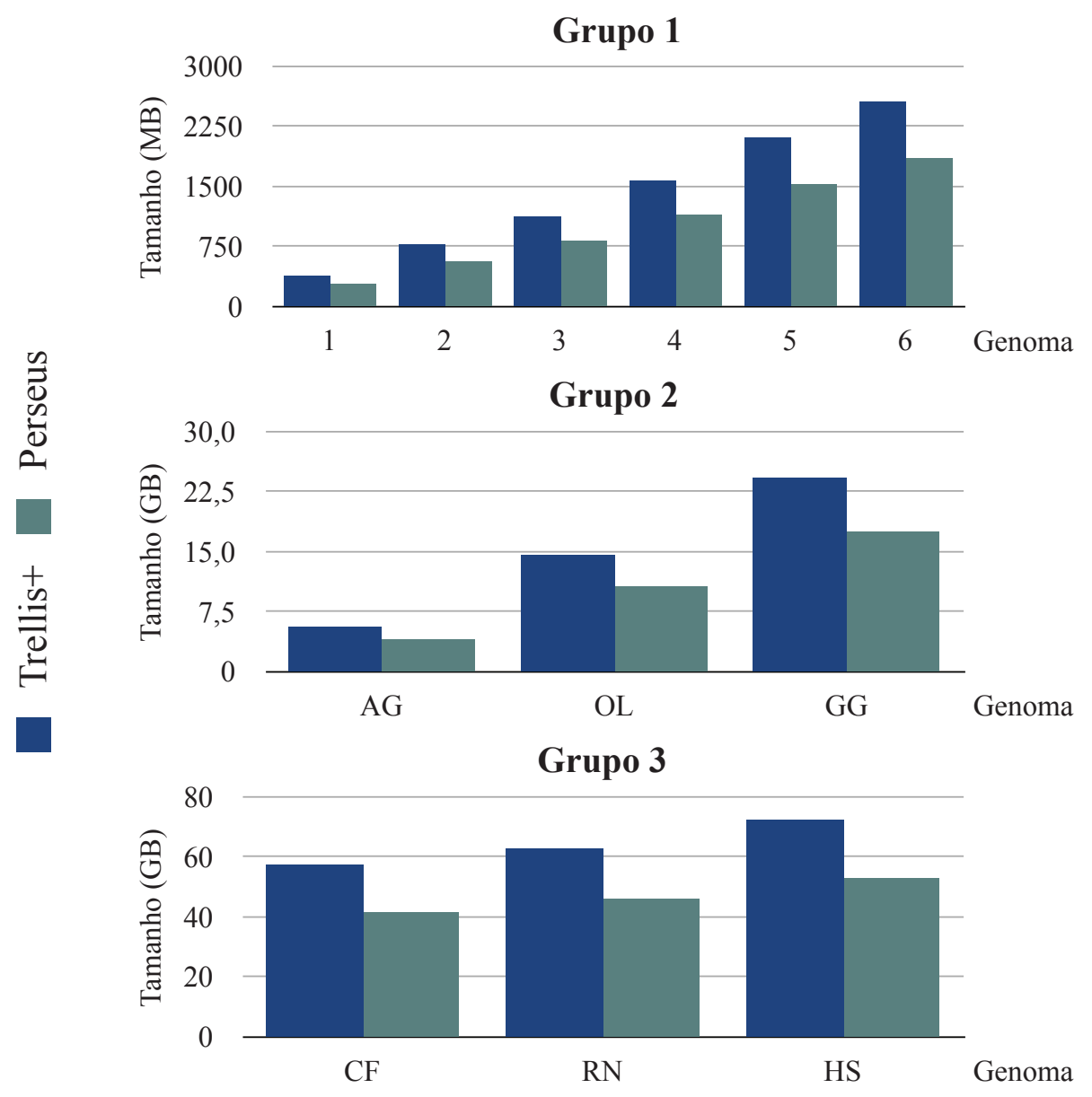

Figura 5.2: Utilização do espaço em memória secundária.

Tabela 5.4: Resultados experimentais da construção das árvores de sufixo.

\begin{tabular}{crrrr}
\hline \multirow{2}{*}{ Genoma } & \multicolumn{2}{c}{ Tamanhos dos prefixos } \\
& TrEllis + & Perseus & \multicolumn{2}{c}{ Número de prefixos } \\
TRELlS + & Perseus \\
\hline CE & $1-2$ & $1-1$ & 10 & 4 \\
AG & $2-3$ & $1-1$ & 22 & 4 \\
OL & $2-4$ & $2-2$ & 67 & 16 \\
GG & $2-4$ & $2-3$ & 172 & 28 \\
CF & $3-6$ & $2-4$ & 331 & 73 \\
RN & $3-5$ & $2-4$ & 424 & 79 \\
HS & $3-6$ & $2-4$ & 613 & 157 \\
\hline
\end{tabular}

valos de tamanhos variando entre 40 e $10.000 \mathrm{bps}$. Estes intervalos cobrem os tamanhos de consultas mais comuns no processamento de casamentos exatos.

Foram utilizados três tipos de conjuntos de consultas. O primeiro tipo é composto por seqüências de nucleotídeos criadas artificialmente. Estas seqüências foram geradas utilizando uma distribuição de nucleotídeos de $30 \%$ de A, 20\% de C, 20\% de G e $30 \%$ de T, que é a distribuição aproximada encontrada em seqüências reais. O segundo tipo, composto por seqüências reais, foi formado por subseqüências randomicamente retiradas do genoma 
do organismo Gorilla gorilla. Já o terceiro tipo, também composto por seqüências reais, foi formado por subseqüências randomicamente retiradas dos genomas aos quais as consultas estavam sendo submetidas, gerando, desta forma, casamentos exatos que sempre retornam pelo menos uma ocorrência. Os conjuntos deste último tipo são chamados de conjuntos individuais.

A Figura 5.3 mostra os resultados dos casamentos exatos para todos os conjuntos de consultas descritos. Com relação ao tempo total gasto, os resultados mostraram que o PERSEus sempre produziu os melhores resultados, processando casamentos exatos em média $49 \%$ mais rápido do que o TRELlis + . Os resultados também mostraram que o ganho de desempenho do Perseus é maior conforme o número de ocorrências das consultas aumenta. Isto é verificado à medida que, para os conjuntos sintéticos, que resultam nos menores números de ocorrências, o ganho de desempenho do PeRseus é menor do que para os conjuntos individuais, dado que as seqüências de consulta nestes conjuntos individuais são retiradas dos genomas aos quais as consultas foram submetidas e, portanto, ocorrências sempre acontecem. O ganho de desempenho variou entre 20\% e $56 \%$ para os conjuntos sintéticos, entre $19 \%$ e $64 \%$ para os conjuntos compostos por subseqüências do genoma do organismo Gallus gallus, e entre $23 \%$ e $74 \%$ para os conjuntos individuais.

Ainda na Figura 5.3, as retas indicam o crescimento do tempo gasto em função do crescimento do tamanho do genoma indexado. Para o Perseus, esse crescimento é suave, enquanto que para o TRELLIS + esse crescimento é mais acentuado, especialmente para os conjuntos individuais, que possuem o maior número de ocorrências. O bom comportamento do PERSEus é devido ao fato da iTree-representation não armazenar nós folhas. Desta forma, PERSEus realiza um menor número de acessos à memória secundária quando ocorrências acontecem, o que conduz a um processamento de casamentos exatos mais rápido.

\subsection{Influência do Tamanho das Consultas no Proces- samento de Casamentos Exatos}

Também foram realizados testes de desempenho para investigar a influência do tamanho das consultas no processamento de casamentos exatos. Para isto, foram utilizadas as árvores de sufixo em memória secundária dos genomas dos organismos Caenorhabditis elegans (CE), Gallus gallus (GG) e Homo sapiens (HS), que são os maiores organismos de cada um dos três grupos. Nestes experimentos, foram criados conjuntos de consultas com 14 tamanhos diferentes variando entre 40 e 10.000 bps. Além disso, cada conjunto foi composto por 1.400 seqüências de nucleotídeos randomicamente retiradas dos genomas aos quais as consultas foram submetidas, visando sempre obter ocorrências. 


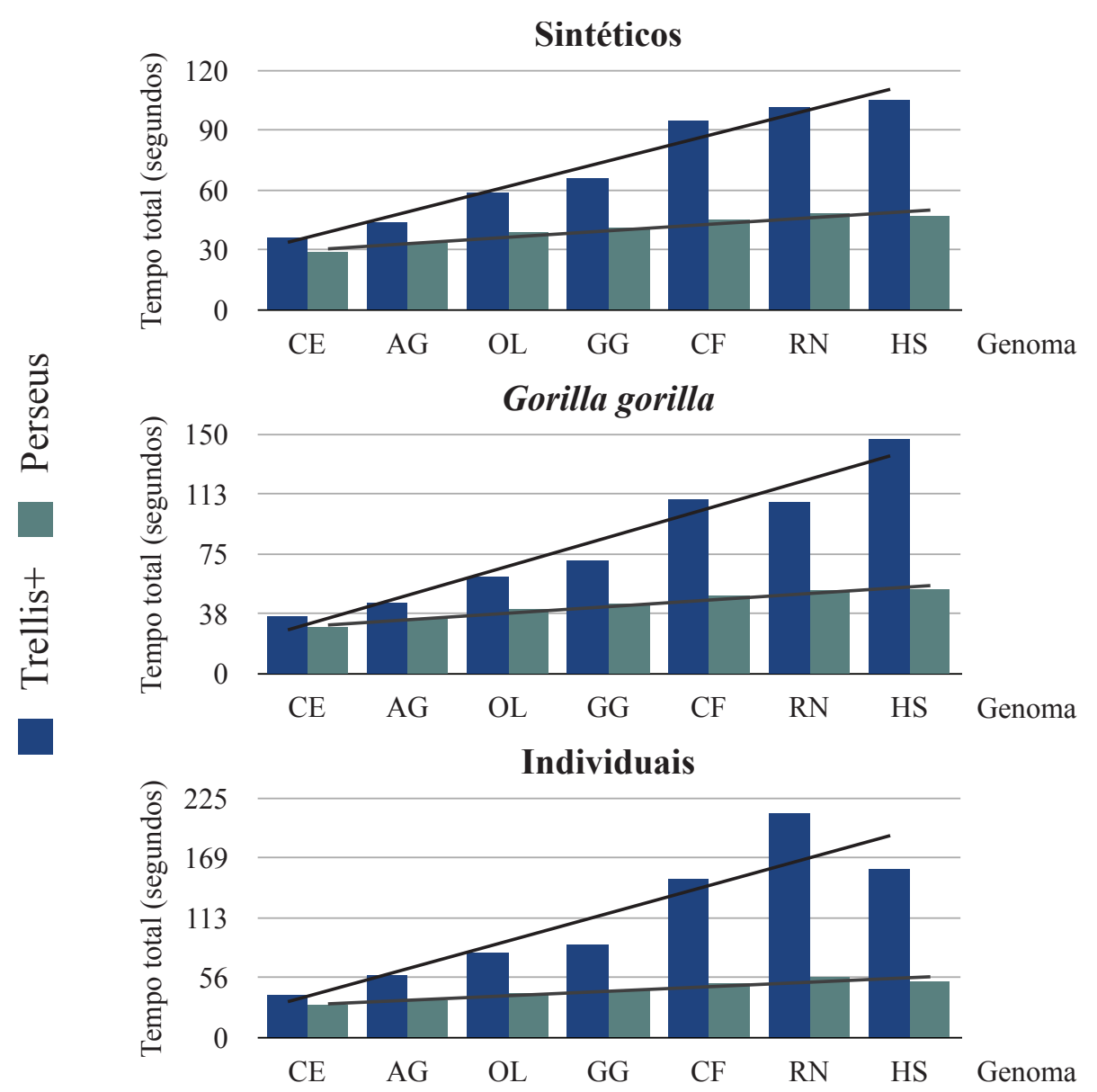

Figura 5.3: Resultados dos casamentos exatos.

A Figura 5.4 mostra os resultados obtidos no processamento dos casamentos exatos. Com relação ao tempo total, o ganho de desempenho proporcionado pelo Perseus foi muito significativo, de até $78 \%$. Mais especificamente, o ganho variou entre $20 \%$ e $25 \%$ para o organismo Caenorhabditis elegans (CE), entre $47 \%$ e $50 \%$ para organismo Gallus gallus (GG), e entre $65 \%$ e $78 \%$ para o organismo Homo sapiens (HS). Analisando-se os resultados obtidos, é possível tirar duas conclusões. A primeira delas é que o ganho de desempenho do Perseus aumentou à medida que o tamanho do genoma aumentou. Isto é principalmente importante porque, cada vez mais, genomas maiores estão sendo descobertos. A segunda conclusão é que o PERSEus é robusto, dado que, considerando cada genoma individualmente, o aumento no tamanho da consulta não degradou o tempo de processamento dos casamentos exatos.

Para investigar situações nas quais as consultas apresentam alta taxa de ocorrência, também foram realizados testes de desempenho com conjuntos de consultas compostos por seqüências de nucleotídeos menores. A Figura 5.5 mostra os resultados para consultas de tamanhos entre 10 e 35 bps. Nesta figura, o tempo total gasto está em escala logarítmica, provendo uma melhor visualização dos resultados. O resultados mostraram que o ganho alcançado pelo Perseus com consultas menores foi ainda melhor do que 

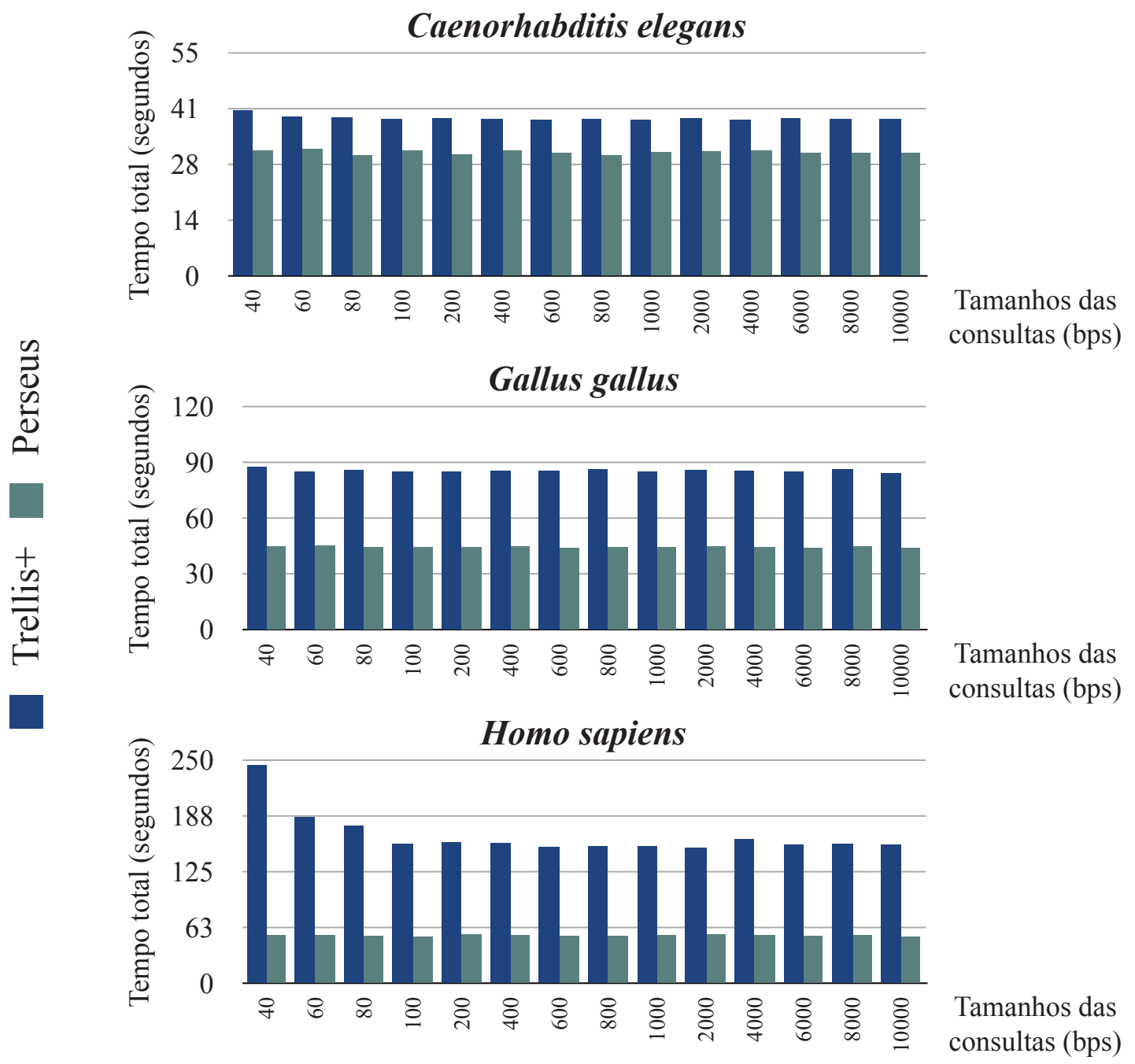

Figura 5.4: Casamentos exatos para consultas de tamanho entre 40 e 10,000 bps.

o ganho apresentado na Figura 5.4. Com relação ao tempo total gasto, o ganho variou entre $25 \%$ e $78 \%$ para o organismo Caenorhabditis elegans (CE), entre $49 \%$ e $95 \%$ para organismo Gallus gallus (GG), e entre $78 \%$ e $98 \%$ para o organismo Homo sapiens (HS). Além disto, as mesmas conclusões anteriores também podem ser identificadas: o ganho de desempenho do PERseus aumentou à medida que o tamanho do genoma aumentou, e o aumento no tamanho da consulta não degradou o tempo de processamento dos casamentos exatos.

\subsection{Benefícios Proporcionados pela Construção Gui- ada pelo Usuário}

A construção guiada pelo usuário permite que os usuários indiquem quais subseqüências da seqüência de entrada devem ser indexadas, de acordo com suas necessidades. Isto é um requisito importante em diversas aplicações, principalmente aquelas que executam 

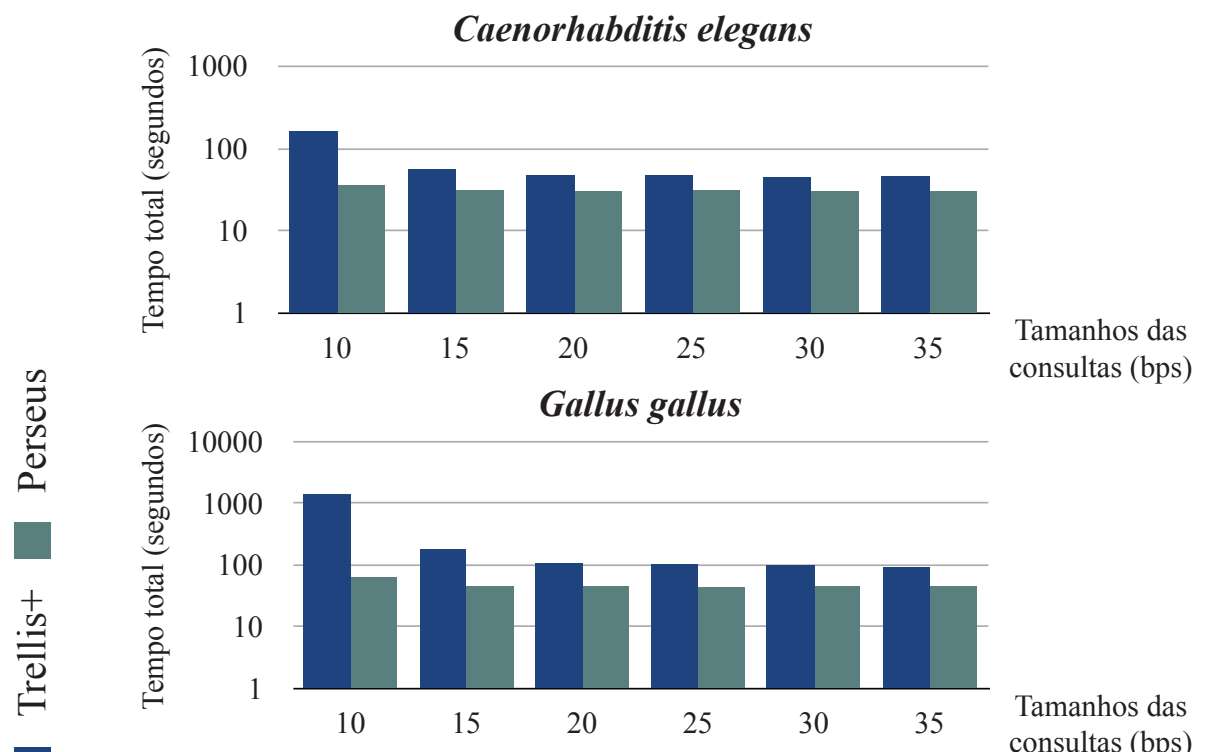

Tamanhos das consultas (bps)

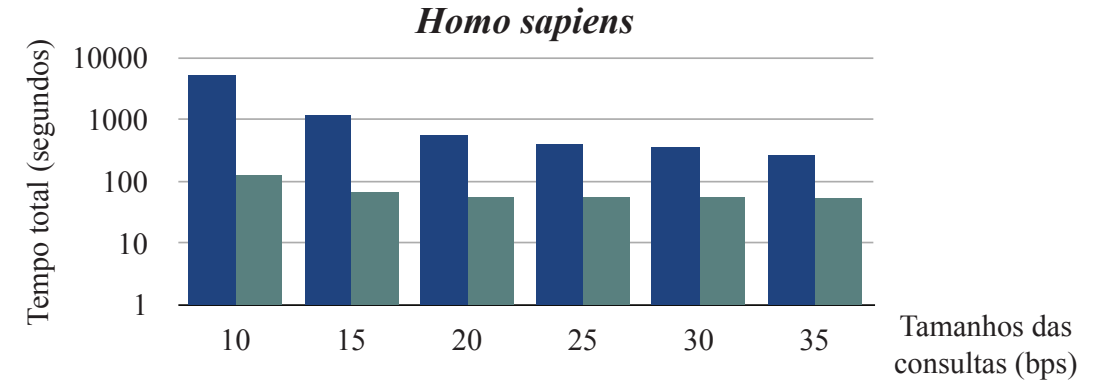

Figura 5.5: Casamentos exatos para consultas de tamanho entre 10 e 35 bps.

consultas específicas. Por exemplo, aplicações que buscam por genes precisam indexar apenas os sufixos de um genoma que começam com ATG.

Para analisar os benefícios proporcionados pela construção guiada pelo usuário, também foram realizados testes de desempenho sobre árvores de sufixo que indexam apenas os genes dos sete genomas selecionados. Isto foi realizado definindo-se o conjunto do usuário $U=\{$ ATG $\}$ e criando-se conjuntos de consultas compostos de 100 genes retirados randomicamente de cada genoma.

Como esperado, os resultados mostraram que o uso da construção guiada pelo usuário melhorou muito tanto o tempo de construção das árvores de sufixo quanto o tempo total gasto no processamento dos casamentos exatos. Esses resultados são descritos nas Tabelas 5.5 e 5.6, respectivamente. Comparando os resultados obtidos com o Trellis+, os testes mostraram que houve uma redução no tempo de construção de árvores de sufixo de $97 \%$ na média e uma redução no tempo gasto no processamento de casamentos exatos de genes de $93 \%$ na média. Por exemplo, PERSEus demorou aproximadamente apenas 6 minutos para indexar todos os genes do organismo Homo sapiens (HS) e respondeu cada casamento exato em $\approx 29$ milissegundos. Em contrapartida, TrELLIS + demorou aproximadamente 4,2 horas para indexar todo o genoma deste organismo e respondeu cada casamento exato em $\approx 1,09$ segundos. 
Tabela 5.5: Resultados experimentais da construção guiada pelo usuário.

\begin{tabular}{|c|c|c|c|}
\hline \multirow{2}{*}{ Genoma } & \multicolumn{2}{|c|}{ Construção (segundos) } & \multirow{2}{*}{$\begin{array}{l}\text { Redução no } \\
\text { tempo total }\end{array}$} \\
\hline & TRELLIS + & PERseus & \\
\hline $\mathrm{CE}$ & 302 & 8,05 & $97,33 \%$ \\
\hline $\mathrm{AG}$ & 840 & 18,1 & $97,84 \%$ \\
\hline $\mathrm{OL}$ & 2.533 & 51 & $97,98 \%$ \\
\hline GG & 4.575 & 86 & $98,12 \%$ \\
\hline $\mathrm{CF}$ & 11.816 & 311 & $97,36 \%$ \\
\hline $\mathrm{RN}$ & 12.573 & 393 & $96,87 \%$ \\
\hline HS & 15.342 & 378 & $97,53 \%$ \\
\hline
\end{tabular}

Tabela 5.6: Resultados experimentais da construção guiada pelo usuário.

\begin{tabular}{crcc}
\hline Genoma & $\begin{array}{c}\text { Casamento exato (segundos) } \\
\text { TrELLIS }+\end{array}$ & $\begin{array}{c}\text { Redução no } \\
\text { PerseUS }\end{array}$ & tempo total \\
\hline CE & 2,823 & 0,372 & $86,80 \%$ \\
AG & 10,203 & 1,280 & $87,44 \%$ \\
OL & 34,114 & 2,324 & $93,18 \%$ \\
GG & 35,707 & 2,259 & $93,67 \%$ \\
CF & 70,124 & 2,399 & $96,57 \%$ \\
RN & 146,846 & 5,164 & $96,48 \%$ \\
HS & 109,883 & 2,943 & $97,32 \%$ \\
\hline
\end{tabular}

\subsection{Considerações Finais}

Este capítulo definiu o ambiente de testes utilizado na investigação do PERSEus e descreveu os resultados dos testes de desempenho realizados. Os resultados obtidos foram comparados com a técnica TRELLIS +, a qual representa o estado da arte nesta linha de pesquisa. Nos testes, foram analisados o custo de construção de árvores de sufixo e o custo de processamento de casamentos exatos.

Com relação ao custo de construção, os testes indicaram que o PERSEUs construiu árvores de sufixo mais rapidamente do que o TRELLIS + para a maioria dos testes. Além disso, Perseus criou árvores de sufixo mais compactas do que o principal concorrente. Já com relação ao processamento de casamentos exatos, PERSEus sempre produziu os melhores resultados. Desta forma, pode-se concluir que o Perseus é uma técnica robusta que permite rápida construção de árvores de sufixo e processamento de casamentos exatos. 


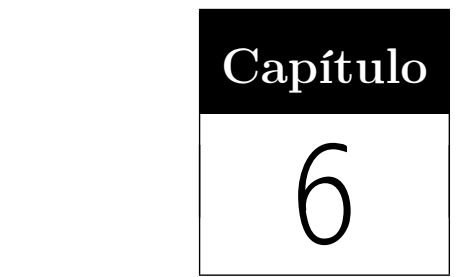

Conclusões

Esta dissertação enfoca o uso de árvores de sufixo na indexação de dados biológicos. A árvore de sufixo é um método de aceso utilizado por muitas aplicações que requerem soluções lineares com relação ao tempo para problemas que envolvem pesquisa por similaridade. Como exemplo, pode-se citar o casamento exato e o casamento aproximado. Entretanto, o custo de construção das árvores de sufixo é muito alto devido a dois motivos principais. Primeiro, árvores de sufixo geralmente são muito volumosas, e usualmente excedem os tamanhos dos BDBs que elas indexam em uma ou duas ordens de magnitude. Depois, a construção de árvores de sufixo com complexidade linear em relação ao tempo requer que essas árvores caibam em memória principal (Weiner, 1973; McCreight, 1976; Ukkonen, 1995).

Esta dissertação propõe o PERSEus, uma nova técnica para tratar árvores de sufixo persistentes. A técnica Perseus apresenta os seguintes diferenciais. Ela introduz uma abordagem que realiza a construção de árvores de sufixo persistentes cujos tamanhos podem exceder a capacidade da memória principal, garantindo que o problema das partições não ocorra. Além disso, ela identifica automaticamente como árvores de sufixo podem ser particionadas, sem a necessidade de intervenção do usuário. Outra vantagem é que ela define um algoritmo de construção de árvores de sufixo que particiona as árvores somente quando necessário. Este algoritmo também permite que o usuário escolha quais subseqüências de uma seqüência devem ser indexadas, um importante requisito em aplicações que realizam consultas específicas, como a busca por determinados genes em genomas. Por fim, a técnica proposta também introduz um algoritmo de casamento exato 
que permite a busca por uma seqüência de consulta em árvores de sufixo que podem estar particionadas.

A validação do Perseus foi realizada por meio de testes de desempenho considerando genomas de vários organismos, os quais possuem diferentes ordens de magnitude de tamanho (i.e., $10^{7} \mathrm{bps}, 10^{8} \mathrm{bps}$ and $10^{9} \mathrm{bps}$ ). Os resultados obtidos foram comparados com a técnica TRELlis + (Phoophakdee e Zaki, 2007, 2008), a qual representa o estado da arte nesta linha de pesquisa. Nos testes, foram analisados o custo de construção de árvores de sufixo e o custo de processamento de casamentos exatos.

Com relação ao custo de construção, os testes indicaram que o PERSEus construiu árvores de sufixo mais rapidamente do que o TRELLIS + para a maioria dos testes, chegando a reduzir o tempo total gasto na construção em até $24 \%$. Além disso, Perseus criou árvores de sufixo mais compactas do que o principal concorrente, atingindo uma redução média de $27 \%$ no espaço de memória secundária utilizado.

Já com relação ao processamento de casamentos exatos, PERSEus sempre produziu os melhores resultados, respondendo consultas em média $49 \%$ mais rápido do que o Trellis+. Mais especificamente, os ganhos de desempenho do Perseus foram de $20 \%$ a $78 \%$ com consultas de tamanhos entre 40 bps e 10.000 bps, e de $25 \%$ a $98 \%$ com consultas de tamanhos entre 10 bps e 35 bps.

Também foram realizados testes específicos visando mostrar os benefícios proporcionados pelo uso da construção guiada pelo usuário, a qual permite que o usuário escolha quais subseqüências de uma seqüência devem ser indexadas. Comparando os resultados obtidos com o Trellis+, os testes mostraram que houve uma redução no tempo de construção de árvores de sufixo de $97 \%$ na média e uma redução no tempo gasto no processamento de casamentos exatos de genes de $93 \%$ na média. Esses resultados ainda são mais importantes porque PERSEus é a única técnica existente na literatura que oferece essa funcionalidade.

\subsection{Principais Contribuições}

As principais contribuições decorrentes da realização deste trabalho são:

- Proposta do Perseus, uma nova técnica para tratar árvores de sufixo persistentes cujos tamanhos podem exceder a capacidade da memória principal;

- Possibilidade do usuário escolher quais subseqüências de uma seqüência devem ser indexadas, de acordo com as necessidades de sua aplicação;

- Redução no tempo de construção de árvores de sufixo;

- Redução da memória secundária necessária para armazenar árvores de sufixo; 
- Redução no tempo médio no processamento de casamentos exatos; e

- Validação do Perseus por meio da realização de um conjunto amplo de testes, os quais evidenciaram o avanço no estado da arte introduzido por esta nova técnica.

Uma proposta inicial do PERseus pode ser encontrada na publicação intitulada "Melhorando o Desempenho de Árvores de Sufixo na Indexação de Grandes Seqüências de Nucleotídeos" no VII Workshop de Teses e Dissertações em Bancos de Dados do XXIII Simpósio Brasileiro de Banco de Dados (Carélo e Ciferri, 2008). Os resultados desta dissertação também estão sendo usados para a escrita de um artigo a ser submetido a um periódico na área de bioinformática.

Além da proposta central desta dissertação, durante o desenvolvimento das atividades de mestrado foram investigados outros dois métodos de acesso. Estas contribuições adicionais são:

- nsP-index: um método de acesso voltado à construção de estruturas de dados compactas para indexar grandes seqüências de nucleotídeos (Ciferri et al, 2008); e

- Onion-Tree: um método de acesso dinâmico voltado à indexação de dados métricos em memória principal (Carélo et al, 2009).

Outra atividade complementar realizada durante o mestrado foi a participação no desenvolvimento de um protótipo chamado GMine, o qual permite a navegação interativa de grandes grafos armazenados em memória secundária. Esta participação gerou a publicação intitulada "GMine: Interactive Browsing of Large Graphs" no Workshop on Information Visualization and Analysis in Social Networks do XXIII Simpósio Brasileiro de Banco de Dados (Rodrigues-Jr et al, 2008).

\subsection{Trabalhos Futuros}

Várias extensões podem ser realizadas ao trabalho efetuado nesta dissertação. Tópicos a serem abordados em trabalhos futuros incluem:

- O desenvolvimento de uma estratégia para utilizar o PERSEus quando o espaço em memória requerido para armazenar a seqüência de entrada é maior do que a capacidade da memória principal. Nestes casos, deve-se propor um gerenciamento de buffer para que os acessos randômicos à seqüência de entrada não degradem a construção da árvore de sufixo;

- A proposta de uma modificação para a iTree-representation, visando o uso de listas encadeadas ao invés de vetores de tamanhos fixos. Por um lado, esta modificação permite que a representação de árvores de sufixo de seqüências com alfabetos 
maiores seja mais compacta. Por outro lado, o uso de listas encadeadas introduz a necessidade de processamento adicional, além de requerer um gerenciamento de leitura e escrita em memória secundária mais sofisticado;

- A paralelização da construção guiada pelo usuário, dado que seu algoritmo pode ser adaptável a um ambiente distribuído. Neste desenvolvimento, deve-se verificar se o custo adicional relacionado à troca de mensagens e dados não torna a paralelização ineficiente; e

- A implementação e a realização de testes de desempenho em estruturas com elos de sufixo. Apesar da técnica proposta não utilizar estes ponteiros durante a construção das árvores de sufixo, a fase de recuperação de elos de sufixo do TRELLIS + pode ser aplicada às estruturas geradas pelo Perseus. Isso é possível porque ambas técnicas produzem árvores de sufixo logicamente idênticas. No desenvolvimento deste trabalho futuro, deve-se verificar a necessidade de modificações na iTree-representation para garantir um bom desempenho. 


\section{Referências Bibliográficas}

Altschul, S. F.; Gish, W.; Miller, W.; Myers, E. W.; Lipman, D. J. Basic local alignment search tool. Journal of Molecular Biology (JMB), v. 215, n. 3, p. 403-410, 1990.

Augen, J. Bioinformatics in the post-genomic era. 1 ed. Addison Wesley, 408 p., 2004.

Barsky, M.; Stege, U.; Thomo, A.; Upton, C. A new method for indexing genomes using on-disk suffix trees. In: Proceedings of the 17th ACM Conference on Information and Knowledge Management (CIKM), Napa Valley, USA, 2008, p. 649-658.

Baxevanis, A. D.; Ouellette, B. F. F. Bioinformatics: a practical guide to the analysis of genes and proteins. 3 ed. Wiley-Interscience, 540 p., 2005.

BAyer, R.; MCCReight, E. M. Organization and maintenance of large ordered indices. Acta Informatica, v. 1, p. 173-189, 1972.

Beckmann, N.; Kriegel, H.-P.; Schneider, R.; Seeger, B. The R*-tree: an efficient and robust access method for points and rectangles. In: Proceedings of the 1990 ACM SIGMOD International Conference on Management of Data, Atlantic City, USA, 1990, p. 322-331.

Bedathur, S. J.; Haritsa, J. R. Engineering a fast online persistent suffix tree construction. In: Proceedings of the 20th International Conference on Data Engineering (ICDE), Boston, USA, 2004, p. 720-731.

Belussi, A.; Faloutsos, C. Estimating the selectivity of spatial queries using the 'correlation' fractal dimension. In: Proceedings of the 21th International Conference on Very Large Data Bases (VLDB), Zurich, Switzerland, 1995, p. 299-310.

Bender, M. A.; Farach-Colton, M.; Kuszmaul, B. C. Cache-oblivious string B-trees. In: Proceedings of the 25th ACM SIGMOD-SIGACT-SIGART Symposium on Principles of Database Systems (PODS), Chicago, USA, 2006, p. 233-242.

Bentley, J. L. Multidimensional binary search trees used for associative searching. Communications of the ACM (CACM), v. 18, n. 9, p. 509-517, 1975. 
Bentley, J. L.; Friedman, J. H. Data structures for range searching. ACM Computing Surveys (CSUR), v. 11, n. 4, p. 397-409, 1979.

Bieganski, P. Genetic sequence data retrieval and manipulation based on generalized suffix trees. Tese de Doutoramento, University of Minnesota, 1995.

Bieganski, P.; Riedl, J.; Carlis, J. V.; Retzel, E. F. Generalized suffix trees for biological sequence data: Applications and implementation. In: Proceedings of the 27th Annual Hawaii International Conference on System Sciences (HICSS), Maui, Hawaii, 1994, p. 35-44.

Bolsover, S. R.; Hyams, J. S.; Shephard, E. A.; White, H. A.; Wiedemann, C. G. Cell biology: a short course. 2 ed. John Wiley \& Sons, 531 p., 2004.

Bovet, D.; Cesati, M. Understanding the linux kernel. 3 ed. O'Reilly, 942 p., 2005.

BRIN, S. Near neighbor search in large metric spaces. In: Proceedings of the 21th International Conference on Very Large Data Bases (VLDB), 1995, p. 574-584.

Burkhard, W. A.; Keller, R. M. Some approaches to best-match file searching. Communications of the $A C M$ (CACM), v. 16, n. 4, p. 230-236, 1973.

Calladine, C. R.; Drew, H. R.; Luisi, B. F.; Travers, A. A. Understanding DNA: the molecule and how it works. 3 ed. Elsevier Academic Press, 334 p., 2004.

Carélo, C. C. M.; Ciferri, C. D. A. Melhorando o desempenho de árvores de sufixo na indexação de grandes seqüências de nucleotídeos. In: VII Workshop de Teses e Dissertações em Bancos de Dados do XXIII Simpósio Brasileiro de Banco de Dados (WTDBD), Campinas, Brasil, 2008, p. 91-96.

Carélo, C. C. M.; Pola, I. R. V.; Ciferri, C. D. A.; Ciferri, R. R.; TrainaJR, C.; TrainA, A. J. M. The Onion-tree: quick indexing of complex data in the main memory. In: Proceedings of the 13th East European Conference on Advances in Databases and Information Systems (ADBIS), Riga, Latvia, 2009, p. 1-17.

Chávez, E.; Navarro, G.; Baeza-Yates, R. A.; Marroquín, J. L. Searching in metric spaces. ACM Computing Surveys (CSUR), v. 33, n. 3, p. 273-321, 2001.

Chen, Z.; Fowler, R. H.; Fu, A. W.-C.; Wang, C. Fast construction of generalized suffix trees over a very large alphabet. In: Proceedings of the 9th Annual International Conference on Computing and Combinatorics (COCOON), Big Sky, USA, 2003, p. 284-293.

Cheung, C.-F.; Yu, J. X.; Lu, H. Constructing suffix tree for gigabyte sequences with megabyte memory. IEEE Transactions on Knowledge and Data Engineering (TKDE), v. 17, n. 1, p. 90-105, 2005.

Ciaccia, P.; Patella, M.; Zezula, P. M-tree: an efficient access method for similarity search in metric spaces. In: Proceedings of the 23rd International Conference on Very Large Data Bases (VLDB), Athens, Greece, 1997, p. 426-435.

Ciferri, R. R. Análise da influência do fator distribuição espacial dos dados no desempenho de métodos de acesso multidimensionais. Tese de Doutoramento, Universidade Federal de Pernambuco (UFPE), 2002. 
Ciferri, R. R.; Ciferri, C. D. A.; Carélo, C. C. M.; Traina-Jr, C. nsP-index: a robust and persistent index for nucleotide sequences. In: Proceedings of the 12th East European Conference on Advances in Databases and Information Systems (ADBIS), Pori, Finland, 2008, p. 28-41.

Cohen, J. Bioinformatics - an introduction for computer scientists. ACM Computing Surveys (CSUR), v. 36, n. 2, p. 122-158, 2004.

Comer, D. The ubiquitous B-tree. ACM Computing Surveys (CSUR), v. 11, n. 2, p. 121-137, 1979.

Crauser, A.; Ferragina, P. A theoretical and experimental study on the construction of suffix arrays in external memory. Algorithmica, v. 32, n. 1, p. 1-35, 2002.

Dementiev, R.; KärkkÄinen, J.; Mehnert, J.; Sanders, P. Better external memory suffix array construction. ACM Journal of Experimental Algorithmics (JEA), v. 12 , p. 1-24, 2008.

Ferragina, P.; Grossi, R. The string B-tree: a new data structure for string search in external memory and its applications. Journal of the ACM (JACM), v. 46, n. 2, p. 236-280, 1999.

Finkel, R. A.; Bentley, J. L. Quad trees: a data structure for retrieval on composite keys. Acta Informatica, v. 4, p. 1-9, 1974.

Gaede, V.; GÜnther, O. Multidimensional access methods. ACM Computing Surveys (CSUR), v. 30, n. 2, p. 170-231, 1998.

Gibas, C.; Jambeck, P. Developing bioinformatics computer skills. 1 ed. O'Reilly, 440 p., 2001.

Grossi, R.; Vitter, J. S. Compressed suffix arrays and suffix trees with applications to text indexing and string matching. SIAM Journal on Computing (SICOMP), v. 35, n. 2, p. 378-407, 2005.

Gusfield, D. Algorithms on strings, trees, and sequences: computer science and computational biology. 1 ed. Cambridge University Press, 534 p., 1997.

Guttman, A. R-trees: a dynamic index structure for spatial searching. In: Proceedings of the 1984 ACM SIGMOD International Conference on Management of Data, Boston, USA, 1984, p. 47-57.

Hualtason, G. R.; Samet, H. Index-driven similarity search in metric spaces. ACM Transactions on Database Systems (TODS), v. 28, n. 4, p. 517-580, 2003.

Hunt, E.; Atkinson, M. P.; Irving, R. W. A database index to large biological sequences. In: Proceedings of the 27th International Conference on Very Large Data Bases (VLDB), Roma, Italy, 2001, p. 139-148.

Hunt, E.; Atkinson, M. P.; Irving, R. W. Database indexing for large DNA and protein sequence collections. The International Journal on Very Large Data Bases (VLDB J.), v. 11, n. 3, p. 256-271, 2002. 
Kahveci, T.; Luosa, V.; Singh, A. K. Speeding up whole-genome alignment by indexing frequency vectors. Bioinformatics, v. 20, n. 13, p. 2122-2134, 2004.

Kahveci, T.; Singh, A. K. Efficient index structures for string databases. In: Proceedings of the 27th International Conference on Very Large Data Bases (VLDB), Roma, Italy, 2001, p. 351-360.

Kahveci, T.; Singh, A. K. Fast alignment of large genome databases. In: Proceedings of the 19th International Conference on Data Engineering (ICDE), Bangalore, India, 2003, p. 768-770.

Korf, I.; Yandell, M.; Bedell, J. BLAST. 1 ed. O’Reilly, 339 p., 2003.

Lengauer, T.; Mannhold, R.; Kubinyi, H.; Timmerman, H. Bioinformatics: from genomes to drugs. 1 ed. Wiley-VCH, 648 p., 2001.

LESK, A. M. Introduction to bioinformatics. 1 ed. Oxford University Press, 283 p., 2002.

LeVEnshtein, V. I. Binary codes capable of correcting deletions, insertions and reversals. Soviet Physics Doklady, v. 10, n. 8, p. 707-710, 1966.

Li, D.; GaO, W.; Ling, C. X.; Wang, X.; Sun, R.; He, S. IndexToolkit: an open source toolbox to index protein databases for high-throughput proteomics. Bioinformatics, v. 22, n. 20, p. 2572-2573, 2006.

Lifschitz, S. Gerenciadores de dados biológicos: Genéricos ou ad-hoc? In: $X X$ XIV Seminário Integrado de Software e Hardware (SEMISH) do XXVII Congresso da Sociedade Brasileira de Computação, Rio de Janeiro, Brasil, 2007, p. 2085-2099.

Lima, E. L. Espacos métricos. 1 ed. Impa, 382 p., 1975.

Lodish, H.; Berk, A.; Matsudaira, P.; Kaiser, C. A.; Krieger, M.; Scott, M. P.; Zipursky, L.; DARnell, J. Molecular cell biology. 5 ed. W. H. Freeman, 973 p., 2004.

Manber, U.; Myers, E. W. Suffix arrays: a new method for on-line string searches. SIAM Journal on Computing (SICOMP), v. 22, n. 5, p. 935-948, 1993.

MCCReight, E. M. A space-economical suffix tree construction algorithm. Journal of the ACM (JACM), v. 23, n. 2, p. 262-272, 1976.

NA, J. C.; PARK, K. Simple implementation of string B-trees. In: Proceedings of the 11th International Conference on String Processing and Information Retrieval (SPIRE), Padova, Italy, 2004, p. 214-215.

Navarro, G.; Baeza-Yates, R. A. A new indexing method for approximate string matching. In: Proceedings of the 10th Annual Symposium on Combinatorial Pattern Matching (CPM), Warwick University, UK, 1999, p. 163-185.

Neelapala, N.; Mittal, R.; Haritsa, J. R. SPINE: Putting backbone into string indexing. In: Proceedings of the 17th International Conference on Data Engineering (ICDE), Boston, USA, 2004, p. 325-337. 
PeARson, W. R.; Lipman, D. J. Improved tools for biological sequence comparison. Proceedings of the National Academy of Sciences (PNAS), v. 85, n. 8, p. 2444-2448, 1988.

Phoophakdee, B.; Zaki, M. J. Genome-scale disk-based suffix tree indexing. In: Proceedings of the 2007 ACM SIGMOD International Conference on Management of Data, Beijing, China, 2007, p. 833-844.

Phoophakdee, B.; Zaki, M. J. Trellis+: an effective approach for indexing genomescale sequences using suffix trees. In: Pacific Symposium on Biocomputing (PSB), Hawaii, USA, 2008, p. 90-101.

Pola, I. R. V.; Traina-Jr, C.; Traina, A. J. M. The MM-tree: A memory-based metric tree without overlap between nodes. In: Proceedings of the 12th East European Conference on Advances in Databases and Information Systems (ADBIS), 2007, p. $157-171$.

Ramakrishnan, R.; Gehrke, J. Database management systems. 3 ed. McGraw-Hill, 936 p., 2002.

Rodrigues-Jr, J. F.; Carélo, C. C. M.; Traina, A. J. M.; Ciferri, C. D. A.; TrainA-JR, C. GMine: interactive browsing of large graphs. In: Workshop on Information Visualization and Analysis in Social Networks (WIVA), Campinas, Brasil, 2008, p. 51-59.

Russo, L. M. S.; Navarro, G.; Oliveira, A. L. Dynamic fully-compressed suffix trees. In: Proceedings of the 19th Annual Symposium on Combinatorial Pattern Matching (CPM), Pisa, Italy, 2008, p. 191-203.

SADAKAnE, K. Compressed suffix trees with full functionality. Theory of Computing Systems (TOCS), v. 41, n. 4, p. 589-607, 2007.

SAmet, H. The Quadtree and related hierarchical data structures. ACM Computing Surveys (CSUR), v. 16, n. 2, p. 187-260, 1984.

Santos-Filho, R. F.; Traina, A. J. M.; Traina-Jr, C.; Faloutsos, C. Similarity search without tears: the OMNI family of all-purpose access methods. In: Proceedings of the 17th International Conference on Data Engineering (ICDE), Heidelberg, Germany, 2001, p. 623-630.

Seibel, L. F. B.; Lifschitz, S. An overview of genomic databases research issues. In: XVII Simpósio Brasileiro de Bancos de Dados (SBBD), Gramado, Brasil, 2002, p. 10.

Sellis, T. K.; Roussopoulos, N.; Faloutsos, C. The R+-tree: a dynamic index for multi-dimensional objects. In: Proceedings of the 13th International Conference on Very Large Data Bases (VLDB), Brighton, England, 1987, p. 507-518.

Setubal, J. C.; Meidanis, J. Introduction to computational molecular biology. 1 ed. PWS Publishing, 296 p., 1997.

Silberschatz, A.; Korth, H. F.; Sudarshan, S. Database system concepts. 5 ed. McGraw-Hill, 1142 p., 2005. 
Skopal, T.; Hoksza, D.; Pokorný, J. Construction of tree-based indexes for levelcontiguous buffering support. In: Proceedings of the 12th International Conference on Database Systems for Advanced Applications (DASFAA), Bangkok, Thailand, 2007, p. 361-373.

Skopal, T.; Pokorný, J.; SNÁsel, V. PM-tree: pivoting metric tree for similarity search in multimedia databases. In: Proceedings of the 8th East European Conference on Advances in Databases and Information Systems (ADBIS), Budapest, Hungary, 2004 .

Sun, H.; Ozturk, O.; Ferhatosmanoglu, H. CoMrI: a compressed multi-resolution index structure for sequence similarity queries. In: Proceedings of the 2nd IEEE Computer Society Bioinformatics Conference (CSB), Stanford, USA, 2003, p. 553-559.

SUNDAY, D. M. A very fast substring search algorithm. Communications of the $A C M(C A C M)$, v. 33, n. 8, p. 132-142, 1990.

Tamminen, M. Comment on Quad- and Octtrees. Communications of the $A C M(C A C M)$, v. 27, n. 3, p. 248-249, 1984.

Tata, S.; Hankins, R. A.; Patel, J. M. Practical suffix tree construction. In: Proceedings of the 30th International Conference on Very Large Data Bases (VLDB), Toronto, Canada, 2004, p. 36-47.

Tian, Y.; Tata, S.; Hankins, R. A.; Patel, J. M. Practical methods for constructing suffix trees. The International Journal on Very Large Data Bases (VLDB J.), v. 14, n. 3, p. 281-299, 2005.

Traina-Jr, C.; Santos Filho, R. F.; Traina, A. J. M.; Vieira, M. R.; Faloutsos, C. The Omni-family of all-purpose access methods: a simple and effective way to make similarity search more efficient. The International Journal on Very Large Data Bases (VLDB J.), v. 16, n. 4, p. 483-505, 2007.

Traina-Jr, C.; Traina, A. J. M.; Faloutsos, C.; Seeger, B. Fast indexing and visualization of metric data sets using Slim-trees. IEEE Transactions on Knowledge and Data Engineering (TKDE), v. 14, n. 2, p. 244-260, 2002.

Traina-Jr, C.; Traina, A. J. M.; Seeger, B.; Faloutsos, C. Slim-trees: high performance metric trees minimizing overlap between nodes. In: Proceedings of the rth International Conference on Extending Database Technology (EDBT), Konstanz, Germany, 2000, p. 51-65.

Uhlmann, J. K. Satisfying general proximity/similarity queries with metric trees. Information Processing Letters, v. 40, n. 4, p. 175-179, 1991.

UkKonen, E. On-line construction of suffix trees. Algorithmica, v. 14, n. 3, p. 249-260, 1995.

VÄlimäki, N.; Gerlach, W.; Dixit, K.; MÄkinen, V. Compressed suffix tree - a basis for genome-scale sequence analysis. Bioinformatics, v. 23, n. 5, p. 629-630, 2007. 
Venkateswaran, J.; Lachwani, D.; Kahveci, T.; Jermaine, C. M. Referencebased indexing of sequence databases. In: Proceedings of the 32nd International Conference on Very Large Data Bases (VLDB), Seoul, Korea, 2006, p. 906-917.

Vieira, M. R.; Traina-Jr, C.; Chino, F. J. T.; Traina, A. J. M. DBM-tree: A dynamic mmetric access method sensitive to local density data. In: XIX Simpósio Brasileiro de Bancos de Dados (SBBD), Distrito Federal, Brasil, 2004, p. 163-177.

WeIner, P. Linear pattern matching algorithms. In: Proceedings of the 14 th Annual Symposium on Switching and Automata Theory (FOCS), The University of Iowa, USA, 1973, p. 1-11.

Wilson, D. R.; Martinez, T. R. Improved heterogeneous distance functions. Journal of Artificial Intelligence Research (JAIR), v. 6, p. 1-34, 1997.

YiAnilos, P. N. Data structures and algorithms for nearest neighbor search in general metric spaces. In: Proceedings of the 4 th Annual ACM-SIAM Symposium on Discrete Algorithms (SODA), 1993, p. 311-321. 


\section{Apêndice \\ A \\ nsP-index: a Robust and Persistent Index for Nucleotide Sequences}

Ricardo Rodrigues Ciferri ${ }^{1}$, Cristina Dutra de Aguiar Ciferri ${ }^{2}$, Caio César Mori Carélo ${ }^{2}$ and Caetano Traina-Jr²

${ }^{1}$ Departamento de Computação, Universidade Federal de São Carlos 13.565-905, São Carlos - SP, Brasil ricardo@icmc.usp.br

2 Departamento de Ciências de Computação, Universidade de São Paulo 13.560-970, São Carlos - SP, Brasil $\{$ cdac, ccarelo, caetano\}@icmc.usp.br

\section{Abstract}

Finding similarities in sequences stored in biological databases has become a core problem in bioinformatics. An example using sequence similarity search is the discovery of homology relationships. In this paper, we focus on the persistent storage of index data aiming at the similarity search of nucleotide sequences. We propose the nsP-index, which allows the management of voluminous nucleotide databases that require an index whose size exceeds the capacity of the main memory. The nsP-index is compact, requiring a small fraction of the database volume (about 8.5\%). Performance tests with both synthetic and real databases using different volumes of nucleotide sequences (from 0.13 GB to $23 \mathrm{~GB}$ ) showed that the nsP-index manages small and large data volumes efficiently. Compared 
to the MRS index (i.e., in-memory index), the nsP-index reduced the time spent on query processing of synthetic data by up to $75 \%$ and real data by up to $82 \%$.

\section{A.1 Introduction}

Biological databases (BDB) store data related to living organisms, such as biological sequences of nucleotides and amino acids, genetic maps, gene annotation, three-dimensional structures of proteins, related scientific papers and any other information required for the comprehension of the biological data (Augen, 2004; Baxevanis and Ouellette, 2005). In these $\mathrm{BDB}$, the nucleotide sequences are composed of strings that represent the nitrogen bases adenine $(\mathrm{A})$, cytosine $(\mathrm{C})$, guanine $(\mathrm{G})$ and thymine $(\mathrm{T})$.

Searching these BDB for strings has become a core problem in bioinformatics. There is a widespread need to find similarities among sequences. In medical systems, sequence similarity search is used to compare two or more sequences and determine if they are homologous (Korf et al, 2003). According to Kahveci and Singh (2001), major advances have already been achieved through the use of sequence similarity search, such as the discovery of the genetic code of the E. coli bacterium, genetic clues for fibrodysplasia ossificans progressive (FOP) disease, or the genes that hasten the healing of some venous ulcers. Another example is the identification of consensus regulatory patterns such as those representing transcription factor binding sites, promoter recognition signals and mRNA splicing sites (Li et al, 2006).

Sequence similarity search in BDB has been performed in two main ways. On the one hand, algorithms scan BDB sequentially to answer queries. Tools widely used are BLAST (Altschul et al, 1990) and FASTA (Pearson and Lipman, 1988). On the other hand, indexes for nucleotide sequences reduce the search space, leading the search to portions of the BDB where the stored sequences probably have higher similarity with the query. The MRS (Multi Resolution String) (Kahveci and Singh, 2001) is a prominent index in the literature.

However, the MRS is designed to handle data only in the main memory. Nowadays, BDB are extremely voluminous and tend to become more voluminous as data on new genome organisms become available. This rapid data growth is a strong drawback to the applicability of an in-memory index, because the index size will no doubt soon exceed the main memory capacity. Furthermore, similarity search has frequently been accomplished in local laboratories composed of computers with small main memory (typically from $1 \mathrm{~GB}$ to 4 GB) and disk capacities. Examples include stand-alone desktops and small database servers. This situation calls for the extension of the MRS aiming at indexing nucleotide sequences on disk.

In this paper, we focus on the persistent storage of the MRS. We propose a new robust index for sequence similarity search, called the nsP-index. We validate the nsP-index 
through performance tests using both synthetic and real genomic data with increasing volumes of nucleotide sequences (from $0.13 \mathrm{~GB}$ to $23 \mathrm{~GB}$ ).

The differentials of the nsP-index are:

- It is stored on disk. Therefore, the index size can exceed the main memory size.

- It also efficiently indexes nucleotide sequences in the main memory. Therefore, it can be used instead of the MRS, but allowing persistency.

- It is very compact. The size of the index is a small fraction of the BDB volume.

This paper is organized as follows. Section A.2 reviews related work, while Section A.3 summarizes the MRS. Section A.4 describes the proposed nsP-index, and Section A.5 details its components. Section A.6 discusses the experiments and Section A.7 concludes the paper.

\section{A.2 Related Work}

The MRS (Kahveci and Singh, 2001) has been applied successfully in different situations and has been a focus of interest for researchers (Kahveci and Singh, 2003; Kahveci et al, 2004; Sun et al, 2003). New functionalities have been proposed for the MRS. In (Kahveci and Singh, 2003), the authors introduce a new distance function and propose an algorithm to integrate the MRS with a string tool resident in the main memory. Kahveci et al (2004) describe the F-index for aligning large genomes. Sun et al (2003) introduce the CoMRI index, which uses VBR (virtual bounding rectangle) in addition to MBR (minimum bound rectangle). However, these related works do not focus on the storage of the MRS on disk, which is the objective of our work.

An alternative index for strings is the suffix tree. The Suffix Sequoia adapts the suffix tree on disk (Hunt et al, 2002). The SPINE (Neelapala et al, 2004) accomplishes a horizontal compaction of the underlying suffix tree. Cheung et al (2005) allows constructing suffix trees using small bounded main memory. However, suffix trees have a major problem (Venkateswaran et al, 2006): they are very voluminous (usually exceeding the BDB size). Although Neelapala et al (2004) reduce the size of the suffix tree, the proposed nsP-index is even more compact (i.e., one or two orders of magnitude smaller).

Related work has also addressed protein databases (Li et al, 2006), while our work addresses nucleotide databases. Finally, the nsP-index uses a buffer-pool to decrease the number of disk accesses (Section A.5.1). The use of a buffer-pool is frequently reported in the literature (Skopal et al, 2007). 


\section{A.3 The MRS Index}

We briefly present here the fundamental concepts of the MRS (Kahveci and Singh, 2001), which are based on the extraction of the wavelet transformation from each string to be stored in the BDB. Let $S=s_{1}, \ldots, s_{d}$ be a BDB composed of $d$ strings and $w=2^{a}$ be the length of the shortest query sequence. The MRS stores a set of elements $T_{i, j}$, where $a \leq i \leq b$ (i.e., $b=a+L-1$ ), and $1 \leq j \leq d$. The parameter $a$ is computed from $w$. The parameter $L$ represents the maximum number of resolution levels that will be available in the index. Therefore, each element $T_{i, j}$ indexes the $j^{\text {th }}$ string in the resolution $2^{i}$.

Fig. A.1 shows the MRS as a matrix. Each row represents a distinct resolution level. The $i^{\text {th }}$ row is the set $R_{i}=\left\{T_{i, 1}, \ldots, T_{i, d}\right\}$ that represents all the elements at resolution $2^{i}$. The $j^{\text {th }}$ column is the set $C_{j}=\left\{T_{a, j}, \ldots, T_{a+L-1, j}\right\}$ that corresponds to all the elements for the $j^{\text {th }}$ string. Each element $T_{i, j}$ consists of several MBRs (minimum bound rectangles). This matrix is completely stored in the main memory.

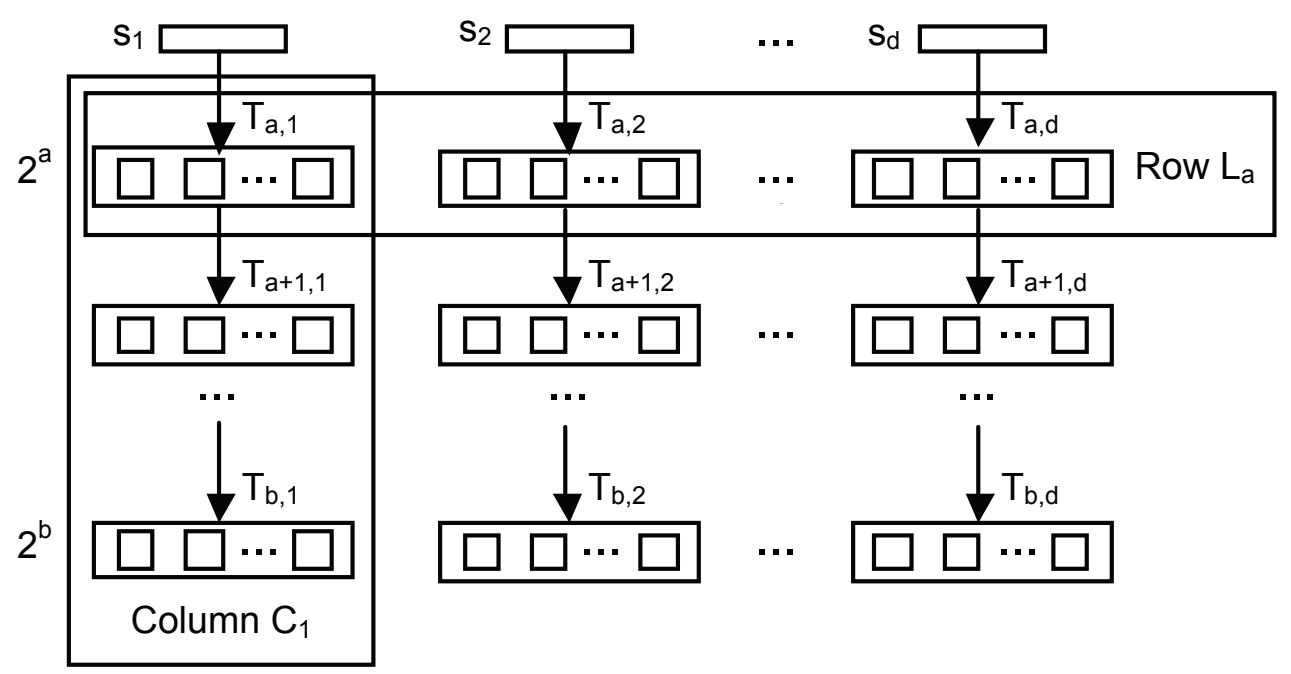

Figure A.1: Diagram of the MRS.

To build $T_{i, j}$, a window of length $2^{i}$ is slid on the string $s_{j}$. For each possible placement of the window, the wavelet transformation of the substring $s_{j}$ is calculated. Therefore, each substring is mapped in the index as a point in the multidimensional space. Regarding the first substring, a MBR is built to encompass its wavelet transformation. This MBR is extended to cover the wavelet transformations of the subsequent substrings until its size is reached. A new MBR is then created and the process is repeated. This is performed until reaching the end of the string $s_{j}$. At the end, each MBR stores two points that delimit it, and the initial position of its first substring. Therefore, a MBR is the minimum bound rectangle that encompasses a set of multidimensional points, where each point represents a specific substring of a given string. 
A string $s_{1}$ can be transformed into another string $s_{2}$ using edit operations (i.e., insert, delete and replace) on individual characters of the string $s_{1}$. The distance between these two strings, called the edit distance, is the smallest number of operations required to accomplish this transformation. In this paper, we focus on the range query algorithm, which is used as a basis for sequence similarity searches. The algorithm returns the strings of the BDB that satisfy an edit distance $r$ of a query string $q$, where $r$ is its radius. The error rate is defined as $\varepsilon=\frac{r}{|q|}$.

\section{A.4 The Proposed nsP-index}

In this section, we describe the nsP-index (nucleotide sequence Persistent index), a new and robust index that performs the persistent storage of MBRs aiming at similarity searches of nucleotide sequences. The nsP-index stores the MBRs that index the BDB strings on disk. Therefore, the index size can exceed the main memory capacity. Furthermore, the index remains on disk, and does not need to be rebuilt after each system shutdown.

To adapt the MRS on disk, the nsP-index answers four fundamental questions:

1. What is the unit of data storage and transfer between disk and main memory?

2. How to represent MBRs and elements $T_{i, j}$ on disk.

3. How to adapt the pointers between the elements $T_{i, j}$ to allow the navigation of rows and columns.

4. How to define the sequence of disk access operations in the range query algorithm in order to assume an efficient use of disk $\mathrm{I} / \mathrm{O}$ operations.

The unit of data storage and transfer is a disk page of fixed size $c$. The disk page size normally used by operating systems and databases today ranges from $4 \mathrm{~KB}$ to $8 \mathrm{~KB}$ (Bovet and Cesati, 2005). This choice answers Question 1.

In the nsP-index, MBRs and elements $T_{i, j}$ are specially organized on disk pages. The relationship of an element $T_{i, j}$, disk pages and MBRs is as follows. While each $T_{i, j}$ in the MRS contains $m_{i, j}$ MBRs, in the nsP-index the element $T_{i, j}$ is stored in $k$ pages. Altogether, these pages store a total of $m_{i, j}$ MBRs. As for pages of size $c$ and MBRs of size MBRsize, the disk page capacity is obtained from Equation 1.

$$
\text { page_capacity }=\left\lceil\frac{c}{M B R s i z e}\right\rceil \text { MBRs }
$$

Each disk page stores MBRs related to only one element $T_{i, j}$. This is a key concept of the nsP-index design, since it facilitates the search for the MBRs of an element. Otherwise, these MBRs could be stored on several pages, causing a substantial increase in disk 
accesses. Wasted storage space can occur on the last page that stores the MBRs of $T_{i, j}$. However, this waste is less than the size of a page. The technique described in the last two paragraphs answers Question 2.

Fig. A.2 shows the physical organization of the nsP-index file. Disk pages related to $T_{i, j}$ are stored sequentially in the index file. This organization improves the search for the MBRs of $T_{i, j}$, by avoiding disk accesses. The determination of the page that contains a given MBR is computed from Equation 2. The table findMBR (Section A.5.2) is also used to allow the navigation among elements in the index. This explanation answers Question 3.

$$
\begin{aligned}
& \text { required_page }=\text { inicital_page }+\left\lfloor\frac{\text { required_MBR }}{\text { page_capacity }}\right\rfloor
\end{aligned}
$$

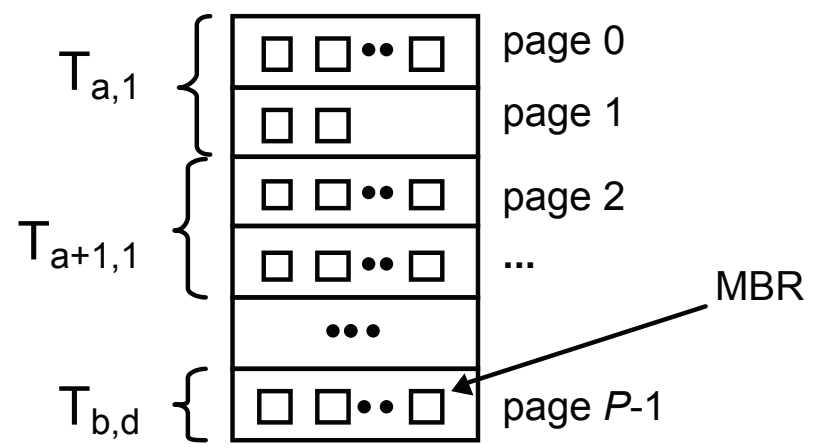

Figure A.2: Organization of the nsP-index file.

The nsP-index is built as follows (Fig. A.3). For each string $s_{i}$ in each resolution $r_{j}$, a window $w_{k}$ of size $2^{r_{j}}$ is slid on the string (line 5). For each placement of $w_{k}$, a substring of $s_{i}$ is transformed into a point (line 12) and encompassed by a MBR of the current disk page (line 13). When this page is full, it is written on disk (lines 9 and 15). The sequence of the written MBRs follows closely the order they are scanned in the query algorithm, so it fulfills the requirement of Question 4.

\section{A.5 Components of the nsP-index}

The components of the nsP-index are (Fig. A.4):

- The complete index stored on disk, called diskIndex.

- The partial index stored in a buffer-pool in the main memory, called bufferIndex.

- The buffer-pool manager resident in the main memory, called managerBuffer.

- The table verifyPage, which is stored in the main memory. 


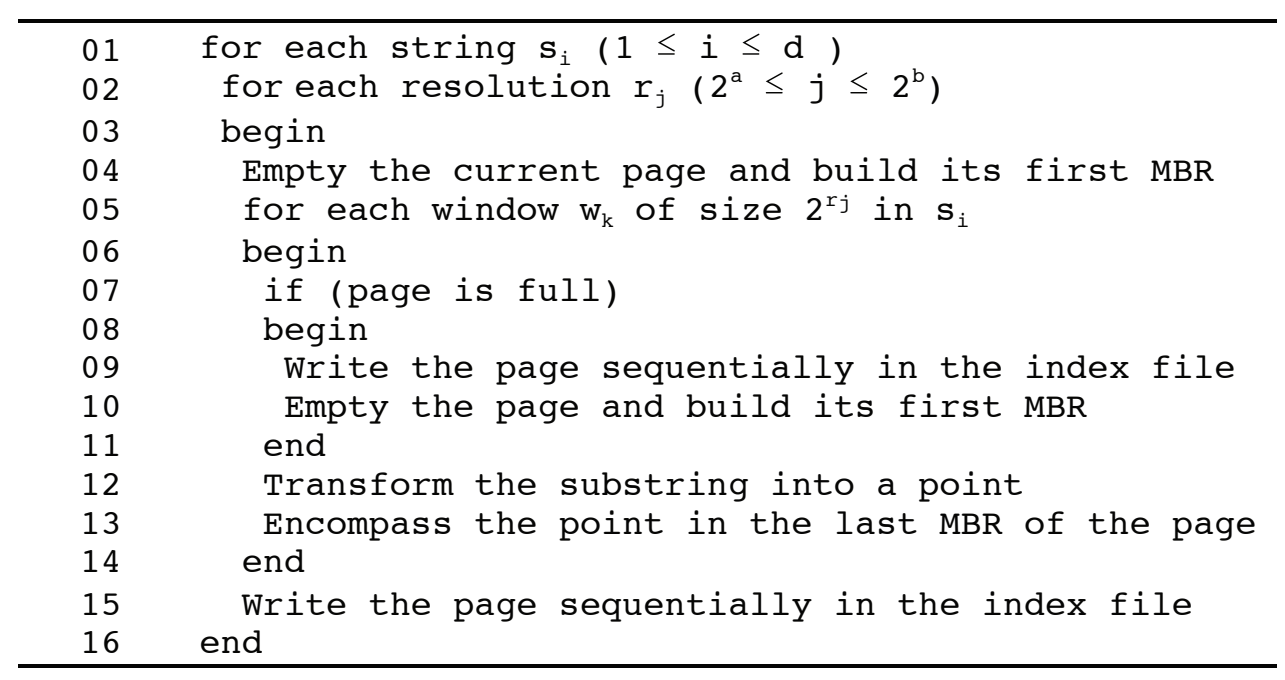

Figure A.3: Building code of the nsP-index.

- The table findMBR, which is stored in the main memory and on disk.

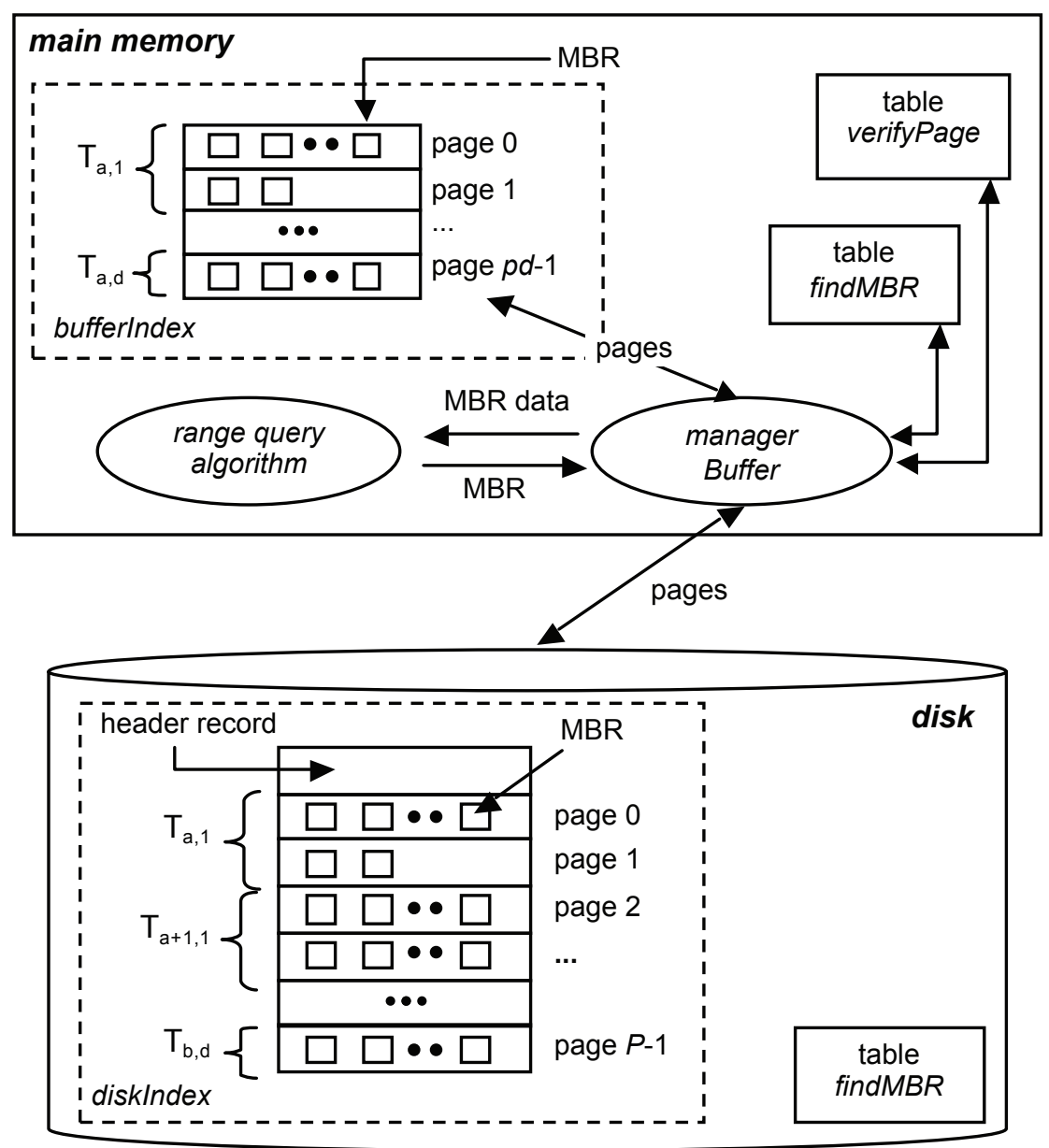

Figure A.4: Organization of the nsP-index. 


\section{A.5.1 The Core Components}

The bufferIndex is a main memory cache used for the temporary storage of disk pages related to the elements $T_{i, j}$ resident on disk. It contains some elements $T_{i, j}$ or parts of an element $T_{i, j}$. Furthermore, the bufferIndex is composed of $p d$ disk pages of size $c$ KB. The bufferIndex can be customized to occupy a portion of the main memory (e.g., typically from $30 \%$ to $85 \%$ ).

The diskIndex stores the MBRs indexed by the nsP-index in an index file. It contains all the elements $T_{i, j}$ that index the nucleotide sequences. The index file is divided into two parts. The first part is a header record of fixed size, which is used to store any information related to the management of the diskIndex. The second part is a set of $P$ disk pages of $c$ KB.

The managerBuffer receives requests for MBR from the range query algorithm and returns the data of the requested MBR to this algorithm. It also transparently exchanges pages between the bufferIndex and the diskIndex. We have adopted a simple and widely used page replacement policy, called LRU (least recently used). However, any other policy could be adopted instead.

\section{A.5.2 The Tables verifyPage and findMBR}

The table verifyPage allows one to determine if a page related to a requested MBR is stored only on disk or is also already replicated in the main memory (Table A.1a). This table contains two columns (page and localization), and stores information about all the pages of the diskIndex. A value of -1 in the column localization indicates that the corresponding page is stored only in the diskIndex. A value between 0 and $p d-1$ indicates that the page is also replicated in the bufferIndex.

The table findMBR (Table A.1b) stores the number of MBRs that represent each element $T_{i, j}$, which is specified in terms of its string and resolution. The table findMBR also records the placement of the initial page of $T_{i, j}$, allowing the identification of the page that contains a required MBR (Equation 2).

Table A.1: (a) The table verifyPage. (b) The table findMBR.

\begin{tabular}{cc}
\hline Page & Localization \\
\hline 0 & 5 \\
1 & 6 \\
2 & -1 \\
$\cdots$ & $\cdots$ \\
$P-1$ & -1 \\
\hline
\end{tabular}

\begin{tabular}{cccc}
\hline String & Resolution & $\begin{array}{c}\text { Number } \\
\text { of MBRs }\end{array}$ & $\begin{array}{c}\text { Initial } \\
\text { page }\end{array}$ \\
\hline$s_{1}$ & $2^{a}$ & 80 & 0 \\
$s_{1}$ & $2^{a+1}$ & 80 & 12 \\
$\ldots$ & $\ldots$ & $\ldots$ & $\ldots$ \\
$s_{d}$ & $2^{b}$ & 78 & 23 \\
\hline
\end{tabular}




\section{A.5.3 Additional Aspects of the nsP-index}

The original range query algorithm uses the MRS index to obtain a MBR. This algorithm accesses an element $T_{i, j}$ using pointers in the main memory. For joint use with the nsP-index, this algorithm was adapted to send requests for MBR to the managerBuffer and to receive the data of the requested MBR from this component (Fig. A.5; line 10).

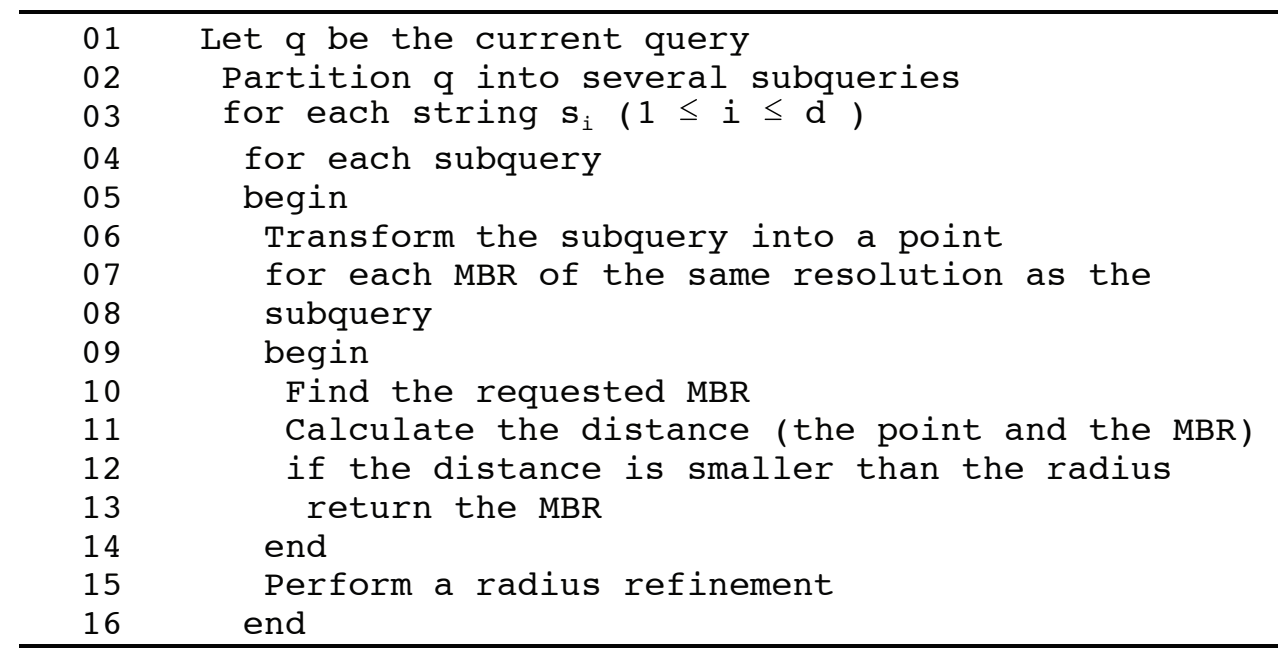

Figure A.5: The range query algorithm.

\section{A.6 Performance Tests}

The advantages of the nsP-index over the MRS were investigated through performance tests involving synthetic and real nucleotide sequences $(\Sigma=\{\mathrm{A}, \mathrm{C}, \mathrm{G}, \mathrm{T}, \mathrm{N}\}$, where $\mathrm{N}$ means unknown base pairs).

Experiments using both the synthetic and the real BDB were performed submitting 100 range queries to each BDB and taking the average of the measurements. The size of the queries ranged from 512 to 10,000 characters. We used the error rate $\varepsilon=0.05$ to calculate the query radius $r$. We issued 20 queries of 512 characters with $r=25,20$ queries of 1,000 characters with $r=50,20$ queries of 4,000 characters with $r=200,20$ queries of 7,000 characters with $r=350$, and 20 queries of 10,000 characters with $r=500$. The use of different query sizes allows queries to be decomposed into several resolutions. Therefore, many elements of the index must be used in the query processing.

The MRS and the nsP-index were both implemented in $\mathrm{C}++$. We used four resolutions with window sizes of 128, 256, 512 and 1,024 characters, and set the MBR capacity to 4,000 strings. The bufferIndex size was defined as $60 \%$ of the main memory and the disk page size $c$ was set to $4 \mathrm{~KB}$.

The experiments were conducted in the Linux Ubuntu 7.04 operating system running on an AMD Athlon 64 X2 Dual Core Processor 4200+ stand-alone computer with 1 GB of 
main memory and $250 \mathrm{~GB}$ of disk. We analyzed the cost of building the index and the cost of range query processing. The elapsed time (seconds) and the space required to store the index (bytes) were recorded for the former. As for the latter, we recorded the elapsed time (seconds) and the disk accesses to the nsP-index.

In our tests, we did not compare the nsP-index with works based on suffix trees, since those indexes are not only extremely voluminous but also incompatible with the restrictions of the environments that motivated our work.

\section{A.6.1 Synthetic Databases}

The size of each sequence was $7,804,765$ bytes, reproducing the size of the bacterium "Rhodococcus sp. RHA1", which is the largest genome at http://cmr.tigr. org/tigrscripts/CMR/shared/Genomes.cgi?bacteria_only=1. The composition of the genome was $27 \%$ of A, $19 \%$ of C, $19 \%$ of $\mathrm{G}, 27 \%$ of $\mathrm{T}$ and $8 \%$ of $\mathrm{N}$.

The performance tests were carried out using increasingly large BDB sizes ranging from 1 GB to 23 GB. We defined smaller BDB (from 1 GB to 11 GB), to allow the MRS index to be stored entirely in the main memory. Larger BDB (from 13 GB to 23 GB) were defined to show the limitations of the MRS using virtual memory and the advantages of the nsP-index.

Performance Results. Fig. A.6 shows the time spent on building the indexes. As expected, the time spent on the nsP-index was slightly longer than that spent on the MRS. However, the difference in the elapsed time was very slight, indicating that the nsP-index incurs almost no additional overhead (Table A.2). This difference lies in the fact that the MRS stores MBRs only in the main memory, while the nsP-index also stores them on disk. A major advantage of the nsP-index is that its building cost can be diluted quickly over time. The MRS must be rebuilt after each system shutdown, while the nsP-index does not require reconstruction. Our measurements indicate that just one reconstruction of the MRS causes the time spent on it to far exceed the time spent on the nsP-index.

Regarding the storage space of the index, the MRS required $8.40 \%$ of the BDB size, which was almost matched by the nsP-index (i.e., 8.47\%). These measurements show that, albeit comprising several components, the nsP-index is a very compact index.

As for the range query processing (Fig. A.7), the nsP-index provided a much shorter elapsed time than the MRS for larger BDB (from 13 GB to 23 GB). Furthermore, as the volume of data increased, the nsP-index quickly provided a greater reduction in elapsed time. The peak reduction was about $75 \%$. In fact, the MRS cannot be applied satisfactorily to these larger BDB. In order to index these volumes, the MRS uses the virtual memory of the operating system. As a result, the MRS performs poorly.

For smaller BDB (from 1 GB to 11 GB), the time spent by the nsP-index was almost the same as that of the MRS, although the nsP-index design does not index data only 


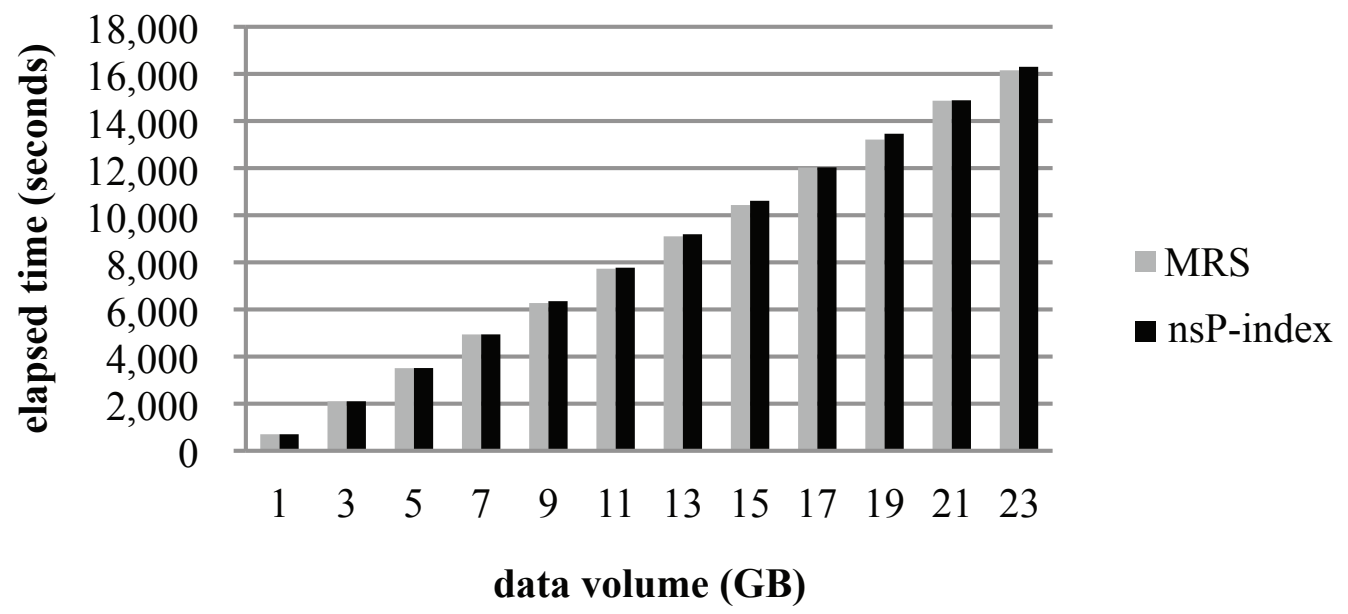

Figure A.6: Elapsed time in building the indexes.

Table A.2: Increase in building costs.

\begin{tabular}{cccc}
\hline Data volume & MRS & nsP-index & Increase \\
\hline 1 & 702 & 702 & $0.00 \%$ \\
3 & 2,096 & 2,102 & $0.29 \%$ \\
5 & 3,508 & 3,513 & $0.14 \%$ \\
7 & 4,940 & 4,942 & $0.04 \%$ \\
9 & 6,272 & 6,352 & $1.28 \%$ \\
11 & 7,730 & 7,773 & $0.56 \%$ \\
13 & 9,104 & 9,193 & $0.98 \%$ \\
15 & 10,433 & 10,613 & $1.73 \%$ \\
17 & 12,024 & 12,034 & $0.08 \%$ \\
19 & 13,212 & 13,460 & $1.88 \%$ \\
21 & 14,862 & 14,880 & $0.12 \%$ \\
23 & 16,153 & 16,301 & $0.92 \%$ \\
\hline
\end{tabular}

in the main memory. With regard to the volume of $11 \mathrm{~GB}$, the difference in the elapsed times is due to the fact that the size of the bufferIndex is $60 \%$ of the main memory. Therefore, the nsP-index needs to start performing disk accesses before the MRS uses all the main memory, so far the MRS does not yet require the use of the virtual memory for the volume of $11 \mathrm{~GB}$. These results indicate that the nsP-index can also replace the MRS satisfactorily to index small volumes of sequences in the main memory.

The nsP-index proved to be scalable in the management of different BDB sizes, since the elapsed time (Fig. A.7) and the disk accesses (Table A.3) showed a linear increase in the volume for both smaller and larger BDB. Therefore, the increase in the volume did not impair the performance of the nsP-index. In other words, the results demonstrate that the efficiency of the nsP-index in exchanging pages between disk and main memory was not affected by the increase in data volume. 


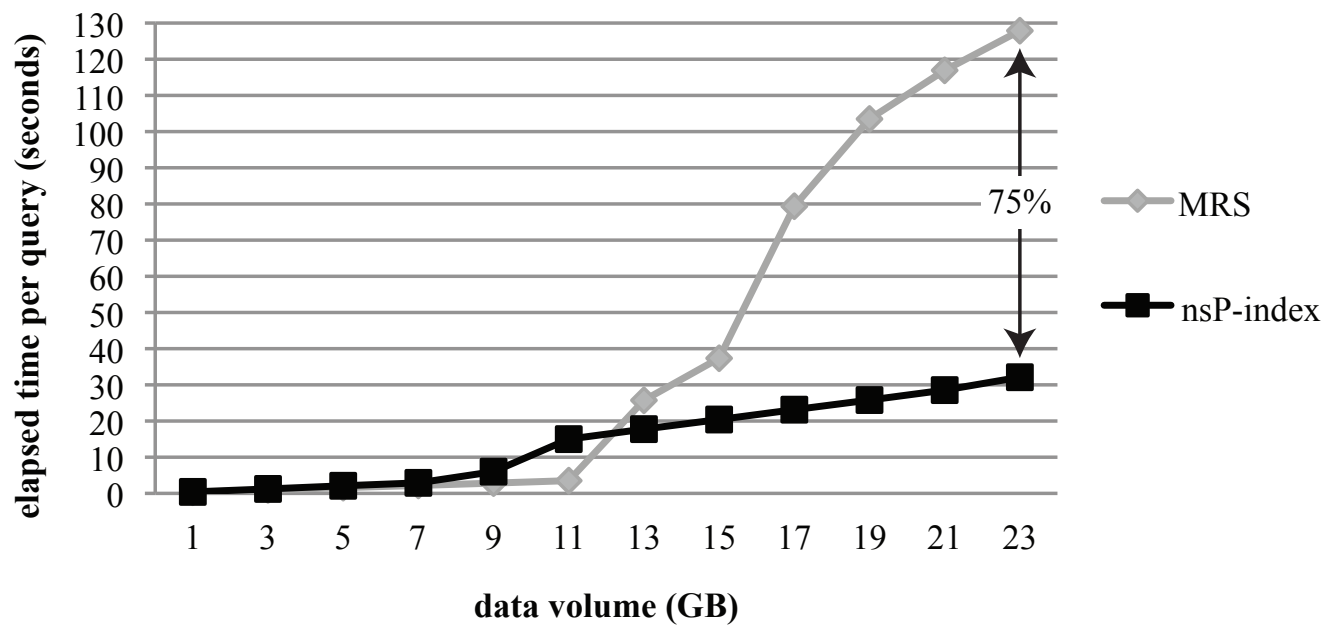

Figure A.7: Elapsed time in query processing.

Table A.3: Disk accesses per query.

\begin{tabular}{cccc}
\hline Data volume & nsP-index & Data volume & nsP-index \\
\hline $1 \mathrm{~GB}$ & 221 & $13 \mathrm{~GB}$ & 187,363 \\
$3 \mathrm{~GB}$ & 664 & $15 \mathrm{~GB}$ & 216,311 \\
$5 \mathrm{~GB}$ & 1,107 & $17 \mathrm{~GB}$ & 245,259 \\
$7 \mathrm{~GB}$ & 1,550 & $19 \mathrm{~GB}$ & 274,207 \\
$9 \mathrm{~GB}$ & 42,206 & $21 \mathrm{~GB}$ & 303,155 \\
$11 \mathrm{~GB}$ & 158,415 & $23 \mathrm{~GB}$ & 332,103 \\
\hline
\end{tabular}

\section{A.6.2 Real Databases}

We used 8 real BDB varying from small (0.13 GB) to large ones (20.41 GB). The first 5 BDB contained one organism each, namely: Drosophila melanogaster (0.13 GB), Anopheles gambiae (0.26 GB), Gallus gallus (0.98 GB), Canis familiaris (2.40 GB) and Homo sapiens $(2.92 \mathrm{~GB})$. The last $3 \mathrm{BDB}$ contained a mix of organisms, and their volumes were: 13.29 GB, 17.62 GB and 20.41 GB. The genomes of the organisms were obtained at ftp://ftp.ensembl.org/pub/current_fasta.

Performance Results. The nsP-index also indexed real data efficiently. The results described in this section indicated a behavior very similar to that obtained with synthetic data:

- The times spent to build the nsP-index and the MRS were almost the same (Fig. A.8).

- The nsP-index required almost the same storage space as the MRS. The nsP-index required $8.28 \%$ of the $\mathrm{BDB}$ size, while the MRS required $8.26 \%$. 
- The nsP-index required much less time spent on query processing than the MRS for larger BDB (from 13.2 GB to $20.4 \mathrm{~GB}$ ). The highest reduction was about $82 \%$ (Fig. A.9).

- The nsP-index required almost the same time spent on query processing as the MRS for smaller BDB (from 0.13 GB to $2.92 \mathrm{~GB}$ ).

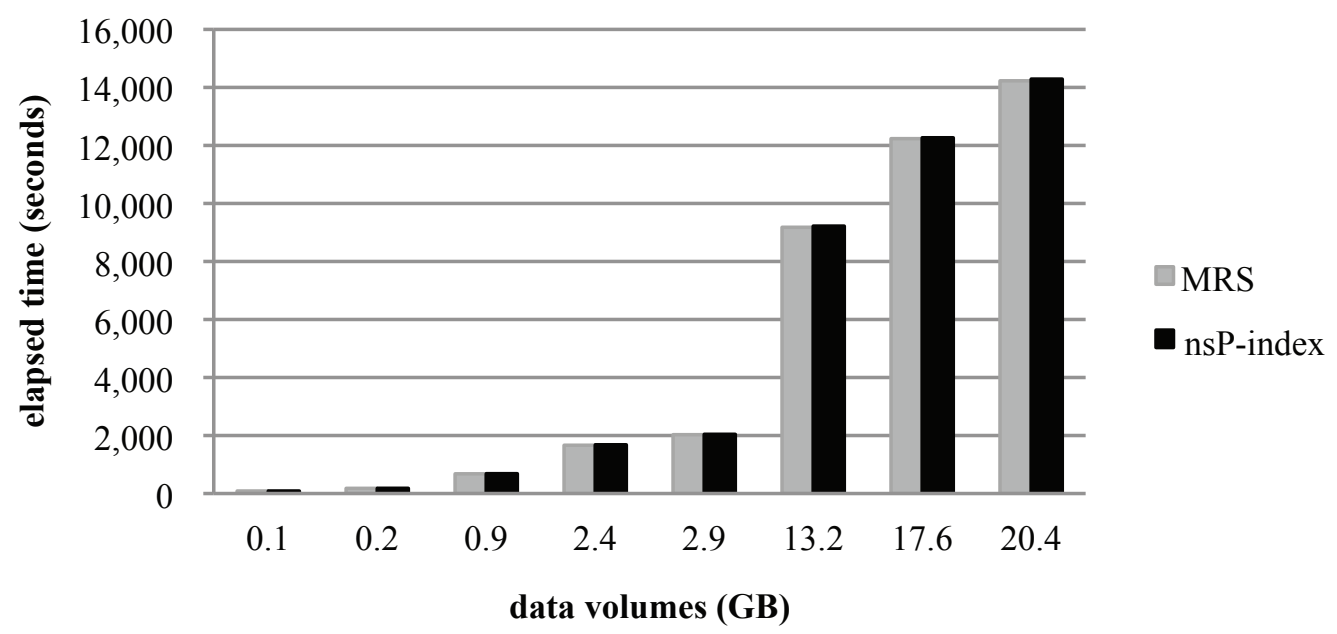

Figure A.8: Elapsed time in building the indexes.

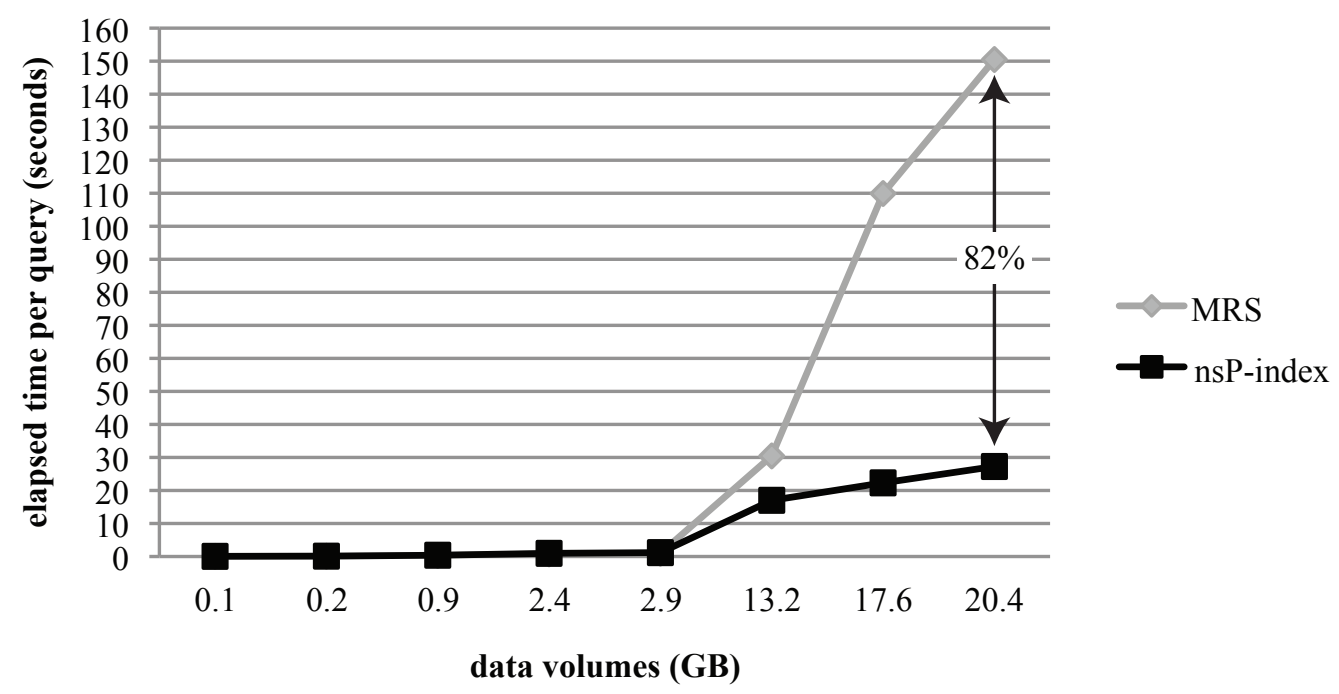

Figure A.9: Elapsed time in query processing.

\section{A.7 Conclusions and Future Work}

In this paper, we focused on the persistent storage of index data aimed at similarity searches of nucleotide sequences. Our main contribution is the nsP-index, which allows 
the management of large databases that require an index whose size exceeds the capacity of the main memory. Therefore, the nsP-index extends the MRS index, overcoming its major limitation. Furthermore, while the MRS must be rebuilt after each system shutdown, the nsP-index does not require reconstruction.

Aiming at improving the query performance, the design of the nsP-index is based on the following characteristics. In the nsP-index, MBRs and elements are specially organized on disk pages. Each disk page stores MBRs related to only one element. Furthermore, pages related to a given element are stored sequentially in the index file. This organization improves the search for the MBRs of an element, by avoiding disk accesses. The nsP-index also uses a buffer-pool to decrease the number of disk accesses. Another characteristic of the nsP-index is that the sequence of the written MBRs follows closely the order they are scanned in the range query algorithm.

The nsP-index was validated through performance tests using synthetic and real databases with different volumes of nucleotide sequences. The results showed that the nsP-index is very compact, requiring a small fraction of the database volume (about 8.5\%). As for query processing, the nsP-index was also able to index larger databases (from $13 \mathrm{~GB}$ to $23 \mathrm{~GB}$ ), greatly improving the query performance in comparison to the MRS. The nsP-index reduced the time spent on query processing of synthetic data by up to $75 \%$ and real data by up to $82 \%$. Moreover, the nsP-index suitably showed a linear growth in query cost in response to increased volumes of data. Therefore, the increase in volume did not impair the performance of the nsP-index.

We are currently investigating the influence of the size of the bufferIndex on the performance of the nsP-index. We are also addressing page replacement policies that take into account the characteristics of the nsP-index. Another extension is the adaptation of the nsP-index focusing on amino acids sequences using the PAM (Point Accepted Mutation) and the BLOSUM (BLOcks SUbstitution Matrix) transformation matrices.

Acknowledgments. This work has been supported by the following Brazilian research agencies: FAPESP, CNPq, CAPES and FINEP. 


\title{
Apêndice \\ B \\ The Onion-tree: Quick Indexing of Complex Data in the Main Memory
}

\author{
Caio César Mori Carélo ${ }^{1}$, Ives Renê Venturini Pola ${ }^{1}$, \\ Ricardo Rodrigues Ciferri ${ }^{2}$, Agma Juci Machado Traina ${ }^{1}$, \\ Caetano Traina-Jr ${ }^{1}$ and Cristina Dutra de Aguiar Ciferri ${ }^{1}$ \\ ${ }^{1}$ Departamento de Ciências de Computação, Universidade de São Paulo \\ 13.560-970, São Carlos - SP, Brazil \\ \{ccarelo|ives|agma|caetano|cdac\}@icmc.usp.br \\ 2 Departamento de Computação, Universidade Federal de São Carlos \\ 13.565-905, São Carlos - SP, Brazil \\ ricardo@icmc.usp.br
}

\section{Abstract}

Searching for elements in a dataset that are similar to a given query element is a core problem in applications that use complex data, and has been carried out aided by a metric access method (MAM). A growing number of these applications require indices that can be built faster and for several times, in addition to providing smaller response times for similarity queries. Besides, the increase in the main memory capacity and its lowering costs also motivate using memory-based MAMs. In this paper, we propose the ONION-TREE, a new and robust dynamic memory-based MAM that performs a hierarchical division of the metric space into disjoint subspaces. The ONION-TREE is very compact, requiring a small 
fraction of the main memory (e.g., at most 4.8\%). Comparisons of the OnION-TREe, a memory-based version of the Slim-tree, and the memory-based MM-tree showed that the ONION-TREE always produced the smallest elapsed time to build the index. Our experiments also showed that the ONION-TREE produced the best query performance results, followed by the MM-tree, which in turn outperformed the Slim-tree. With regard to the MM-tree, the ONION-TREE provided a reduction in the number of distance calculations that ranged from $1 \%$ to $11 \%$ in range queries and from $16 \%$ up to $64 \%$ in $k$-NN queries. The ONION-TREE also significantly improved the required elapsed time, which ranged from $12 \%$ to $39 \%$ in range query processing and from $40 \%$ up to $70 \%$ in $k$-NN query processing, as compared to the MM-tree, its closest competitor. The ONION-TREE source code is available at http://gbd.dc.ufscar.br/download/Onion-tree.

Keywords: metric access method, complex data, similarity search.

\section{B.1 Introduction}

A metric access method (MAM) is designed aiming at providing efficient access to the growing number of applications that demands to compare complex data, such as images, audio and video. To improve complex data access, MAMs reduce the search space, leading the search to portions of the dataset where the stored elements probably have higher similarity with a given query element. A similarity measure between two elements can be expressed as a metric that becomes smaller as the elements are more similar (Hjaltason and Samet, 2003). Therefore, MAMs partition the metric space into subspaces so that queries do not have to access the complete dataset.

Formally, a metric space is an ordered pair $<\mathbb{S}, d>$, where $\mathbb{S}$ is the domain of data elements and $d: \mathbb{S} \times \mathbb{S} \rightarrow \mathbb{R}^{+}$is a metric. For any $s_{1}, s_{2}, s_{3} \in \mathbb{S}$, the metric must hold the following properties: (i) identity: $d\left(s_{1}, s_{1}\right)=0$; (ii) symmetry: $d\left(s_{1}, s_{2}\right)=d\left(s_{2}, s_{1}\right)$; (iii) non-negativity: $d\left(s_{1}, s_{2}\right) \geq 0$; and (iv) triangular inequality: $d\left(s_{1}, s_{2}\right) \leq d\left(s_{1}, s_{3}\right)+d\left(s_{3}, s_{2}\right)$ (Chávez et al, 2001). For instance, elements of a dataset $S \subset \mathbb{S}$, which may be represented by numbers, vectors, matrices, graphs or even functions, can be indexed with a MAM using metrics such as the Manhattan $\left(L_{1}\right)$ or the Euclidean $\left(L_{2}\right)$ distances (Wilson and Martinez, 1997).

Searching for elements close to a given query element $s_{q} \in \mathbb{S}$ is a core problem in applications that manage complex data. The two most useful types of similarity queries are the range and the $k$-nearest neighbor $(k$-NN) queries, which are defined as follows: 
- Range query: given a query radius $r_{q}$, this query retrieves every element $s_{i} \in S$ that satisfies the condition $d\left(s_{i}, s_{q}\right) \leq r_{q}$. An example is: "Select the images that are similar to the image $P$ by up to five similarity units".

- $k$-NN query: given a quantity $k \geq 1$, this query retrieves the $k$ elements in $S$ that are the nearest from the query center $s_{q}$. An example is: "Select the three images most similar to the image $P^{\prime \prime}$.

There are disk-based (Ciaccia et al, 1997; Traina-Jr et al, 2002; Vieira et al, 2004; Skopal et al, 2004; Traina-Jr et al, 2007) and memory-based MAMs (Uhlmann, 1991; Brin, 1995; Yianilos, 1993; Pola et al, 2007). Memory-based MAMs are useful for applications that require to build indices several times, in a very fast way. For instance, they are applied to optimize subqueries in the processing of complex queries. Furthermore, memory-based MAMs do not need to minimize disk accesses as disk-based MAMs do. Thus, memorybased MAMs can provide better partitioning of the metric space, allowing similarity queries to be answered faster. Moreover, the increase in the main memory capacity and its lowering costs motivate the use of memory-based MAMs.

The MM-tree (Pola et al, 2007) is the fastest memory-based MAM to date. However, the partitioning of the MM-tree may generate subspaces of very different sizes, therefore producing highly unbalanced structures. Although Pola et al propose a policy to minimize this issue, it introduces an additional processing that takes quadratic time. This increases the cost of building the index, which is an important feature for memory-based MAMs. Furthermore, our preliminary experiments showed that the MM-tree is not suitable for high dimensional data. These drawbacks call for improvements on the MM-tree.

In this paper, we propose a new and robust dynamic memory-based MAM that extends the MM-tree, called the OnION-TREE. We validate the OnION-TREE through performance tests using datasets that exploits different properties that affect the general behavior of MAMs, such as data volume and data dimensionality. In the experiments, we compare the proposed ONION-TREE with a memory-based version of the Slimtree (Traina-Jr et al, 2002) and with the MM-tree.

The distinctive properties of the ONION-TREE are as follows:

- A new partitioning method that controls the number of disjoint subspaces generated. This method allows for the creation of shallower and wider structures and does not impair the cost of building the index.

- A technique that prevents the creation of subspaces that are too small or too big. This ensures a better division of the metric space, improving both the cost of building the index and the cost of query processing. 
- Extensions of the MM-tree's range and $k$-NN algorithms to support the new partitioning method of the ONION-TREE, which include a proper visit order of the subspaces in $k$-NN queries.

This paper is organized as follows. Section B.2 reviews related work, while Section B.3 summarizes the MM-tree. Section B.4 overviews the main characteristics of the proposed Onion-Tree, and Sections B.5 to B.7 detail its properties. Section B.8 discusses the experimental results and Section B.9 concludes the paper.

\section{B.2 Related Work}

The pioneering work of Burkhard and Keller (1973) introduces approaches to index data in metric spaces, while the works of Chávez et al (2001) and Hjaltason and Samet (2003) survey existing MAMs. The work on MAMs is quite extensive.

The GH-tree (Uhlmann, 1991) is a static MAM that chooses recursively two pivots per node and defines a generalized hyperplane between them, creating two subspaces. Each remaining element is assigned to the subspace of the closest pivot. The GNAT (Brin, $1995)$ tree extends the GH-tree to choose $m \geq 2$ pivots per node, creating $m$ subspaces. Conversely, the partitioning of the VP-tree (Yianilos, 1993) selects a representative element and defines a ball with covering radius $r$, which is the average distance between all the elements. The remaining elements are associated to the left subtree if their distances are less or equal than $r$ or to the right subtree otherwise. Differently from these static MAMs, the ONION-TREE is a dynamic MAM. So, it supports further insertions without compromising its structure.

The first dynamic disk-based MAM is the M-tree (Ciaccia et al, 1997). Its leaf nodes store all the elements, while its internal nodes store elements called representatives, which have a covering radius and are chosen by promotion algorithms. The Slim-tree (Traina-Jr et al, 2002) is the first index explicitly designed to reduce the degree of overlap between nodes in a metric tree, improving query performance. The OMNI concept (Traina-Jr et al, 2007) allows to store distances between indexed elements and strategically positioned elements (foci), which are used to improve the prunability during the query processing. The PM-tree (Skopal et al, 2004) proposes the use of OMNI concept to reduce the M-tree node space search. The DBM-tree (Vieira et al, 2004) minimizes the overlap between high-density nodes by relaxing the height-balancing rule. Differently from these diskbased MAMs, the ONION-TREE is a memory-based MAM that defines disjoint regions, allowing similarity queries to be answered without node overlapping.

To the best of our knowledge, the MM-tree (Pola et al, 2007) is the fastest memorybased MAM in the literature. The experiments described in (Pola et al, 2007) showed that the MM-tree always outperformed a memory-based version of the Slim-tree, which 
in turn outperformed the VP-tree. The MM-tree is summarized in Section B.3, since the ONION-TREE extends this structure.

\section{B.3 The MM-tree}

The MM-tree (Pola et al, 2007) is a memory-based MAM that divides the metric space into four disjoint regions by selecting two pivots per node. Fig. B.1a shows the structure of a MM-tree that indexes the elements of $S=\left\{s_{1}, s_{2}, s_{3}, s_{4}, s_{5}, s_{6}, s_{7}, s_{8}\right\}$, using $\left\{s_{1}, s_{2}\right\}$ as pivots. The distance $r$ between the pivots (i.e., $\left.d\left(s_{1}, s_{2}\right)\right)$ defines the ball radius of each pivot, creating four disjoint regions: I, II, III and IV. Each element of $S-\left\{s_{1}, s_{2}\right\}$ is assigned to a specific region according to Table B.1. For instance, the element $s_{5}$ is assigned to region II, since $d\left(s_{5}, s_{1}\right)<r$ and $d\left(s_{5}, s_{2}\right) \geq r$. The MM-tree is built recursively, and requires only two distance calculations per level to determine the region of an element.

(a)
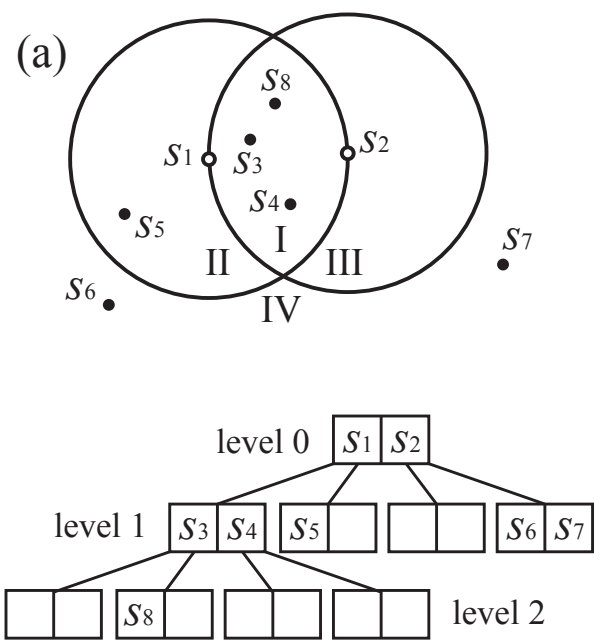

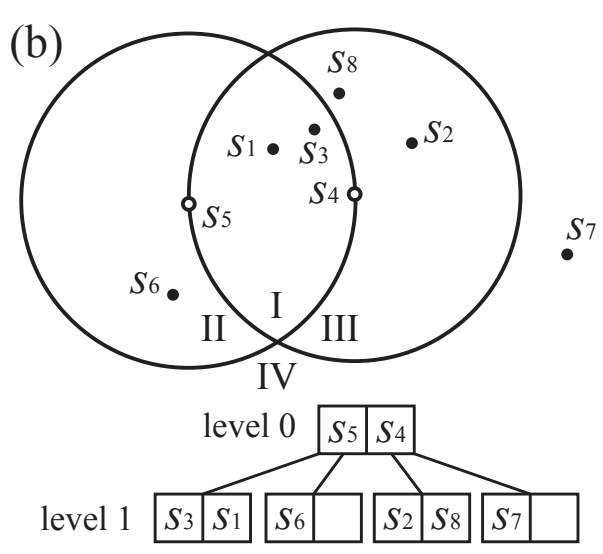

Figure B.1: (a) Example of a MM-tree. (b) Example of the semi-balancing technique.

Table B.1: Regions of space where the element $s_{i}$ can be assigned.

\begin{tabular}{ccc}
\hline$d\left(s_{i}, s_{1}\right) \theta r$ & $d\left(s_{i}, s_{2}\right) \theta r$ & Region \\
\hline$<$ & $<$ & I \\
$<$ & $\geq$ & II \\
$\geq$ & $<$ & III \\
$\geq$ & $\geq$ & IV \\
\hline
\end{tabular}

The MM-tree may generate highly unbalanced structures. To overcome this issue, it uses a semi-balancing technique that is applied when a new element is assigned to a leaf node that is full, but has siblings with space to hold the new element. The technique attempts to replace the pivots on the parent node, avoiding creating a new level. Fig. B.1b exemplifies the semi-balancing technique. 
The MM-tree's algorithms for range and $k$-NN queries detect overlaps between the query ball and the balls of a node. Unlike the range query that already presents a query radius, the $k$-NN query uses an active radius that starts with the maximum distance and decreases as nearest elements are found.

\section{B.4 The Proposed Onion-tree}

In this section, we describe the ONION-TREE, a new and robust dynamic memorybased MAM that extends the MM-tree. Like the MM-tree, the ONION-TREE also divides the metric space into disjoint regions by using two pivots per node. However, the ONION-TREE can divide the metric space into more than four disjoint regions per node. The ONION-TREE introduces the following properties:

- Expansion procedure: a method that increases the number of disjoint regions defined by the pivots of a node. Experimental evidence suggests that a disadvantage in the MM-tree's partitioning is the size of region IV, which is bigger than the size of regions I, II and III. This generates unbalanced structures because many elements are assigned to region IV. The MM-tree's semi-balancing policy minimizes this disadvantage, but it degrades the cost of building the index due to an additional processing that takes quadratic time to determine the best-suited to be the new pivots. Conversely, the ONION-TREE's expansion procedure divides region IV to generate more balanced structures. This procedure creates shallower and wider structures and does not impair the elapsed time to build the ONION-TREE, since it does not require additional distance calculations. Fig. B.2a shows the expansion procedure, which is detailed in Section B.5.

- Replacement technique: a policy that may replace the pivots of a leaf node in the insertion operation. In the ONION-TREE, if the pivots are too close, many expansion procedures are applied to the node. Alternatively, if the pivots are too distant, no expansion procedure is done and most of the node's subspace is assigned to region I. The ONION-TREE's replacement technique minimizes these cases, ensuring a hierarchical division of the metric space. This technique takes constant time and does not require additional distance calculations. Fig. B.2b shows the replacement of the pivot $s_{1}$ with the element $s_{i}$. The replacement technique is detailed in Section B.6.

- Extended query algorithms: extensions of the MM-tree's range and $k$-NN algorithms to support the additional regions created by the expansion procedure. Furthermore, we added to the ONION-TREE's $k$-NN query a sequence order to visit the disjoint regions of a node (e.g., Fig. B.2c), which improves the prunability. The extended algorithms are detailed in Section B.7. 


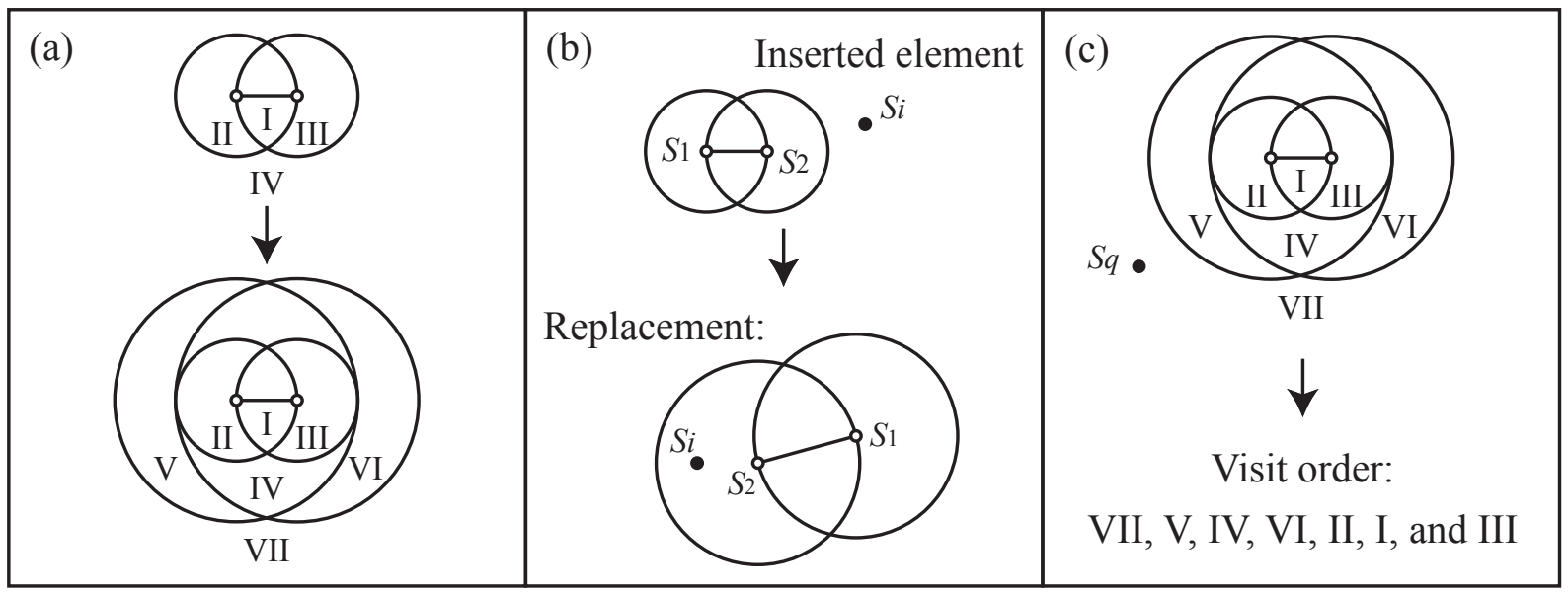

Figure B.2: Overview of the ONION-TREE's distinctive properties.

To support the aforementioned properties, the structure of each node $N$ of the ONION-TREE is composed of the attributes described in Table B.2.

Table B.2: The structure of an OnION-TREE's node $N$.

\begin{tabular}{cl}
\hline Symbol & Description \\
\hline$N . s_{1}$ & first pivot \\
$N . s_{2}$ & second pivot \\
$N . r$ & distance between the pivots (i.e., radius) \\
N.Expansion & number of expansions \\
N.Region & number of regions \\
$N . F$ & link to the parent node \\
N.Son $[1 \ldots N$. Region $]$ & links to the node's regions \\
\hline
\end{tabular}

\section{B.5 The Expansion Procedure}

The expansion procedure divides recursively the external region of a node into four regions. Each expansion procedure adds three regions to the node, since the previous external region becomes the first region of the expansion.

Fig. B.3 shows two expansion procedures applied to an node $N$, which is initially divided into regions I, II, III and IV. The first procedure (i.e., expansion 1) generates a node $N^{\prime}$ with seven regions: regions IV, V, VI and VII in addition to regions I, II and III of expansion 0 (i.e., initial configuration without expansion). The previous external region IV, therefore, is divided into regions IV to VII. The second procedure (i.e., expansion 2) produces a node $N$ " with ten regions: regions VII, VIII, IX and X plus regions I, II and III of expansion 0 and regions IV, V and VI of expansion 1. 
Each expansion procedure increases the pivots radius by $r$. This ensures the division of only the external region of a node. In Fig. B.3, the radius in the first expansion is 2 N.r, while the radius in the second one is $3 N . r$.

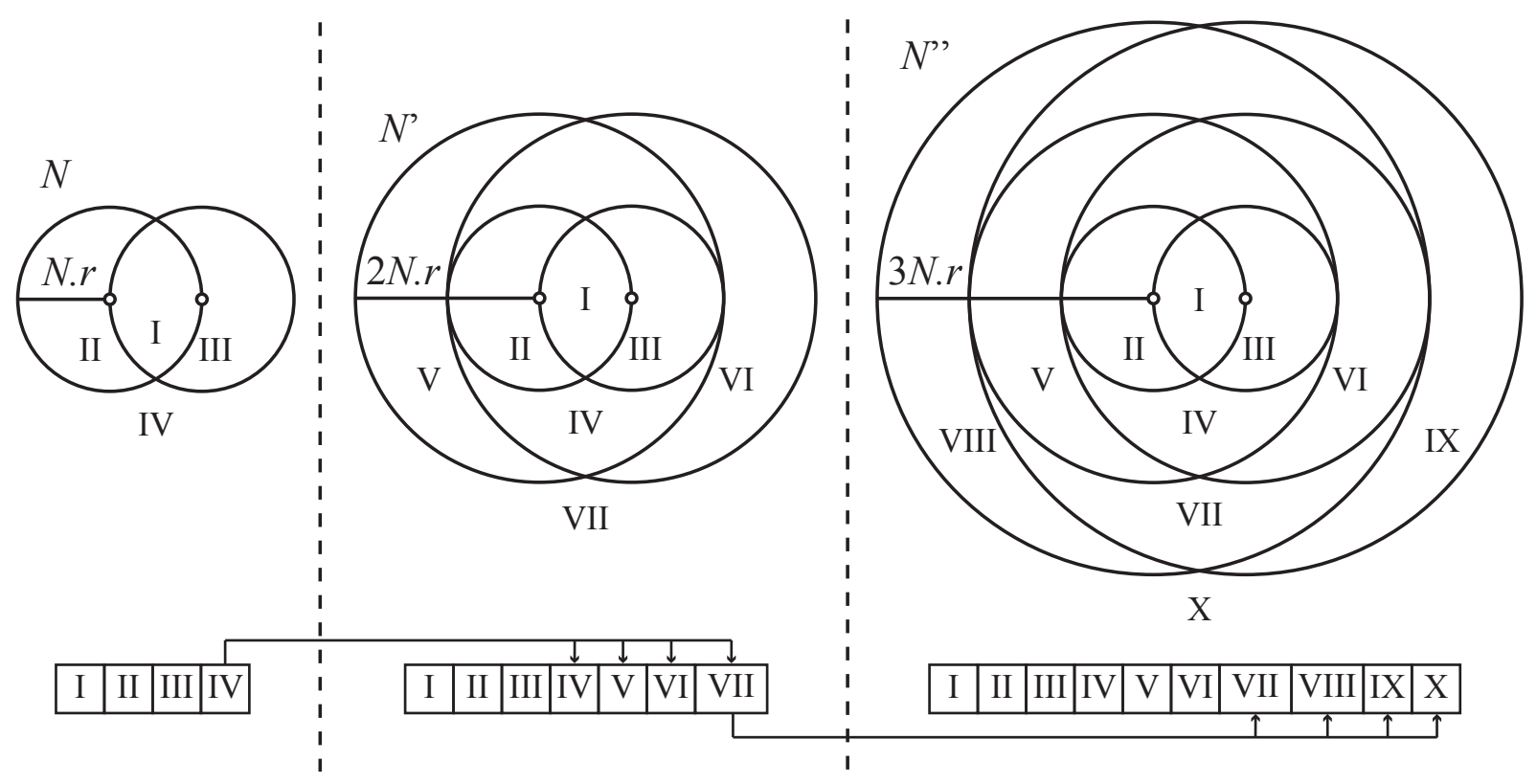

Figure B.3: Nodes $N, N^{\prime}$ e $N^{\prime \prime}$, their pivots and regions.

Two additional aspects related to the use of expansions are defining how many expansions should be applied to a node (Section B.5.1) and the identification of the region to which an element should be assigned to (Section B.5.2).

\section{B.5.1 Creating Expansions and Regions}

The ONION-TREE proposes two policies to determine the number of expansions that can be applied to its nodes: fixed and variable. The fixed expansion applies the same number of expansions to each node, according to an input parameter. For instance, the number of expansions equal to one establishes that all the nodes have seven regions. Conversely, the variable policy applies different numbers of expansions to each node. Therefore, a node can have ten regions (i.e., two expansions), while another can have four regions (i.e., zero expansion).

The objective of the variable policy is to keep the external region small. Thus, the strategy adopted by this policy defines that expansions are needed only when the radius of the current node is less than half of the radius of the parent node. Otherwise, the node's regions already cover its subspace and there is no need for further expansions. We call this approach keep-small strategy.

The CreateRegions algorithm (Algorithm B.1) determines the number of expansions that should be applied to a node $N$, as a function of an input integer $E$. If $E>0$, the policy is set to fixed and the value of $E$ is used as the number of expansions (line 1 ). 
Otherwise, the policy is set to variable and the number of expansions is calculated by the keep-small strategy (lines 2 to 4 ). Finally, the algorithm determines the number of regions of $N$ (line 5).

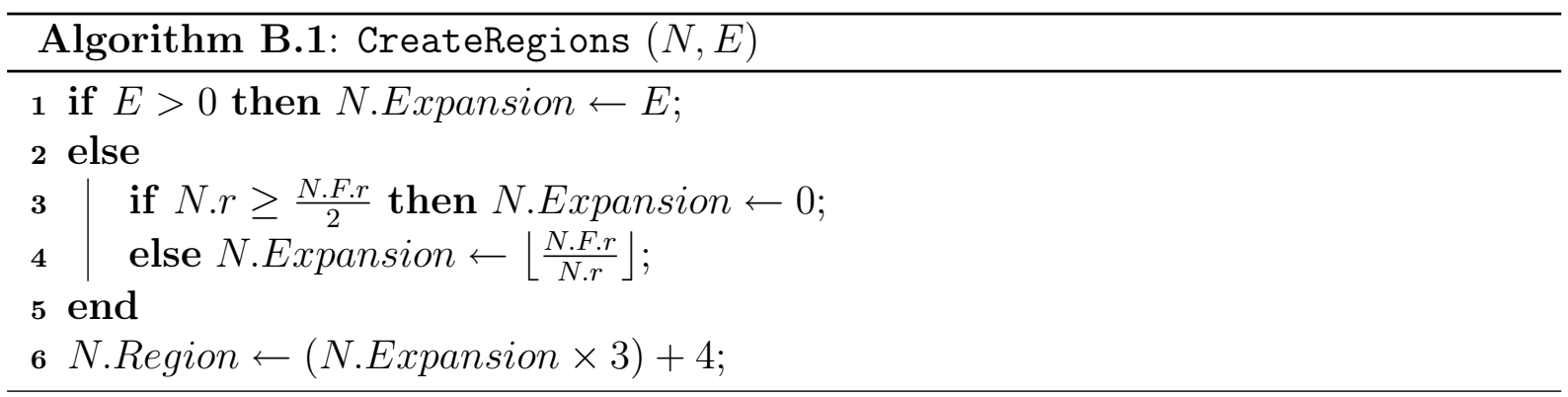

\section{B.5.2 Choosing a Region}

The ChooseRegion algorithm (Algorithm B.2) determines the region to which an element $s_{i}$ is assigned to. Its inputs are a node $N$ (as defined in Table B.2), whose regions were defined by the CreateRegions algorithm, and $d_{1}$ and $d_{2}$, which are the distances of $s_{i}$ to the pivots of $N$. The algorithm analyzes each region to determine the one that encompasses $d_{1}$ and $d_{2}$ (lines 2 to 6 ). If no region is found, $s_{i}$ is associated to the external region of $N$ (lines 7 to 9 ).

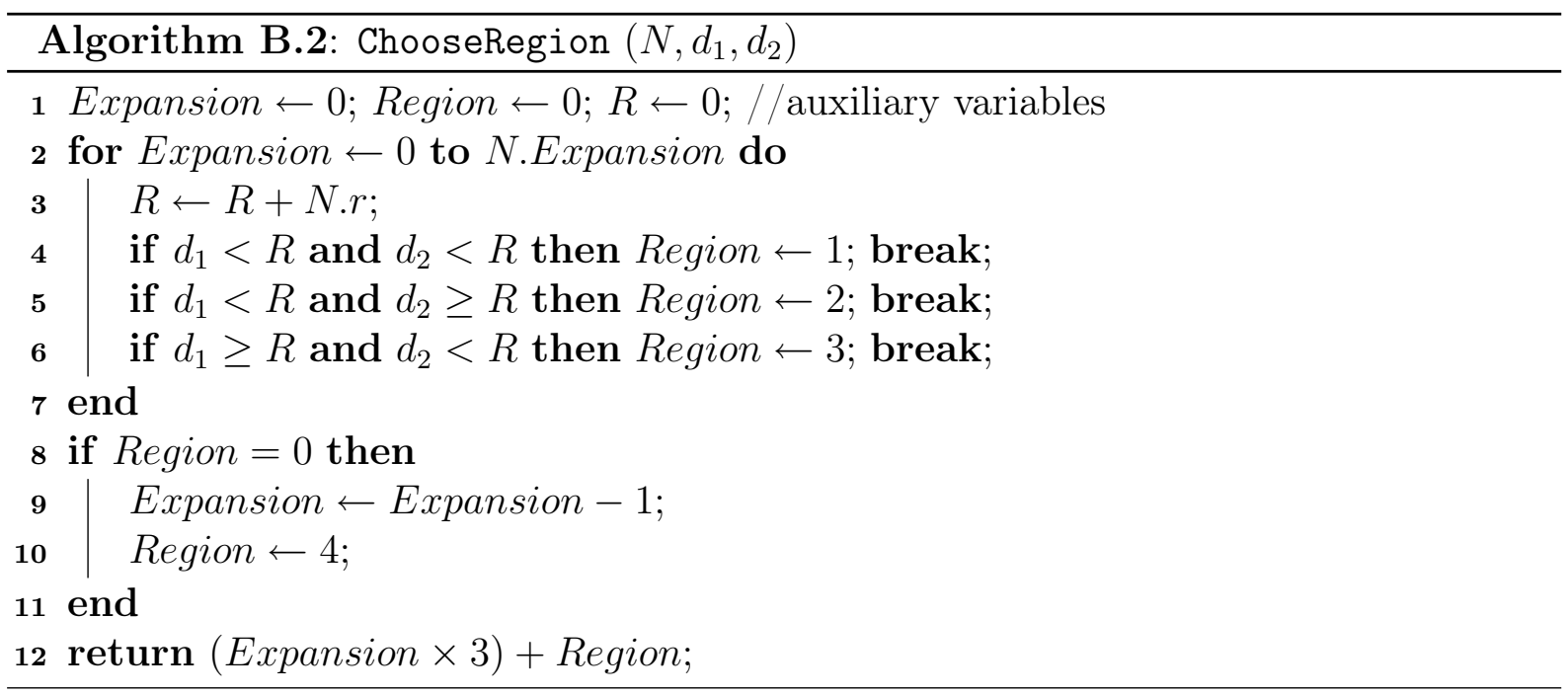

\section{B.6 The Replacement Technique}

The replacement technique is applied before the insertion of an element $s_{i}$ into a full leaf node. It determines if the subspace of a node $N$ is better partitioned if any of its pivots (e.g., $s_{1}$ ) changes position with $s_{i}$. This technique also replaces the radius of $N$ with the distance between $s_{i}$ and the non-chosen pivot (e.g., $s_{2}$ ). Fig. B.4 shows an example of 
the replacement technique. In this example, $s_{i}$ changes position with $s_{1}$, and $r$ and $d_{2}$ are replaced properly.
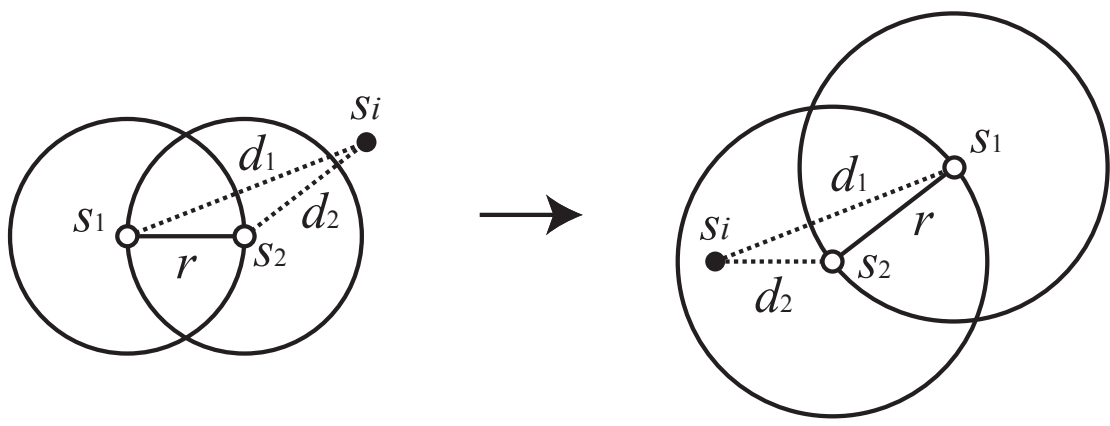

Figure B.4: Example of the replacement technique.

The Replace algorithm (Algorithm B.3) determines whether the insertion of an element $s_{i}$ into a node $N$ requires a replacement, using the distances between $s_{i}$ and each node's pivot (i.e., $d_{1}$ and $d_{2}$ ). First, the algorithm uses the keep-small strategy to determine the value of $\alpha$, so that no expansion procedure will be applied if $N \cdot r=\alpha$ (line 1). Then, it calculates the absolute values of the differences between $\alpha$ and the distances N.r, $d_{1}$ and $d_{2}$ (line 2). If $d_{1}$ is the closest value to $\alpha$, the pivot $N . s_{2}$ is replaced with $s_{i}$ (line 4). Alternatively, if $d_{2}$ is the closest value to $\alpha, N . s_{1}$ is replaced with $s_{i}$ (line 6). When the algorithm ends, the distance between the pivots is the closest one to $\alpha$.

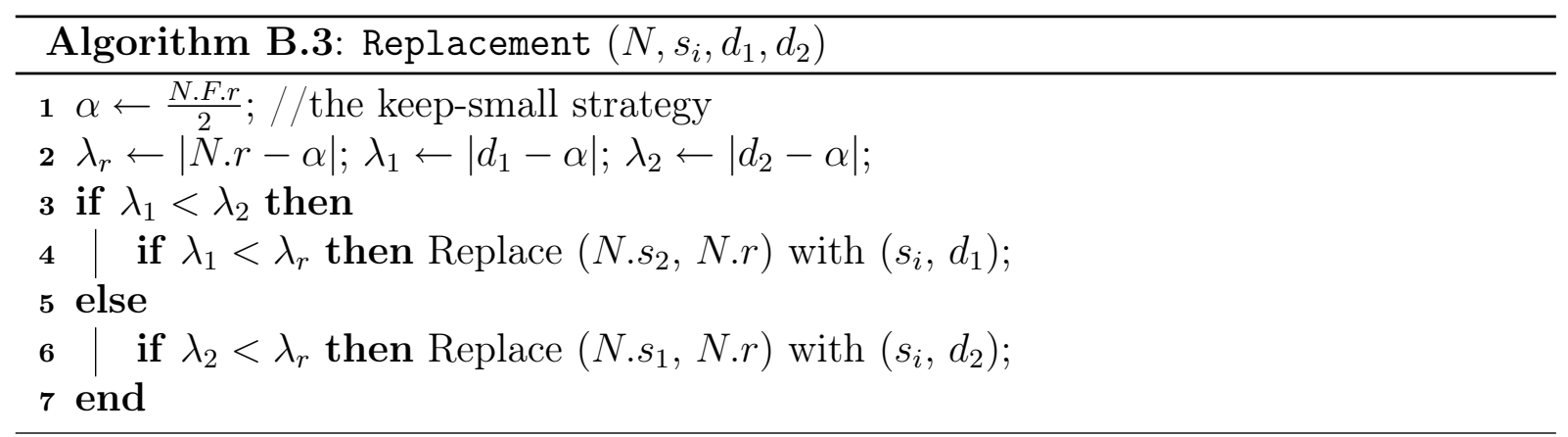

The replacement technique is used in Algorithm B.4 to insert an element $s_{i}$ into a node $N$ as follows. If the node is empty, $s_{i}$ is inserted as its first pivot (line 1), and if the node has only one element, $s_{i}$ is inserted as its second pivot (line 3). Otherwise, the algorithm first calculates the distances between $s_{i}$ and each pivot (lines 5 and 6 ). Then, it checks whether $\mathrm{N}$ is a leaf node, and if so, calculates the radius of $\mathrm{N}$ (line 8), verifies if $s_{i}$ should be replaced with one of the pivots (line 9 ), and defines the number of expansions to be applied to N (line 10). Finally, the insertion continues recursively in the subtree defined by the ChooseRegion algorithm (lines 11 and 12). 


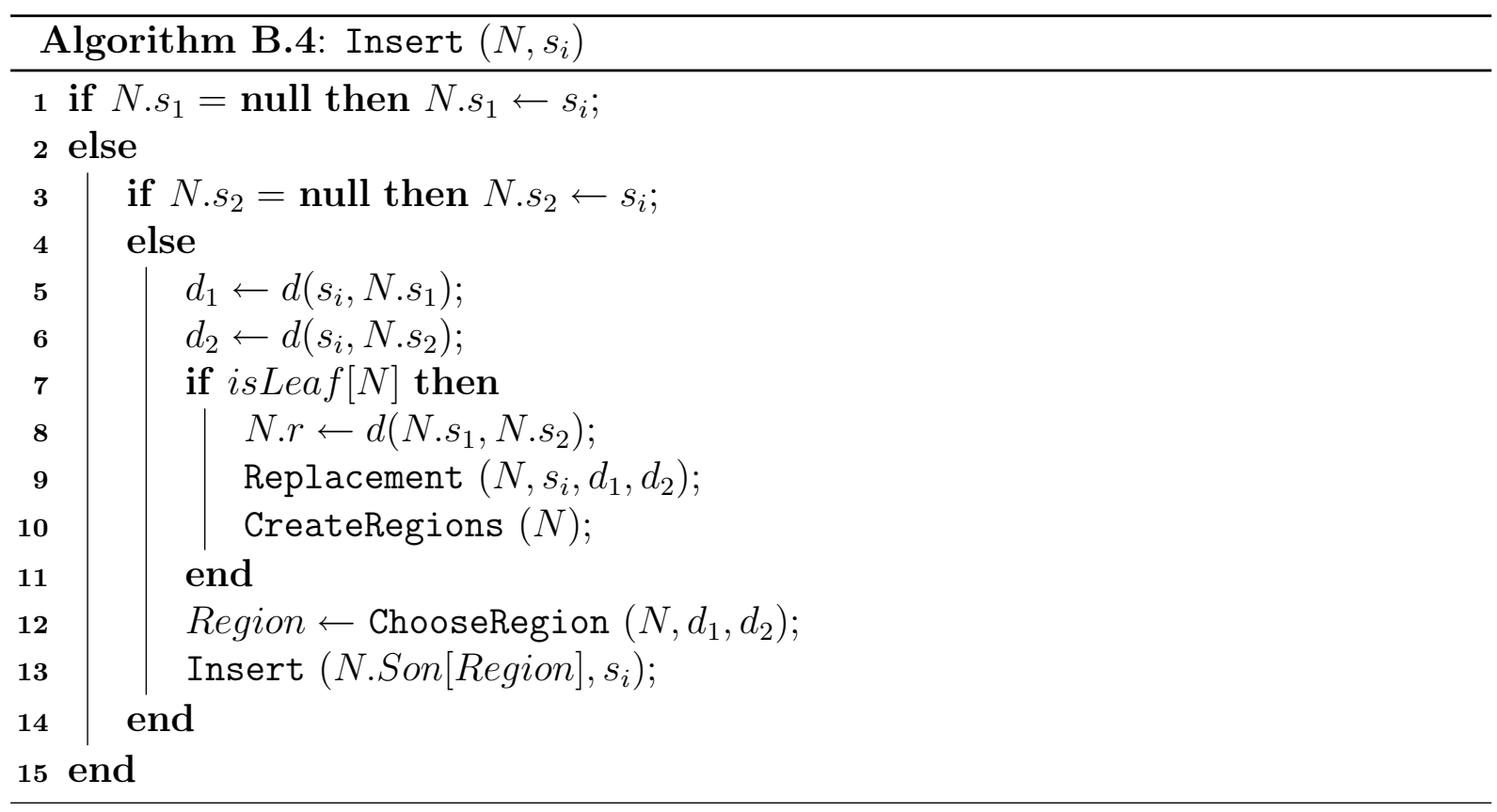

\section{B.7 Extended Query Algorithms}

The MM-tree's range and $k$-NN queries deal with only four regions per node. For joint use with the ONION-TREE, these queries were adapted to allow the search for elements in all the regions created by the expansion procedures (line 8 of Algorithm B.5 and line 13 of Algorithm B.6).

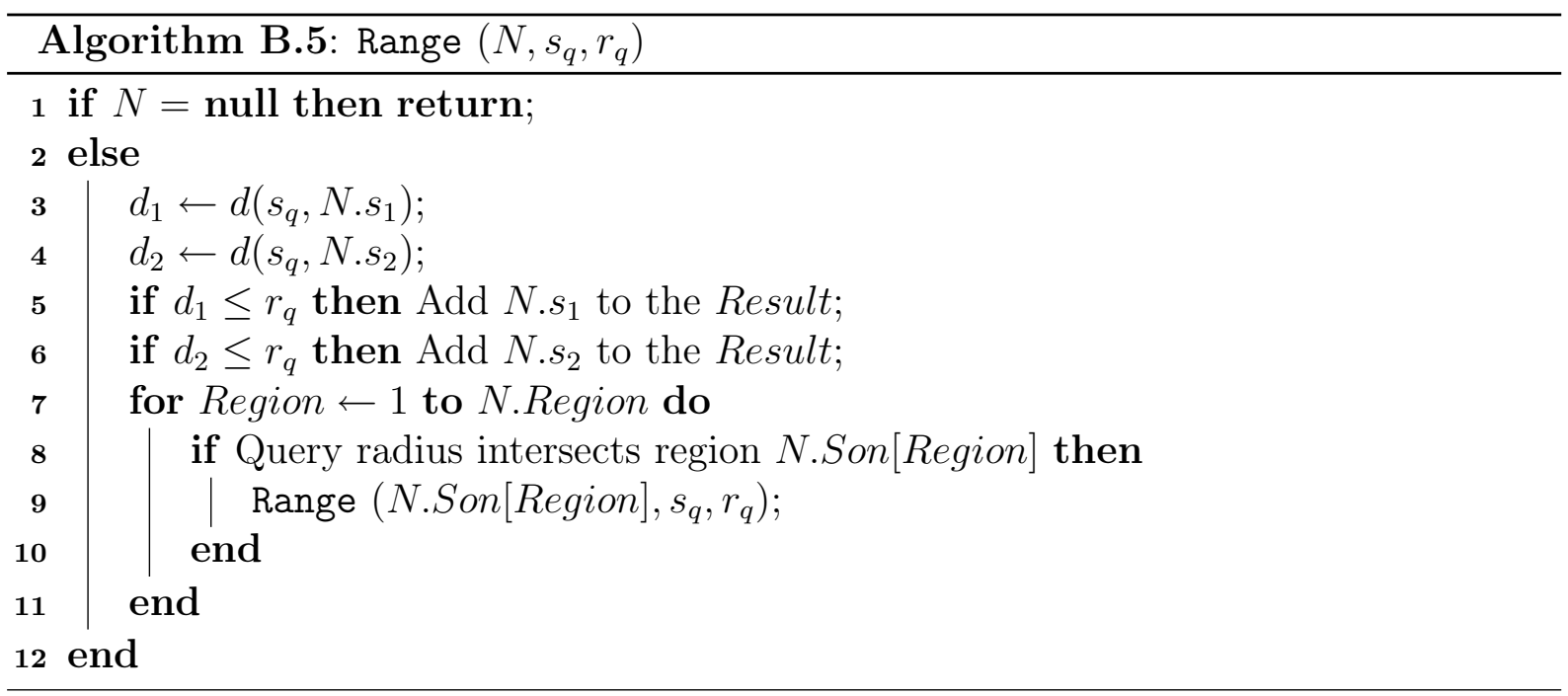

A novelty introduced by the ONION-TREE in the KNN algorithm is a new policy to choose the visit order of the regions of a node (lines 11 to 13). Although the best possible visit order depends on data distribution, we assume that the datasets have clusters and the elements are inserted randomly. This reflects the most common scenario regarding real world datasets. 


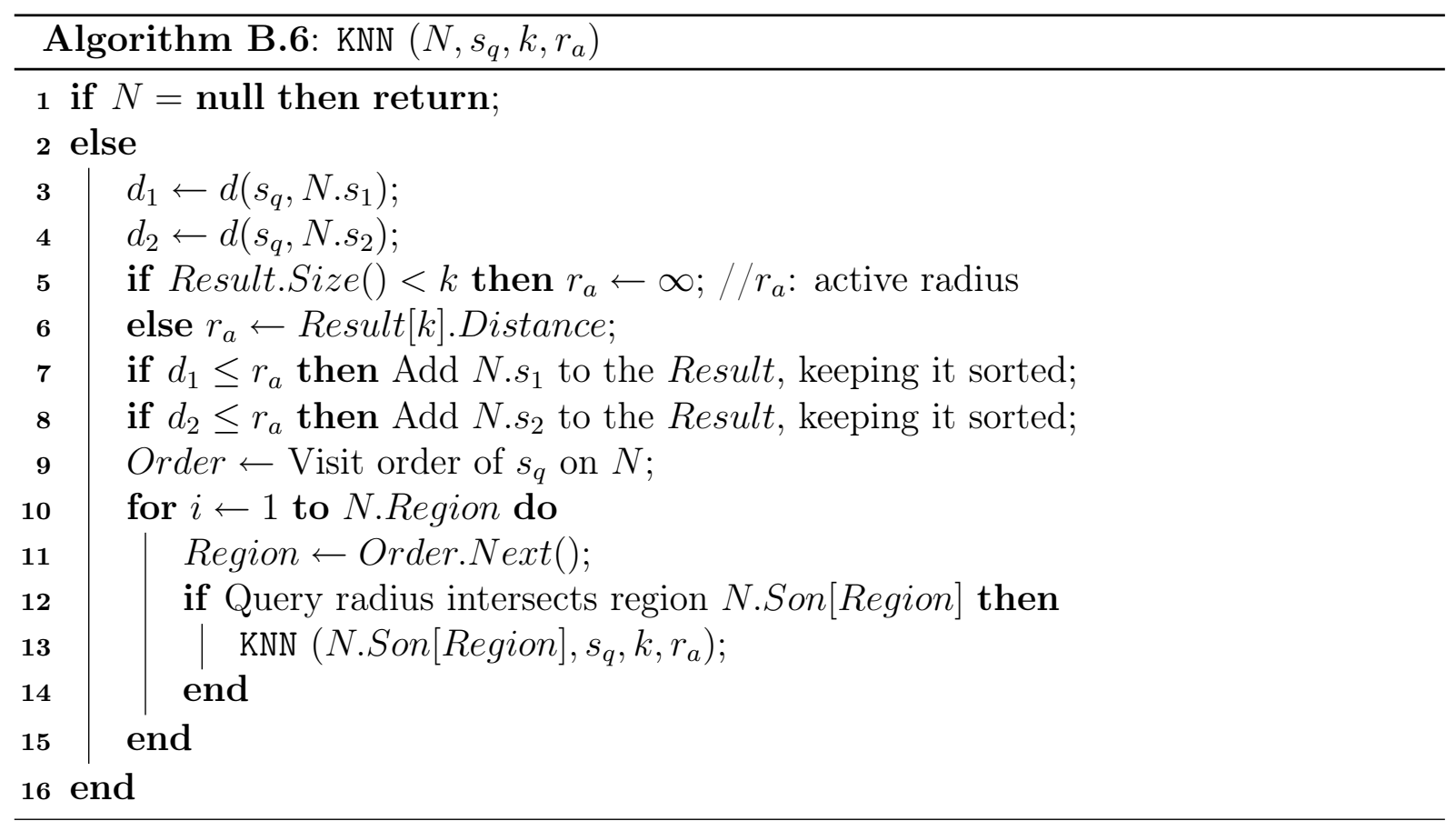

The proposed policy works as follows. First, visit the region of a node $N$ where the query element $s_{q}$ lies. Then, visit the remaining regions of $N$ according to their proximity to $s_{q}$. The policy determines both the visit order of the expansions of $N$ and the visit order of their regions. The expansions are visited in the following order: (i) expansion $E$ to which $s_{q}$ is assigned to; (ii) expansions $E-1$ and $E+1$; (iii) expansions $E-2$ and $E+2$; and so on. Visiting an internal expansion (e.g., $E-1$ ) before an external one (e.g., $E+1$ ) leads to a faster active radius reduction, as internal expansions are smaller and have higher probability to contain closer elements. This order improves the prunability.

With regard to the regions of the expansions, they are visited in the order specified in Table B.3. In this table, the regions of $E$ are defined using the modulo 3 operator, since each expansion procedure adds three regions to the node, and $R$ is the covering radius used in $E$ (i.e., $R=(E+1) \times N . r)$.

Fig. B.5 shows the visit order of a query element $s_{q}$, which is assigned to region IV of a node with two expansions. According to the proposed policy, the visit order of the expansions is 1, 0 and 2. Furthermore, since $s_{q}$ is assigned to region IV and is closer to $s_{2}$ (i.e., 4 modulo $3=1$ and $d_{1}>d_{2}$ ), the visit order of the regions is IV, VI and V (second line in Table B.3).

\section{B.8 Experimental Results}

The ONION-TREE was analyzed through performance tests using datasets that exploits different properties that affect the general behavior of MAMs, such as data volume and data dimensionality. We used three datasets with data volumes of different magnitude 
Table B.3: Visit order of the regions.

\begin{tabular}{cccccc}
\hline \multirow{2}{*}{$\begin{array}{c}\text { Region of } \\
S_{q} \bmod 3\end{array}$} & \multirow{2}{*}{ Condition } & 1st & 2nd & $3 \mathrm{rd}$ & 4 th \\
\hline 1 & $d_{1} \leq d_{2}$ & $3 E+1$ & $3 E+2$ & $3 E+3$ & $3 E+4$ \\
1 & $d_{1}>d_{2}$ & $3 E+1$ & $3 E+3$ & $3 E+2$ & $3 E+4$ \\
2 & $d_{2}-R \leq R-d_{1}$ & $3 E+2$ & $3 E+1$ & $3 E+4$ & $3 E+3$ \\
2 & $d_{2}-R>R-d_{1}$ & $3 E+2$ & $3 E+4$ & $3 E+1$ & $3 E+3$ \\
3 & $d_{1}-R \leq R-d_{2}$ & $3 E+3$ & $3 E+4$ & $3 E+1$ & $3 E+2$ \\
3 & $d_{1}-R>R-d_{2}$ & $3 E+3$ & $3 E+1$ & $3 E+4$ & $3 E+2$ \\
4 & $d_{1} \leq d_{2}$ & $3 E+4$ & $3 E+2$ & $3 E+1$ & $3 E+3$ \\
4 & $d_{1}>d_{2}$ & $3 E+4$ & $3 E+3$ & $3 E+1$ & $3 E+2$ \\
\hline
\end{tabular}
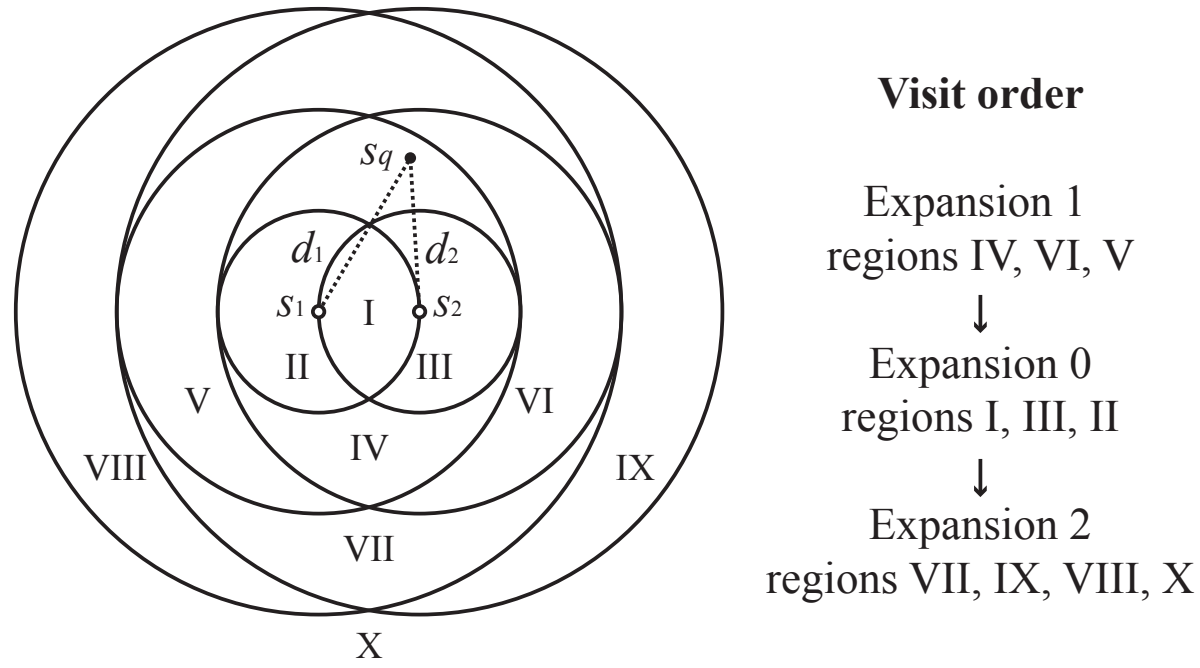

Figure B.5: Visit order of the expansions and their regions for $s_{q}$.

orders (i.e., $10^{3}, 10^{4}$ and $10^{5}$ elements), and applied the metric $L_{2}$ to compare the elements. Table B.4 shows the characteristics of these datasets, where the dimensionality of the elements is represented by $\mathrm{D}$.

We compared two versions of the ONION-TREE with a memory-based version of the Slim-tree and with the MM-tree. The first version of the OnION-TREE used the variable policy, while the second one used the fixed policy (Section B.5.1). We call the former version V-Onion-tree and the latter one F-Onion-tree. For the F-Onion-tree, we applied seven expansions to its nodes. We experimentally found that this number of expansions is the best value among the values of one, three, five, seven and nine expansions for the selected datasets. The optimum number of expansions depends on the characteristics of the dataset, especially data distribution. The Slim-tree was built using the min-occupation and the minimum spanning tree policies with 50 elements per node, and the MM-tree was built using the semi-balancing technique. These are the best configurations of these structures according to their authors. Due to space limitations, we only present here the results of the OnION-TREe, the MM-tree and the Slim-tree, since Pola et al has 
Table B.4: Datasets used in the experiments.

\begin{tabular}{|c|c|c|c|}
\hline Dataset & Elements & $\mathrm{D}$ & Description \\
\hline Brazilian cities & 5507 & 2 & 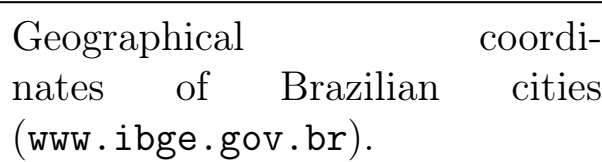 \\
\hline Color histograms & 68025 & 32 & $\begin{array}{l}\text { Color image histograms from the } \\
\text { KDD repository of the University } \\
\text { of California at Irvine (kdd.ics. } \\
\text { uci.edu). }\end{array}$ \\
\hline KDD Cup 2008 & 102240 & 117 & $\begin{array}{l}\text { Training dataset containing } \\
\text { breast cancer suspicious regions } \\
\text { (www.kddcup } 2008 . \mathrm{com} \text { ). }\end{array}$ \\
\hline
\end{tabular}

already compared the MM-tree with the VP-tree and showed that the MM-tree always outperformed the VP-tree.

The OnION-TREE was implemented in $\mathrm{C}++$ using the arboretum framework (gbdi. icmc.usp.br/arboretum). The source codes of the Slim-tree and the MM-tree were obtained from this framework and compiled under the same settings. The experiments were conducted on a computer with a $2.4 \mathrm{GHz}$ Intel Core 2 Duo Processor and 2 GB 1067 MHz DDR3 of main memory.

In our tests, we analyzed the cost of building the index as well as the cost of the query processing. The number of distance calculations and the elapsed time were recorded for the former (Section B.8.1). As for the latter, we recorded the average number of distance calculations and the elapsed time needed to process 500 random queries (Sections B.8.2 and B.8.3).

\section{B.8.1 Performance Results for Building the Index}

For dynamic memory-based MAMs, the cost of building the index is one of the most important aspects. These MAMs are frequently used to optimize subqueries. Therefore, the index is often built several times, such as when a user interacts with an application that searches for similarity. Table B.5 and Fig. B.6 show the performance results when building the indices.

The results indicated that the ONION-TREE is a very compact index. Both the F-Onion-tree and the V-Onion-tree required a very small fraction of the available main memory. The size of the ONION-TREE was about $100 \mathrm{MB}$ (i.e., $4.8 \%$ of the main memory) for the biggest dataset (KDD Cup 2008 dataset), against the size of $223 \mathrm{MB}$ of the Slim-tree (i.e., $10.8 \%$ of the main memory).

Regarding the number of distance calculations, the ONION-TREE produced the best performance results for the Brazilian cities and the Color histograms datasets. Com- 
pared to the MM-tree, the performance gain was of $41.46 \%$ and $18.36 \%$, respectively, and compared to the Slim-tree, it was of $85.33 \%$ and $78.49 \%$, respectively. Therefore, the ONION-TREE provided a great reduction in the number of distance calculations. For the KDD Cup 2008 dataset, which has the highest dimensionality, the MM-tree required the smallest number of distance calculations. The F-Onion-tree, however, required only a slightly increase of $7.63 \%$. As for the elapsed time, the OnION-TREE always produced the smallest overhead to build the index. The MM-tree took more time because its semibalancing technique is very costly (see Section B.4 for details).

Comparing the F-Onion-tree and the V-Onion-tree, the F-Onion-tree required less distance calculations than the V-Onion-tree for all the datasets. The difference in the performance results ranged from $9 \%$ to $26 \%$. This gain is very important for high-cost metrics, for which the F-Onion-tree showed to be the best OnION-TREE version. Similarly to the number of distance calculations, the F-Onion-tree produced the best results for the elapsed time to index the Color histograms and the KDD Cup 2008 datasets. However, the difference in the elapsed time of these two versions was very slight: at most $9 \%$. We conclude that the F-Onion-tree generates less overhead than the V-Onion-tree to be built.

As discussed in Section 1, memory-based MAMs do not need to minimize disk accesses, so they can provide better partitioning of the metric space. This conclusion was confirmed in our experiments, since the ONION-TREE required less distance calculations (from $60 \%$ to $85 \%$ ) and was built faster (from $30 \%$ to $79 \%$ ) than the Slim-tree. This is due to the memory-based Slim-tree applies the same partitioning technique of the original disk-based Slim-tree.

Table B.5: Number of distance calculations to build the indices.

\begin{tabular}{lrrrr}
\hline Dataset & Slim-tree & MM-tree & V-Onion-tree & F-Onion-tree \\
\hline Brazilian cities & 358,236 & 89,783 & 68,443 & 52,555 \\
Color histograms & $5,135,030$ & $1,352,870$ & $1,498,686$ & $1,104,375$ \\
KDD Cup 2008 & $5,727,850$ & $2,075,798$ & $2,455,598$ & $2,234,211$ \\
\hline
\end{tabular}

\section{B.8.2 Performance Results for Range Query Processing}

The radius of range queries ranged from $1 \%$ to $10 \%$ of the dataset radius (i.e., half of the largest distance among all pairs of dataset elements) for the Brazilian cities and the Color histograms datasets. As for the KDD Cup 2008 dataset, the radius of range queries was set to higher values, due to the curse of dimensionality (Chávez et al, 2001). For this dataset, the radius ranged from $31 \%$ to $40 \%$ of the largest distance among all the pairs of the query elements, and the queries recovered from $1 \%$ to $10 \%$ of the number of elements.

Both the F-Onion-tree and the V-Onion-tree outperformed the MM-tree and the Slim-tree for all the datasets, with regard to the number of distance calculations and the 


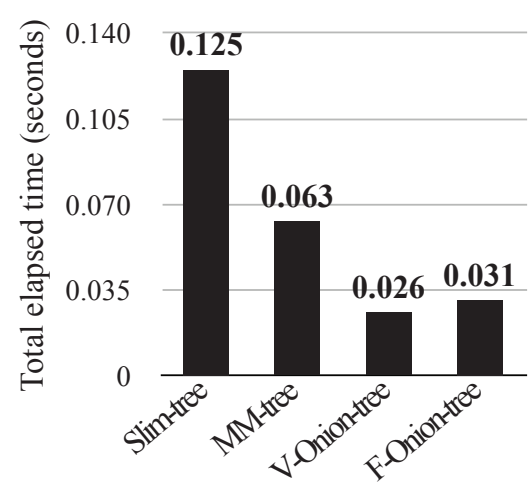

(a) Brazilian cities

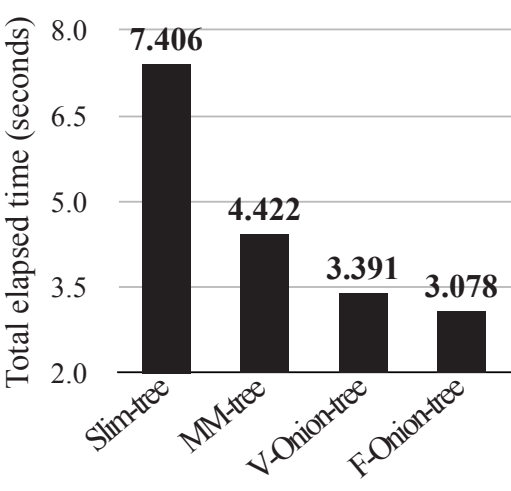

(b) Color histograms

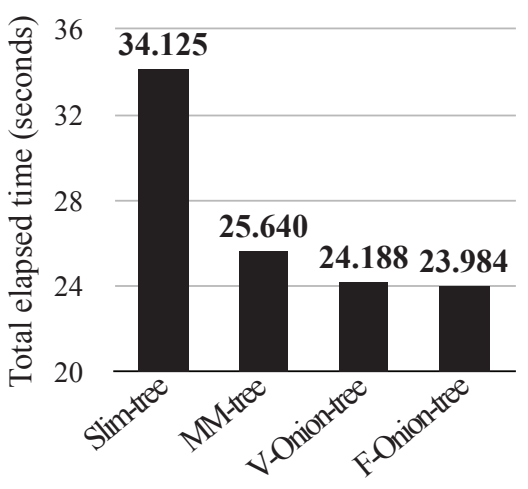

(c) KDD Cup 2008

Figure B.6: Elapsed time to build the indices.

elapsed time in query processing. As the MM-tree outperforms the Slim-tree, table B.6 shows the performance gain of the ONION-TREE compared with only the MM-tree, i.e., it compares how much faster the ONION-TREE is than the MM-tree. While the V-Onion-tree obtained a slightly gain (from $1.38 \%$ to $2.54 \%$ ) in the number of distance calculations, the F-Onion-tree obtained a higher gain (from $4.01 \%$ to $11.3 \%$ ). Regarding the elapsed time for query processing, the ONION-TREE also produced better results: the V-Onion-tree obtained a performance gain ranging from $15 \%$ up to $33 \%$, while the F-Onion-tree obtained a gain ranging from $12 \%$ up to $39 \%$.

Comparing the two versions of the ONION-TREE, the F-Onion-tree produced a slightly better performance than the $\mathrm{V}$-Onion-tree for datasets using high-cost metrics, such as the Color histograms and the KDD Cup 2008 datasets. For these datasets, the high data dimensionality increased the cost of the distance calculations, which impaired the elapsed time and benefited the F-Onion-tree.

Fig. B.7 shows the average number of distance calculations and the elapsed time for range queries, as a function of the radius. Note that Fig. B.7a, B.7c and B.7d are in $\log$ scale for better results visualization. For all the datasets and the two performance measures, both versions of the ONION-TREE outperformed both the MM-tree and the Slim-tree.

Table B.6: The OnION-TREE's performance gains (range queries).

\begin{tabular}{lcccc}
\hline \multirow{2}{*}{ Dataset } & \multicolumn{2}{c}{ Distance calculations } & \multicolumn{2}{c}{ Elapsed time } \\
& V-Onion-tree & F-Onion-tree & V-Onion-tree & F-Onion-tree \\
\hline Brazilian cities & $2.54 \%$ & $8.16 \%$ & $15.04 \%$ & $12.59 \%$ \\
Color histograms & $2.47 \%$ & $11.32 \%$ & $32.98 \%$ & $39.01 \%$ \\
KDD Cup 2008 & $1.83 \%$ & $4.01 \%$ & $25.13 \%$ & $26.69 \%$ \\
\hline
\end{tabular}




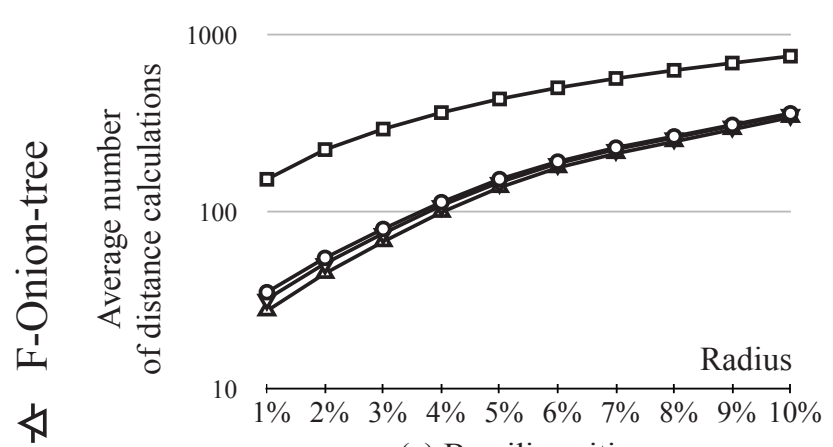

(a) Brazilian cities

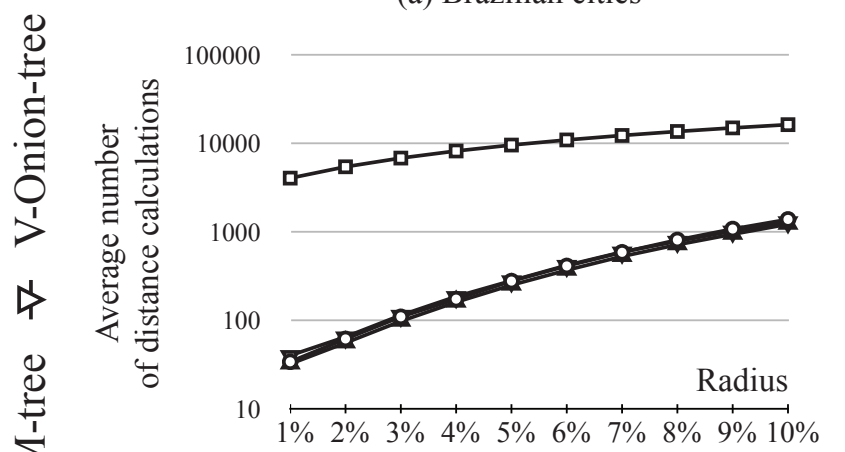

(c) Color histograms

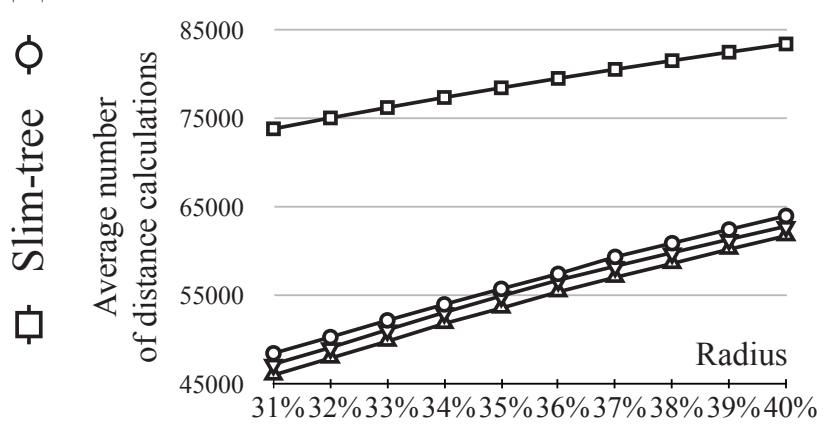

(e) KDD Cup 2008

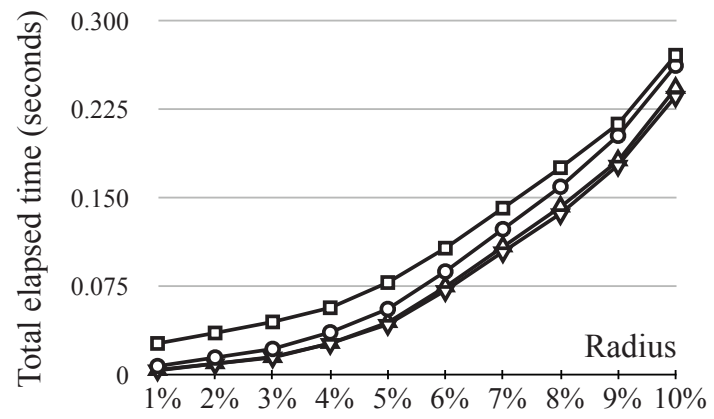

(b) Brazilian cities

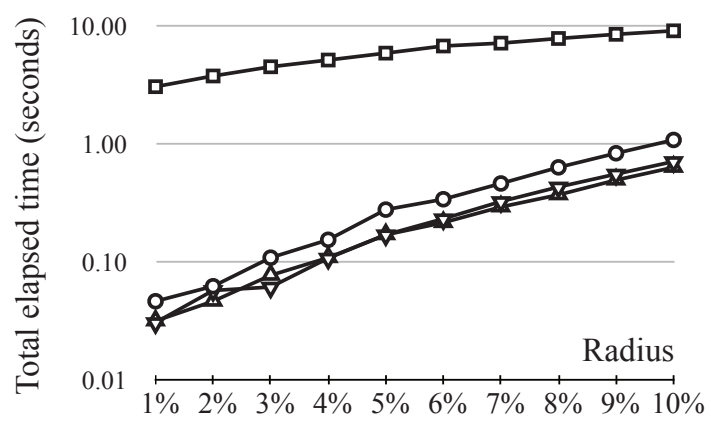

(d) Color histograms

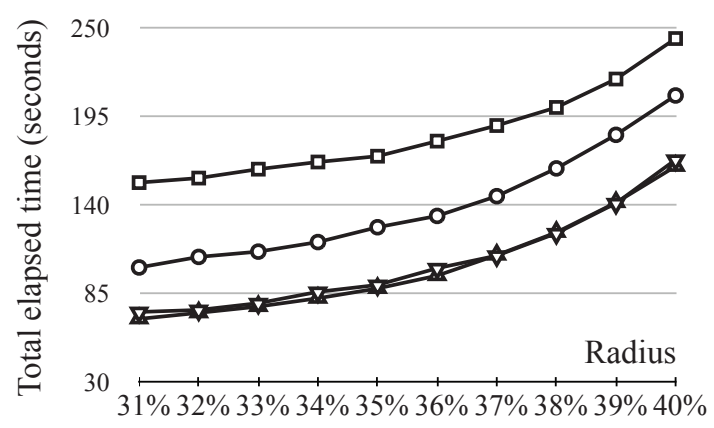

(f) KDD Cup 2008

Figure B.7: Range queries results.

\section{B.8.3 Performance Results for $k$-NN Query Processing}

The gains achieved by the ONION-TREE to execute $k$-NN queries are even better than to execute range queries. Table B.7 shows the ONION-TREE's gains when compared to the MM-tree. The value of $k$ ranged from 2 to 20, encompassing the most common values used when performing $k$-NN queries.

Regarding the number of distance calculations, the V-Onion-tree produced a performance gain from $16 \%$ up to $64 \%$ with respect to the MM-tree, while the F-Onion-tree produced a performance gain from $22 \%$ up to $64 \%$. Comparing the two versions of the ONION-TREE, the V-Onion-tree was more efficient than the F-Onion-tree, generating an impressive elapsed time gain that ranged from $40 \%$ up to $70 \%$ with regard to the MM-tree. This difference is related to the fact that, although the number of distance calculations required by both versions are similar, there are more regions per node to be visited in the F-Onion-tree. 
Fig. B.8 shows the average number of distance calculations and the elapsed time for different $k$ values for $k$-NN queries. Fig. B.8a is in log scale for better results visualization. The two versions of the OnION-TREE outperformed the MM-tree and the Slim-tree. For the highest dimensionality dataset (i.e., the KDD Cup 2008 dataset), the MM-tree presented the worst results, surpassing the cost of the sequential search (i.e., more than 102,240 distance calculations). Using the expansion procedure, the replacement technique and the extended query algorithms allowed the F-Onion-tree and the V-Onion-tree to maintain good performance even over high dimensional data. Therefore, we conclude that the ONION-TREE is a robust MAM to index complex data.

Table B.7: The OnION-TREE's performance gains ( $k$-NN queries).

\begin{tabular}{lcccc}
\hline \multirow{2}{*}{ Dataset } & \multicolumn{2}{c}{ Distance calculations } & \multicolumn{2}{c}{ Elapsed time } \\
& V-Onion-tree & F-Onion-tree & V-Onion-tree & F-Onion-tree \\
\hline Brazilian cities & $16.17 \%$ & $22.32 \%$ & $40.15 \%$ & $38.83 \%$ \\
Color histograms & $43.82 \%$ & $42.02 \%$ & $45.55 \%$ & $45.38 \%$ \\
KDD Cup 2008 & $64.26 \%$ & $64.51 \%$ & $70.24 \%$ & $67.85 \%$ \\
\hline
\end{tabular}

\section{B.9 Conclusions and Future Work}

In this paper, we propose the ONION-TREE, a new and robust dynamic memory-based metric access method, which divides the metric space into several disjoint subspaces to index complex data. The ONION-TREE introduces the following distinctive good properties. It is based on an expansion procedure that controls the number of disjoint subspaces generated in the index building. It also applies a replacement technique that prevents the creation of subspaces that are too small or too big. Furthermore, the Onion-tree proposes similarity search algorithms to support its new partitioning method without overlap, in addition to a different visit order of the subspaces in $k$-NN queries.

The ONION-TREE was validated through performance tests that issued range and $k$-NN queries over datasets with different data volumes and dimensionalities. The results showed that the ONION-TREE is very compact, requiring a small fraction of the main memory. Comparisons of the ONION-TREE, a memory-based version of the Slim-tree and the MM-tree indicated that the ONION-TREE always required the smallest elapsed time to build the index. The query processing results also showed that the ONION-TREE obtained the best performance results, followed by the MM-tree, which in turn outperformed the Slim-tree in almost all the experiments. The ONION-TREE also required less distance calculations in query processing. Compared with the MM-tree, the OnION-TREE reduction in the number of distance calculations ranged from $1 \%$ to $11 \%$ in range query processing, and from $16 \%$ up to $64 \%$ to answer $k$-NN queries. The OnION-TrEe also 


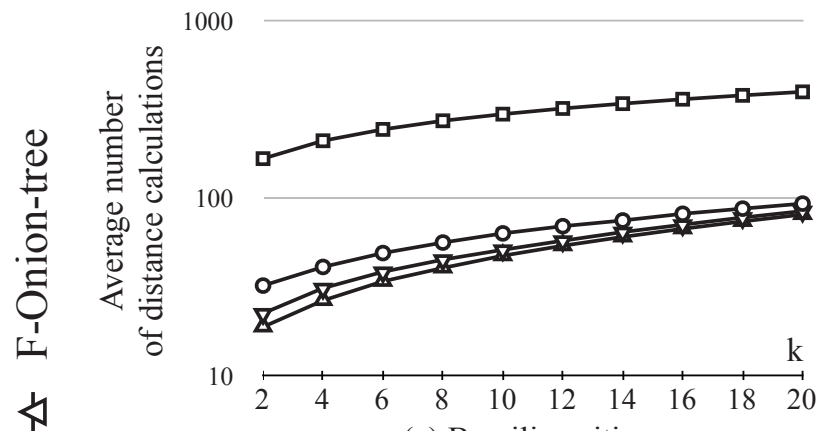

(a) Brazilian cities

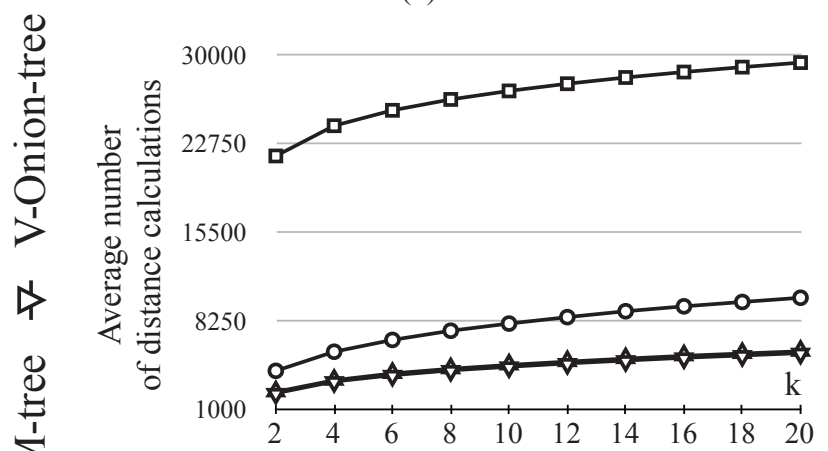

(c) Color histograms

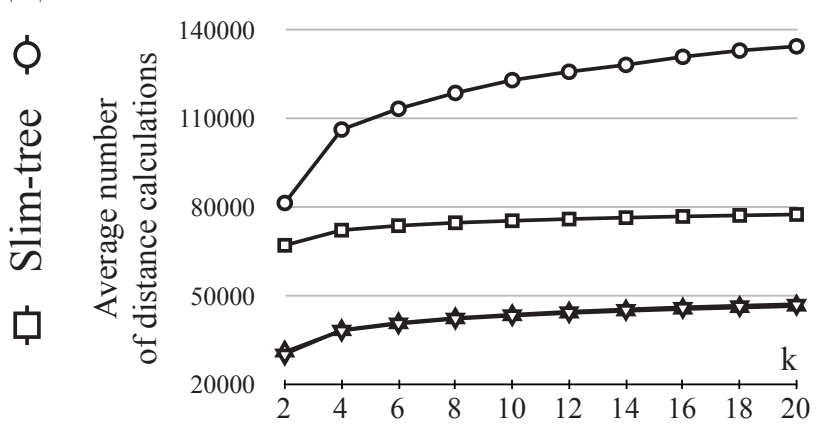

(e) KDD Cup 2008

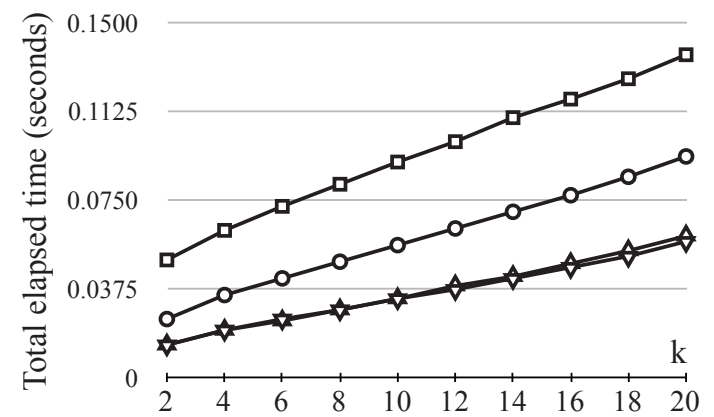

(b) Brazilian cities

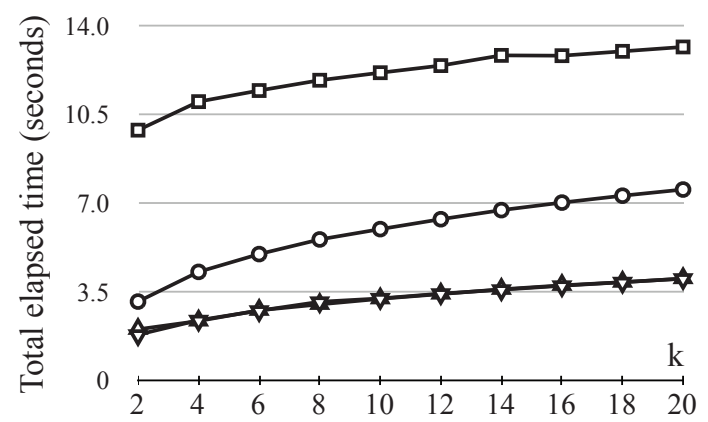

(d) Color histograms

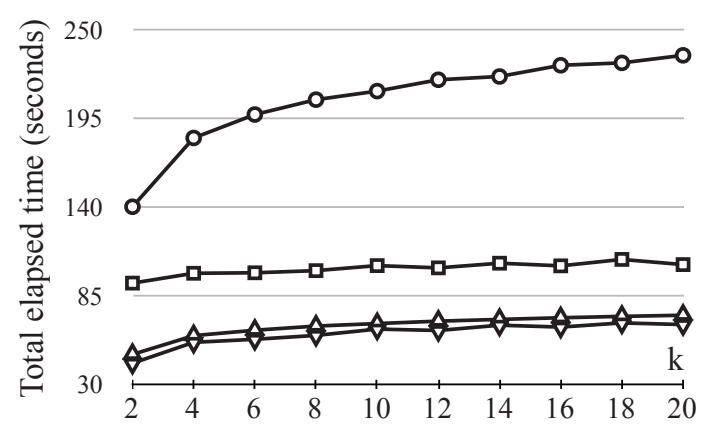

(f) KDD Cup 2008

Figure B.8: $k$-NN queries results.

significantly reduced the elapsed time in query processing. Compared with the MM-tree, the improvement ranged from $12 \%$ up to $39 \%$ in range query processing, and from $40 \%$ up to $70 \%$ in $k$-NN query processing.

We also conducted experiments using two versions of the ONION-TREE. The V-Onion-tree applied a variable expansion procedure policy, while the F-Onion-tree applyed a fixed policy. In general, the F-Onion-tree slightly outperformed the V-Onion-tree. However, the use of different policies ensures flexibility to the ONION-TREE. Moreover, the F-Onion-tree requires obtaining a proper value for the (fixed) number of expansions. Therefore, the fixed policy is indicated in situations where data are well known. On the other hand, the variable policy is well-suited for different types of data distribution, since it automatically identifies the need for expansions, and performs as expected.

We are currently extending the ONION-TREE to investigate different replacement policies. In order to complement our investigation into datasets that exploits different proper- 
ties that affect the general behavior of MAMs, we are also planning to run new experiments using different metrics and other policies.

Acknowledgments. This work has been supported by the following Brazilian research agencies: FAPESP, CNPq, CAPES, INEP and FINEP. The third author also thanks the Web-PIDE Project (Observatory of the Education). 